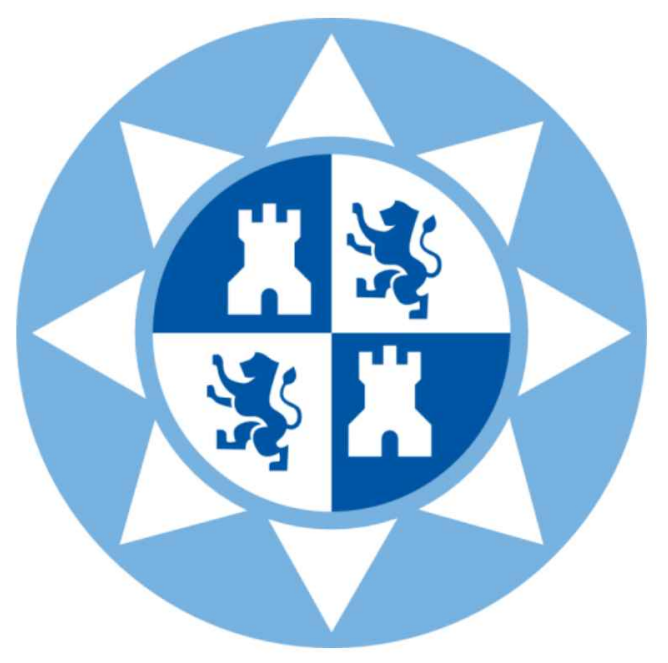

Universidad Politécnica de Cartagena

Departamento de Métodos Cuantitativos e Informáticos

\title{
ANÁLISIS Y APLICACIONES DE LOS SISTEMAS DE MEDICIÓN DE LA REPUTACIÓN ONLINE DE LOS HOTELES
}

Juan Pedro Mellinas Cánovas 


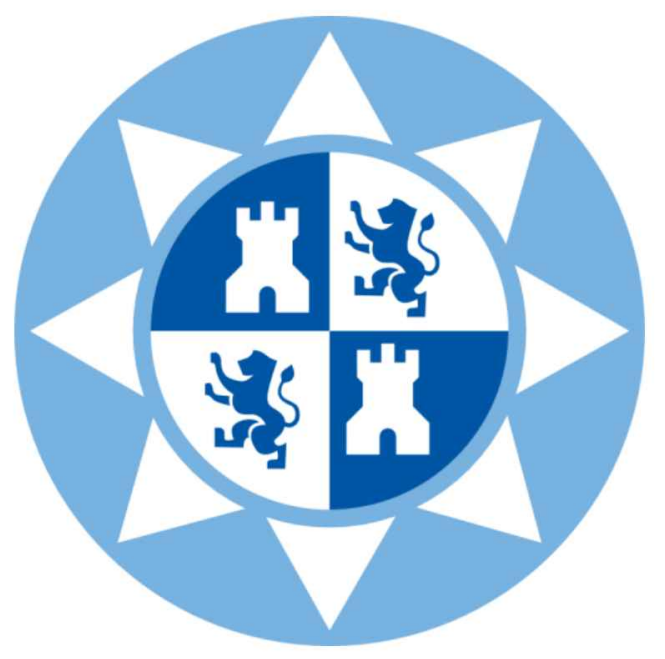

Universidad Politécnica de Cartagena

Departamento de Métodos Cuantitativos e Informáticos

\section{ANÁLISIS Y APLICACIONES DE LOS SISTEMAS DE MEDICIÓN DE LA REPUTACIÓN ONLINE DE LOS HOTELES}

\section{Juan Pedro Mellinas Cánovas}

Directores:

Dra. Dña. Soledad María Martínez María-Dolores

Dr. D. Juan Jesús Bernal García 


\section{Universidad}

Politécnica

de Cartagena

DT-16

\section{CONFORMIDAD DE SOLICITUD DEAUTORIZACIÓN DE DEPÓSITO DE TESIS DOCTORAL POR EL/LA DIRECTOR/A DE LA TESIS}

D. JUAN JESÚS BERNAL GARCÍA y $\mathrm{D}^{\text {naa }}$. SOLEDAD Ma MARTÍNEZ $\mathrm{M}^{\mathrm{a}}$ DOLRES, Directores de la Tesis doctoral "ANÁLISIS Y APLICACIONES DE LOS SISTEMAS DE MEDICIÓN DE LA REPUTACIÓN ONLINE DE LOS HOTELES".

\section{INFORMA:}

Que la referida Tesis Doctoral, ha sido realizada por D. JUAN PEDRO MELLINAS CÁNOVAS, dentro del programa de doctorado en ADMINISTRACIÓN Y DIRECCIÓN DE EMPRESAS dando nuestra conformidad para que sea presentada ante la Comisión de Doctorado para ser autorizado su depósito.

La rama de conocimiento en la que esta tesis ha sido desarrollada es:

X Ciencias Sociales y Jurídicas

En Cartagena, a 8 de Enero de 2015

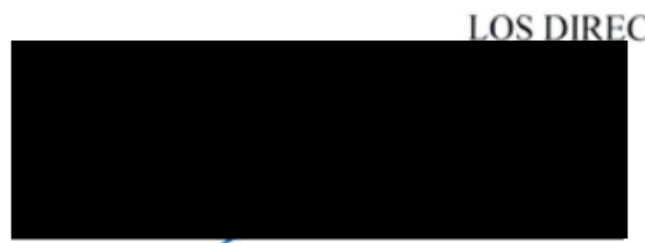

Fdo.: Juan Jesús Bernal García

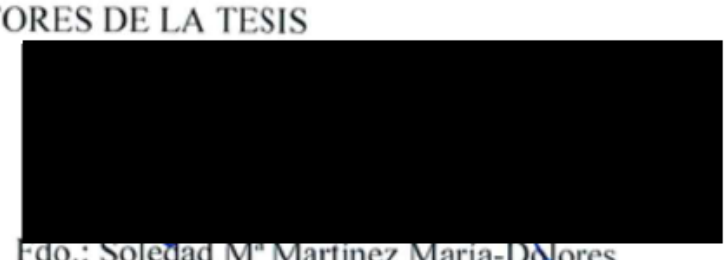

\section{COMISIÓN DE DOCTORADO}




\section{CONFORMIDAD DE DEPÓSITO DE TESIS DOCTORAL POR LA COMISIÓN ACADÉMICA DEL PROGRAMA}

D/Dª CARMELO REVERTE MAYA Presidente/a de la Comisión Académica del Programa ADMINISTRACIÓN Y DIRECCIÓN DE EMPRESAS.

\section{INFORMA:}

Que la Tesis Doctoral titulada, "ANÁLISIS Y APLICACIONES DE LOS SISTEMAS DE MEDICIÓN DE LA REPUTACIÓN ONLINE DE LOS HOTELES".," ha sido realizada, dentro del mencionado programa de doctorado, por D/D JUAN PEDRO MELLINAS CÁNOVAS,

bajo la dirección y supervisión del Dr/ Dra. D. JUAN JESÚS BERNAL GARCIA y D ${ }^{\text {naa }}$, SOLEDAD M MARTINEZ M MOLORES,

En reunión de la Comisión Académica de fecha 21 de enero de 2015 , visto que en la misma se acreditan los indicios de calidad correspondientes y la autorización del Director de la misma, se acordó dar la conformidad, con la finalidad de que sea autorizado su depósito por la Comisión de Doctorado.

La Rama de conocimiento por la que esta tesis ha sido desarrollada es:

Ciencias

$\mathrm{X}$ Ciencias Sociales y Juridicas

Ingenieria y Arquitectura

En Cartagena, a 21 de Enero de 2015

EL PRESIDENTE DE LA COMISIÓN ACADÉMICA DEL PROGRAMA

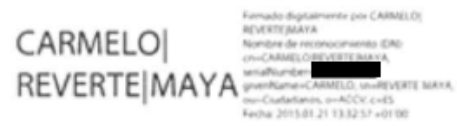

Fdo. CARMELO REVERTE MAYA 


\section{Agradecimientos}

Me gustaría expresar mi agradecimiento a los directores de esta Tesis doctoral, Doña Soledad Ma Martínez y Don Juan Jesús Bernal. Quiero destacar especialmente su labor en reorientar mi natural tendencia literaria y bloguera, tan lejana a veces del sistema de trabajo científico. Gracias también por hacerme ver que mi afición y experiencia planificando viajes a través de Internet, podía ser algo valioso y convertirse en un campo de investigación.

La casualidad y mi propensión a cuestionar lo establecido, me han conducido a la realización de un análisis crítico de las prácticas de ciertas organizaciones. Pero la única motivación que me ha guiado ha sido la de investigar aspectos novedosos de la temática elegida, con la libertad e independencia que me confiere la ausencia de vinculación con agentes del sector. En este sentido, agradezco la colaboración de TripAdvisor España a través de Twitter y espero que los hallazgos y conclusiones de esta Tesis puedan servir para la mejora de sus procedimientos.

Agradezco también a mi esposa, la orientación, ayuda y apoyo en todo este camino hacia el doctorado. Si ella no estuviera en el ámbito académico antes que yo, no sé si me habría animado a emprender esta aventura. 


\section{Resumen}

Internet se ha convertido en la principal vía de venta y promoción para el sector hotelero, cobrando especial importancia las opiniones difundidas por los huéspedes, sobre la experiencia vivida a través de la red, lo que demanda una especial atención por parte de los hoteleros. Este es un fenómeno propio de la llamada Web 2.0, que implica gran cantidad de contenido generado por millones de usuarios (UGC) y la extensión del tradicional "boca a boca" a través de Internet (eWom). Su desarrollo ha dado lugar a grandes bases de datos estructuradas, como las de Booking y TripAdvisor, que permiten a los investigadores el desarrollo de estudios específicos sobre el sector, de una forma rápida, económica y fiable.

Analizamos en profundidad el sistema de valoraciones de Booking, descubriendo ciertas peculiaridades inesperadas, que no habían sido tenidas en cuenta en estudios previos utilizando esta base de datos. Tratamos el controvertido tema de la fiabilidad de las opiniones en TripAdvisor usando diferentes enfoques y metodologías. Por una parte no encontramos indicios de manipulación masiva y relevante en las puntuaciones, pero paralelamente descubrimos una serie de casos de incumplimiento de su normativa, que plantean serias dudas sobre los sistemas de control establecidos por esta web.

Utilizando una amplia muestra de hoteles de costa españoles y las citadas bases de datos de TripAdvisor y Booking, desarrollamos diversas investigaciones, que incluyen el estudio del grado de implementación de redes sociales y la relación entre el uso adecuado de estas herramientas y las valoraciones que los hoteles obtienen. Adicionalmente, tratamos la evolución de sus puntuaciones en el periodo 2011-2014, así como los factores más relevantes que las condicionan.

Palabras clave: opiniones, redes sociales, web 2.0, turismo, hoteles, TripAdvisor, Booking. 


\begin{abstract}
Internet has become the main channel of sales and promotion for the hotel industry, having particular importance the opinions disseminated by the guest about their experiences through Internet, which requires special attention from hoteliers. This is a phenomenon of the so-called Web 2.0, which involves large amount of user generated content (UGC) and the extension of the traditional "word of mouth" through Internet (eWom). It has also resulted in large structured databases, like Booking and TripAdvisor, which allow researchers to develop specific sector studies in a rapid, inexpensive and convenient manner.
\end{abstract}

When analyzing the Booking score system, we discovered some unexpected peculiarities, which were not considered in previous studies using this database. We deal with the controversial issue of TripAdvisor reliability using different approaches and methodologies. We conclude that there is no evidence of massive manipulation, but we found a number of cases of infringement of its rules, that makes us hesitate about the control systems implemented by this website.

Using a large sample of Spanish coast hotels and TripAdvisor and Booking databases, we conducted several investigations, including implementation level of social media and relation between the proper use of these tools and the scores obtained by hotels. Additionally, we studied scores evolution during the period 2011-2014, as well as relevant factors affecting it.

Keywords: reviews, social media, web 2.0, tourism, hotels, TripAdvisor, Booking. 


\section{ÍNDICE GENERAL}

1. INTRODUCCIÓN 1

2. PLANTEAMIENTO Y OBJETIVOS _ 5

3. REVISION BIBLIOGRÁFICA - contexto científico __ 10

3.1. Uso de Internet en la Web 2.0 y el Turismo $2.0 \_10$

3.1.1. La nueva dimensión de Internet___ 10

3.1.2. Comercio electrónico en el sector turístico __ 14

3.1.3. Uso de Internet por los turistas __ 16

3.1.4. Herramientas de la Web $2.0 \_19$

3.2. Antecedentes y limitaciones en el uso del contenido generado por los usuarios en Internet

3.2.1. Opiniones de los usuarios en Internet ___ 21

3.2.2. Uso de las bases de datos de opiniones en Internet ___ 27

3.2.3. Spam y opiniones falsas en Internet ___ 29

3.3. TripAdvisor __ 32

3.4. Booking __ 41

3.5. Principales Redes Sociales __ 45

3.5.1. Facebook _ 45

3.5.2. Twitter 49

3.5.3. YouTube

3.5.4. Flickr_L 52

4. METODOLOGÍA GENERAL Y DISEÑO MUESTRAL___ 53

4.1. Metodología empleada __ 53

4.2. Tipos de webs que recogen opiniones sobre hoteles___ 54

4.3. Webs de opiniones de hoteles más usadas en España ___ 57

4.4. Diferencias entre los sistemas de TripAdvisor y Booking ___ 61

4.5. Representatividad de Booking y TripAdvisor como bases de datos. Diseño de la muestra general __ 63

4.5.1. Metodología de selección de la muestra general____ 63

4.5.2. Magnitudes principales de la muestra ___ 64

4.6. Conclusiones sobre las bases de datos de opiniones de hoteles___ 67

5. FUNCIONAMIENTO DEL SISTEMA DE PUNTUACIONES DE BOOKING 70

5.1. La escala 2,5 - 10 de Booking ___ 71

5.2. Efectos de la escala del sistema de puntuaciones de Booking ___ 75

5.2.1. Priceline 75

5.2.2. Objetivos y Metodología___ 78

5.2.3. Muestra__ 80

5.2.4. Resultados de la comparación entre Booking y Priceline ___ 82

5.2.5. El caso del Hotel Pennsylvania ___ 88 
6. EVOLUCIÓN DE LAS VALORACIONES DE LOS HOTELES ESPAÑOLES DE COSTA (2011-2014)

6.1. Introducción y Metodología____ 95

6.2. Resultados obtenidos___ 96

6.3. Conclusiones__ 99

7. FACTORES QUE INFLUYEN EN LA PUNTUACIÓN DE LOS HOTELES 102

7.1. Relación entre número de estrellas y puntuación del hotel 102

7.2. Relación entre el tamaño del hotel y su número de estrellas y empleados 104

7.3. Relación entre el tamaño de un hotel y el número de opiniones 105

7.4. Relación entre el número de estrellas y el número de opiniones de un hotel 105

7.5. Relación entre el número de opiniones y las puntuaciones de un hotel 106

7.6. Conclusiones sobre los factores que influyen en las puntuaciones __ 108

8. USO DE LAS REDES SOCIALES POR LOS HOTELES ___ 113

8.1. Introducción — 113

8.2. Metodología___ 115

8.3. Resultados__ 117

8.4. Conclusiones 122

9. RELACIÓN ENTRE EL USO DE REDES SOCIALES Y LA PUNTUACIÓN DE LOS HOTELES — 125

9.1. Introducción — 125

9.2. Metodología ___ 125

9.3. Resultados___ 126

9.4. Conclusiones___ 131

10. INDICIOS DE ALGUNAS ANOMALÍAS EN LAS PUNTUACIONES DE HOTELES EN TRIPADVISOR__ 133

10.1. Introducción _ـ 133

10.2. Metodología y muestra ___ 133

10.3 Resultados _ 136

10.4. Interpretación de los resultados __ 140

10.5. Conclusiones e implicaciones para el sector hotelero ___ 144

11. APROXIMACIÓN CUALITATIVA AL PROBLEMA DE LA FIABILIDAD EN TRIPADVISOR 
11.2. Opiniones incentivadas en TripAdvisor

11.2.1. Introducción

11.2.2. Metodología

11.2.3. Casos detectados

11.2.4. Verificaciones a través de Twitter

11.2.5. Cuantificación del efecto causado al incentivar las opiniones 158

11.3. Tarjetas invitando a opinar en TripAdvisor 159

11.4. Generación de opiniones falsas en TripAdvisor 166

11.5. Verificación humana de las opiniones en TripAdvisor 170

11.6. La reputación de TripAdvisor ante la difusión de noticias negativas 177

11.6.1. Introducción

11.6.2. Metodología 178

11.6.3. TripAdvisor designa al "hotel más sucio de América" ___ 180

11.6.4. Demanda judicial por el "Cuadro Rojo" ___ 182

11.6.5. Presiones a hoteleros___ 183

11.6.6. Hoteles con descuentos por escribir opiniones positivas _ 185

11.6.7. Investigación de la Advertising Standards Authority ___ 186

11.6.8. El grupo Carlton y las opiniones de sus empleados __ 189

11.6.9. Ramada Hotel de Glasgow haciendo que sus empleados escriban opiniones _ 191

11.6.10. Un ejecutivo de Accor escribiendo opiniones __ 194

11.6.11. "Albergue de vagabundos" en Glasgow____ 195

11.6.12. Un Restaurante inexistente ___ 198

11.6.13. Una señora escocesa clasificada como atracción turística ___ 200

11.6.14. TripAdvisor multada en Italia __ 201

11.7. Conclusiones__ 204

12. CONCLUSIONES GENERALES, LIMITACIONES, LÍNEAS FUTURAS DE INVESTIGACIÓN Y APORTACIONES _ 211

12.1. Conclusiones generales___ 211

12.2. Futuras líneas de investigación___ 214

12.3. Aportaciones de la investigación __ 216

13. REFERENCIAS BIBLIOGRÁFICAS _ 218

14. ANEXOS 229

ANEXO 1: Opiniones de hoteles registradas en Booking __ 229

ANEXO 2: Ejemplos de puntuaciones individuales de hoteles en Booking__232

ANEXO 3: Incentivos para opinar en TripAdvisor (Twitter) __ 236

ANEXO 4: Guía "reputación online" del Instituto tecnológico hotelero ${ }_{2} 243$

ANEXO 5: Contratación de freelancers para escribir en TripAdvisor___ 251

ANEXO 6: Opiniones sin haber estado en hoteles ___ 254

ANEXO 7: Material gráfico contra TripAdvisor 259 


\section{ÍNDICE DE TABLAS}

Tabla 1. Tamaño muestral del estudio de audiencias en Internet ............................. 10

Tabla 2. Evolución de los datos generales de uso de Internet. .................................. 11

Tabla 3. Uso de redes sociales (último acceso) .................................................. 13

Tabla 4. Redes sociales más utilizadas. ................................................................... 13

Tabla 5. Acceso a través de dispositivos móviles ........................................................ 14

Tabla 6. Productos y servicios más comprados a través de Internet........................... 15

Tabla 7. Webs más utilizadas para servicios turísticos. ........................................... 16

Tabla 8. Uso de Internet por los turistas que visitan España (2012).......................... 17

Tabla 9. Decisión de compra informada a través de Internet ...................................22

Tabla 10. Boca a boca en Internet. .................................................................. 22

Tabla 11. The Nielsen Global Survey of Trust in Advertising................................... 23

Tabla 12. Opiniones de hoteles en Suiza.............................................................. 29

Tabla 13. Número de alojamientos por país disponibles en Booking ..........................42

Tabla 14. Terminologías empleadas para describir Facebook ..................................4 4

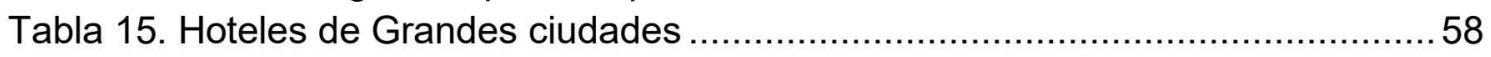

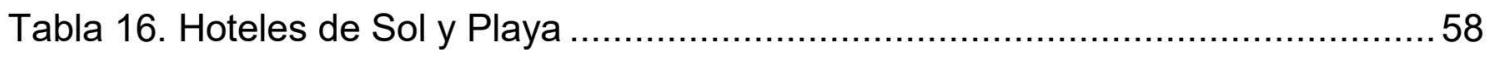

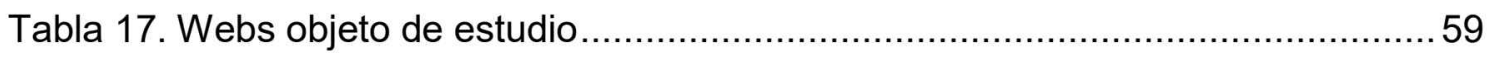

Tabla 18. Composición de la muestra por número de opiniones registradas. .............67

Tabla 19. Opiniones registradas por fuente de información ......................................67

Tabla 20. Resultados de las encuestas completadas en Booking ............................. 72

Tabla 21. Distribución de la muestra por categorías ............................................. 84

Tabla 22. Puntuaciones del Hotel Pensylvania. ..................................................... 90

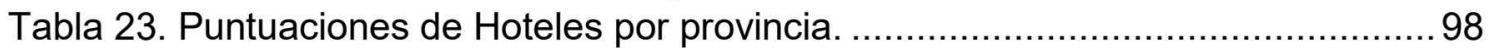

Tabla 24. Porcentaje de hoteles por provincia según número de estrellas ................ 103

Tabla 25. Plazas por hotel y habitaciones por empleado ....................................... 104

Tabla 26. Número de opiniones en función del número de habitaciones ................... 105

Tabla 27. Numero de estrellas y número de opiniones registradas ........................... 106

Tabla 28. Puntuaciones en función de las opiniones............................................... 107

Tabla 29. Puntuaciones en función de las opiniones (Booking) ............................... 107

Tabla 30. Puntuaciones en función de las opiniones (TripAdvisor) .......................... 108

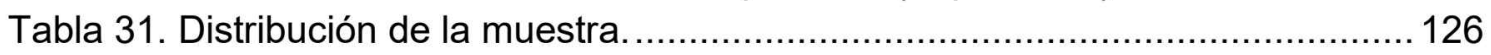

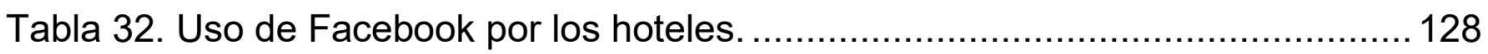

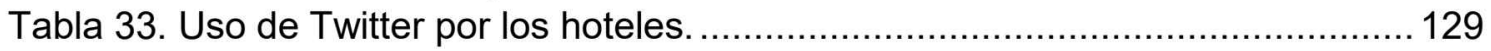

Tabla 34. Uso de YouTube por los hoteles ......................................................... 129

Tabla 35. Uso de Flickr por los hoteles .......................................................... 130

Tabla 36. Datos estadísticos de las distribuciones .............................................. 139

Tabla 37. El hotel "más sucio" de América.............................................................. 181

Tabla 38. Demanda judicial por el "cuadro rojo".......................................................... 183

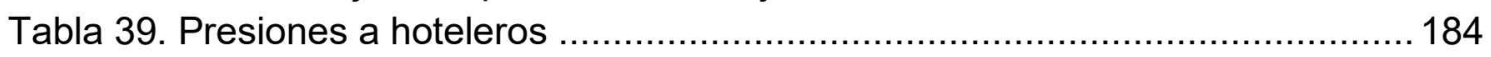

Tabla 40. Hoteles con descuentos por escribir opiniones positivas........................... 186

Tabla 41. Investigación de la Advertising Standards Authority ................................ 187

Tabla 42. El grupo Carlton y las opiniones de sus empleados ................................ 190

Tabla 43. Ramada Hotel de Glasgow haciendo que sus empleados escriban opiniones

Tabla 44. Ejecutivo de Accor escribiendo opiniones 


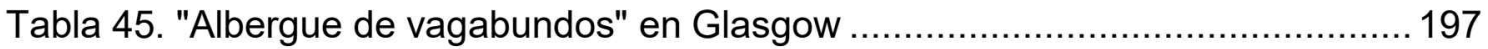

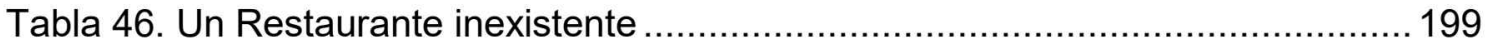

Tabla 47. Una señora escocesa clasificada como atracción turística .......................... 201

Tabla 48. TripAdvisor investigada en Italia............................................................ 202

Tabla 49. TripAdvisor multada por las opiniones falsas. ..................................... 204 


\section{ÍNDICE DE GRÁFICOS}

Gráfico 1. Perfil por edad de usuarios de Internet .......................................... 12

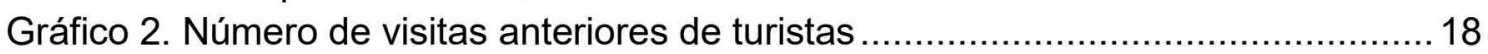

Gráfico 3. Evolución del precio de las acciones de TripAdvisor ................................... 32

Gráfico 4. Millones de usuarios activos en Facebook (2008-2014) ...........................46

Gráfico 5. Edad de los usuarios de Facebook en España ............................................ 48

Gráfico 6. Porcentaje de opiniones de hoteles en Webs .............................................60

Gráfico 7. Porcentaje de opiniones de hoteles en Webs según tipología .....................60

Gráfico 8. Porcentaje de hoteles de Playa/Costa por provincia ..................................65

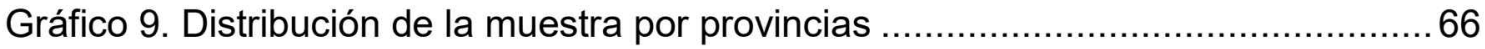

Gráfico 10. Diferencias de puntuaciones entre Priceline y Booking............................ 82

Gráfico 11. Distribución de frecuencias de la muestra de hoteles. .............................. 84

Gráfico 12. Distribución de frecuencias de la muestra. ............................................. 85

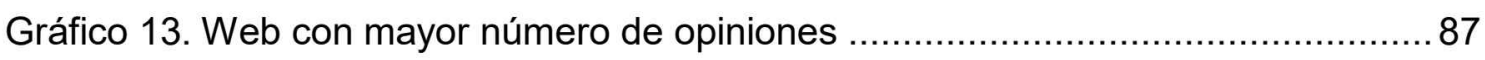

Gráfico 14. Puntuaciones provinciales por cuartiles (2011)....................................97

Gráfico 15. Puntuaciones provinciales por cuartiles (2014)................................... 99

Gráfico 16. Uso de redes sociales por los hoteles ............................................ 117

Gráfico 17. Uso de Facebook por los hoteles ..................................................... 118

Gráfico 18. Uso de Facebook según el número de estrellas .....................................119

Gráfico 19. Uso de Twitter por los hoteles ............................................................ 120

Gráfico 20. Uso de Twitter según el número de estrellas .................................... 121

Gráfico 21. Uso de YouTube por los hoteles................................................... 121

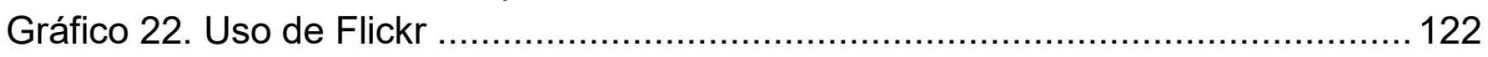

Gráfico 23. Distribución de la muestra en TripAdvisor........................................... 127

Gráfico 24. Distribución de la muestra en Booking .................................................. 128

Gráfico 25. Distribución de la muestra en TripAdvisor ........................................... 135

Gráfico 26. Hoteles con 3 estrellas en TripAdvisor ........................................... 137

Gráfico 27. Hoteles con 3,5 estrellas en TripAdvisor ............................................ 137

Gráfico 28. Hoteles con 4 estrellas en TripAdvisor.................................................. 138

Gráfico 29. Hoteles con 4,5 estrellas en TripAdvisor .............................................. 138

Gráfico 30. Test de Kolmogorov-Smirnov para hoteles con 3 estrellas ..................... 140

Gráfico 31. Ejemplo de situación con hoteles sospechosos ................................... 142

Gráfico 32. Opiniones no condicionadas (Beech Hill Hotel) ................................... 158

Gráfico 33. Opiniones no condicionadas (Tempo Hotel) ....................................... 159

Gráfico 34. Valor de la acción Enero-Abril 2012 ................................................ 189

Gráfico 35. Valor de la acción Septiembre-Diciembre 2012 ................................... 193

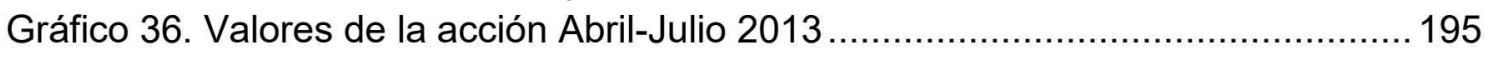

Gráfico 37. Valores de la acción Marzo-Junio 2013 ................................................... 198

Gráfico 38. Valores de la acción Junio-Septiembre 2013 ...................................... 200

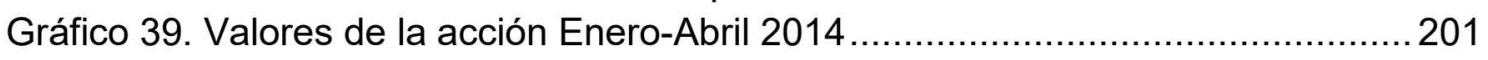

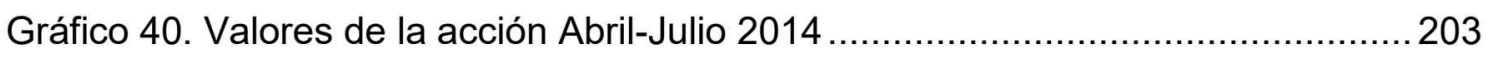




\section{ÍNDICE DE FIGURAS}

Figura 1. Esquema gráfico de Tesis.......................................................................... 4

Figura 2. Porcentaje del uso de Internet de los turistas que visitan España ................ 18

Figura 3. Representación gráfica de las Redes Sociales (2013) ................................. 20

Figura 4. Factores que influyen en la planificación de viajes......................................25

Figura 5. Principales cifras de TripAdvisor (2013) .................................................... 33

Figura 6. Países con más contribuciones en TripAdvisor (2013)................................ 33

Figura 7. Utilidad de TripAdvisor para los usuarios ............................................... 34

Figura 8. Puntuación y ranking de hoteles en TripAdvisor .........................................34

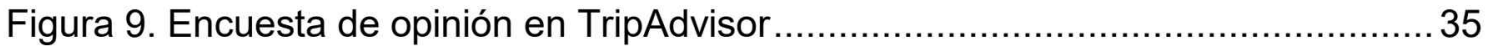

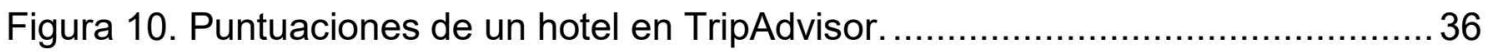

Figura 11. Segmentación por número de estrellas del hotel.................................... 36

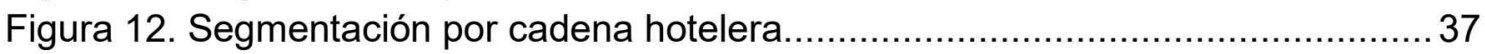

Figura 13. Segmentación por servicios que presta el hotel ...................................... 37

Figura 14. Advertencias al escribir una crítica en TripAdvisor. ................................... 38

Figura 15. Ejemplo de hotel penalizado por TripAdvisor ......................................... 40

Figura 16. Detalle del "aviso en rojo" para un hotel penalizado ................................. 40

Figura 17. Presentación de datos de opiniones en Booking ...................................... 44

Figura 18. Segmentación de hoteles en Booking ................................................... 44

Figura 19. Email de Booking para rellenar encuesta................................................ 71

Figura 20. Encuesta de valoración del hotel en Booking ...................................... 72

Figura 21. Nuevo cuestionario de Booking.................................................... 74

Figura 22. Presentación de la información de un hotel en Priceline y Booking.............76

Figura 23. Email de Priceline para rellenar su encuesta. ........................................ 77

Figura 24. Encuesta de valoración del hotel en Priceline .......................................... 77

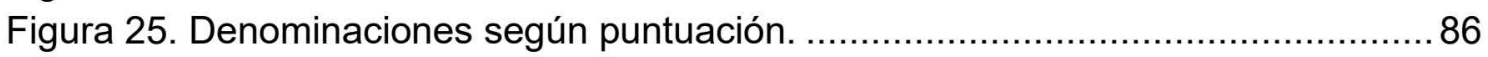

Figura 26. Puntuaciones del Hotel Pensylvania en Priceline y Booking ...................... 89

Figura 27. Relación Componentes vs Puntuación...................................................... 111

Figura 28. Ficha técnica del estudio de HostelMarket .............................................. 113

Figura 29. Principales resultados del estudio de Hostelmarket .................................... 114

Figura 30. Ejemplos de puntuaciones en TripAdvisor ............................................. 144

Figura 31. Códigos para participar en concurso ................................................ 151

Figura 32. Ejemplo de participación en concurso de Marina D'Or .............................. 153

Figura 33. Promoción de Poseidón Hoteles publicada en Facebook y Twitter .......... 155

Figura 34. Conversación en Twitter con TripAdvisor ............................................. 156

Figura 35. Promoción de Lancaster y conversación con TripAdvisor ........................ 157

Figura 36. Ejemplos de tarjetas que invitan a opinar a los clientes ......................... 160

Figura 37. Tarjeta del Hotel Extended Stay America Renton ..................................161

Figura 38. Extracto de las instrucciones del manual del ITH .................................... 163

Figura 39. Conversación por Twitter con TripAdvisor y el ITH.................................. 164

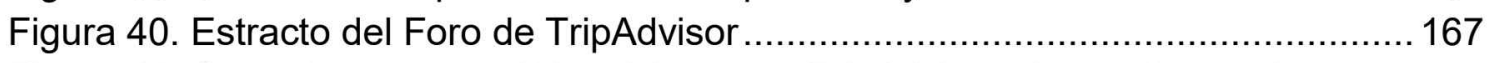

Figura 41. Consejos para escribir opiniones en TripAdvisor sin ser detectado.......... 168

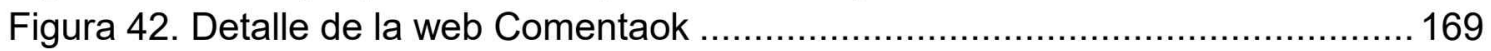

Figura 43. Artículo New York Times.................................................................. 170

Figura 44. Opinión real, aceptada y publicada en TripAdvisor ............................... 173

Figura 45. Pregunta en Twitter al perfil oficial TripAdvisor en España...................... 176 
Figura 46. Pregunta en Twitter al perfil oficial TripAdvisor Internacional 176

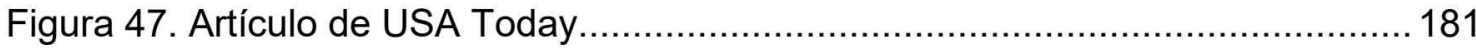

Figura 48. Noticia sobre sentencia del hotel más sucio de América........................... 182

Figura 49. Artículo en The Telegraph............................................................. 183

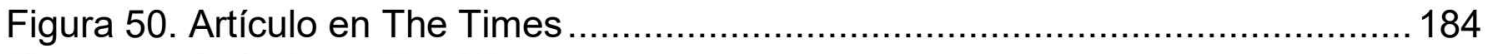

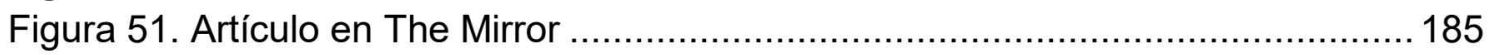

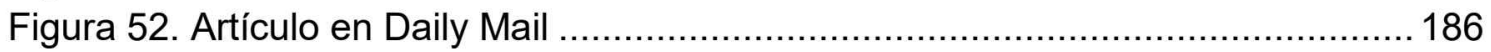

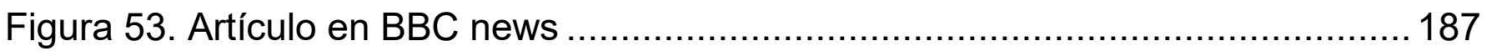

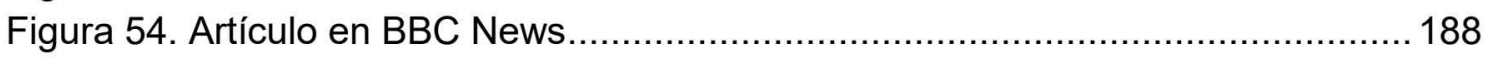

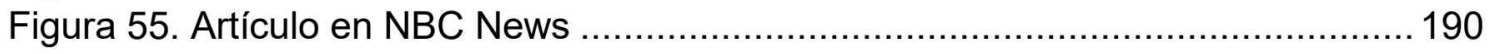

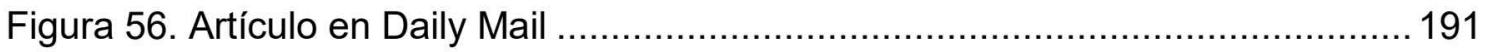

Figura 57. Valoraciones del hotel en TripAdvisor ................................................... 192

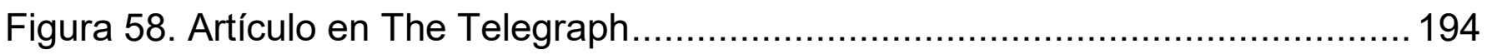

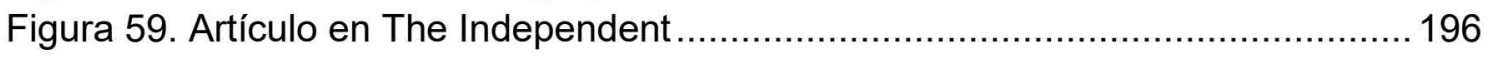

Figura 60. Perfil eliminado del Bellgrove Hotel...................................................... 197

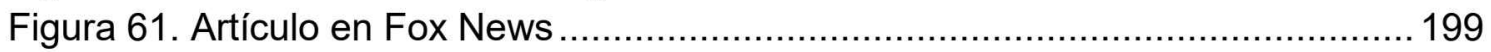

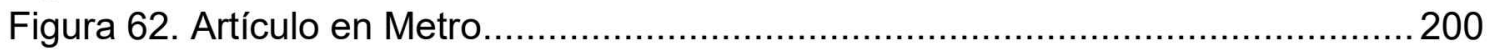

Figura 63. Artículo en Financial Times .............................................................. 202 


\section{INTRODUCCIÓN}

Internet cobra cada vez más importancia en la vida cotidiana de la mayor parte de los ciudadanos, así como en los procesos de comunicación y venta en la mayoría de los sectores de la economía. El turístico es uno de los más afectados por esta nueva realidad desde hace años, como indican los datos de diferentes estudios sobre internautas y turismo. Los que consultan Internet antes de decidir el destino de sus vacaciones o contratan su hotel a través de la web son ahora mayoría frente a los que utilizan las vías tradicionales.

Entre finales del pasado siglo y principios del presente, los hoteles de todo el mundo fueron entendiendo progresivamente la importancia que tiene Internet para sus negocios, adaptándose progresivamente a esa nueva realidad. En una primera fase, ese proceso consistía básicamente en la creación de una página web del hotel y acuerdos con las agencias de viajes ya existentes en la red, para la venta de sus servicios, de igual forma que hasta ese momento se hacía con las agencias de viajes convencionales.

Pero en los últimos años se ha producido un nuevo fenómeno, denominado Web 2.0, que si bien fue definido en 2005, ha alcanzado una dimensión realmente significativa hacia 2009, con la popularización de las redes sociales encabezadas por Facebook y Twitter. El concepto de Web 2.0 trata de describir el fenómeno por el cual los usuarios pasan a ser partícipes de la web y no meros espectadores que visualizan información. El usuario aporta contenidos, realiza comentarios, comparte ideas, imágenes y vídeos con toda la web o con comunidades de usuarios. Que sean los usuarios los que aporten los contenidos hace necesariamente sencillas todas estas aplicaciones, de forma que su uso resulte muy asequible a millones de personas.

Para los hoteles ese contenido generado por los usuarios, resulta determinante para el éxito de sus negocios. La mayor parte de los viajeros consultan las opiniones de otros individuos diseminadas por la red, a las que conceden altos niveles de credibilidad. Además, la venta está cada vez más canalizada a través de agencias de viaje online, ante las que todos los establecimientos tienen unas condiciones similares. En un mercado dominado 
por la distribución a través de agencias online y en el que las opiniones compartidas por los clientes resultan un factor determinante, la búsqueda de la mejora de la experiencia de los clientes se convierte en la principal vía de crecimiento de los hoteles.

Esta nueva situación conduce a un replanteamiento de las estrategias de Marketing de este tipo de organizaciones, que ven como lo relativo a la publicidad convencional y la optimización de los sistemas de intermediación, pasa a un segundo plano. Esto supone que la imagen que proyecta el hotel escapa del control de sus gestores y pasa a depender de un grupo de clientes que, generalmente amparados en el anonimato, expresan libremente su opinión subjetiva sobre sus experiencias.

En redes sociales convencionales como Facebook o Twitter, los hoteles tienen la posibilidad de interactuar con los usuarios, generar sus propios contenidos y ser proactivos en la gestión de su marca. Pero en webs como Booking o TripAdvisor, que recogen las opiniones y puntuaciones que los usuarios dan a los hoteles, las posibilidades de intervención o influencia de la empresa resultan mínimas.

El desarrollo de la presente Tesis gira alrededor de esos aspectos, que forman parte de la llamada Web 2.0 en relación a los hoteles. Concretamente trabajamos sobre tres ejes principales, a partir de los cuales desarrollamos la mayor parte de los contenidos:
a) Redes Sociales
b) Booking
c) TripAdvisor

Analizamos el uso de las redes sociales en los hoteles de costa españoles y utilizamos las grandes bases de datos de puntuaciones asignadas a los hoteles de Booking y TripAdvisor, como indicativo del nivel de satisfacción de los clientes, para el desarrollo de diversos estudios.

Pero la principal aportación esta Tesis proviene del análisis crítico que se hace precisamente de esos tres elementos, incidiendo en cuestionar los 
procedimientos e ideas de los estudios que tratan del uso de redes sociales o que usan las bases de datos de Booking y TripAdvisor. De forma resumida, éstas son las cuestiones sobre las que pretendemos realizar un análisis:

- Redes Sociales: Ampliamos el espectro de los estudios convencionales, evitando limitarnos a describir el porcentaje de hoteles que utilizan una $u$ otra red social. Establecemos una novedosa metodología que permite determinar de manera objetiva que hoteles no hacen un uso adecuado de estas herramientas. Complementamos este análisis estableciendo posibles relaciones entre el nivel de implantación de las redes sociales y el desempeño de los hoteles, medido por sus puntuaciones en Booking y TripAdvisor.

- Booking: Realizamos un profundo análisis del sistema de puntuaciones que utiliza esta web. Las conclusiones indican un sorprendente e inesperado sistema, diferente al que diversos autores daban como cierto en sus publicaciones. Este hallazgo obliga a cuestionar los resultados de gran parte de los estudios que han utilizado las valoraciones de Booking en el pasado y podrá ser tenido en cuenta en futuras investigaciones que utilicen esta metodología. Adicionalmente determinamos los efectos que tiene este peculiar sistema sobre las valoraciones que obtienen los hoteles, observando como contribuye a incrementarlas, especialmente en los casos de los hoteles con valoraciones medias o bajas.

- TripAdvisor: Abordamos la problemática de la fiabilidad de los datos que proporciona esta web desde diferentes enfoques. Por una parte, realizamos un estudio cuantitativo, que demuestra que su incidencia no parece ser significativa en los casos de establecimientos con un número mínimo de opiniones. Por otro lado, utilizando una perspectiva más cualitativa, describimos las diferentes formas que hemos encontrado de posible incumplimiento de la normativa de TripAdvisor. La cantidad y variedad de los casos descritos ponen de manifiesto la relativa facilidad con la que es posible incluir contenido manipulado y la aparente falta de control de este problema que parece existir. 
Presentamos en la Figura 1 un esquema gráfico de la Tesis, en el que los círculos representan las fuentes de información o cuestiones tratadas, mientras los cuadrados, representan los análisis desarrollados que corresponden con capítulos o apartados de la misma.

Figura 1. Esquema gráfico de Tesis

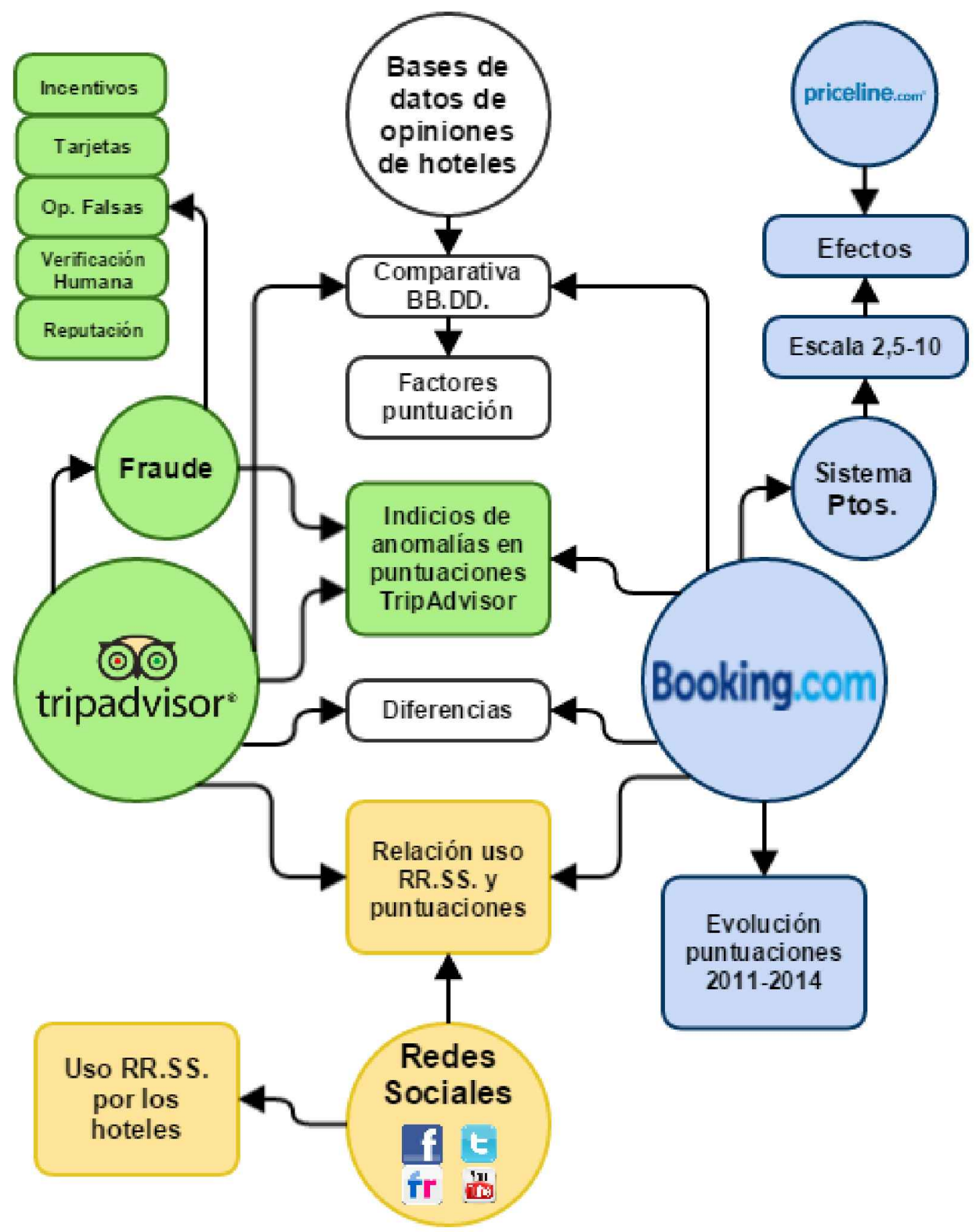

Fuente: Elaboración propia 


\section{PLANTEAMIENTO Y OBJETIVOS}

Esta Tesis parte de la importancia que tiene Internet para el sector turístico y, paralelamente, la importancia que ha alcanzado todo lo relacionado con la llamada Web 2.0 en Internet en los últimos años. La comercialización de estancias en hoteles se encuentra estrechamente ligada a Internet, por lo que lo relativo a los nuevos usos de este medio resulta de vital importancia para el sector.

Pero lo que se entiende como Web 2.0 engloba multitud de tipos de webs, herramientas y aplicaciones (webs, foros, blogs, redes sociales, etc.), siendo incluso complejo determinar exactamente qué engloba la Web 2.0 y sus diferencias con lo que se conoce como "social media" 0 Web social. Realizaremos una descripción general de este complejo mundo, pero por su amplitud nos vemos obligados a centrarnos en una serie de webs y herramientas, que creemos que son las que, de forma efectiva, resultan de mayor interés para el sector hotelero.

Dedicaremos gran parte de nuestro análisis a las webs que recogen opiniones y puntuaciones de los viajeros sobre hoteles. Nos centraremos especialmente en Booking y TripAdvisor, por ser las de mayor relevancia cuantitativa y cualitativa en la actualidad. Por otra parte, analizaremos el uso que hacen los hoteles de cuatro redes sociales especialmente significativas en la actualidad: Facebook, Twitter, YouTube y Flickr.

Al elegir una muestra de hoteles, sobre la que realizar los principales análisis cuantitativos, optamos por una muestra amplia y homogénea. Por este motivo, se realiza una selección de hoteles españoles orientados al "Turismo de Sol y Playa", por el importante peso de este tipo de turismo en la industria hotelera española y europea.

En cuanto a la metodología empleada para la realización del estudio cuantitativo, se opta principalmente por aprovechar las propias oportunidades que ofrece la Web 2.0. Utilizando las bases de datos que configuran las webs de opiniones sobre hoteles, indagamos directamente en Internet sobre el uso de las redes sociales que hacen estos establecimientos. De forma 
complementaria se realizaron reservas reales en hoteles, para posteriormente exponer nuestros comentarios y ver los efectos que se obtenían. También interactuamos a través de Twitter con TripAdvisor y descartamos explícitamente las encuestas directas a usuarios de hoteles sobre su grado de satisfacción y las realizadas a hoteles sobre su uso de las redes sociales. De esta forma obtenemos tamaños muestrales mucho más amplios, a un coste económico y de tiempo más reducido. Además evitamos ciertos sesgos, lo que aumenta la fiabilidad de los resultados obtenidos. Se trata de una metodología novedosa y todavía poco utilizada hasta ahora en los estudios sobre el sector hotelero.

La literatura académica previa existente sobre los distintos conceptos tratados en este estudio resulta especialmente escasa, en muchos casos. Además los datos cuantitativos que proporciona pueden haber quedado anticuados, debido a la rápida evolución de las cifras de usuarios, opiniones, etc. Por esta razón, resulta obligado recurrir a datos proporcionados por instituciones públicas o privadas, disponibles a través de Internet. Esta es, en muchas ocasiones, la única forma de acceder a información actualizada y con tamaños muestrales lo suficientemente amplios para proporcionar la fiabilidad requerida.

En el capítulo 3 se realiza una revisión bibliográfica de la literatura sobre los diferentes aspectos tratados en el ámbito de esta Tesis, que combinamos con algunos datos cuantitativos de estudios ajenos al ámbito académico y que complementamos con diversa información publicada en Internet. También se dedican apartados específicos a la descripción de los tres principales ejes sobre los que basamos esta Tesis: Redes Sociales, Booking y TripAdvisor.

En el capítulo 4 se establece la metodología empleada con carácter general, a partir de la comparación entre las diferentes webs que ofrecen valoraciones de hoteles, y realizamos la selección de la principal muestra empleada. En los capítulos posteriores se abordan diferentes análisis de forma independiente. 
A través de diversas investigaciones cualitativas y cuantitativas, pretendemos conseguir los siguientes objetivos, que dividimos en dos áreas principales: las opiniones en hoteles y las redes sociales.

1. Opiniones sobre establecimientos hoteleros:

a) Realizar una clasificación de las distintas webs que incluyen valoraciones de hoteles, explicando su funcionamiento y principales características. Realizar además una cuantificación de la importancia de éstos a través de datos ya publicados y de un estudio específico sobre los hoteles en España.

b) Describir las principales diferencias entre Booking y TripAdvisor. Ambas webs son exponentes de los principales tipos de webs de opiniones: las que se abastecen de opiniones verificadas de sus propios clientes y las que permiten que cualquier usuario anónimo pueda escribir una opinión.

c) Cuantificar el valor de Booking y TripAdvisor como bases de datos útiles para la realización de estudios científicos sobre la satisfacción de los clientes de hoteles. Se analizará la información pública presente en ambas webs, la resultante de estudios previos y se desarrollará un estudio propio con la base de datos de hoteles españoles de "Sol y Playa"

d) Realizar un análisis del sistema de funcionamiento y puntuaciones de Booking, como una de las principales bases de datos de valoraciones de hoteles en Europa. Se busca identificar las peculiaridades del sistema, de forma que las conclusiones obtenidas orienten, tanto en la presente investigación como en la de futuros investigaciones que otros académicos pudieran hacer basándose en dichos datos.

e) Realizar un estudio sobre las puntuaciones obtenidas por los hoteles de "Sol y Playa" de España, utilizando las opiniones registradas en Booking entre los años 2011 y 2014. Mediremos las diferentes valoraciones obtenidas por los hoteles en función de parámetros geográficos. 
f) Analizar las relaciones entre las puntuaciones obtenidas por los hoteles en Booking y los factores tales como el número de estrellas, el tamaño del hotel y el número de opiniones registradas.

g) Tratar de detectar el volumen de "opiniones falsas" existentes en TripAdvisor, comparando las puntuaciones en esta web con las registradas en Booking. Considerando como hipótesis que las opiniones de Booking son totalmente fiables, detectamos hoteles cuyas puntuaciones en TripAdvisor difieran sustancialmente de las obtenidas en Booking. Esas variaciones podrían indicar la existencia de cierto número de opiniones falsas.

h) Realizar un acercamiento cualitativo a la problemática de la fiabilidad de la información en TripAdvisor. Para ello se describirán diversas formas de incumplimiento de su normativa mediante ejemplos reales. Adicionalmente realizaremos una valoración de los sistemas de detección y procedimientos de actuación ante este tipo de situaciones.

i) Analizar la problemática de la difusión de noticias sobre casos de fraude en TripAdvisor, profundizando en la crisis de reputación que esta situación pudiera estar provocando. Describimos la casuística existente, realizando una recopilación de la información diseminada por Internet y en los principales medios de comunicación mundiales.

\section{Uso de redes sociales}

a) Analizar el nivel de uso de los hoteles de "Sol y Playa" españoles de las redes sociales, centrándonos en las cuatro que entendemos más destacadas: Facebook, Twitter, YouTube y Flickr.

b) Establecer unos criterios que nos indiquen, de forma objetiva, que hoteles usan las redes sociales de forma inadecuada, para poder cuantificar además este fenómeno, ya que consideramos que el hecho de poder estar presente en las redes sociales sea gratuito y no requiera de profesionales formados, puede propiciar que en algunos casos la incorporación de los hoteles se realice de una forma deficiente.

c) Estudiar las posibles relaciones que pudieran existir entre las puntuaciones recibidas por los hoteles y su uso de las redes sociales. Partiendo de la hipótesis de que un hotel bien gestionado usará 
redes sociales, la buena gestión también tendrá como consecuencia la obtención de puntuaciones medias más altas que los de su competencia directa. Para este análisis utilizaremos la base de datos de hoteles de "Sol y Playa" recopilada y los datos obtenidos en investigaciones previas. 


\section{REVISION BIBLIOGRÁFICA - CONTEXTO CIENTÍFICO}

\subsection{Uso de Internet en la Web 2.0 y el Turismo 2.0}

La evolución de Internet en los últimos años ha venido acompañada de la incorporación de una serie de nuevas herramientas, englobadas en los que se conoce como Web 2.0. La posibilidad de que los usuarios generen contenidos y los compartan a través de las redes sociales, junto con la irrupción de los dispositivos móviles con acceso a Internet, ha cambiado sustancialmente la forma en la que las empresas deben enfocar sus estrategias de comunicación online. Los servicios turísticos son comercializados y promocionados por estas vías, cada vez en un mayor porcentaje, lo que obliga al sector a prestar una especial atención a todos estos fenómenos.

\subsubsection{La nueva dimensión de Internet}

El avance de Internet en nuestra sociedad, no se limita a un progresivo aumento en el número de usuarios, implica también cambios en su perfil y en su comportamiento cuando usan Internet. Tomamos como referencia para mostrar esta evolución el Estudio General de Medios (EGM, 2014), en su parte correspondiente a las "Audiencias en Internet", que cuenta con una serie temporal especialmente extensa y una muestra de un tamaño considerable (Tabla 1). También utilizamos los datos del estudio "Navegantes en la red", correspondiente a su edición número dieciséis de Febrero de 2014, que desarrolla la Asociación para la Investigación de Medios de Comunicación (AIMC, 2014) y que colabora también en el EGM.

Tabla 1. Tamaño muestral del estudio de audiencias en Internet

\begin{tabular}{|cc|cc|}
\hline PERIODO TEMPORAL & MUESTRA ÚTIL & PERIODO TEMPORAL & MUESTRA ÚTIL \\
\hline Primavera 1998 & 32.408 & Otoño 2006 & 49.418 \\
Otoño 1999 & 35.234 & Otoño 2007 & 41.667 \\
Primavera 2001 & 43.942 & Otoño 2008 & 40.446 \\
Otoño 2002 & 47.068 & Otoño 2009 & 36.000 \\
Otoño 2003 & 40.865 & Otoño 2010 & 39.709 \\
Otoño 2004 & 53.647 & Otoño 2011 & 34.656 \\
Otoño 2005 & 57.310 & Otoño 2012 & 33.254 \\
\hline
\end{tabular}

Fuente: $16^{\circ}$ Navegantes en la red (AIMC). 
El primer factor a destacar es el crecimiento en la frecuencia de uso de Internet. Si tomamos como referencia el periodo 2005-2013 según se muestra en la Tabla 2, observamos cómo el número de usuarios de Internet ha pasado de representar el $34 \%$ de la población al $66 \%$, lo que significa casi duplicar el número de usuarios. Pero si nos fijamos en los usuarios que usan Internet cada día, vemos como la cifra pasa del $20 \%$ al $56 \%$, lo que supone casi triplicar el número de usuarios habituales de Internet. No sólo hay cada día más usuarios de Internet, sino que cada vez es usado con mayor frecuencia y dedicamos más tiempo a consultar datos en la red.

Tabla 2. Evolución de los datos generales de uso de Internet.

(Datos en miles. Individuos de 14 años o más)

\begin{tabular}{|c|c|c|c|c|c|c|c|c|}
\hline \multirow[b]{2}{*}{1996} & \multicolumn{2}{|c|}{ Usan ordenador } & \multicolumn{2}{|c|}{$\begin{array}{l}\text { Usan ordenador } \\
\text { habitualmente }\end{array}$} & \multicolumn{2}{|c|}{$\begin{array}{c}\text { Usan Internet } \\
\text { último mes }\end{array}$} & \multicolumn{2}{|c|}{$\begin{array}{c}\text { Usan Internet } \\
\text { aver }\end{array}$} \\
\hline & 6568 & $(19.4 \%)$ & 4449 & $(13.2 \%)$ & 342 & $(1.0 \%)$ & -. & \\
\hline 1997 & 7 & & & $(15.0 \%)$ & 931 & & 321 & $(0.9 \%$ \\
\hline 1998 & & & & $(17.5 \%)$ & 1579 & & 27 & $1.8 \%$ \\
\hline 1999 & & & & $(19.2 \%)$ & 2429 & $(7.0 \%)$ & 003 & $2.9 \%$ \\
\hline 2000 & 103 & $(29.8 \%)$ & 7567 & $(21.8 \%)$ & 4363 & $(12.6 \%)$ & 943 & $5.6 \%$ \\
\hline 2001 & 312 & $(33.1 \%)$ & 8551 & $(24.6 \%)$ & 7120 & ) & 143 & $(9.0 \%$ \\
\hline 2002 & 731 & $(33.7 \%)$ & 8457 & $(24.3 \%)$ & 7828 & $\%$ & 3693 & $(10.6 \%$ \\
\hline 2003 & 0 & $(37.1 \%)$ & 9715 & $(27.6 \%)$ & 9472 & $\%)$ & 4797 & $13.6 \%$ \\
\hline 2004 & 8 & $(40.7 \%)$ & 10518 & $(28.9 \%)$ & 1181 & \%) & 6132 & $(16.8 \%$ \\
\hline 2005 & 6 & $(42.2 \%)$ & 11102 & $(29.9 \%)$ & 127 & & 7292 & $(19.7 \%$ \\
\hline 2006 & 24 & $(43.4 \%)$ & 11812 & $(31.6 \%)$ & 140 & \%) & 8317 & $(22.2 \%$ \\
\hline 2007 & 291 & $(45.6 \%)$ & 12995 & $(34.3 \%)$ & 15563 & $(41.1 \%)$ & 9944 & $(26.2 \%$ \\
\hline 2008 & 90 & $(49.5 \%)$ & 14567 & $(38.1 \%)$ & 173 & $(45.4 \%)$ & 11443 & $(29.9 \%$ \\
\hline 2009 & 10 & $(52.8 \%)$ & 16368 & $(41.5 \%)$ & 19468 & $(49.3 \%)$ & 13525 & $(34.3 \%$ \\
\hline 2010 & 188 & $(55.5 \%)$ & 17571 & $(44.6 \%)$ & 2089 & $(53.0 \%)$ & 15127 & $(38.4 \%$ \\
\hline 2011 & 23343 & $(59.1 \%)$ & 19059 & $(48.3 \%)$ & 22529 & $(57.1 \%)$ & 16768 & $(42.5 \%$ \\
\hline $\mathrm{Feb} / \mathrm{Mc}$ & 2411 & $(61.1 \%)$ & 19672 & $(49.9 \%)$ & 23466 & $(59.5 \%)$ & 17911 & $(45.4 \%$ \\
\hline$A b r / A$ & 2433 & $(61.7 \%)$ & 20083 & $(50.9 \%)$ & 23815 & $(60.4 \%)$ & 18372 & $(46.6 \%$ \\
\hline Oct $/ \Lambda$ & 245 & (6 & 202 & $(51.4 \%)$ & 24204 & $(61.4 \%)$ & 19029 & $(48.2 \%$ \\
\hline Feb & 236 & & & & 24827 & & 20567 & $(52.3 \%$ \\
\hline$A b r / t$ & $23 \mathrm{c}$ & & & & 25160 & & 20588 & $(52.3 \%$ \\
\hline Oct/Nov 2013 & 24301 & $(61.8 \%)$ & 20893 & $(53.1 \%)$ & 26151 & $(66.5 \%)$ & 22192 & $(56.4 \%$ \\
\hline
\end{tabular}

Fuente: $16^{\circ}$ Navegantes en la red (AIMC).

En los inicios el perfil de usuario era bastante joven, pero esta tendencia ha ido cambiando progresivamente (Gráfico 1). Mientras que en 2007 el segmento de mayores de 55 años apenas representaba el 5\% de los usuarios, a principios de 2014 ya era casi el 20\%. Si a esto sumamos el segmento comprendido entre los 45 y los 54 años, observamos como más de un tercio de 
los usuarios de Internet tienen más de 45 años actualmente. Estos datos no implican una bajada en el número de usuarios jóvenes, entre los que ya se ha convertido en algo casi consustancial a su vida diaria, lo que demuestran claramente es un creciente interés de las personas de más edad por descubrir y usar este medio.

Gráfico 1. Perfil por edad de usuarios de Internet

(Base: usaron Internet ayer)

$\%$ individuos

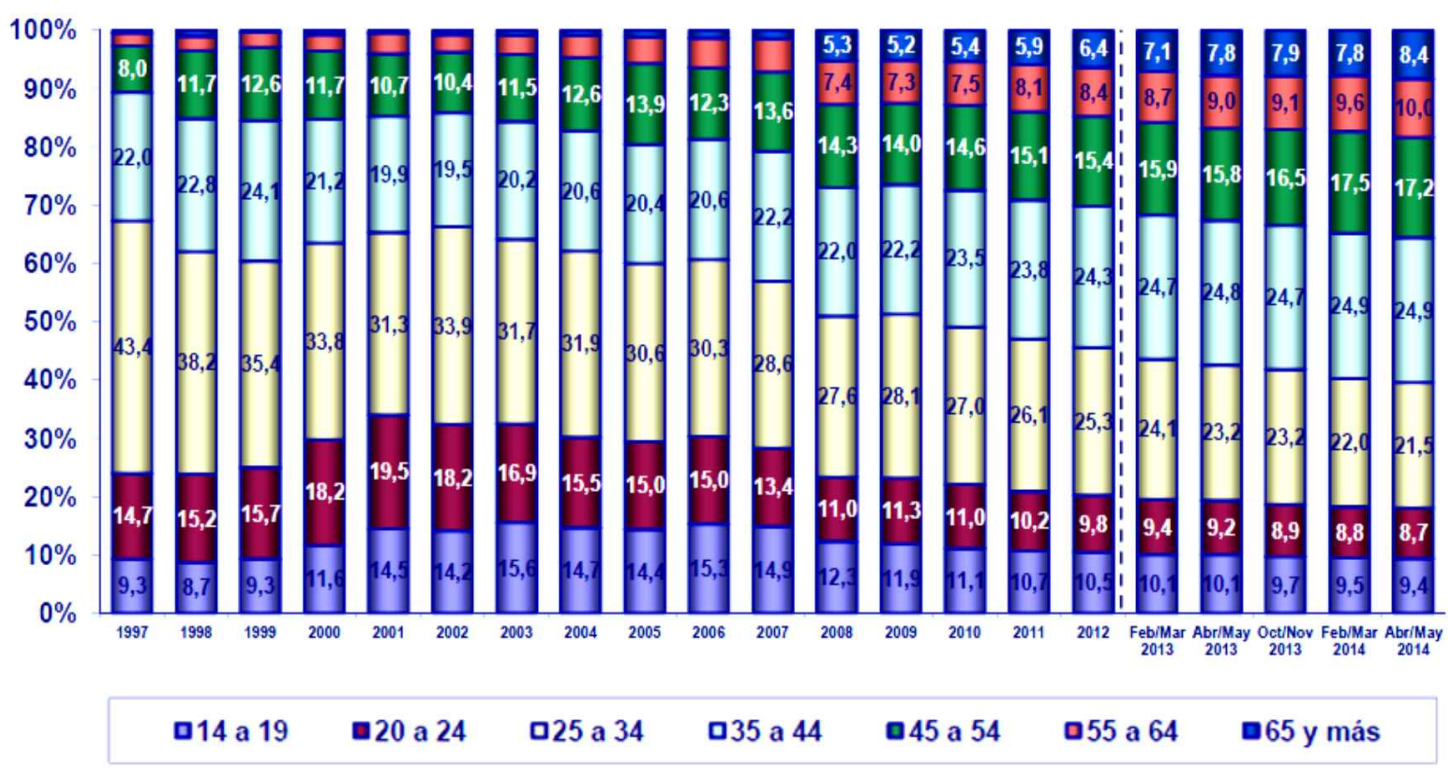

Fuente: Estudio General de Medios. Audiencia en Internet (Abril/Mayo 2014)

El fenómeno de las redes sociales, que comienza a ser conocido en España en el periodo 2008-2009, se ha situado en poco tiempo como el segundo servicio más utilizado en Internet, sólo superado por el correo electrónico. Para 2014, más del $90 \%$ de los internautas usaban redes sociales, accediendo al $74 \%$ el porcentaje de usuarios que lo hacen a diario (Tabla 3 ).

La implantación de redes sociales viene liderada por Facebook, aunque resulta destacable también el número de usuarios de otras redes sociales, según se muestra en la Tabla 4. 
Tabla 3. Uso de redes sociales (último acceso)

Sin contar el día de hoy ¿cuándo ha sido la última vez que ha accedido a una red social de Internet

\begin{tabular}{|lcc|}
\hline Periodo & Absolutos & $\%$ \\
\hline Ayer & 17.672 & 74,2 \\
\hline Últimos 7 días & 2.757 & 11,6 \\
\hline Últimos 30 días & 987 & 4,1 \\
\hline Último año & 566 & 2,4 \\
\hline Hace más tiempo/Nunca & 1.817 & 7,6 \\
\hline NS/NC & 12 & 0,1 \\
\hline
\end{tabular}

Fuente: $16^{\circ}$ Navegantes en la red (AIMC)

Tabla 4. Redes sociales más utilizadas.

¿Qué redes sociales utiliza?

Acceso en los últimos 30 días. Base: 21.416

\begin{tabular}{|lcc|}
\hline Red social & Absolutos & $\%$ \\
\hline Facebook & 19.331 & 90,3 \\
\hline Twitter & 9.662 & 45,1 \\
\hline Google+ & 8.077 & 37,7 \\
\hline Linkedin & 5.190 & 24,2 \\
\hline Instagram & 4.298 & 20,1 \\
\hline Tuenti & 2.283 & 10,7 \\
\hline Flickr & 1.600 & 7,5 \\
\hline Pinterest & 1.379 & 6,4 \\
\hline
\end{tabular}

Fuente: $16^{\circ}$ Navegantes en la red (AIMC)

De forma paralela al incremento en el uso de redes sociales, el uso de Internet a través de dispositivos móviles ha aumentado de forma espectacular desde 2008. En 2014, la gran mayoría de los internautas accedía a Internet a través de dispositivos móviles (Tabla 5). De hecho, el espectacular crecimiento de las redes sociales, no se entiende sin la popularización de los smartphones y tablets con acceso a Internet en estos años. 
Tabla 5. Acceso a través de dispositivos móviles

Sin contar el día de hoy ¿Cuándo ha sido la última vez que ha accedido a Internet a través de dispositivos móviles (teléfono móvil, tablet tipo

iPad,...)?

Base: 23.811

\begin{tabular}{|lcc|}
\hline Periodo & Absolutos & $\%$ \\
\hline Ayer & 19.606 & 82,3 \\
\hline Últimos 7 días & 1.734 & 7,3 \\
\hline Últimos 30 días & 649 & 2,7 \\
\hline Hace más tiempo & 579 & 2,4 \\
\hline Nunca & 1.216 & 5,1 \\
\hline NS/NC & 27 & 0,1 \\
\hline
\end{tabular}

Fuente: $16^{\circ}$ Navegantes en la red (AIMC).

\subsubsection{Comercio electrónico en el sector turístico}

El crecimiento de Internet ha venido acompañado de un uso cada vez más intenso de la red por parte de empresas o instituciones. Pero hay ciertos productos y servicios que, por sus propias características o por el perfil de sus clientes, son más propensos a la utilización de la red como herramienta de comunicación y venta.

Los servicios turísticos ocupan un lugar destacado en este aspecto. En la Tabla 6 podemos observar como las categorías Billetes, Alojamiento, Ocio y Paquetes vacacionales ocupan los primeros lugares en la compra de productos o servicios a través de Internet. 
Tabla 6. Productos y servicios más comprados a través de Internet Producto o servicio comprado a través de Internet en el último año Base (menciones): 87.771

\begin{tabular}{|lll|}
\hline Producto & Absolutos & $\%$ \\
\hline Billetes (avión, tren, barco, autocar) & 9.702 & 11,1 \\
\hline Electrónica, aparatos electrónicos & 9.699 & 11,1 \\
\hline Alojamiento (hotel, casa rural,...) & 8.960 & 10,2 \\
\hline Ocio/Tiempo libre/Entradas espectáculos & 8.386 & 9,6 \\
\hline Ropa y complementos & 7.911 & 9,0 \\
\hline Telefonía/Servicios telefónicos & 5.367 & 6,1 \\
\hline Libros/Revistas & 4.988 & 5,7 \\
\hline Ordenadores/componentes/periféricos & 4.772 & 5,4 \\
\hline Juegos de azar (loterías, apuestas,...) & 3.967 & 4,5 \\
\hline Alimentación/Droguería/Perfumería & 3.582 & 4,1 \\
\hline Software & 3.487 & 4,0 \\
\hline Paquetes vacacionales & 2.756 & 3,1 \\
\hline Música & 2.543 & 2,9 \\
\hline Alquiler de coches & 2.427 & 2,8 \\
\hline
\end{tabular}

Fuente: $16^{\circ}$ Navegantes en la red (AIMC)

En cuanto a las empresas más utilizadas para la contratación de servicios turísticos a través de Internet, destacan las agencias de viaje online, con Booking a la cabeza, así como las empresas de transporte (Tabla 7). 
Tabla 7. Webs más utilizadas para servicios turísticos.

Indique a través de qué sitios web ha comprado/contratado paquetes vacacionales, alojamiento, billetes (tren, avión, autocar,...) o ha alquilado coches a través de Internet en el último año

Base: 25.118

\begin{tabular}{|lcc|}
\hline Web & Absolutos & $\%$ \\
\hline Booking.com & 2.818 & 11,2 \\
\hline Renfe & 2.181 & 8,7 \\
\hline Ryanair & 1.920 & 7,6 \\
\hline Atrapalo.com & 1.259 & 5,0 \\
\hline Iberia & 1.217 & 4,8 \\
\hline Vueling & 1.126 & 4,5 \\
\hline Rumbo & 850 & 3,4 \\
\hline eDreams & 752 & 3,0 \\
\hline Trivago & 745 & 3,0 \\
\hline Alsa & 547 & 2,2 \\
\hline El Corte Inglés & 484 & 1,9 \\
\hline Logitravel & 407 & 1,6 \\
\hline EasyJet & 406 & 1,6 \\
\hline Otros & 10.406 & 41,4 \\
\hline
\end{tabular}

Fuente: $16^{\circ}$ Navegantes en la red (AIMC)

\subsubsection{Uso de Internet por los turistas}

Si nos referimos a los turistas extranjeros que nos visitan cada año, la influencia de Internet en la toma de sus decisiones de compra es también muy relevante. Hemos utilizado en este caso, como fuente de información los datos proporcionados por el "Instituto de Estudios Turísticos" en su informe anual de 2012 sobre movimientos turísticos en fronteras y encuesta de gasto turístico (Egatur/Frontur, 2012), ya que consideramos que resulta una fuente de información fiable, por la entidad que los confecciona y por la amplia muestra utilizada.

El 65\% de los turistas extranjeros que visitan España usa Internet para diferentes cuestiones relativas a su viaje (Tabla 8). Cabe destacar que existe 
un porcentaje de turistas que aún no se atreve a realizar su reserva a través de Internet, pero que utiliza este medio para obtener información sobre su viaje.

Tabla 8. Uso de Internet por los turistas que visitan España (2012)

\begin{tabular}{|ccc|}
\hline Uso de Internet & $\begin{array}{c}\text { Porcentaje de } \\
\text { turistas }\end{array}$ & $\begin{array}{c}\text { Tasa de } \\
\text { Variación (\%) }\end{array}$ \\
\hline Usa Internet & $\mathbf{3 5 \%}$ & $\mathbf{- 6 \%}$ \\
\hline Consulta & $\mathbf{6 5 \%}$ & $\mathbf{8 \%}$ \\
\hline Transporte & $\mathbf{6 4 \%}$ & $\mathbf{9 \%}$ \\
\hline Alojamiento & $60 \%$ & $8 \%$ \\
\hline Actividades & $48 \%$ & $14 \%$ \\
\hline Reserva & $27 \%$ & $11 \%$ \\
\hline Transporte & $\mathbf{5 9 \%}$ & $\mathbf{1 2 \%}$ \\
\hline Alojamiento & $56 \%$ & $11 \%$ \\
\hline Actividades & $43 \%$ & $19 \%$ \\
\hline Pago & $11 \%$ & $25 \%$ \\
\hline Transporte & $\mathbf{5 6 \%}$ & $\mathbf{1 3 \%}$ \\
\hline Alojamiento & $55 \%$ & $12 \%$ \\
\hline Actividades & $34 \%$ & $20 \%$ \\
\hline
\end{tabular}

Fuente: IET. Encuesta de Gasto Turístico (Egatur) 2012

Si analizamos estas cifras por comunidad autónoma, observamos importantes diferencias (Figura 2). Las comunidades autónomas del Mediterráneo, junto con Canarias y Madrid, concentran los mayores porcentajes de uso de Internet. 
Figura 2. Porcentaje del uso de Internet de los turistas que visitan España

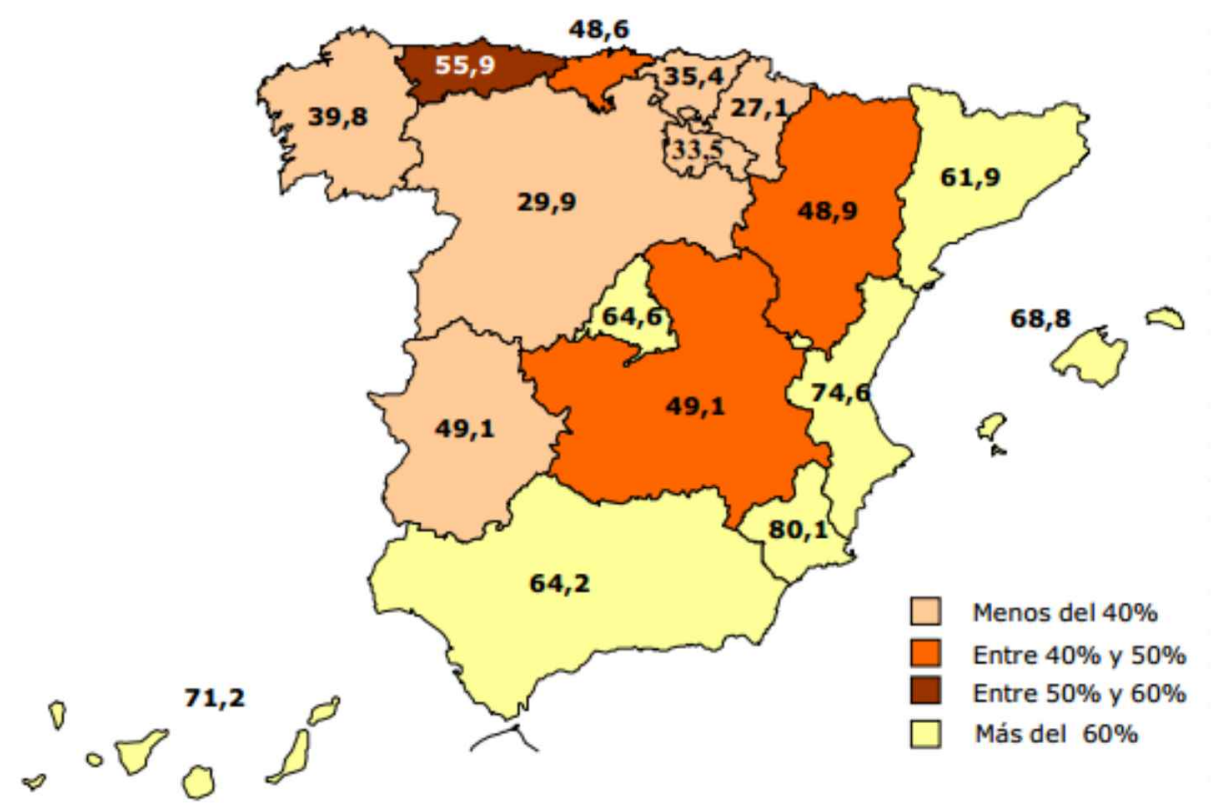

Fuente: IET. Encuesta de Gasto Turístico (Egatur) 2012

Cuando analizamos estos datos a nivel de países emisores, las cifras indican que los turistas de los países escandinavos utilizaron Internet en un $76,5 \%$ de los casos, mientras que los británicos lo hicieron en el $74,2 \%$. En el lado opuesto se situaron los franceses, que recurrieron a Internet en un 34,6\% de los casos (Egatur/Frontur, 2012). Parece que en el caso de Francia, la posibilidad de desplazarse en coche, influye en estas cifras.

Gráfico 2. Número de visitas anteriores de turistas

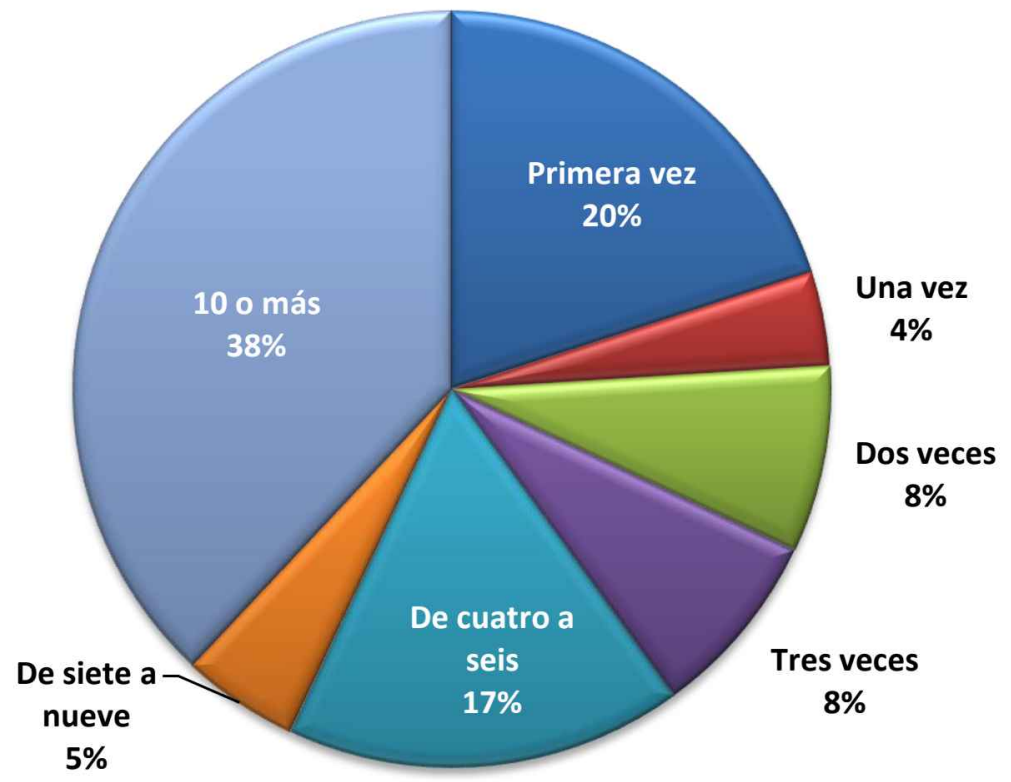

Fuente: IET. Encuesta de Gasto Turístico (Egatur, 2012) 
Para analizar los datos de uso de Internet por parte de los turistas, debe tenerse también en cuenta el alto índice de repetición de visitas que tiene España (Gráfico 2). Otros datos como las entradas por carretera (18,5\%) y el porcentaje de turistas que no se alojan en hoteles $(52,6 \%)$, configuran un perfil de turista que no usa Internet para su viaje.

Hay un tipo de turista, que conoce sobradamente el destino al que se dirige en España, porque ya ha estado más veces, que disfruta de sus vacaciones en una vivienda de su propiedad o de familiares y que se desplaza en coche a su destino. Por lo tanto, el que un $35 \%$ de los turistas que nos visitan no usen Internet para sus visitas a España, no quiere decir que usen agencias de viaje convencionales. Muchos de ellos son usuarios activos de Internet y lo usan para la planificación de viajes en otras ocasiones.

Hay que destacar que estos datos están referidos a 2012 (a final de 2014 todavía no se había publicado el informe correspondiente a 2013), por lo que previsiblemente la tasa de uso de Internet por parte de turistas extranjeros sea aún mayor en la actualidad. Al igual que cada día crecen los hogares conectados a Internet o los usuarios de redes sociales, la importancia de Internet para la comercialización y promoción de servicios turísticos adquiere también cada día una mayor relevancia.

En cuanto al volumen de facturación que supone el comercio electrónico, dentro de la industria hotelera, los datos son también muy reveladores a nivel nacional. Para 2015, está previsto que en España los touroperadores tradicionales facturen 2.600 millones de euros, frente a los 3.500 millones de las agencias online (Vargas, 2014).

\subsubsection{Herramientas de la Web 2.0}

En 2005, surge el concepto de Web 2.0, para tratar de explicar un nuevo fenómeno en Internet, por el cual los usuarios pasaban a ser partícipes de la web (O'reilly, 2005). Los usuarios generan contenidos, que comparten a través de webs y aplicaciones que se han desarrollado en Internet. 
Estas herramientas, que forman parte de la Web 2.0 proporcionan medios para conectar a las personas alrededor del mundo (Gershon, 2008). Con mucha frecuencia se identifica cualquier medio de compartir información con los términos "social media" o "redes sociales", que engloban todo el universo 2.0, incluyendo las redes sociales (Correa et al., 2010; Gallon, 2010; Kaplan \& Haenlein, 2010; Rettberg, 2009).

La frontera para definir qué se considera Web 2.0 y qué son simplemente nuevas webs o aplicaciones no está muy clara, ya que puede englobar diferentes aspectos, según el autor que consultemos. Mostramos en la Figura 3 un tipo de representación gráfica, muy popular en los últimos años para representar esta nueva realidad, clasificándola en diferentes apartados.

Figura 3. Representación gráfica de las Redes Sociales (2013)

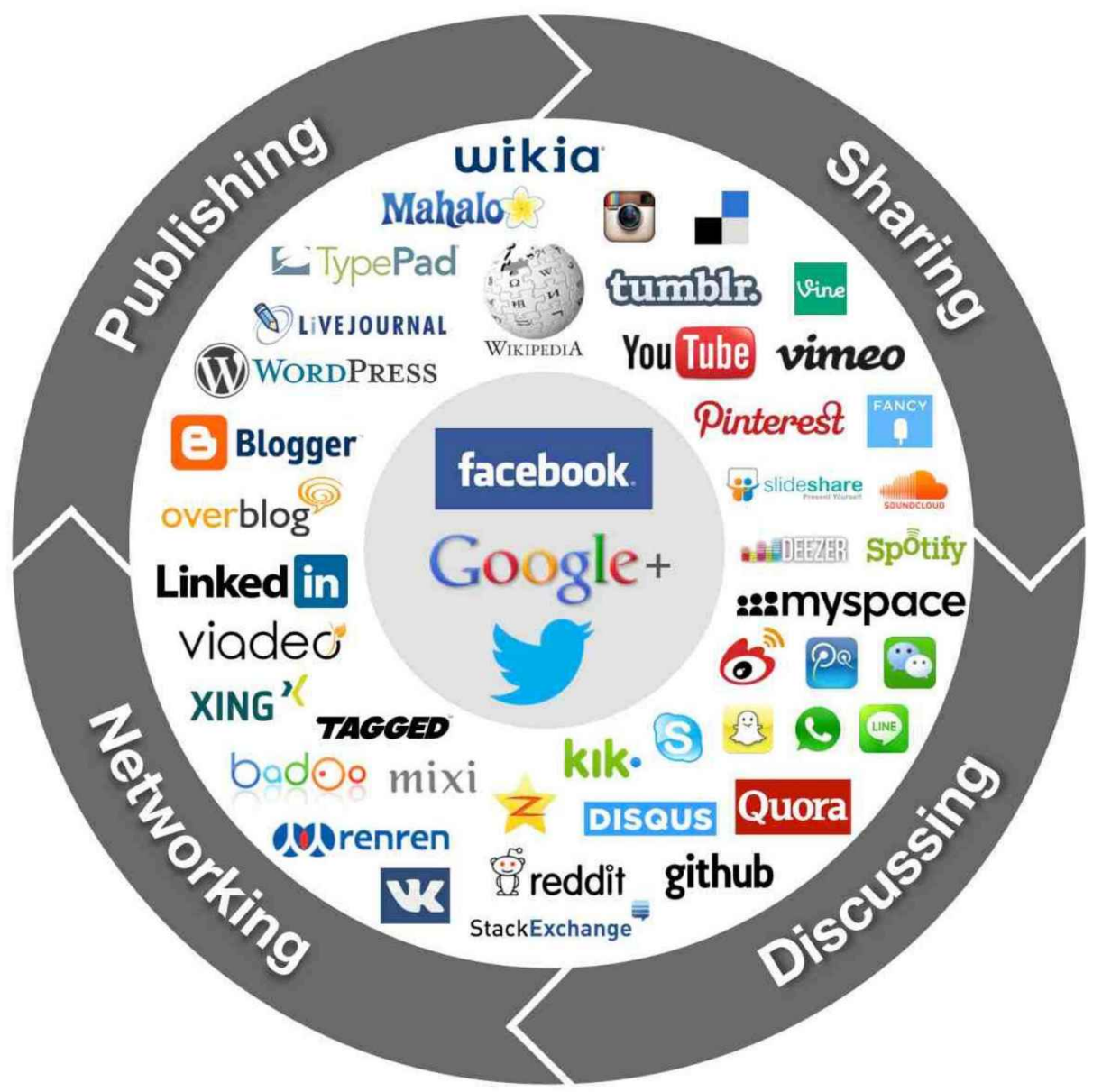

Fuente: Fred Cavazza. Social Media Landscape 2013 (www.fredcavazza.net)

Hay que insistir en que éste es solamente un pequeño resumen de lo más relevante de lo que se puede considerar Web 2.0. Existen muchas más páginas 
y aplicaciones que cumplen funciones similares a las aquí descritas. Para ciertos campos de conocimiento y actividades concretas existen webs y aplicaciones especializadas, que pueden ser de gran utilidad para estos grupos, como veremos al analizar el sector del turismo.

A partir de la idea de Web 2.0, surge también y de forma análoga, el concepto de Turismo 2.0 (Travel 2.0), íntimamente relacionado con el proceso de regeneración de Internet mencionado (Conrady, 2007; Del Chiappa, 2011). Consiste básicamente en el uso de las herramientas de la Web 2.0 por parte de los usuarios de productos y servicios turísticos, donde cobran especial importancia los comentarios de los turistas sobre sus experiencias de viajes, bien sea compartiendo fotos, vídeos y opiniones o escribiendo blogs y diarios de viaje sobre estos temas. Algunos autores (Pan \& Fesenmaier, 2006) utilizan el término "online tourism information space" (espacio de información turística en línea) para describir la colección de contenido hipertextual de información disponible para los viajeros en Internet.

\subsection{Antecedentes y limitaciones en el uso del contenido generado por los usuarios en Internet}

\subsubsection{Opiniones de los usuarios en Internet}

La página web de una empresa aporta menos de un tercio de la imagen de una empresa en Internet, el resto de su prestigio viene determinado por lo que se dice sobre ella en foros, redes sociales, blogs, etc. (Celaya, 2000). $74 \%$ de los consumidores españoles realiza compras influenciados por la información encontrada en Internet (Tabla 9). Esa información incluye la proporcionada por las propias marcas, pero también el contenido generado por usuarios independientes. 
Tabla 9. Decisión de compra informada a través de Internet

Durante el último año ¿ha tomado una decisión de compra de productos o servicios orientado, motivado o informado por contenidos de Internet?

Base: 23.811

\begin{tabular}{|lcc|}
\hline Respuesta & Absolutos & $\%$ \\
\hline Sí & 17.678 & 74,2 \\
\hline No & 5.993 & 25,2 \\
\hline NS/NC & 140 & 0,6 \\
\hline
\end{tabular}

Fuente: $16^{\circ}$ Navegantes en la red (AIMC)

Los datos en España muestran que dos tercios de los usuarios confían en esas opiniones anónimas, según se muestra en la Tabla 10.

Tabla 10. Boca a boca en Internet.

En los últimos 30 días ¿ha consultado opiniones o comentarios de otras personas hechos a través de Internet acerca de algún producto o servicio?

Base: 23.811

\begin{tabular}{|lcc|}
\hline Periodo & Absolutos & $\%$ \\
\hline $\begin{array}{l}\text { Sí, y les concedo gran } \\
\text { confianza }\end{array}$ & 10.709 & 45,0 \\
\hline $\begin{array}{l}\text { Sí, pero no me inspiran mucha } \\
\text { confianza }\end{array}$ & 6.924 & 29,1 \\
\hline No & 6.133 & 25,8 \\
\hline NS/NC & 45 & 0,2 \\
\hline
\end{tabular}

Fuente: $16^{\circ}$ Navegantes en la red (AIMC)

Un estudio similar a nivel internacional (Tabla 11), obtiene resultados similares en cuanto al nivel de confianza que se atribuye a las opiniones online con un $68 \%$.

En el ámbito científico este fenómeno no ha pasado desapercibido y en los últimos años se ha desarrollado una amplia literatura sobre estudios que utilizan las opiniones de usuarios en Internet como principal fuente de información (Trenz \& Berger, 2013). 
Tabla 11. The Nielsen Global Survey of Trust in Advertising

To what extend do you trust the following forms of advertising? Global average - Percent completly/somewhat trust ${ }^{1}$

\begin{tabular}{|lccc|}
\hline Tipo de publicidad & 2013 & 2007 & $\begin{array}{c}2013 \\
\text { Vs. } \\
2007\end{array}$ \\
\hline Recommendations from people I know & $84 \%$ & $78 \%$ & $6 \%$ \\
\hline Branded websites & $69 \%$ & $60 \%$ & $9 \%$ \\
\hline Consumer opinions posted online & $68 \%$ & $61 \%$ & $7 \%$ \\
\hline $\begin{array}{l}\text { Editorial content such as newspaper } \\
\text { articles }\end{array}$ & $67 \%$ & $*$ & $*$ \\
\hline Ads on TV & $62 \%$ & $56 \%$ & $6 \%$ \\
\hline Brand sponsorships & $61 \%$ & $49 \%$ & $12 \%$ \\
\hline Ads in newspapers & $61 \%$ & $63 \%$ & $-2 \%$ \\
\hline Ads in magazines & $60 \%$ & $56 \%$ & $4 \%$ \\
\hline $\begin{array}{l}\text { Billboards and other outdoor } \\
\text { advertising }\end{array}$ & $57 \%$ & $*$ & $*$ \\
\hline Ads on radio & $57 \%$ & $54 \%$ & $3 \%$ \\
\hline Emails I signed up for & $56 \%$ & $49 \%$ & $7 \%$ \\
\hline Ads before movies & $56 \%$ & $38 \%$ & $18 \%$ \\
\hline TV program product placements & $55 \%$ & $*$ & $*$ \\
\hline Ads served in search engine results & $48 \%$ & $34 \%$ & $14 \%$ \\
\hline Online video ads & $48 \%$ & $*$ & $*$ \\
\hline Ads on social networks & $48 \%$ & $*$ & $*$ \\
\hline Display ads on mobile devices & $45 \%$ & $*$ & $*$ \\
\hline Online banner ads & $37 \%$ & $18 \%$ & $19 \%$ \\
\hline Text ads on mobile phones & & & $* 6 \%$ \\
\hline
\end{tabular}

Fuente: Under the influence: Consumer trust in advertising (Nielsen, 2013)

Las críticas de clientes en Internet son de gran ayuda para los consumidores (Chevalier \& Mayzlin, 2006), convirtiéndose en muchos casos en la principal fuente de información previa a la compra (Goldsmith \& Horowitz, 2006). Varios estudios demuestran que los individuos dan a este contenido generado por otros consumidores mayor credibilidad que la información que proporcionan críticos profesionales o las propias empresas (Chen \& Xie, 2005;

\footnotetext{
${ }^{1}$ ¿Hasta que punto confía en las siguientes formas de publicidad? Media global, Porcentaje que confían totalmente/algo.
} 
Lewis \& Bridger, 2001). Otros autores han tratado de cuantificar la influencia de las opiniones de otros consumidores en la decisión de compra de productos y servicios (Duan et al., 2008a-2008b).

Se han identificado 8 razones por las que las personas buscan información sobre productos y servicios a través de las opiniones de otros usuarios (Goldsmith \& Horowitz, 2006):

1. Reducir el riesgo de compra.

2. Porque otros lo hacen.

3. Para conseguir mejores precios.

4. Acceder a información fácilmente.

5. De manera accidental.

6. Porque está de moda.

7. Estimulados por medios externos, como la televisión.

8. Para conseguir información previa a la compra.

Las opiniones de usuarios en Internet muestran lo mejor y lo peor de las personas (Whitty \& Joinson, 2008). Por un lado, el anonimato favorece que los usuarios den opiniones más sinceras y honestas. Pero por otro, ese anonimato, propicia que algunos usuarios mientan más de lo que lo harian en la vida real, además de abrir las puertas a que agentes con intereses económicos incluyan opiniones manipuladas para su propio beneficio.

Este "contenido generado por los consumidores", que en inglés se denomina "User Generated Content" (UGC), se asemeja al conocido tradicionalmente como "boca a boca" o "boca a oreja". La traducción al inglés de estas expresiones es "Word of mouth" (WOM) y se trata de una realidad cuya importancia en la actividad económica ha sido ampliamente descrita en la literatura científica (Duan et al., 2008b; Goldenberg et al., 2001; Stokes \& Lomax, 2002; Zhu \& Zhang, 2010).

Cuando este sistema de transmisión de la información se adapta a Internet, a través de un sistema organizado de críticas y puntuaciones, su importancia se multiplica y abre una nueva vía de oportunidades para todos los participantes en el sistema (Pan et al., 2007). Pero la existencia de partes 
interesadas que realizan comentarios con identidades falsas puede ser un peligro para la credibilidad de la información (Dellarocas, 2003). Actualmente, el fenómeno de la extensión del WOM a través de Internet y de la Web 2.0 es conocido como eWOM (electronic Word of Mouth) o "Word of Mouse" (Gruen et al., 2006). Una vez que las opiniones de los usuarios se difunden a través de Internet, dejan de ser "User Generated Content" y se convierten en eWom (Cheong \& Morrison, 2008).

A su vez, el eWOM está estrechamente relacionado con el concepto de reputación online (C. Park \& Lee, 2009) y la confianza que los consumidores depositan en las empresas que comercializan productos o servicios. Diversos estudios han demostrado que el nivel de confianza en una marca, afecta positivamente a las posibilidades de compra final (Comegys et al., 2009; Sichtmann, 2007).

Un estudio de 2013 realizado por StrategyOne para TripAdvisor (StrategyOne, 2013) con datos basados en los resultados de una encuesta online a 15.595 viajeros (Figura 4), muestra la creciente importancia del "boca a boca" en la planificación de los viajes, tanto a nivel nacional, como a nivel global. Según estos datos, el $93 \%$ de los viajeros a nivel mundial dice que sus decisiones de reserva se ven influenciadas por las opiniones online.

Figura 4. Factores que influyen en la planificación de viajes.

\section{LA PLANIFICACIÓN DE VIAJES ESTÁ DOMINADA POR LOS RECURSOS ONLINE}

EL BOCA-A-BOCA SE AMPLIFICA ONLINE

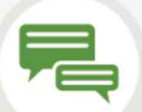

WEBS DE OPINIONES DE VIAJEROS

\section{Global}

España
$69 \%$

$83 \%$

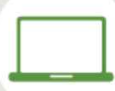

$57 \%$

$62 \%$

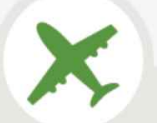

NEBS DE OPERADORES

TURISTICOS

$56 \%$

$60 \%$

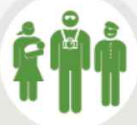

FAMILIA

YAMIGOS

$36 \%$

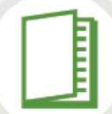

REVISTAS

FOLLTOS

$30 \%$

$23 \%$

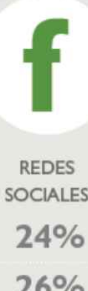

$26 \%$

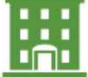

AGENCIA DE VIAJES

TRADICIONAL

$18 \%$

$24 \%$

Fuente: Tripbarometer 2013 (StrategyOne, 2013).

Un estudio de PhoCusWright (TripAdvisor Insights, 2013a), en el que participaron 12.225 personas de todo el mundo, preparado para TripAdvisor en 
Diciembre de 2013, aporta información adicional en el mismo sentido. El 50\% declara que generalmente o siempre consulta las opiniones antes de elegir un hotel. El $80 \%$ de los viajeros lee un mínimo de entre 6 y 12 opiniones antes de reservar un hotel.

El sector turístico y más concretamente el hotelero, son especialmente susceptibles de verse afectados por las opiniones vertidas por sus clientes (Buhalis \& Law, 2008), siendo un perfecto ejemplo de sector en el que el eWom ejerce gran influencia (Bronner \& de Hoog, 2011; Filieri \& McLeay, 2014). Diversos estudios demuestran que las opiniones de viajeros en Internet tienen gran influencia en las decisiones de los consumidores (Fotis et al., 2012; Gretzel \& Yoo, 2008; Sigala et al., 2012; Vermeulen \& Seegers, 2009; Wilson et al., 2012). Se ha demostrado que las recomendaciones de amigos y las opiniones en Internet son los dos factores que más influyen a los consumidores a la hora de elegir un hotel (Dickinger \& Mazanec, 2008). Los consumidores perciben que estas opiniones aportan más objetividad que la información comercial (Ricci \& Wietsma, 2006). En la misma línea, otros investigadores (Blackshaw \& Nazzaro, 2006) demostraron que los consumidores dan más credibilidad a las opiniones de otros consumidores, que perciben como más confiables, que a la información de marketing de las agencias.

Estas opiniones son la principal vía de creación de "reputación online" para los hoteles, entendiendo este concepto como el conjunto de contenidos que hay en Internet, sobre una marca, bien o servicio (Dellarocas, 2003). Millones de viajeros escriben críticas sobre sus experiencias de viajes sin recibir nada a cambio aparentemente. Este fenómeno altruista es considerado como una reproducción en el mundo online, de fenómenos similares de amabilidad y colaboración que se dan en el mundo offline o "vida real" (Resnick \& Zeckhauser, 2002). Aunque también suponen una vía para plantear quejas por parte de los viajeros insatisfechos (Del Chiappa \& Dall'Aglio, 2012).

Los hoteles con mejores calificaciones, aumentarán sus probabilidades de ser elegidos por los consumidores y esto repercutirá en un aumento de los precios que pueden cobrar a sus clientes (Yacouel \& Fleischer, 2012). Si el resto de factores permanecen constantes, unas buenas calificaciones del hotel, 
deberían suponer un aumento del precio que los consumidores están dispuestos a pagar por una habitación de hotel (Melnik \& Alm, 2002).

\subsubsection{Uso de las bases de datos de opiniones en Internet}

La obtención de conclusiones sobre un tema, tras recabar las opiniones de miles de individuos, es un método objeto de estudio por diversos autores. James Surowiecki publicó en 2004 "The wisdom of crowds: Why the Many Are Smarter Than the Few and How Collective Wisdom Shapes Business, Economies, Societies and Nations"² en él explica cómo, al agregar información desde diferentes grupos, resulta un sistema de toma de decisiones en gran parte superior al que la mayoría de los integrantes de esos grupos podrían llegar actuando en solitario.

La "Inteligencia Colectiva" es un concepto inicialmente referido a una forma de conocimiento que surge de la colaboración y concurso de muchos individuos o seres vivos de una misma especie. Toby Segaran aplica este concepto de Inteligencia Colectiva (Collective Intelligence) al ámbito de Internet, basándose en la idea de captar información relevante de las grandes bases de datos de opiniones en la red, a través de sofisticados algoritmos matemáticos (Segaran, 2007).

La llegada de Internet ha proporcionado a investigadores en campos como el de la Sociología, Psicología o la Economía, una valiosa fuente de información que presenta una serie de importantes ventajas respecto a los métodos tradicionales. De esta forma los estudios pueden abarcar áreas geográficas mucho mayores, (todos los países con cierto nivel de conexiones a Internet) y los datos pueden ser recogidos en cualquier lugar y en cualquier momento (Mann \& Stewart, 2000). Se trata de métodos menos intrusivos y sobre todo más económicos que los tradicionales (Kozinets, 2002).

\footnotetext{
${ }^{2}$ La sabiduría de las masas: por qué un grupo es más listo que unos pocos y como la sabiduría colectiva moldea negocios, economías, sociedades y naciones
} 
Los investigadores en Etnografía ${ }^{3}$ han puesto especial atención a Internet como fuente de datos totalmente válida y recomendable para la investigación académica (Hine, 2000; Kozinets, 2002, 2006). Hine usa la denominación virtual etnography (etnografía virtual) para referirse a esta forma de investigación, mientras Kozinets acuñó el término netnography, para referirse a un concepto similar.

Surgen también términos como webnography y cyberethnography (Catterall \& Maclaran, 2002; Constable, 2003; Puri, 2007, 2009; M. Williams, 2007) para referirse a la misma idea de utilizar como datos las opiniones registradas en Internet por millones de individuos.

Basándose específicamente en estas metodologías y utilizando esa terminología, han comenzado a aparecer estudios sobre su uso en el Sector Hotelero (Mkono, 2012a, 2012b; Mkono et al., 2013) utilizando para ello la base de datos de TripAdvisor. Pero también se cuentan por decenas los estudios que usan esta misma metodologia para estudios en dicho sector, aunque sin hacer referencia a esta terminología basada en la etnografía. Además de TripAdvisor (O'Connor, 2010; O'Mahony et al., 2010; Wu et al., 2010a-2010b), se usan otras fuentes de información, como Booking (Bjørkelund et al., 2012; Costantino et al., 2012a, 2012b; de Albornoz, et al., 2011; Filieri \& McLeay, 2014; Grinshpoun et al., 2009; Korfiatis \& Poulos, 2013; Plata-Alf, 2013; Yacouel \& Fleischer, 2012). En otras ocasiones se opta por el uso de una combinación de varias bases de datos de opiniones sobre hoteles (Chaves et al., 2012; Marchiori et al., 2011).

El centro de innovación turística de Andalucía, dependiente de la Consejería de Turismo y Comercio en colaboración con la fundación Cinnta ${ }^{4}$, ha desarrollado un estudio que analiza la reputación online de la planta hotelera de tres, cuatro y cinco estrellas con presencia en Internet (Andalucía Lab, 2014). Utilizando datos del mes de Mayo de 2014, recogieron más de 400.000 comentarios de 793 hoteles andaluces situados en las ocho capitales

\footnotetext{
${ }^{3}$ La etnografía es un método de investigación que consiste en observar las prácticas culturales de los grupos sociales

${ }^{4}$ www.cinnta.com
} 
de provincias andaluzas, la Costa del Sol, Costa de la Luz y Costa Tropical. Destacan claramente en la recolección de datos la web de Booking, con 220.000 opiniones (55\%) y TripAdvisor con 120.000 (30\%). El resto de opiniones se reparte entre las otras seis fuentes estudiadas.

Similares resultados se obtienen en un estudio desarrollado sobre la planta hotelera suiza (Marchiori et al., 2011), utilizando una muestra también amplia de hoteles de este país (Tabla 12).

Tabla 12. Opiniones de hoteles en Suiza.

\begin{tabular}{|lccc|}
\hline Fuente & Ciudades & Hoteles & Opiniones \\
\hline Booking & 146 & $\begin{array}{c}1.442 \\
\text { (max: 102, min: 1, med: 9.87) }\end{array}$ & $\begin{array}{c}\text { 94.102 } \\
\text { (max: 820, min: 5, med: 79.61) }\end{array}$ \\
\hline Tripadvisor & 162 & $\begin{array}{c}1.818 \\
\text { (max: 115, min: 1, med: 11.22) }\end{array}$ & (max: 418, min: 1, med: 18.58) \\
\hline Venere & 108 & $\begin{array}{c}639 \\
\text { (max: } 54, \text { min: } 1, \text { med: } 5.91)\end{array}$ & (max: 93, min: 1, med: 9.00) \\
\hline
\end{tabular}

Fuente: Harvesting Online Contents: an Analysis of Hotel Reviews Websites (Marchiori et al. 2011)

Se debe señalar que TripAdvisor tiene una cobertura prácticamente mundial y la influencia de Booking está muy limitada al ámbito europeo. Los datos existentes a nivel mundial, por lo tanto, no resultan totalmente extrapolables ámbito español o europeo.

\subsubsection{Spam y opiniones falsas en Internet}

El término "spam" no tiene una traducción clara al castellano, ni está recogido en el diccionario de la Real Academia Española de la Lengua, aunque nos solemos referir a esta práctica como "correo basura" o "mensaje basura". Son mensajes no solicitados, no deseados, habitualmente de tipo publicitario, generalmente enviados en grandes cantidades, que molestan y/o perjudican de alguna manera al receptor.

Se trata de personas y organizaciones que pretenden un lucro económico, aprovechando las posibilidades que ofrece Internet. Este fenómeno ha sido estudiado en el ámbito científico en lo relativo al uso masivo de emails con contenido publicitario (Drucker et al., 1999) y en la web (Gyöngyi et al., 2004; Ntoulas et al., 2006). 
Con la aparición del fenómeno de la web 2.0 y las aportaciones masivas de contenido por parte de millones de usuarios, el "spam" se reinventa a través las críticas falsas en comunidades dedicadas a la evaluación de bienes y servicios. Este fenómeno, aunque diferente al "spam", tiene las mismas intenciones publicitarias, que pasan también por el fraude a los usuarios. La posibilidad de que parte de esas opiniones puedan ser falsas, pone en grave riesgo la credibilidad de cualquier comunidad online y hace necesario el establecimiento de algunos sistemas de control para evitarlo (O'Mahony et al., 2004).

La veracidad de estas opiniones es cuestionada en blogs sobre turismo (Mack et al., 2008). Pero diversos autores afirman que el contenido falso o manipulado es mínimo y, en todo caso resulta más creíble que el facilitado directamente por las marcas que comercializan productos turísticos (Papathanassis \& Knolle, 2011). En 2012, la consultora Gartner anunciaba que para 2014 entre el 10 y el $15 \%$ de las opiniones en Internet serían falsas (Sussin \& Thompson, 2012).

Se han descrito sistemas complejos de usuarios organizados para la generación de opiniones falsas en grupo (Mukherjee et al., 2011). Amazon, una de las mayores tiendas en Internet, fue de las primeras en comenzar a admitir opiniones de compradores y ha sido utilizada como base de estudios para la detección de opiniones falsas a través de modelos cualitativos y cuantitativos (Jindal et al., 2010; Staddon \& Chow, 2008).

Yelp.com es una web norteamericana que permite a sus usuarios realizar comentarios sin probar haber disfrutado del servicio sobre el que opinan, lo que puede propiciar la inclusión de opiniones falsas malintencionadas. Un estudio realizado en 2013 (Luca \& Zervas, 2013) sobre opiniones de restaurantes en esta web, arroja porcentajes del $16 \%$ identificadas como fraudulentas.

El sector turístico no es ajeno al mencionado fenómeno de las críticas falsas (Yoo \& Gretzel, 2009). TripAdvisor, como principal exponente de la recopilación de opiniones de usuarios en Internet, ha sido cuestionado en cuanto a su veracidad (Keates, 2007). El valor y relevancia de TripAdvisor no 
se basa solamente en los millones de usuarios y críticas que alberga, sino en la credibilidad de esa información y la sospecha de existencia de críticas falsas pone en peligro esa credibilidad (Ayeh et al., 2013; Jeacle \& Carter, 2011). Estudios sobre el sector hotelero, basándose en las opiniones de TripAdvisor, hacen referencia a la problemática de las críticas fraudulentas (Smyth et al., 2010). Un estudio del año 2008, cuando la situación comenzaba a ser preocupante (O'Connor, 2008) concluye que en ese momento, aunque existían indicios de manipulación de opiniones, su incidencia no era realmente significativa. Similares conclusiones obtiene otra investigación desarrollada usando una muestra de hoteles en Singapur (Chua \& Banerjee, 2013).

Un estudio sobre 25 grandes ciudades de Estados Unidos (Mayzlin et al., 2012) detectó que los hoteles independientes son más propensos a escribir opiniones positivas falsas sobre sus establecimientos y a escribir opiniones negativas sobre sus competidores. Este efecto parece acentuarse cuando el hotel tiene competidores cercanos geográficamente.

Los modelos de detección de opiniones falsas, centrados en TripAdvisor pueden basarse en la aplicación de un modelo conocido (Wu et al., 2010a) o en la integración de diferentes sistemas (Wu et al., 2010b). También se ha analizado el fenómeno desde el punto de vista de la Psicología y la Lingüística Computacional (Ott et al., 2011) tratando de buscar una metodología que pueda detectar el contenido fraudulento.

Para entender la dimensión de TripAdvisor y abordar el estudio de la problemática de su fiabilidad, resulta recomendable un análisis de la información pública difundida por la compañía en cuanto a sus cifras de negocio, influencia en los viajeros, procedimientos y medidas para evitar las opiniones falsas, tal y como hacemos en el punto siguiente. 


\subsection{TripAdvisor}

TripAdvisor es la comunidad de viajes más grande del mundo con más de 280 millones de visitantes al mes, 60 millones de miembros registrados y más de 170 millones de opiniones. Formó parte de Expedia Inc. (USA), que además posee otras conocidas marcas como Hotels, Venere, Egencia o Hotwire. En Diciembre de 2011, TripAdvisor fue escindida de Expedia, comenzando a cotizar por separado en la bolsa de Nueva York, incluida en el índice Nasdaq y en el S\&P 500. Su valoración en bolsa, rondaba en ese momento los 3.500 millones de dólares. Para 2014 su valor en bolsa se había triplicado, superando los 10.000 millones de dólares (Gráfico 3).

Gráfico 3. Evolución del precio de las acciones de TripAdvisor

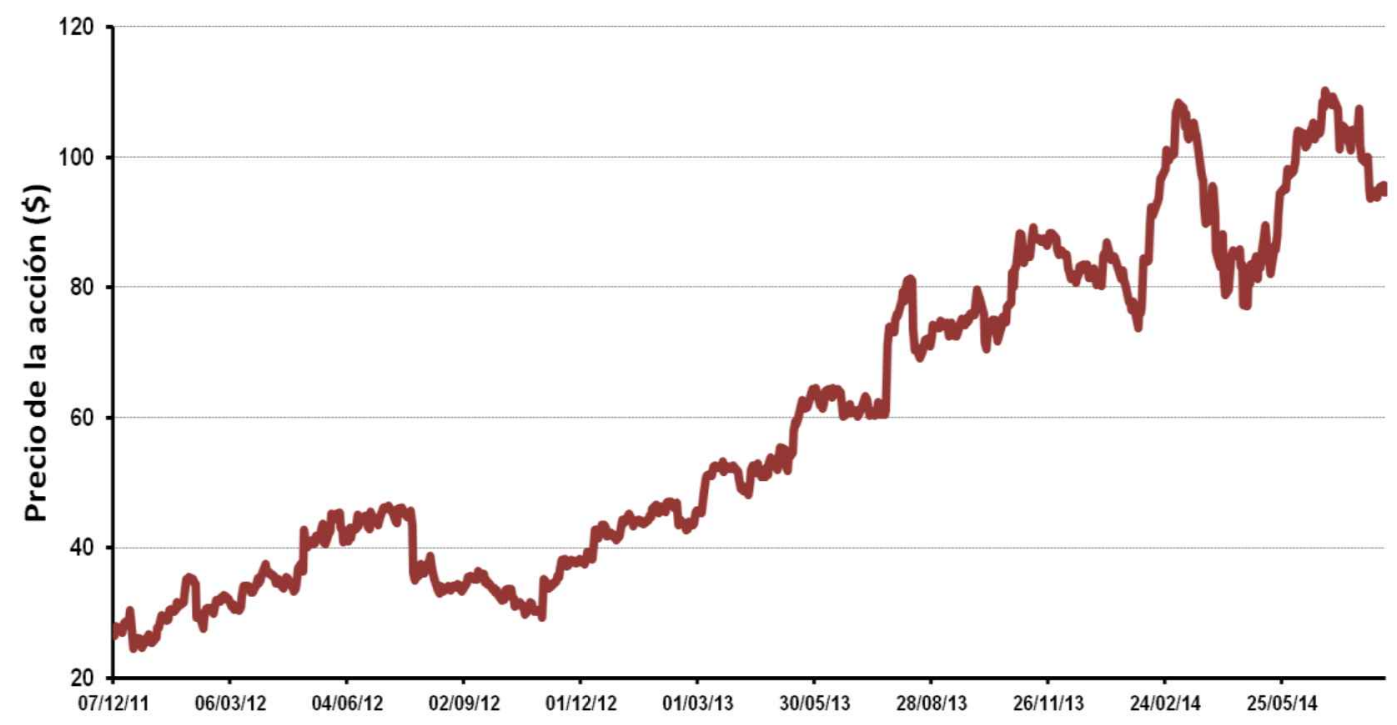

Fuente: Elaboración propia con datos extraídos de Nasdaq

TripAdvisor, ha sido identificada desde hace años como la mayor fuente de información sobre opiniones de viajeros del mundo por investigadores académicos (Fernández-Barcala, et al., 2009; Huang et al., 2010; Jeong \& Mindy, 2008). En la Figuras 5 y 6, realizadas por TripAdvisor al finalizar 2013, se muestra una imagen gráfica de las cifras relevantes y curiosas que nos dan una idea de la dimensión alcanzada por TripAdvisor. 
Figura 5. Principales cifras de TripAdvisor (2013)

\section{¿NECESITAS CONSEJO बศtripadvisor SOBRE VIAJES?}

Pregunta a la comunidad de viajes más grande del mundo.

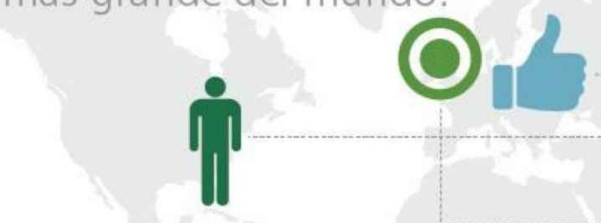

TRIPADVISOR DE UN VISTAZO

Más de 260000000 de VISITANTES MENSUALES ÚNICOS

Más de 125000000 de comentARIOS Y OPINIONES DE VIAIES

Más de 17000000 de FOTOS ENVIADAS POR VIAUEROS

Más de 3000000 de LUGARES PARA COMER, DORMIR Y DIVERTIRSE

Más de 200 países

Más de 80 PUBLICACIONES NUEVAS CADA MINUTO

21 IDIOMAS

$1^{\text {a }}$ COMUNIDAD DE VIAJES MÁS GRANDE DEL MUNDO

Fuente: Blog de TripAdvisor (TripAdvisor, 2013a)

Figura 6. Países con más contribuciones en TripAdvisor (2013)

\section{TिMÁS CONTRIBUCIONES}

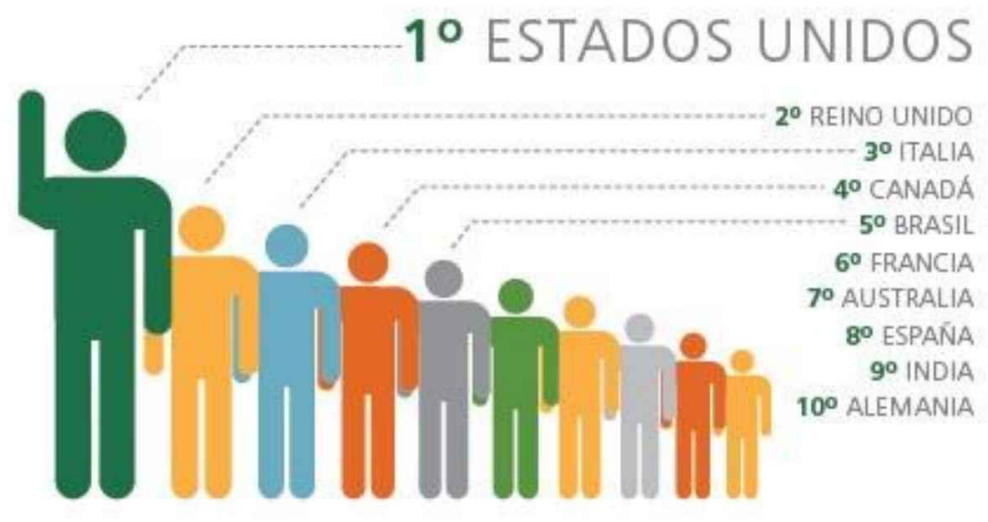

Los viajeros de TripAdvisor de EE. UU. aportaron un $51 \%$ más de contenido que los británicos.

* Según el total de opiniones y comentarios publicados

Fuente: Blog de TripAdvisor (TripAdvisor, 2013a)

El estudio de PhoCusWright (TripAdvisor Insights, 2013a) realizado en Diciembre de 2013 (Figura 7), revela el alto grado de utilidad que para los usuarios de TripAdvisor tiene esta web. 
Figura 7. Utilidad de TripAdvisor para los usuarios

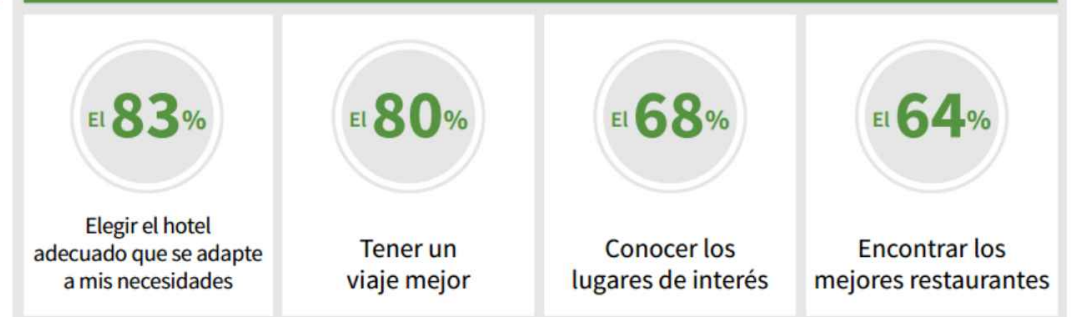

Fuente: TripAdvisor Insights (2013a)

Aunque TripAdvisor tiene su sede en Estados Unidos, de donde proceden gran parte de sus usuarios, ha adquirido una dimensión mundial, como indica su ranking de contribuciones por país. La posición de Alemania en este ranking, a pesar de su gran población es debido a la existencia de Holidaycheck ${ }^{5}$ un importante competidor de TripAdvisor en los países de habla alemana.

TripAdvisor es básicamente una web donde los viajeros realizan críticas sobre los establecimientos y lugares que han visitado. Puntúan los diferentes parámetros y realizan comentarios sobre su experiencia. A partir de estos datos, cada establecimiento obtiene una puntuación y TripAdvisor establece un ranking por destino (Figura 8), para cuya confección se tienen en cuenta diversos factores, entre los que predominan las puntuaciones obtenidas en las críticas más recientes.

Figura 8. Puntuación y ranking de hoteles en TripAdvisor

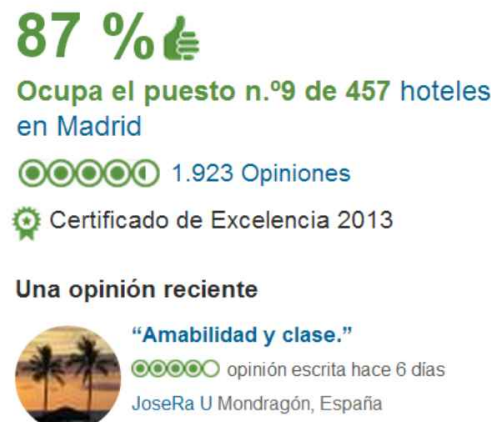

Fuente: www.tripadvisor.es

\footnotetext{
${ }^{5}$ www.holidaycheck.com
} 
El usuario, una vez dado de alta en TripAdvisor, es requerido a proporcionar información de la forma que se muestra en la Figura 9.

Figura 9. Encuesta de opinión en TripAdvisor

El relato de tu experiencia será realmente útil a otros viajeros. ¡Gracias!

Tu puntuación general sobre este establecimiento

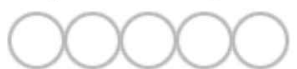

Haz clic para votar

Título de tu crítica

Tu crítica

(50 caracteres mínimo)

Al compartir tu experiencia estás ayudando a que a otros viajeros puedan tomar decisiones informadas a la hora de hacer el viaje de sus sueños. ¡Gracias!

¿Qué tipo de viaje fue?

$\underbrace{\infty}_{\text {Negocios }} \underbrace{\substack{\text { En familia } \\ \text { Amigos }}}_{\text {En pareja }}$

¿Cuándo viajaste?

Selecciona uno

¿Nos puedes contar algo más? (opcional)

Haz clic para seleccionar una puntuación

Servicio

00000

Relación calidad-precio 00000

Calidad del sueño 00000

Limpieza 00000

Ubicación 00000

Habitaciones $\quad 00000$

Spa 00000

Gimnasio 00000

Da un consejo para ayudar a los viajeros a elegir una buena habitación

Añadir fotos a la crítica (opcional)

Añadir fotos

Fuente: www.tripadvisor.es 
El sistema de puntuación de TripAdvisor está constituido por una escala de 1 a 5 , que al mostrar los resultados (Figura 8), tiene una nomenclatura que va de "Pésimo" a "Excelente". El usuario es consultado sobre un número indeterminado de categorías diferentes, aunque finalmente se muestran únicamente seis. Además se solicita una puntuación general del hotel. También se le pregunta sobre el tipo de viaje (familia, pareja, amigos, solitario o negocios), aunque la categoría de "amigos" no aparece en los resultados de los hoteles (Figura 10).

Figura 10. Puntuaciones de un hotel en TripAdvisor.

\begin{tabular}{|c|c|c|c|c|c|}
\hline \multicolumn{4}{|c|}{$\begin{array}{l}1.923 \text { personas han opinado sobre este } \\
\text { hotel }\end{array}$} & \multicolumn{2}{|l|}{ Escribe una opinión } \\
\hline Puntuación de viajeros & & Ver opiniones pare & & Resumen de & untuaciones \\
\hline Excelente & 1.150 & 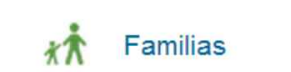 & 358 & Ubicación & 00000 \\
\hline Muy bueno & 533 & En pareja & 760 & $\begin{array}{l}\text { Calidad del } \\
\text { sueño }\end{array}$ & 00000 \\
\hline Normal & 157 & En solitario & 77 & Habitaciones & 00000 \\
\hline Malo & 60 & Cil somilatio & r & Servicio & OOOOO \\
\hline Pésimo | & 23 & $\theta$ De negocios & 284 & $\begin{array}{l}\text { Calidad-precio } \\
\text { Limpieza }\end{array}$ & $\begin{array}{l}\text { 00000 } \\
\text { 00000 }\end{array}$ \\
\hline
\end{tabular}

Fuente: www.tripadvisor.es

TripAdvisor ofrece diferentes posibilidades de segmentar los hoteles encontrados en una búsqueda, según los diferentes criterios mostrados en las Figuras 11, 12 y 13.

Figura 11. Segmentación por número de estrellas del hotel

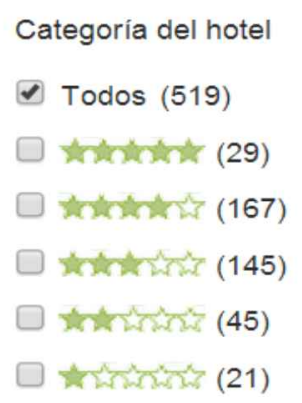

Fuente: www.tripadvisor.es 
Figura 12. Segmentación por cadena hotelera

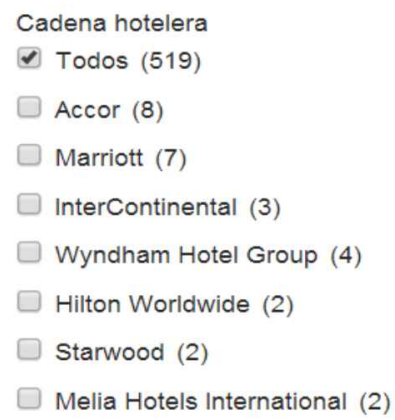

Fuente: www.tripadvisor.es

Figura 13. Segmentación por servicios que presta el hotel

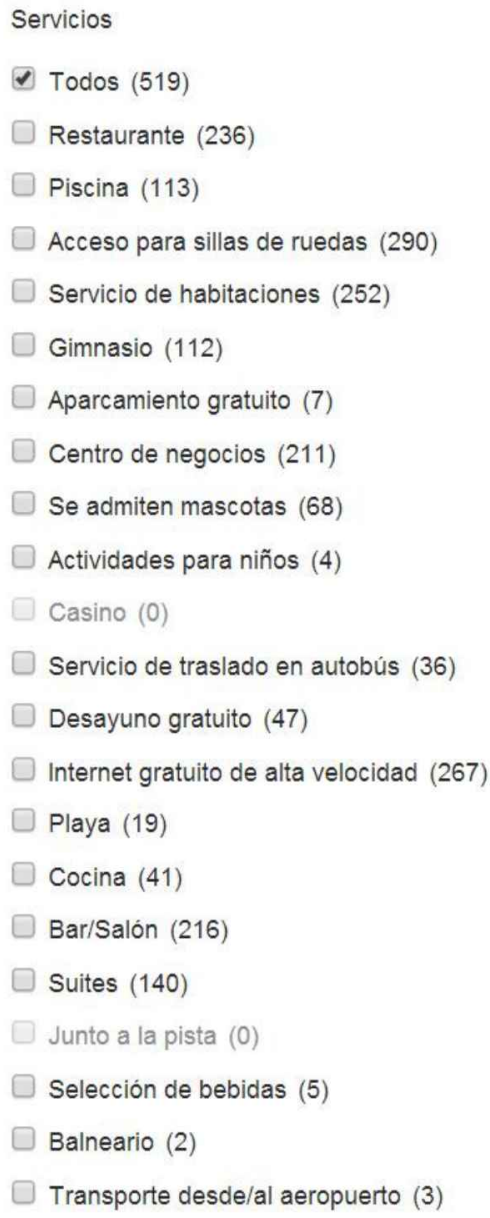

Fuente: www.tripadvisor.es

Al mostrar las puntuaciones medias globales del hotel (Figuras 7) y de cada una de los aspectos evaluados (Figura 9), se realiza un redondeo de 0,5 puntos. Es decir, se ofrecen los resultados con un rango de puntuaciones del tipo $(\ldots 1,5-2,0-2,5-3,0-3,5 \ldots)$. 
El principal interés de esta web, en el ámbito científico, es su utilización como base de datos para la realización de estudios sobre el nivel de satisfacción de los clientes de hoteles. Aunque TripAdvisor ha alcanzado gran popularidad por sus críticas en estos, la web también permite que los viajeros compartan fotos y vídeos, y enlaza a portales web de reservas. También existen apartados dedicados a la reserva de vuelos, a alquileres de alojamientos y a críticas de restaurantes. Además hay un foro para los usuarios de la comunidad y guías de viajes con información turística de los principales destinos.

La fiabilidad de los comentarios de TripAdvisor es algo que preocupa bastante a los propietarios de hoteles en todo el mundo. El hecho de que cualquier persona pueda aportar contenidos, sin acreditar haberse alojado en el hotel, deja una puerta abierta para la inclusión de críticas falsas. Un hotel malintencionado puede, tanto incluir críticas positivas de su establecimiento, como negativas de los establecimientos competidores de su zona.

Por su parte, TripAdvisor afirma hacer todo lo posible para evitar estos intentos de fraude y asegura tener métodos que eviten que éstos se produzcan. Para realizar una crítica, obliga al usuario a señalar una casilla en la que certifica la veracidad de su testimonio, advirtiéndole incluso de que la inclusión de críticas falsas está penado por la ley (Figura 14).

Figura 14. Advertencias al escribir una crítica en TripAdvisor.

\section{Envía tu crítica}

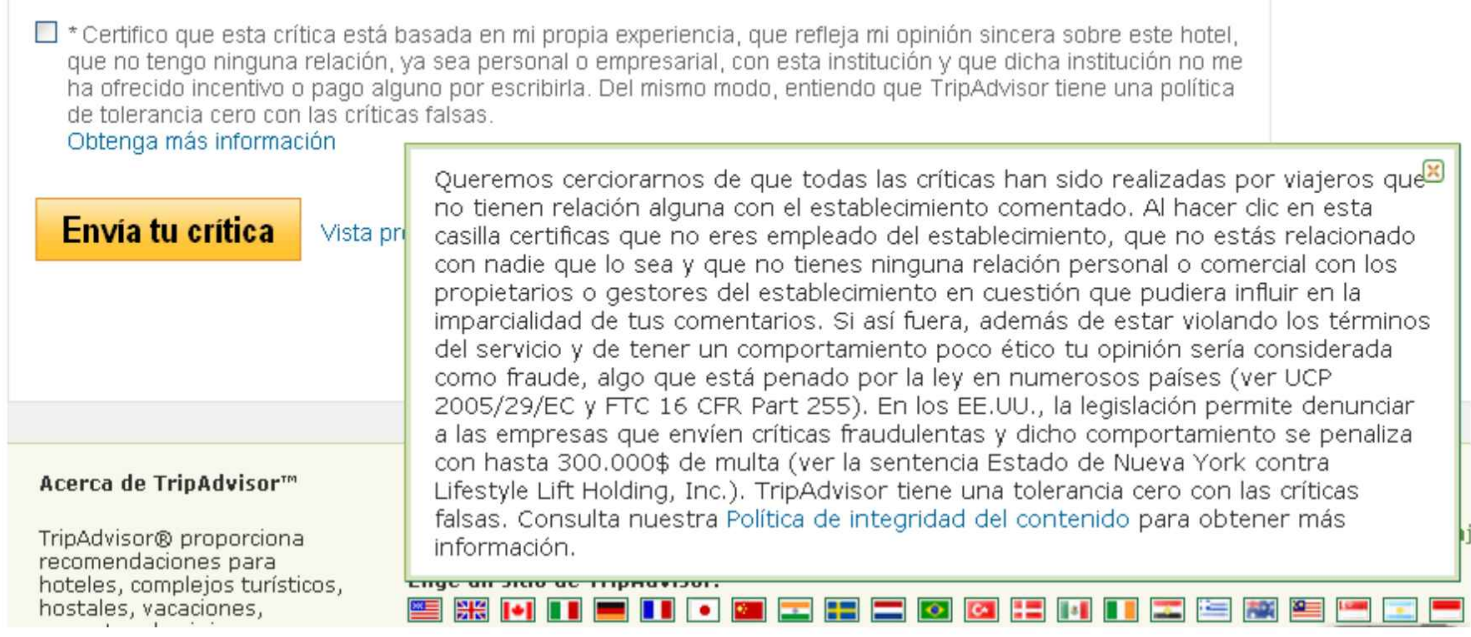

Fuente: www.tripadvisor.es 
Por otra parte, cuando detecta que un hotel puede estar recibiendo críticas falsas positivas, actúa de diversas maneras, según se indica en su propia web (TripAdvisor, 2014a):

"La clasificación del negocio podría caer en el índice de popularidad de TripAdvisor. Como consecuencia, el negocio aparecerá más adelante en una lista de negocios similares. Por ejemplo, podría aparecer en la cuarta página de resultados en lugar de en la primera.

El establecimiento no podrá volver a obtener reconocimiento a través de los premios Travellers' Choice de TripAdvisor, las listas Top 10, los comunicados de prensa, etc.

Es posible que aparezca un aviso en rojo a modo de sanción en la página del perfil que explique que las opiniones del establecimiento son sospechosas. Incluimos estas advertencias en lugar de eliminar el negocio del sitio definitivamente porque ofrecen a los viajeros la información que necesitan para poder protegerse y hacer la mejor elección posible."

En la Figura 15, observamos como queda ese "aviso en rojo" dentro de la ficha de un hotel en TripAdvisor, mientras que en la Figura 16, mostramos su texto en detalle. 
Figura 15. Ejemplo de hotel penalizado por TripAdvisor

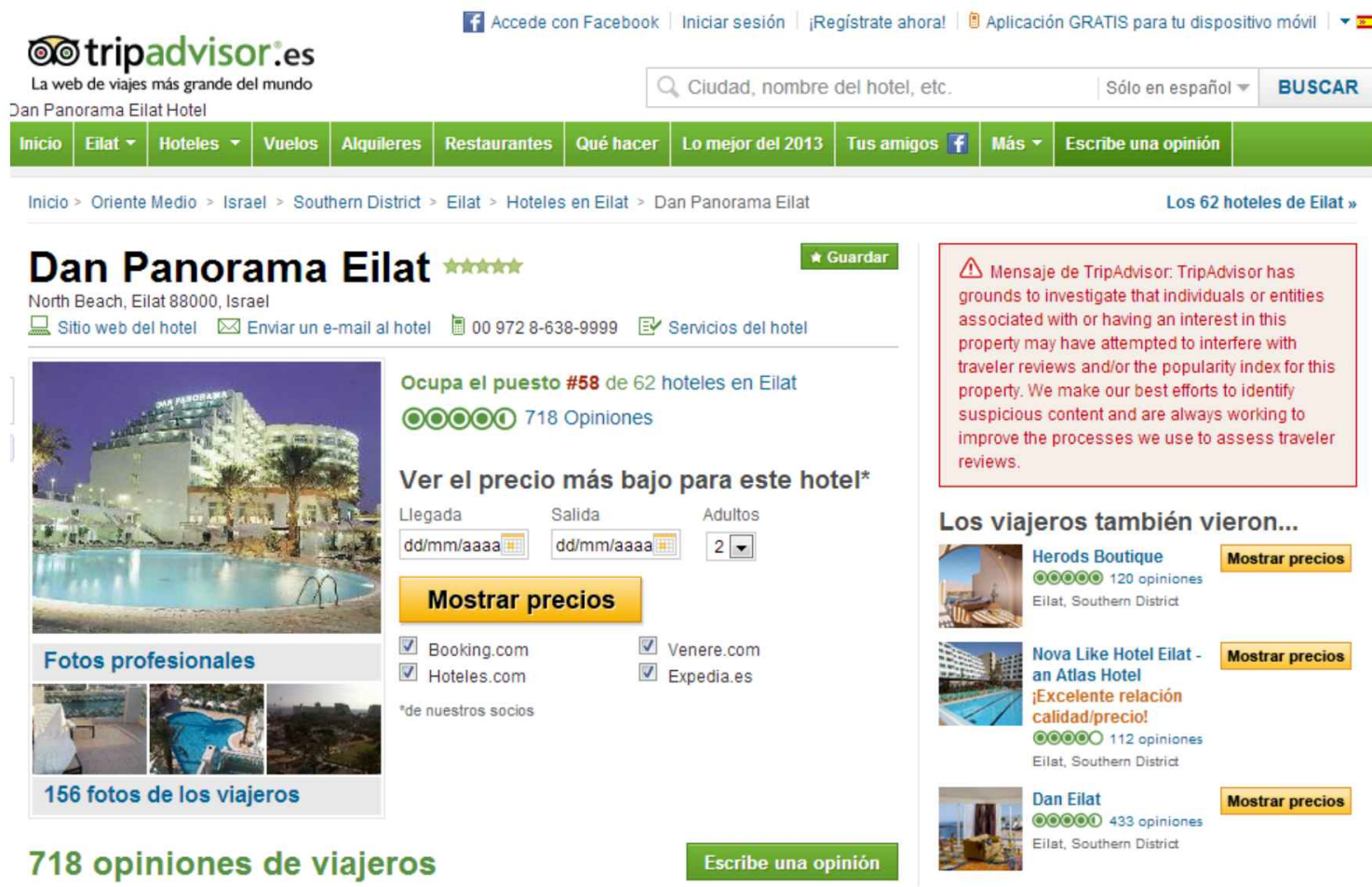

Fuente: www.tripadvisor.es

Figura 16. Detalle del "aviso en rojo" para un hotel penalizado

Mensaje de TripAdvisor: TripAdvisor tiene
razones justificadas para creer que este
establecimiento o individuos asociados al mismo
han intentado manipular nuestro índice de
popularidad interfiriendo con la naturaleza
imparcial de nuestras críticas. En TripAdvisor
hacemos todo lo que está en nuestras manos
para identificar actividades sospechosas y
siempre estamos trabajando en pos de mejorar los
procesos que empleamos para verificar las
críticas de los viajeros.

Fuente: www.tripadvisor.es

En una entrevista concedida al diario británico "The Telegraph", por Adam Medros, responsable de desarrollo de producto de TripAdvisor este declaró que su sistema detecta alrededor de 13.000 opiniones sospechosas cada día (Williams, 2013). La entrevista es de Abril de 2013 y, durante ese año TripAdvisor recibió una media de 137.000 opiniones al día (50 millones en 2013). Ese dato indica que aproximadamente el $10 \%$ de las opiniones recibidas 
resultan ser sospechosas, aunque no se señale qué cantidad acaba finalmente siendo publicada.

Además TripAdvisor ofrece a los hoteleros la posibilidad de registrarse gratuitamente como hotel y responder a cualquier crítica sobre su establecimiento. También pueden solicitar que se retiren críticas que el hotel entienda como falsas.

TripAdvisor obtiene sus ingresos a través de diversas formas de publicidad, desde el tradicional "cobro por click" a productos específicos para los hoteles, como el llamado "Perfil Plus". Este tipo de servicios permiten a los hoteles destacar entre el resto, mejorando su visibilidad y las posibilidades de recibir reservas.

\subsection{Booking}

Booking es una agencia de viajes de Internet, especializada en reservas de hoteles, lo que se denomina generalmente una OTA (Online Travel Agency). Booking está disponible en más de 40 idiomas, con una oferta que supera los 531.831 alojamientos en 206 países y más de 700.000 noches de estancia reservadas cada día (Booking, 2014b).

Booking opera mediante la sociedad "Booking.com B.V." con sede en Amsterdam, pero pertenece al grupo "Priceline", sociedad Norteamericana que cotiza en la Bolsa de Nueva York (Nasdaq). Forma también parte del grupo "Agoda", una OTA especializada en el mercado hotelero del Sureste Asiático, que ha ampliado su ámbito de actuación al resto del mundo. En 2010 Priceline adquirió "Traveljigsaw", especializada en el alquiler de coches, que posteriormente pasó a trabajar bajo la denominación "rentalcars.com". En Noviembre de 2012 se completó el grupo con la adquisición de "Kayak", un importante comparador de vuelos en Internet, que rápidamente extendió su actividad a hoteles y alquiler de coches.

A pesar de la presencia multinacional de Booking, su actividad se sigue centrando en el mercado europeo del que es originaria, como se puede observar en los datos de la Tabla 13 y su correspondiente representación 
gráfica sobre el mapa. Entre los doce principales países del mundo, donde Booking desarrolla su actividad, hay 6 europeos, que ocupan las primeras posiciones de este ranking, contando con más del doble de alojamientos que los otros.

Tabla 13. Número de alojamientos por país disponibles en Booking

\begin{tabular}{|lc|}
\hline PAís & $\begin{array}{c}N^{0} \text { de } \\
\text { alojamientos }\end{array}$ \\
\hline Italia & 51.251 \\
\hline Estados Unidos & 39.455 \\
\hline Francia & 34.969 \\
\hline España & 28.939 \\
\hline Alemania & 24.429 \\
\hline Reino Unido & 15.515 \\
\hline Grecia & 12.914 \\
\hline Brasil & 11.271 \\
\hline Canadá & 7.292 \\
\hline Australia & 6.905 \\
\hline China & 6.326 \\
\hline India & 6.206 \\
\hline
\end{tabular}

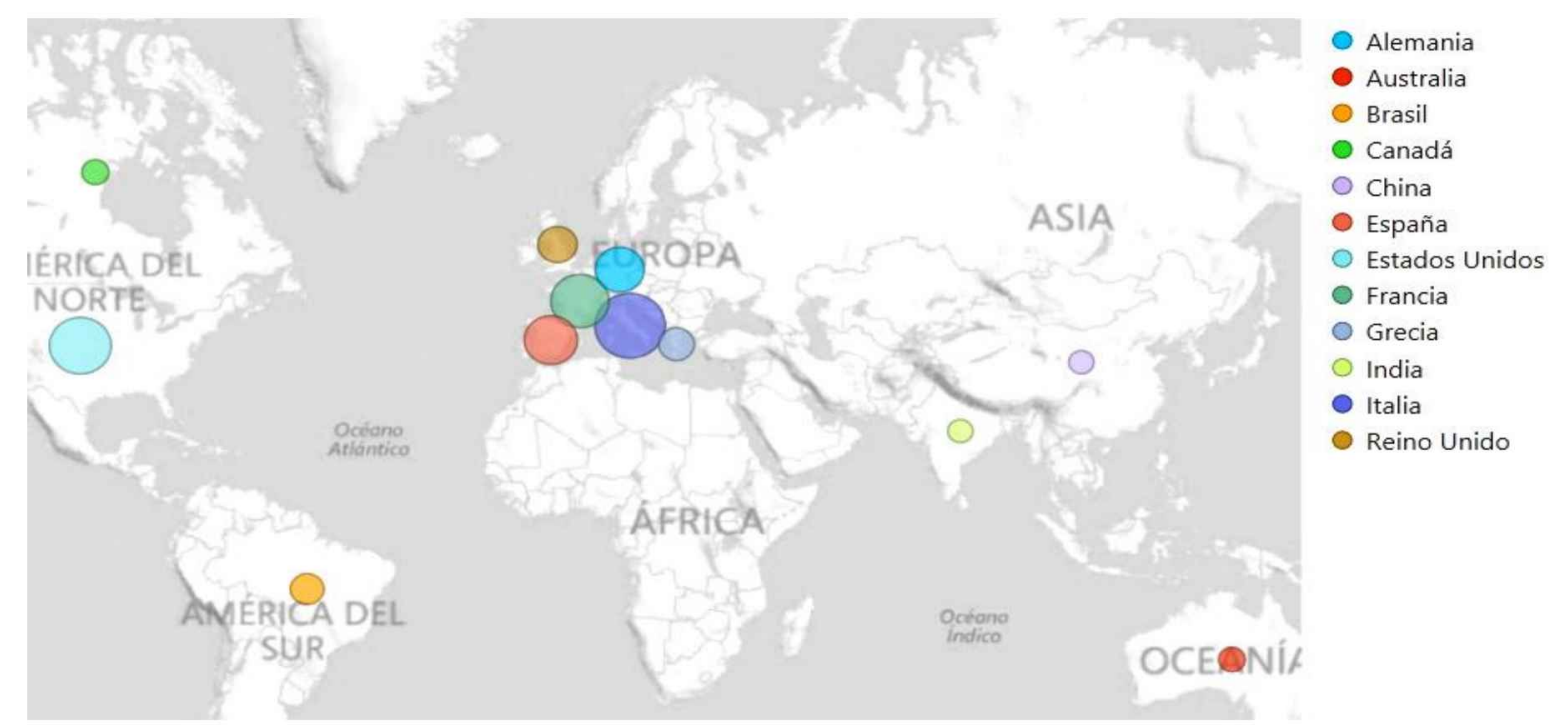

Fuente: Booking.com. Datos Abril de 2014

En España Booking tiene 28.939 alojamientos registrados, de los que unos 12.000 son apartamentos o villas. Por otra parte, Booking tiene más de 35 
millones de comentarios en los últimos catorce meses, de viajeros efectivamente hospedados en los hoteles que comercializan. El hecho de que los comentarios se eliminen tras pasar ese periodo supone una garantía adicional de que las críticas que se leen se refieren a la situación actual del hotel.

Estar en Booking no supone ningún coste fijo para un hotel, ya que solamente cobran en función de las ventas realizadas. La comisión standard de Booking es del 15\% sobre el precio pagado por el cliente (Booking, 2014a), cifra que se puede ver reducida o incrementada, si el hotel se adhiere a algún programa promocional para aparecer en un lugar preferente en ciertas búsquedas.

Cada reserva es garantizada con tarjeta de crédito, pero el cliente no paga a Booking directamente, es el hotel quien cobra al cliente cuando se aloja en el establecimiento. Posteriormente Booking pasa una factura al hotel con el importe de las comisiones sobre las reservas realizadas.

En relación a otras OTA's o mayoristas de viajes convencionales, ese $15 \%$ de comisión no difiere demasiado de lo que éstas suelen tener de tarifa. La principal diferencia es que, en la mayoría de los casos, el turista paga a la agencia de viajes y posteriormente ésta paga al hotel. Dicho pago puede demorarse bastante tiempo después de la estancia del cliente, lo que supone un serio inconveniente financiero respecto a la opción de pago inmediato de Booking.

Como en el caso de TripAdvisor, Booking tiene un especial interés para los investigadores al constituir una gran base de datos de opiniones de huéspedes de hoteles. La web muestra sobre cada hotel una puntuación global y una puntuación de cada una de las 6 categorías establecidas (Figura 17). También existe un desglose por tipo de viajero (Familias, Parejas, Grupos de amigos, etc.). 
Figura 17. Presentación de datos de opiniones en Booking
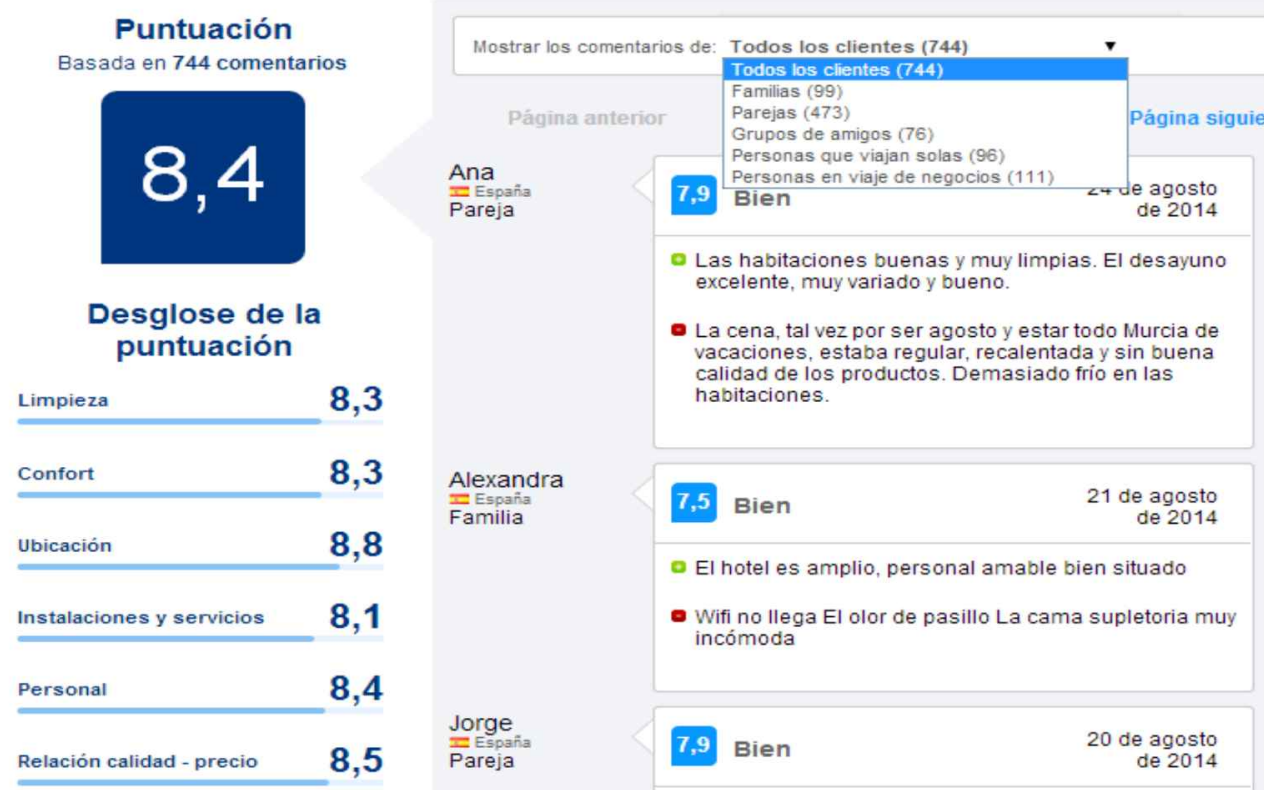

- Acogida en Recepción y habitación muy agradable

\section{Fuente: www.booking.com}

Figura 18. Segmentación de hoteles en Booking

Filtrar por:
Precio (por noche)
$€ 0-€ 49$
$\square € 50-€ 99$
$\square € 100-€ 149$
$\square \in 150-€ 199$
$\square$ Desde $€ 200$
- Oferta
$\square$ Oferta inteligente
- Estrellas
$\square$ estrella (14)
$\square$ 2 estrellas (12)
$\square$ estrellas (24)
$\square$ estrellas (30)
$\square 5$ estrellas (5)
$\square$ Otros (177)

$\square$ Servicios
$\square$ WiFi (232)
$\square$ Aparcamiento (180)
$\square$ Traslado aeropuerto (50)
$\square$ Gimnasio (41)
$\square$ Habitaciones no fumadores (143)
$\square$ Piscina cubierta (8)
$\square$ Spa y centro de bienestar (9)
$\square$ Habitaciones familiares (180)
$\square$ Piscina al aire libre (23)
$\square$ Admite mascotas (81)
$\square$ Adaptado personas de movilidad
reducida (65)
$\square$ Restaurante (50)
$\square$

\begin{tabular}{l|l}
$\square$ Comidas & Zona \\
$\square$ Desayuno incluido (66) & $\square$ Ciutat Vella (122) \\
$\square$ Media pensión (6) & $\square$ Poblados maritimos (23) \\
- Tipo de alojamiento & $\square$ Extramurs (21) \\
$\square$ Hoteles (67) & $\square$ Eixample (20) \\
$\square$ Albergues (10) & Cadena \\
$\square$ Apartamentos (144) & $\square$ Confortel (3) \\
$\square$ Casas y chalets (1) & $\square$ Flatsforyou (7) \\
$\square$ Villas (1) & $\square$ Holiday Inn Express (2) \\
$\square$ Hostales y pensiones (31) & $\square$ Interhome (2) \\
$\square$ Bed and breakfasts (8) & $\square$ NH Hoteles (4) \\
- Puntuación & $\square$ SH Hotels (3) \\
$\square$ Fantástica: 9 o más (12) & $\square$ Tu Apartamento en Valencia \\
$\square$ Muy bien: 8 o más (135) & $\square$ Valencia Luxury (11) \\
$\square$ Bien: 7 o más (203) & $\square$ Valenciaflats (10) \\
$\square$ Agradable: 6 o más (225) & $\square$ Vincci Hoteles (2) \\
$\square$ Sin puntuación (37) &
\end{tabular}

- Perfil del hotel

$\square$ Playa / Costa (15)

$\square$ Romántico / Luna de miel (24)

$\square$ Spa / Relajación (14)

$\square$ Familiar (36)

$\square$ Económico / Mochileros (54)

$\square$ Escapada urbana (91)

$\square$ De lujo (42)

$\square$ De diseño (62)

$\square$ Compras (68)

$\square$ Gourmet (22)

$\square$ Castillo (3)

$\square$ Golf / Deportes (1)

$\square$ Business (57)
- Servicios de la habitación

$\square$ Aire acondicionado (240)

$\square$ Bañera (110)

$\square$ Bañera de hidromasaje (16)

$\square$ Cocina (148)

$\square$ Insonorización (30)

$\square$ Lavadora (116)

$\square$ Patio (12)

$\square$ Piscina privada (2)

$\square$ TV de pantalla plana (174)

$\square$ Terraza (51)

$\square$ Vistas (34) 
Cada vez que se realiza una búsqueda de hoteles en una ubicación geográfica, el sistema permite la aplicación de diferentes filtros (Figura 18). De esta forma se puede realizar un estudio, limitándolo a hoteles con un número determinado de estrellas, que admitan mascotas, que tengan Spa o piscina, etc.

\subsection{Principales Redes Sociales}

Como se ha indicado anteriormente, las redes sociales constituyen el mayor exponente de lo que conocemos como Web 2.0, además de estar estrechamente relacionadas con los también mencionados conceptos de eWom, UGC y reputación online. Las posibilidades de aplicación de estas herramientas al sector hotelero, las hacen especialmente interesantes para el desarrollo de estrategias de promoción en Internet.

Aunque el número y variedad de redes sociales es muy amplio, nos centramos en el análisis y descripción de las cuatro que consideramos más relevantes, por su destacado número de usuarios. En los siguientes apartados se describen las principales características de cada una de ellas, aportando datos cuantitativos, que ayudan a comprender la dimensión e importancia que han adquirido en los últimos años. Así mismo, se realiza una revisión bibliográfica de las publicaciones científicas que han estudiado estas redes sociales, tanto a nivel general, como en el ámbito específico del turismo y en el sector hotelero.

\subsubsection{Facebook}

Mark Zuckerberg creó Facebook en Harvard en Febrero de 2004. En un principio estaba restringido a los estudiantes de esa universidad (Phillips, 2007), aunque después se extendió su uso a otros centros educativos y, finalmente, en 2006 Facebook abrió sus puertas a cualquier individuo del planeta mayor de 13 años (Abram, 2006). Desde ese momento, el número de usuarios se incrementó rápidamente, superando en 2013 los 1.000 millones de usuarios (Gráfico 4). 
Gráfico 4. Millones de usuarios activos en Facebook (2008-2014)

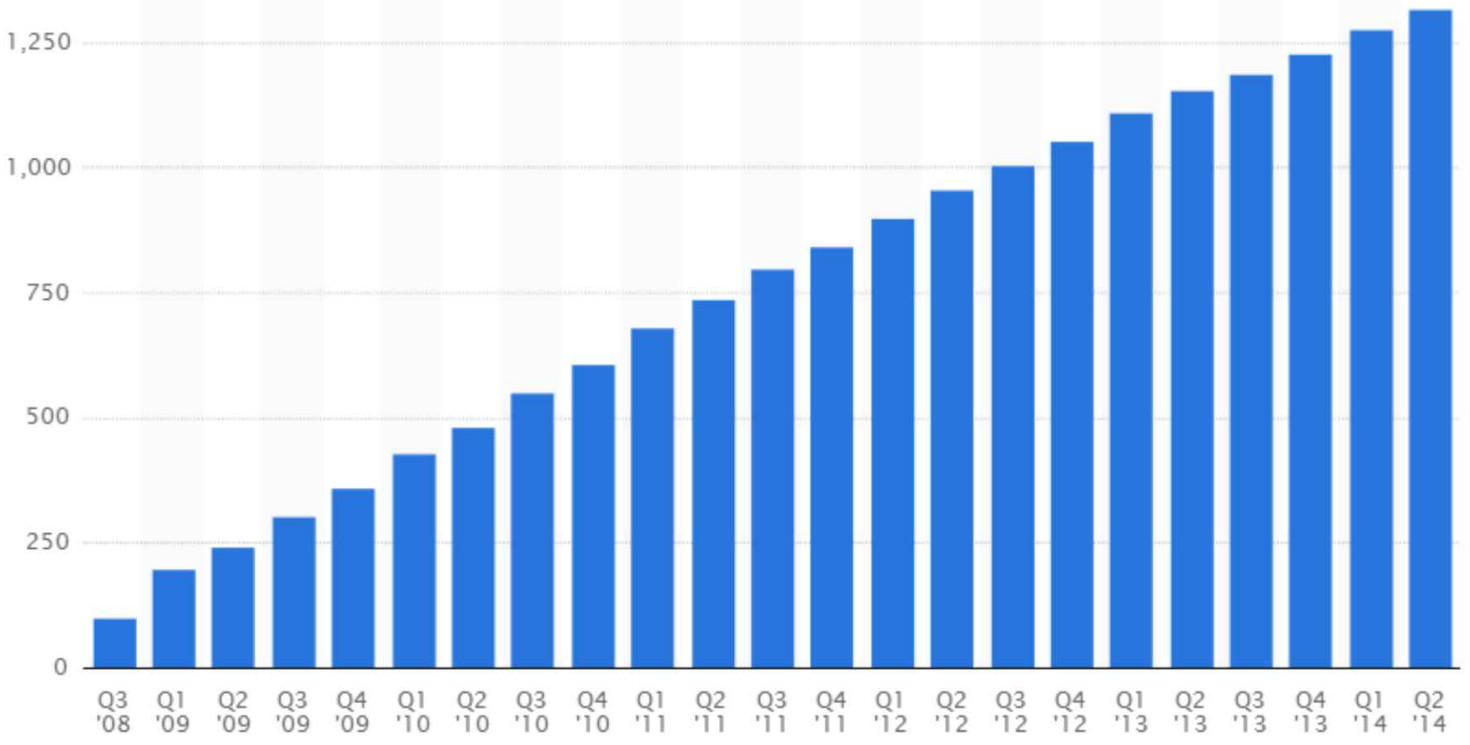

Fuente: Statista

A pesar de lo relativamente reciente de la irrupción de Facebook, ha sido analizada en el ámbito académico desde diferentes puntos de vista y describiéndola con diferentes terminologías. Aunque en español se ha aceptado ampliamente el término "red social", en la literatura científica en inglés Facebook ha sido descrita con diversos términos (Schildgen, 2011) a lo largo de los últimos años (Tabla 14).

Para muchos usuarios, visitar Facebook se ha convertido en parte de su rutina diaria y algunos lo ven como algo casi imprescindible (Roberts, 2010). Tanto las personas, como las organizaciones o las empresas pueden estar en Facebook. Las personas consiguen amigos y las organizaciones consiguen fans (Lewis \& West, 2009), a través del famoso botón de "Me Gusta" (Jacobsen \& Groat, 2009). 
Tabla 14. Terminologías empleadas para describir Facebook

\begin{tabular}{|c|c|}
\hline DENOMINACIÓN & AUTORES \\
\hline $\begin{array}{l}\text { computer mediated } \\
\text { communication }\end{array}$ & Lewis \& West, 2009 \\
\hline digital media & Abroms \& Craig Lefebvre, 2009 \\
\hline friendship network & Seder \& Oishi, 2009 \\
\hline Internet community sites & Maher, 2007 \\
\hline $\begin{array}{l}\text { Internet social network } \\
\text { sites }\end{array}$ & Sledgianowski \& Kulviwat, 2009 \\
\hline networking web sites & Podger, 2009; Billington \& Davidson 2010 \\
\hline new social technology & Gershon, 2008 \\
\hline $\begin{array}{l}\text { online communication } \\
\text { tool }\end{array}$ & $\begin{array}{l}\text { Orr, E. S., Sisic, Ross, Simmering, Arseneault, \& Orr, R. R., } \\
2009\end{array}$ \\
\hline $\begin{array}{l}\text { online social network } \\
\text { sites }\end{array}$ & Tufekci, 2008 \\
\hline online social networking & Weisbuch, Ivcevic, \& Ambady, 2009 \\
\hline $\begin{array}{l}\text { online social networking } \\
\text { website }\end{array}$ & Palser, 2009; Wilson, 2008 \\
\hline $\begin{array}{l}\text { site with blogging } \\
\text { capabilities }\end{array}$ & Hyuk Jun Cheong \& Morrison, 2008 \\
\hline social media & $\begin{array}{l}\text { Information Management, 2009; Grimmelmann, 2010; Podger, } \\
\text { 2009; Kaplan \& Haenlein, 2009b; Rettberg, 2009; Correa, } \\
\text { Hinsley, de Zúñiga, 2010; Gallon, } 2010\end{array}$ \\
\hline social media sites & Hawkins \& Steinman, 2010; Roberts, 2010; Alter, 2009 \\
\hline social media networks & Buttell, 2010 \\
\hline social network & Peluchette \& Karl, 2009;Poynter, 2008; Hoy \& Milne, 2010 \\
\hline social network service & Kwon \& Wen, 2010 \\
\hline social network site & $\begin{array}{l}\text { Muise, Christofides, \& Desmarais, 2009; Walthier, Van Der } \\
\text { Heide, Kim, Westerman, \& Tong, 2008; Boyd \& Ellison, } 2007\end{array}$ \\
\hline social networking & $\begin{array}{l}\text { Bortree \& Seltzer, 2009; Strategic Direction, 2008; Schulte, } \\
2009\end{array}$ \\
\hline social networking site & $\begin{array}{l}\text { Cheung \& Lee, 2010; Computer Fraud \& Security, 2009; } \\
\text { Gangadharbatla, 2008; Madge, Meek, Wellens, \& Hooley, } \\
\text { 2009; Selwyn, 2009; Flint, 2009; Nursing Standard, 2009; } \\
\text { Abroms \& Craig Lefebvre, 2009; Orr, E. S., Sisic, Ross, } \\
\text { Simmering, Arseneault, \& Orr, R. R., 2009; Page, 2010; } \\
\text { Livingstone, 2008; Kaplan \& Haenlein, 2009a; Elzweig \& } \\
\text { Peeples, 2009; Hjorth, 2009; Correa, Hinsley, de Zúñiga, 2010; } \\
\text { Fisher, } 2009\end{array}$ \\
\hline $\begin{array}{l}\text { social networking web } \\
\text { sites }\end{array}$ & $\begin{array}{l}\text { Kluemper \& Rosen, 2009; Gleason, 2009; Dutta \& Fraser, } \\
\text { 2009; Goodman, } 2009\end{array}$ \\
\hline $\begin{array}{l}\text { web sites devoted to user- } \\
\text { generated content }\end{array}$ & Latham, Butzer, \& Brown, 2008 \\
\hline web-based social media & Hawn, 2009 \\
\hline
\end{tabular}

Fuente: Social media tools in integrated marketing strategy. Doctoral dissertation, University of North Carolina (Schildgen, 2011). 
Al igual que las personas, las organizaciones actualizan su estado con frases, fotos, noticias, vídeos, etc. (Page, 2010). Algunas organizaciones creen que usar redes sociales como Facebook requiere de demasiado tiempo y dinero (Kuo, 2009), mientras otras piensan que se trata de una oportunidad totalmente rentable para sus negocios (Poynter, 2008). Las redes sociales no son adecuadas para desarrollar sistemas de venta tradicional, sino para compartir información e interactuar con los usuarios (Dutta \& Fraser, 2009). Facebook proporciona a las organizaciones información demográfica sobre los perfiles de sus fans (Facebook Insights) lo que puede ser aprovechado como un $\mathrm{CRM}^{6}$ (Shih, 2009).

En cuanto al perfil del usuario de Facebook, los datos para España indican una amplia variedad en cuanto a la edad de sus usuarios, siendo los mayores de 35 años aproximadamente la mitad del total (Gráfico 4).

Gráfico 5. Edad de los usuarios de Facebook en España

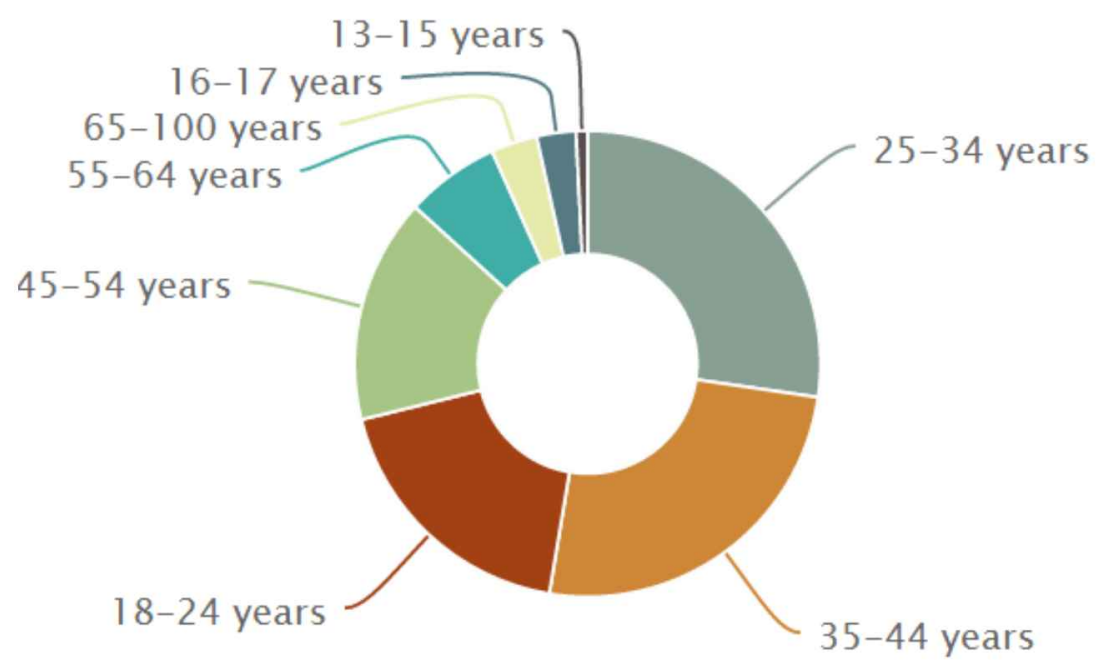

Fuente: Socialbakers (Julio 2014)

Durante los últimos años diversos estudios se han centrado en evaluar la importancia de Facebook como herramienta para la promoción de los hoteles (Hsu, 2012; Salkhordeh, 2010; Terrell \& Kwok, 2011), estableciendo metodologías como el Social Media Management Continuum (O'Connor, 2011)

\footnotetext{
${ }^{6}$ CRM proviene de la sigla del término en inglés "customer relationship management", sistema de gestión basada en la relación con los clientes, obteniendo información detallada sobre éstos.
} 
para la evaluación de su nivel de actividad. También se ha tratado de medir su efectividad y rentabilidad (Leung et al., 2013).

Según un estudio desarrollado por Delloite bajo encargo directo de Facebook (Delloite, 2012) el impacto de esta red social en la economía europea es de más de 15.000 millones de euros y soporta 232.000 puesto de trabajo entre directos e indirectos. Aunque se trata de estimaciones subjetivas sobre el volumen de negocio y ventas que se generan gracias a Facebook, nos da una idea de la relevancia de esta empresa, que va mucho más allá de ser una forma de entretenimiento para millones de internautas.

Facebook ya resultaba una herramienta de Marketing interesante para los hoteles cuando tenía 300 millones de usuarios en 2009, 500 millones en 2010 o 1.000 millones en 2012, años a los que se refiere la mayor parte de la citada literatura científica. La relevancia real de Facebook en la actualidad, cuando el número de usuarios supera los 1.200 millones, es aun mayor de la descrita durante esos años. Todo lo dicho sobre la importancia de Facebook usando datos de 2009 o 2010, debería ser multiplicado por tres o por cuatro en 2014.

\subsubsection{Twitter}

En 2006 una serie de jóvenes emprendedores que trabajaban para la compañía de Podcasts Odeo, Inc., de San Francisco, se vieron inmersos en un día completo de "Brainstorming". En el marco de esas reuniones, Jack Dorsey propuso un sistema de mensajes cortos, para compartir con un grupo pequeño de usuarios. El prototipo inicial fue utilizado entre los empleados de Odeo como un servicio interno y fue lanzado al público en julio de 2006. Twitter estalló al gran público en 2007, y pasó de 20.000 tweets al día a 60.000 . El servicio rápidamente comenzó a ganar adeptos y en marzo de 2007 ganó el premio South by Souhwest Award en la categoría de blog.

Para 2012, Twitter había superado los 500 millones de usuarios, aunque gran parte de esos usuarios presentan altos índices de inactividad. Según un estudio realizado en 2012 (Gabielkov \& Legout, 2012) cuando el número de usuarios era de 537 millones, sólo 268 millones habían escrito algún tweet. Además, sólo 54 millones de cuentas escribían alguno en una semana normal. 
En 2014 los datos de usuarios activos mensuales eran de 271 millones, aunque la propia compañía reconoce que el $8,5 \%$ de sus cuentas operan de forma automática a través de aplicaciones de terceros o mediante los llamados "bots sociales"?

Al poco tiempo de su lanzamiento, el fenómeno de Twitter y las motivaciones de sus usuarios comenzaron a ser estudiadas a nivel académico (Java et al., 2007). Posteriormente otros estudios analizan el comportamiento de los usuarios, tratando de averiguar los factores que les incitan a interactuar (Comarela et al., 2012). También se desarrollan análisis basados en el contexto de los tweets y las listas de Twitter (Pochampally \& Varma, 2011), así como otros dedicados a medir la influencia real de los usuarios de Twitter (Cha et al., 2010).

Investigaciones científicas en turismo han tratado la influencia de Twitter y otras redes sociales en la promoción turística (da Cruz et al., 2011; Richard et al., 2012). Otros estudios tratan también su utilización como herramienta promocional por parte de los hoteles (Hay, 2010; Park, 2012) y tratan de medir su efectividad como herramienta de marketing (Leung et al., 2013).

\subsubsection{YouTube}

YouTube Inc. fue fundada por Chad Hurley, Steve Chen y Jawed Karim en febrero de 2005 en San Bruno (California). Todos ellos se conocieron cuando trabajaban en PayPal. El dominio fue activado el 15 de febrero de 2005 y el 23 de abril fue cargado el primer video, "Me at the Zoo" ('Yo en el zoológico').

En Diciembre de 2005 las páginas de YouTube eran visitadas unos 50 millones de veces al día. Para mayo de 2006, YouTube alcanzó los 2.000 millones de visualizaciones por día, y para mediados de agosto de ese año había alcanzado la marca de 7.000 millones. Además, se había convertido en el décimo sitio más visitado en Estados Unidos. En octubre de 2006 Google

\footnotetext{
7 Bots sociales: También conocidos como "usuarios fantasma", es decir usuarios de redes sociales ficticios, que generan actividad, según las pautas de programación establecidas.
} 
compró YouTube por 1.650 millones de dólares. En agosto de 2014 las cifras oficiales proporcionadas por YouTube (YouTube, 2014) eran las siguientes:

- Más de mil millones de usuarios únicos visitan YouTube cada mes

- Cada mes, los usuarios ven más de 6 mil millones de horas de vídeo... en otras palabras: "ies como si todas las personas del mundo dedicaran una hora al día a ver vídeos en YouTube!"

- Cada minuto se suben 100 horas de vídeo a YouTube.

- El $80 \%$ del tráfico de YouTube procede de fuera de EE.UU.

- YouTube está traducido 61 idiomas.

- Según Nielsen, YouTube llega a más adultos de Estados Unidos de edades comprendidas entre los 18 y los 34 años que cualquier televisión por cable.

YouTube ha sido analizado como herramienta para compartir vídeos a nivel amateur o comercial (Green \& Burgess, 2009). Otros autores se han centrado en sus implicaciones culturales en el ámbito de la comunicación visual (Strangelove, 2010).

Se han editado libros recopilatorios sobre vídeos online y YouTube, (Lovink \& Miles, 2011) en los que diferentes autores, procedentes de diversos ámbitos (académico, periodístico, cultural, etc.) aportan su visión sobre la influencia de YouTube en Internet, la cultura, la política o la economía (Vonderau \& Snickars, 2009).

En el ámbito turístico, se ha medido el impacto de las campañas de vídeos promocionales en la imagen de un destino turístico (Shani, et al., 2010). En lo referente al sector hotelero, cabe citar un estudio sobre el uso que hacen los hoteles del vídeo y cómo es evaluado este uso por los consumidores (Kim \& Mattila, 2011). También se han realizado análisis sobre el uso de YouTube como herramienta para promocionar hoteles y destinos turísticos (Reino \& Hay, 2011). 


\subsubsection{Flickr}

Flickr es una página web donde se pueden almacenar y compartir fotografías. Trata de estructurarse de forma similar a una red social convencional, pero no deja de ser un "almacén" de fotografías, etiquetadas e indexadas mediante diferentes criterios. Tanto el alta en la web, como la subida de fotografías son procesos sencillos y gratuitos.

Nace en marzo de 2004 y con motivo de su décimo aniversario el blog de la marca facilita una completa información sobre su evolución y cifras durante este tiempo (Flickr, 2014). En 2005 es adquirida por Yahoo, continuando su crecimiento hasta alcanzar los 2.000 millones de fotos publicadas en 2007 y los 5.000 millones en 2010. En Mayo de 2013, la web es rediseñada y las limitaciones de inclusión de fotos desaparecen virtualmente al ofrecer de forma gratuita un Terabyte a todos sus usuarios. Actualmente cuenta con 92 millones de usuarios en el mundo y un millón de fotos son compartidas cada día.

Aunque hasta 2011 fue el principal referente de webs para almacenar y compartir fotos, en los últimos años han aparecido opciones alternativas, que han hecho que Flickr pierda su papel protagonista, como Instagram, que cuenta con 200 millones de usuarios o Pinterest que tiene 70 millones.

La fotografía siempre ha tenido gran importancia en la promoción turística, pero desde la popularización del uso de Internet, los medios digitales están adquiriendo una importancia enorme en la construcción y difusión de la imagen turística de un lugar (Donaire \& Gali Espelt, 2011). Por eso la utilización de fotografía en la promoción de un hotel resulta un factor clave.

El número de fotografias que se pueden mostrar en la web de un hotel está limitado por la capacidad de almacenamiento de la propia página o porque resulta poco adecuado saturar excesivamente de fotografías un sitio web. Pero existen usuarios especialmente interesados en ver fotografías del lugar donde se plantean alojar. En este sentido Flickr proporciona al hotel un sitio específico, donde poder almacenar gran cantidad de material fotográfico, orientado a aquellos potenciales clientes, que deseen ver más fotografías del establecimiento. 


\section{METODOLOGÍA GENERAL Y DISEÑO MUESTRAL}

En este capítulo describimos el procedimiento de selección de la muestra de hoteles sobre la que trabajaremos principalmente a lo largo de esta Tesis, justificando su elección en función de los datos obtenidos en estudios previos. Usar el mismo grupo de hoteles, permite mantener cierta unidad en el desarrollo de los análisis planteados y aprovechar el laborioso trabajo de recopilación inicial de información, para el estudio de diversas cuestiones.

Así mismo, una vez seleccionada la muestra, comentamos sus principales valores y peculiaridades. De esta forma, evitamos volver sobre esta misma cuestión, en cada uno de los capítulos en los que se utiliza esta base de datos, sirviendo a su vez de nexo de unión entre éstos.

Planteamos igualmente las principales metodologías seguidas, aunque adelantamos que en cada uno de los capítulos se emplean ciertas técnicas y metodologías específicas, a las que hacemos cumplida referencia en cada momento.

\subsection{Metodología empleada}

Cómo se ha indicado en el capítulo anterior, las opiniones y puntuaciones de los huéspedes de los hoteles, constituyen una importante fuente de información, ya utilizada en diversas investigaciones previamente. Existen multitud de webs que recogen este tipo de opiniones, con diferentes sistemas de funcionamiento y captación de la información, que además difieren en el volumen de opiniones acumuladas. Por ello realizamos una descripción de las diferentes tipologías de webs y lo complementamos con un estudio comparativo básico, que determine cuáles acogen el mayor volumen de información.

Una vez seleccionadas Booking y TripAdvisor, destacamos las diferencias entre ambos sistemas. Finalmente seleccionamos una muestra de hoteles de costa españoles, que tomaremos como base para gran parte de las investigaciones de los siguientes capítulos. Somos conscientes de la existencia de metodologías automatizadas para la recopilación de este tipo de 
información, conocidas como WebCrawler (Gerdes \& Stringam, 2008), pero en este caso optamos por la recopilación manual de la información. Dado que combinamos la información de dos fuentes diferentes de información, esto supondría un trabajo de programación que probablemente sería superior al de hacerlo de forma manual, para este caso concreto.

Para la parte dedicada al estudio cuantitativo del uso de redes sociales, partimos del mismo grupo de hoteles. A partir de esa base, desarrollamos la investigación mediante una exploración real de la actividad de los hoteles en redes sociales, en lugar de optar por la realización de encuestas, como ya hemos indicado anteriormente.

Adicionalmente, utilizaremos metodologías específicas en varios de los capítulos, que son explicadas y justificadas puntualmente en cada caso. A modo de resumen introductorio, adelantamos dichas metodologías adicionales:

- Realizamos reservas de hoteles reales en Booking y Priceline, para poder conocer el funcionamiento exacto de sus sistemas de puntuación.

- Interactuamos con TripAdvisor a través de Twitter para verificar los criterios de control de fraude que aplica.

- Realizamos una búsqueda de casos de incentivación de opiniones en TripAdvisor, a través de Google y Twitter.

- Utilizamos la información de dos concursos que incentivan la aportación de opiniones para comprobar la influencia de estos incentivos en la valoración de los hoteles.

- Realizamos una crítica real en TripAdvisor para comprobar que su sistema de verificación no incluye la lectura por humanos de todos los contenidos.

- Recopilamos noticias relativas a casos de fraude en TripAdvisor que han sido publicadas en medios de comunicación.

\subsection{Tipos de webs que recogen opiniones sobre hoteles}

Existen una gran variedad de webs que muestran las opiniones de viajeros sobre sus estancias en hoteles. Se trata de fuentes de información, susceptibles de ser utilizadas a nivel académico, de acuerdo a lo reseñado en 
el apartado 3.2.2. Algunas recogen los datos de viajeros que efectivamente se han alojado en el hotel, mientras que otras permiten que cualquier persona pueda aportar su opinión, aunque no se haya alojado realmente en el establecimiento consultado.

Detectamos además la existencia de webs que no se adaptan exactamente a ninguno de esos dos modelos, por lo que entendemos necesario aportar una aclaración a este respecto, que permita formarse una mejor idea de la situación actual. Este acercamiento inicial se realiza desde un punto de vista descriptivo y cualitativo para, en apartados posteriores, abordar el tema desde un punto de vista cuantitativo.

En primer lugar se realizó una búsqueda de las comunidades de viajes y agencias de viajes online más populares. Posteriormente, según la información facilitada por cada web, se indagó en la metodología seguida al mostrar las opiniones de viajeros. El análisis se completa con una serie de verificaciones y comprobaciones en hoteles aleatorios registrados en estas webs. Tras la realización del análisis, podemos distinguir cuatro tipos diferentes de webs, en función de la forma en la que se captan y muestran las opiniones de viajeros y que a continuación exponemos:

\section{a) Comunidades de viajeros}

Englobamos en este grupo a webs como TripAdvisor, HolidayCheck, Zoover y MiNube. Se trata de webs donde cualquier persona puede registrarse y dar su opinión sobre diferentes aspectos de su viaje, incluida su experiencia en hoteles.

Los usuarios de estas webs no necesitan justificar haber estado alojados en el hotel sobre el que opinan, por lo que cualquiera puede escribir opiniones positivas sobre su propiedad o negativas sobre los de la competencia. También cabe la posibilidad de que empleados o clientes insatisfechos puedan emprender campañas difamatorias contra los hoteles.

La dudosa fiabilidad de este sistema, resulta ser su principal inconveniente. A pesar de que los responsables de dichos sitios web dicen 
implementar mecanismos de control para evitar el fraude, es posible introducir un número determinado de opiniones falsas sin ser detectado. Aunque estas webs no son agencias de viaje propiamente dichas, proporcionan la posibilidad de realizar búsquedas de hoteles y enlazan con agencias de viajes online y de esta forma obtienen la mayor parte de sus ingresos.

\section{b) Agencias de Viaje online, que requieren verificación}

Dentro de este grupo incluimos a webs como Booking, MuchoViaje, Priceline, Hoteles.com, Rumbo y Destinia. Son agencias de viaje, que piden a sus clientes que opinen sobre su estancia en el hotel contratado. Normalmente les envían un email, días después de haber disfrutado de su estancia solicitándoles su colaboración.

A diferencia del anterior apartado, solamente pueden opinar aquellos usuarios que hayan contratado efectivamente noches de hotel con ellos, por lo que la fiabilidad de las opiniones resulta mucho más alta y se limita así la posibilidad de fraude.

c) Agencias de Viaje online, que requieren verificación, pero recurren a TripAdvisor

Este grupo engloba webs tales como Venere, Logitravel y Atrápalo. Hablamos de agencias de viaje online que, como en el caso anterior, ofrecen a sus clientes la posibilidad de opinar sobre el hotel contratado. Pero, cuando el hotel no cuenta con un número mínimo de opiniones verificadas de clientes reales, estas webs recurren a la información proporcionada por TripAdvisor. De esta forma pueden ofrecer a sus clientes críticas de otros viajeros, aunque para algunos hoteles todavía no tengan una cantidad mínima de opiniones verificadas.

\section{d) Agencias de Viaje online que usan únicamente TripAdvisor}

Dentro de este grupo encontramos sitios como Barceló, eDreams, LastMinute y Halcón Viajes. Dichas páginas no realizan ningún tipo de recopilación de opiniones de sus clientes, limitándose a ofrecer la información facilitada por TripAdvisor. 


\subsection{Webs de opiniones de hoteles más usadas en España}

Nuestra percepción inicial, basada en un estudio previo realizado para los hoteles de la Región de Murcia, (Martínez et al., 2012) nos indica que Booking y TripAdvisor albergan un número de opiniones sobre hoteles significativamente mayor al de resto de webs de uno u otro tipo. El citado estudio regional en Andalucía (Andalucía Lab, 2014), muestra conclusiones similares, así como diversos estudios a nivel internacional (Chaves et al., 2012; Marchiori et al., 2011). Pero entendemos necesario confirmar mediante un estudio centrado en el mercado español la preponderancia de estas dos bases de datos, por lo que formulamos la siguiente hipótesis

$H_{1}$ : Las bases de datos de Booking y TripAdvisor tienen una cantidad de opiniones sustancialmente superior al resto de webs que recogen críticas sobre hoteles.

Para la obtención de datos cuantitativos, se han escogido 30 hoteles españoles, pertenecientes a otros tantos destinos. Quince de ellos corresponden a Grandes Ciudades (Tabla 15) y otros quince a importantes destinos turísticos de "Sol y Playa" (Tabla 16). De esta forma conseguimos estudiar, de forma separada, las dos tipologías de alojamientos.

Se ha realizado una selección aleatoria entre los cinco hoteles con mayor número de opiniones en Booking en cada uno de los destinos. De esta forma pretendíamos evitar la aparición de hoteles sin opiniones en alguna de las bases de datos estudiadas que cuentan con menor cantidad de opiniones registradas.

Finalmente se han seleccionado diez webs para la realización de este estudio, en función de su popularidad y que se relacionan en la Tabla 17. Dos de ellas, TripAdvisor y HolidayCheck, son comunidades de viajeros online, donde cualquiera puede registrarse y compartir contenidos y opiniones. Las otras ocho son agencias de viaje online, que sólo permiten puntuar a clientes verificados, aunque en algún caso puedan recurrir a información de TripAdvisor. En este último supuesto hemos optado no tener en cuenta la información que proviene de TripAdvisor. 
Tabla 15. Hoteles de Grandes ciudades

\begin{tabular}{|ll|}
\multicolumn{2}{|c|}{ GRANDES CIUDADES } \\
\hline DESTINO & HOTEL \\
\hline BARCELONA & ROYAL RAMBLAS \\
\hline MADRID & HOTEL CONVENCION \\
\hline VALENCIA & AYRE ASTORIA PALACE \\
\hline MALAGA & SALLES MALAGA CENTRO \\
\hline ALICANTE & EUROSTARS LUCENTUM \\
\hline MURCIA & CATAL. FLORIDABLANCA \\
\hline BILBAO & SERCOTEL COLISEO \\
\hline SEVILLA & SILKEN AL-ANDALUS \\
\hline GRANADA & HOTEL SARAY \\
\hline ZARAGOZA & HOTEL ALFONSO \\
\hline VALLADOLID & FOXA \\
\hline CORDOBA & CONQUISTADOR \\
\hline SANTIAGO & SAN FRANCISCO \\
\hline S. SEBAST. & ASTORIA 7 \\
\hline GIJÓN & HERNAN CORTES \\
\hline
\end{tabular}

Fuente:Elaboración propia.

Tabla 16. Hoteles de Sol y Playa

\begin{tabular}{|ll|}
\multicolumn{2}{|c}{ SOL Y PLAYA } \\
\hline DESTINO & HOTEL \\
\hline SALOU & DORADA PALACE \\
\hline LA MANGA & ENTREMARES \\
\hline FUENGIROLA & CONF. FUENGIROLA \\
\hline MARBELLA & FUERTE MIRAMAR \\
\hline LLORET MAR & MARSOL \\
\hline PEÑÍSCOLA & RH CASABLANCA \\
\hline LAS PALMAS & AC GRAN CANARIA \\
\hline P. AMÉRICAS & SOL TENERIFE \\
\hline PTO. CRUZ & MONOPOL \\
\hline PTO STA MARIA & PUERTO BAHIA \\
\hline SITGES & SUNWAY PLAYA GOLF \\
\hline PALMA & BELVEDERE \\
\hline PLAYA PALMA & PLAYA GOLF \\
\hline ROQUETAS & DON ANGEL \\
\hline BENIDORM & TORRE DORADA \\
\hline
\end{tabular}

Fuente:Elaboración propia. 
Tabla 17. Webs objeto de estudio

\begin{tabular}{|ll|}
\hline WEBS & Dirección Web \\
\hline BOOKING & www.booking.com \\
\hline VENERE & www.venere.com \\
\hline LOGITRAVEL & www.logitravel.com \\
\hline ATRAPALO & www.atrapalo.com \\
\hline MUCHOVIAJE & www.muchoviaje.com \\
\hline HOTELES & www.hoteles.com \\
\hline RUMBO & www.rumbo.es \\
\hline DESTINIA & www.destinia.com \\
\hline TRIPADVISOR & www.tripadvisor.es \\
\hline HOLYDAYCHECK & www.holidaycheck.es \\
\hline
\end{tabular}

Fuente: Elaboración propia.

Los datos fueron obtenidos durante el mes de Abril de 2012. Aunque se intentó escoger hoteles con un alto número de críticas, en 15 de los 300 registros totales no se obtuvieron datos, es decir, el hotel en cuestión no tenía opiniones registradas en alguna web.

Del resto, cada hotel estudiado tiene un mínimo de 500 opiniones registradas, estando la mayoría de ellos por encima de las 1.000. Estas cifras muestrales creemos que dotan de cierta consistencia a los resultados obtenidos. Todos los hoteles tienen la misma ponderación para el cálculo de los datos globales. Analizando la información de los 30 hoteles utilizados como muestra, se obtienen los resultados que se muestran en el Gráfico 6.

Estos datos confirman la hipótesis $\mathrm{H}_{1}$ sobre el destacado peso que tienen Booking y TripAdvisor en la captación de opiniones de viajeros. Analizamos seguidamente los datos de las dos tipologías de hoteles tratadas, Ciudad y Playa, obteniendo los resultados que se muestran en el Gráfico 7. 
Gráfico 6. Porcentaje de opiniones de hoteles en Webs

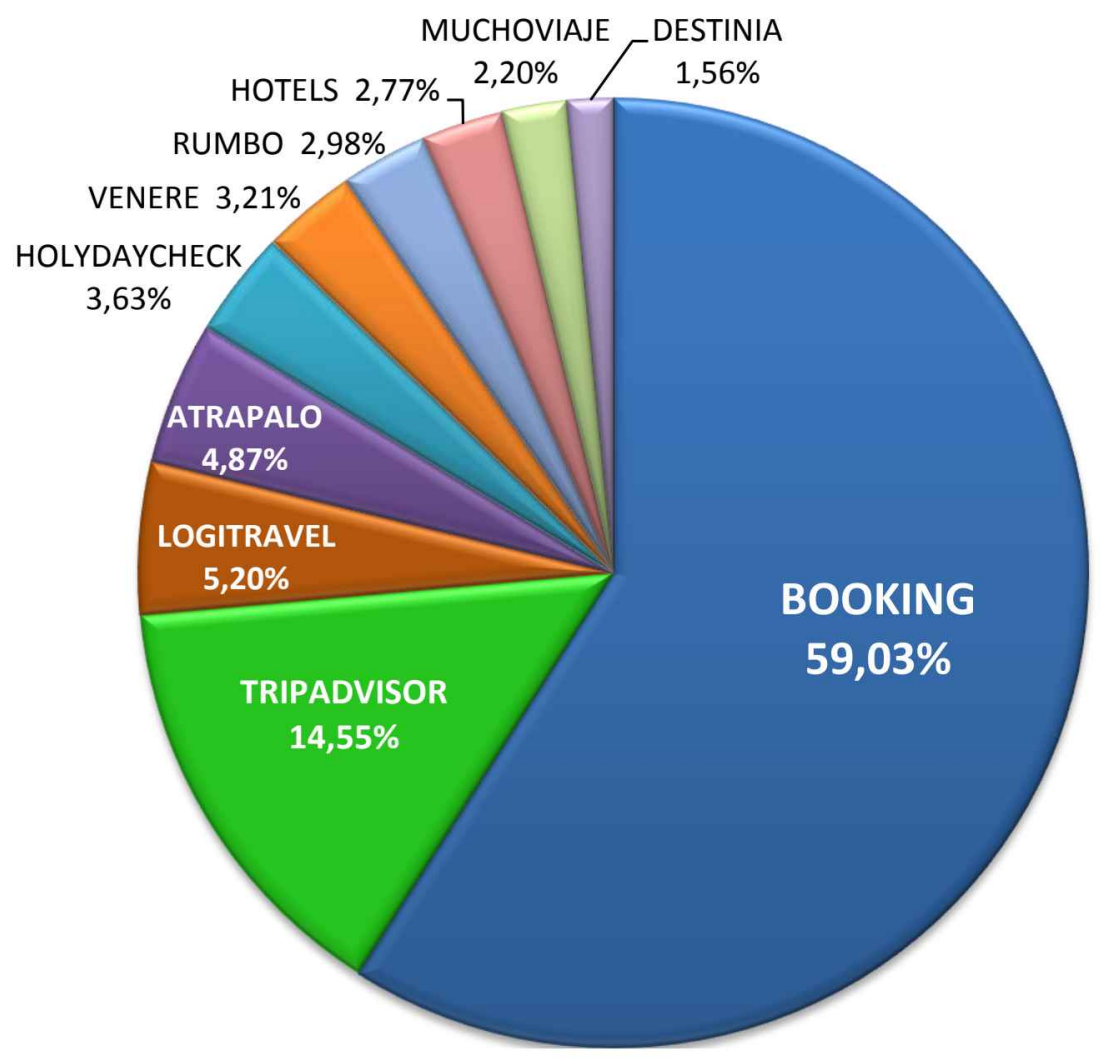

Fuente: Elaboración propia a partir de los datos facilitados en las webs

Gráfico 7. Porcentaje de opiniones de hoteles en Webs según tipología

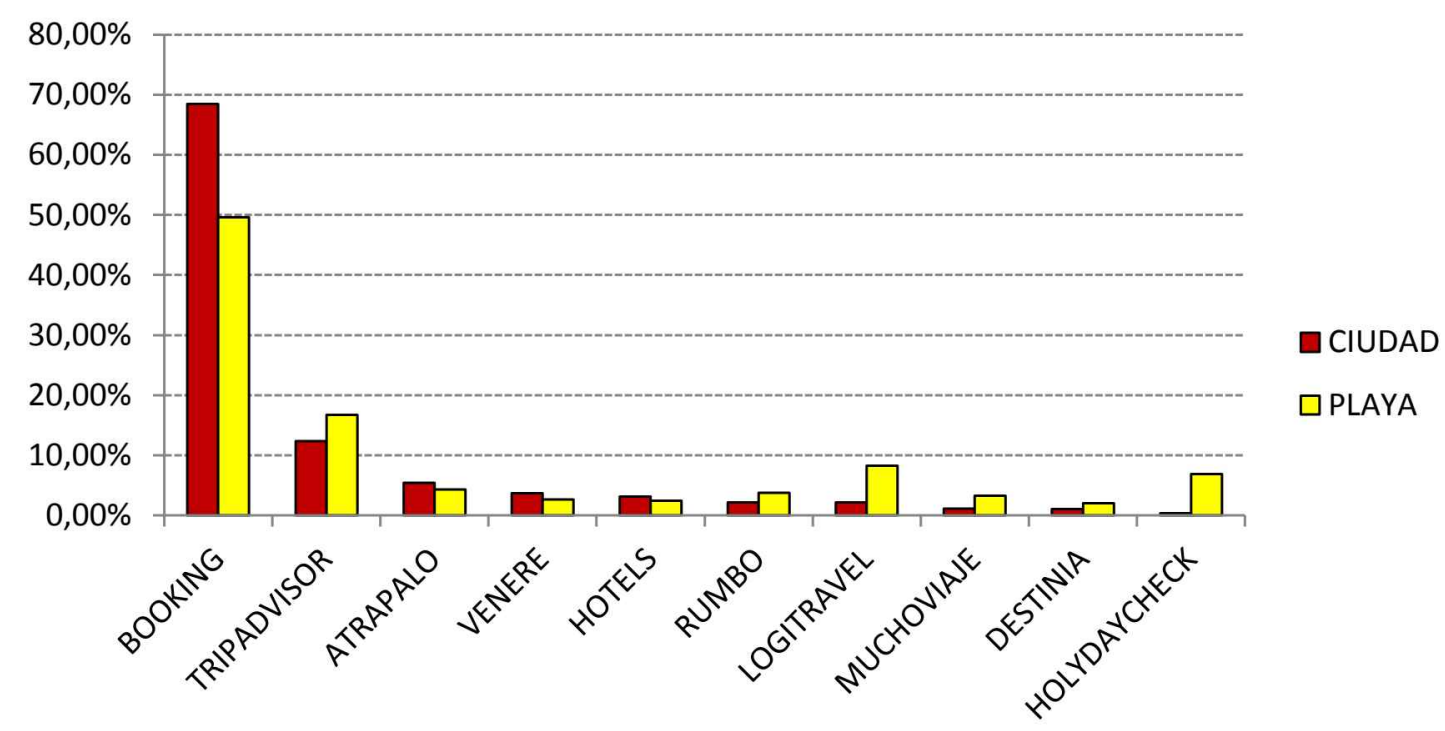

Fuente: Elaboración propia a partir de los datos facilitados en las webs

La cuota de participación en el número de opiniones de Booking es destacable en ambos grupos de hoteles, seguido de TripAdvisor. Las otras ocho webs juntas, apenas suman un $25 \%$ del total de las opiniones registradas. 
En sólo 15 registros, de los 240 existentes para las webs minoritarias, alguno de ellos obtuvo cifras superiores al 10\% de participación en las críticas registradas de un hotel. En 5 de esos 15 casos, el porcentaje obtenido fue incluso superior al $20 \%$.

\subsection{Diferencias entre los sistemas de TripAdvisor y Booking}

Como se ha indicado anteriormente, Booking es con gran diferencia la agencia online que alberga mayor número de opiniones de viajeros en Europa. Pero TripAdvisor es el mayor portal de viajeros en el mundo, registrando el mayor número de opiniones sobre establecimientos hosteleros. Resulta complicado afirmar taxativamente que opción resulta más recomendable para el desarrollo de estudios en este sector.

Por ello creemos útil destacar las siete principales diferencias entre ambas. La revisión de la información proporcionada por ambas webs, los resultados de investigaciones de otros autores, así como nuestro propio acercamiento, mediante el uso real de Booking y TripAdvisor para escribir opiniones, nos ha facilitado una importante cantidad de información al respecto.

Nos centramos en destacar las principales diferencias entre ambas webs, que pueden afectar a aquellos investigadores que decidan nutrirse de este tipo de datos para el desarrollo de sus estudios de satisfacción en el mercado hotelero:

1. La veracidad de las críticas de TripAdvisor es cuestionada, debido a que no resulta necesario que el internauta demuestre haberse alojado en el hotel para escribir una opinión. La literatura científica hace referencia a esta circunstancia, tal y como se detalla en el apartado 3.2.3, tema sobre el que profundizaremos en los capítulos finales de la Tesis. En el caso de Booking, como se ha indicado anteriormente, únicamente pueden escribir críticas aquellos usuarios que efectivamente se han alojado en el hotel, reservando a través de esta agencia, lo que proporciona una cierta seguridad en la veracidad de las críticas. 
2. Booking permite segmentar los hoteles en función de 17 tipologías diferentes (Golf-Deportes, Playa-Costa, Rural, etc.) algo que no es posible con TripAdvisor.

3. Booking permite segmentar el tipo de cliente que realiza críticas en 6 categorías diferentes (Familias con niños pequeños, Parejas mayores, etc.) obteniendo una valoración diferente para cada una de ellas. Aunque TripAdvisor también realiza esa clasificación, solo permite visualizar el grupo de críticas perteneciente a ese segmento, sin proporcionar su puntuación global, aunque se puede obtener, tras una recopilación de datos adicional.

4. El sistema de calificación de TripAdvisor utiliza una escala de 1 a 5 ofreciendo datos con un redondeo de 0,5 puntos, es decir ( $\ldots 1,5$ 2,0 - 2,5 - 3,0 - 3,5..). El sistema de Booking resulta más manejable por utilizar un redondeo de una décima, es decir $(\ldots 7,1$ 7,2 - 7,3 - 7,4 ...), lo que resulta más adecuado para la realización de análisis cuantitativos.

5. Booking ofrece únicamente las opiniones correspondientes a los últimos catorce meses, proporcionando así una imagen actualizada de la situación del hotel. TripAdvisor, por contra, acumula críticas con más de diez años de antigüedad, consiguiendo así mayor cantidad, a costa de incluir comentarios que pueden no reflejar la situación actual del hotel.

6. Booking indica que cuenta con más de 35 millones de opiniones, mientras que TripAdvisor indica 170 millones, de las que 50 millones se realizaron en 2013. Pero debemos tener en cuenta que las críticas en TripAdvisor no son únicamente de hoteles, sino que también se refieren a restaurantes, aerolíneas, atracciones o destinos.

7. TripAdvisor tiene una cobertura prácticamente mundial, siendo Estados Unidos su principal mercado en cuanto a número de usuarios. La presencia en Europa también es destacable, con un importante peso de los usuarios británicos y un peso relativamente 
bajo de los alemanes, en relación a las poblaciones de ambos países y su volumen de emisión de turistas. Por el contrario, la presencia de Booking, aunque también tiene una cobertura mundial, concentra su mayor volumen de negocio en Europa.

\subsection{Representatividad de Booking y TripAdvisor como bases de} datos. Diseño de la muestra general

Pasamos en este punto a justificar la selección de la muestra de hoteles que servirá de eje conductor de la Tesis, definiendo los criterios seguidos para su elección. Cuantificamos además el volumen de información obtenida de cada una de las bases de datos, realizando un análisis inicial de sus principales características y peculiaridades.

\subsubsection{Metodología de selección de la muestra general}

España es el segundo país del mundo en cuanto a ingresos del turismo y disputa la tercera posición en cuanto a número de turistas recibidos con China (UNWTO, 2014). Este éxito es atribuible principalmente al llamado "Turismo de Sol y Playa", que desde los años 60 ha tenido un gran desarrollo. Es cierto que el turismo cultural o el de naturaleza cobran cada vez mayor importancia, pero la realidad nos sigue indicando que la industria turística española está cimentada sobre la base de turistas del centro y Norte de Europa que eligen el clima y las playas españolas.

Por ello nos centramos en el estudio este tipo de turismo, representado por los hoteles de tres, cuatro y cinco estrellas considerados como parte del "Turismo de Sol y Playa", situados en la costa Mediterránea y las islas. Así mismo, en función de los resultados cuantitativos obtenidos, utilizamos Booking y TripAdvisor como bases de datos principales.

La clasificación de los hoteles, en cuanto a su tipología, puede resultar en ocasiones difícil, ya que determinar si un hotel es de ciudad, de playa o de montaña, puede responder a criterios subjetivos. Por esta razón, confiamos en el criterio de clasificación de Booking que dentro de su "Perfil del Hotel" tiene una categoría denominada "Playa/Costa". También se selecciona la categoría 
"Hotel" dentro de la clasificación de Booking, evitando así hostales, apartamentos o albergues.

La extracción de datos en Booking se realiza manualmente con búsquedas por provincias a las que se aplican los filtros de "Playa/Costa", "Hotel" y "3, 4 y 5 estrellas". Posteriormente se realiza una búsqueda de los hoteles seleccionados en TripAdvisor. Los datos fueron tomados durante el mes de Noviembre de 2011, una vez finalizada la temporada veraniega.

\subsubsection{Magnitudes principales de la muestra}

La búsqueda en Booking proporciona un total de 1.440 hoteles, que suman 185.802 opiniones y valoraciones de huéspedes. Todos los hoteles tienen al menos cinco opiniones, ya que el propio sistema de Booking no muestra las puntuaciones de hoteles con menos. La media de opiniones por hotel es de 129 y el $89 \%$ tiene veinte o más opiniones registradas.

España contaba en ese periodo con un total de 16.563 alojamientos turísticos (INE, 2014) con una capacidad total de 1.707 .037 plazas de alojamiento. Se seleccionaron para este estudio los hoteles de 3, 4 y 5 estrellas que, aunque suponen el $32 \%$ del total de establecimientos, albergan el $76 \%$ de las plazas de alojamiento del país.

Las 14 provincias seleccionadas suman un total de 6.840 alojamientos turísticos, es decir, el $41 \%$ del total nacional. Pero en cuanto a plazas de alojamiento, suponen un $70 \%$ de la capacidad hotelera del país. Para un mejor manejo de los datos se considerará Canarias como una Comunidad Autónoma uniprovincial, aun sabiendo que cuenta con dos provincias.

Según los datos obtenidos de Booking, el porcentaje de establecimientos considerados como de "Playa/Costa" en estas provincias es del 50\%, con 4 provincias (Barcelona, Valencia, Murcia y Granada) en las que esta cifra es inferior al 50\%, siendo superior en las otras 10 (Gráfico 8). En el caso de Barcelona y Valencia, sus grandes áreas metropolitanas absorben la mayor planta hotelera de la provincia; la provincia de Granada tiene una franja de 
costa muy limitada y en el caso de Murcia, su desarrollo turístico costero se ha orientado principalmente al alquiler y venta de viviendas de playa.

Gráfico 8. Porcentaje de hoteles de Playa/Costa por provincia

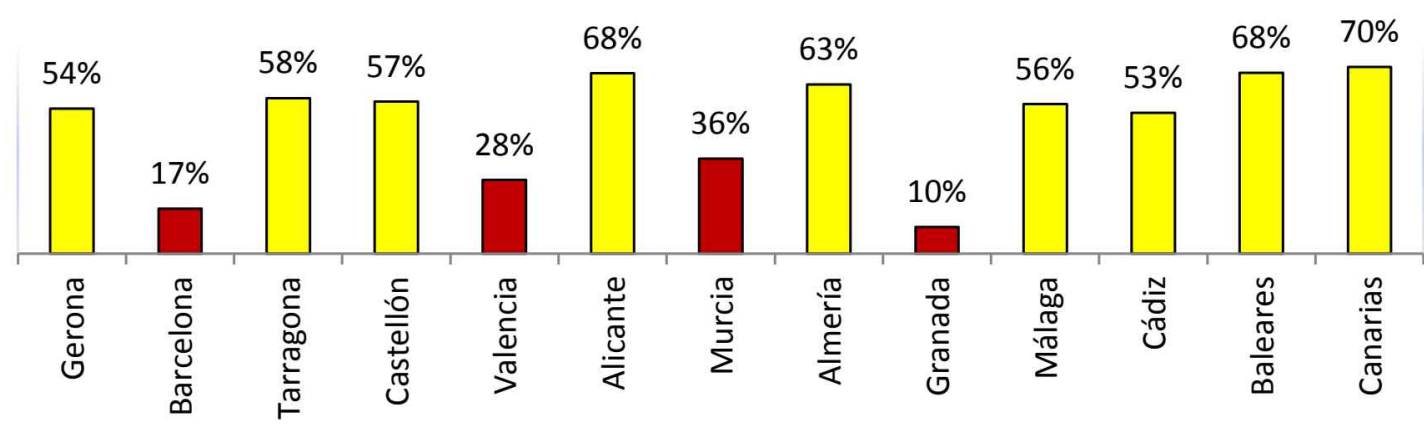

Fuente: Elaboración propia a partir de datos de Booking

Nos ha llamado la atención el hecho de que en Baleares y Canarias el porcentaje de establecimientos calificados como de "Playa/Costa" no supere el $70 \%$ del total, cuando parecería lógico esperar que la práctica totalidad de la planta hotelera de estas islas estuviera orientada al turismo objeto de estudio. Probablemente los criterios de Booking para considerar a un hotel dentro de ésta categoría son bastante estrictos y aquellos establecimientos que no están inequívocamente enfocados a este segmento no son incluidos en él.

En cuanto a la distribución por provincias de la muestra, se refleja la alta concentración de establecimientos hoteleros en seis de las zonas estudiadas, que concentran el $80 \%$ de los hoteles, según se observa en el Gráfico 9 y su correspondiente representación sobre el mapa. Estos datos coinciden básicamente con los que se obtienen de fuentes oficiales de información (INE), lo que confirma la proporcionalidad de la muestra. 
Gráfico 9. Distribución de la muestra por provincias
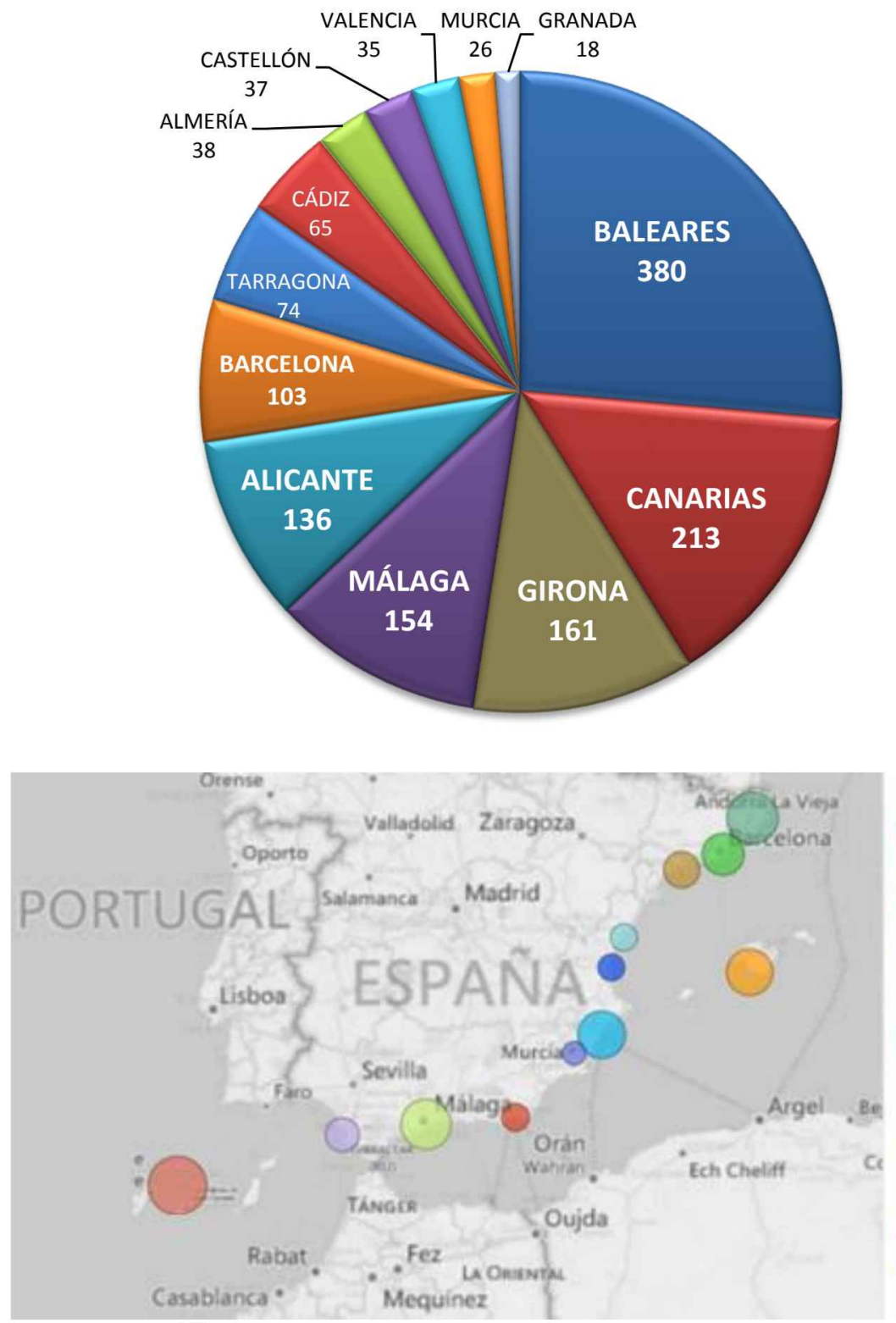

Alicante

- Almería

- Baleares

- Barcelona

- Cádiz

- Canarias

- Castellón

- Girona

- Granada

Málaga

- Murcia

- Tarragona

- Valencia

Fuente: Elaboración propia a partir de datos de Booking.com

Partiendo de la muestra inicial de hoteles de Booking, seleccionamos los 1.384 hoteles que cuentan al menos con diez opiniones. Posteriormente se realiza una búsqueda en TripAdvisor sobre esos hoteles obteniendo los resultados presentados en la Tabla 18. En la Tabla 19 mostramos como queda la muestra, al tener en cuenta únicamente aquellos hoteles con un mínimo de 10 opiniones registradas. 
Tabla 18. Composición de la muestra por número de opiniones registradas.

\begin{tabular}{|ccccc|}
$\begin{array}{c}\mathbf{N}^{0} \text { de } \\
\text { opiniones }\end{array}$ & $\begin{array}{c}\text { Hoteles en } \\
\text { Booking }\end{array}$ & $\begin{array}{c}\% \\
\text { Bk }\end{array}$ & $\begin{array}{c}\text { Hoteles en } \\
\text { TripAdvisor }\end{array}$ & $\begin{array}{c}\% \\
\text { TA }\end{array}$ \\
\hline $\mathbf{0}$ & 0 & $0 \%$ & 11 & $1 \%$ \\
\hline $\mathbf{0 - 9}$ & 0 & $0 \%$ & 91 & $7 \%$ \\
\hline $\mathbf{1 0 - 4 9}$ & 402 & $29 \%$ & 415 & $30 \%$ \\
\hline $\mathbf{5 0 - 9 9}$ & 354 & $26 \%$ & 248 & $18 \%$ \\
\hline $\mathbf{1 0 0 - 2 9 9}$ & 484 & $35 \%$ & 435 & $31 \%$ \\
\hline $\mathbf{+ 3 0 0}$ & 144 & $10 \%$ & 184 & $13 \%$ \\
\hline TOTAL & 1.384 & & 1.384 & \\
\hline
\end{tabular}

Fuente: Elaboración propia a partir de datos de Booking y TripAdvisor

Tabla 19. Opiniones registradas por fuente de información

\begin{tabular}{|cccc|}
$\begin{array}{c}\text { BASE DE } \\
\text { DATOS }\end{array}$ & $\begin{array}{c}\text { Número de } \\
\text { hoteles }\end{array}$ & $\begin{array}{c}\text { Número de } \\
\text { opiniones }\end{array}$ & $\begin{array}{c}\text { Media de } \\
\text { opiniones } \\
\text { por hotel }\end{array}$ \\
\hline BOOKING & 1.384 & 185.408 & 134 \\
\hline TRIPADVISOR & 1.373 & 199.693 & 145 \\
\hline
\end{tabular}

Fuente: Elaboración propia a partir de datos de Booking y TripAdvisor

El número medio de opiniones por hotel, está por encima de las 100 . El $71 \%$ de los hoteles tienen al menos 50 opiniones en Booking y el $63 \%$ alcanza la cifra de 50 opiniones en TripAdvisor.

\subsection{Conclusiones sobre las bases de datos de opiniones de hoteles}

Creemos que no tiene mucho sentido la utilización de "Agencias de Viaje online que usan únicamente TripAdvisor" como fuente de información, ya que se limitan a reproducir los datos de éste. En el caso de aquellas webs que recurren puntualmente a TripAdvisor, el tratamiento de datos puede verse complicado al mezclarse opiniones de la propia web con los de TripAdvisor, lo que puede distorsionar la validez de los datos obtenidos.

Por lo tanto las dos principales opciones de utilización de webs que recogen opiniones de hoteles son las "Comunidades de viajeros" (TripAdvisor, 
HolidayCheck, MiNube) o las "agencias de viaje online, que requieren verificación" (Booking, MuchoViaje, PriceLine, Hoteles.com, Rumbo, Destinia).

Aunque los datos verificados parecen preferibles a los obtenidos en las comunidades de viajeros, queda por cuantificar la potencia de ambos modelos, en cuanto a número de opiniones registradas, para determinar la idoneidad de una $u$ otra fuente de información. Al analizar el número de opiniones registradas en diversos destinos y webs, observamos que existen casos en los que alguna web de las consideradas "minoritarias" cuenta con un alto número de opiniones registradas. Estos casos, que se pueden considerar excepciones, se concentran principalmente en los hoteles de playa, con las webs de Logitravel y HolidayCheck. En el primer caso, Logitravel es una agencia con una clara orientación hacia el turismo vacacional de playa, lo que provoca que obtenga un mayor número de opiniones en ese segmento de hoteles. En el caso de HolydayCheck, sus cifras se explican por los datos de los dos hoteles de la isla de Mallorca, que tienen un $31 \%$ y $40 \%$ de las opiniones registradas en dicha Web. Esta anomalía puede venir dada por la referida importancia de HolidayCheck en los países de habla alemana y la posible orientación de los dos hoteles que forman parte de la muestra hacia el turismo germano, como sucede frecuentemente en Mallorca.

Por otra parte el mayor peso de TripAdvisor en hoteles de playa, puede venir explicado por la presencia del turismo británico, el principal emisor de turistas hacia España. Reino Unido es el país con mayor número de usuarios de TripAdvisor en Europa (TripAdvisor, 2013a). La destacable propensión a utilizar TripAdvisor por parte de este tipo de turistas, que mayoritariamente se dirigen a hoteles de playa, contribuye al mayor peso de TripAdvisor en este segmento hotelero.

En el caso de los hoteles de ciudad, el peso de visitantes extranjeros resulta mucho menor, lo que hace bajar el peso relativo de TripAdvisor, Logitravel y HolidayCheck. De esta forma, el liderazgo de Booking resulta más evidente, recogiendo casi el $70 \%$ de las opiniones registradas. En todo caso, queda patente que, en general, el volumen de información aportada por 
Booking y TripAdvisor resulta sustancialmente superior al resto de las opciones estudiadas, confirmándose así la primera hipótesis planteada $\left(\mathrm{H}_{1}\right)$.

Booking presenta importantes ventajas, como herramienta para la realización de estudios sobre hoteles, respecto a TripAdvisor. Pero en el aspecto cuantitativo, TripAdvisor puede resultar más interesante en mercados donde los usuarios de esta web generan más opiniones que los compradores de Booking.

A nivel global, resulta obvio que TripAdvisor alberga un mayor volumen de opiniones, pero los datos no son tan tajantes al plantear si la velocidad de generación de opiniones sobre hoteles es también mayor. Mientras Booking generó 35 millones de opiniones en 14 meses, TripAdvisor generó 50 millones en 12 meses, aunque desconocemos qué porcentaje de estas opiniones corresponde a hoteles y cuál al resto de establecimientos (Bares, Restaurantes, Atracciones, etc.).

Por una parte, el hecho de que TripAdvisor no borre comentarios transcurrido un tiempo, puede ser un inconveniente para los usuarios, a los que se les puede proporcionar información poco actualizada. Pero por otro lado también puede ser una ventaja en el campo del análisis científico, ya que permite el estudio de la evolución a lo largo del tiempo de las valoraciones de los hoteles.

Al diseñar nuestra muestra, los datos cuantitativos reflejan la idoneidad, tanto de TripAdvisor, como de Booking, como fuentes de información totalmente válidas para su uso en estudios relativos a los hoteles de playa españoles. En los capítulos posteriores, partiremos de esta base datos para el desarrollo de nuestras investigaciones. 


\section{FUNCIONAMIENTO DEL SISTEMA DE PUNTUACIONES DE BOOKING}

Las publicaciones científicas que hacen referencia al sistema de puntuación de Booking, asumen que se utiliza una escala que va de 0 a 10 (Bjørkelund et al., 2012; de Albornoz et al., 2011; Estárico et al., 2012; Gal-Oz et al., 2010; Grinshpoun et al., 2009) o una escala de 1 a 10 (Bouvain, 2011; Marchiori et al., 2011; Chaves et al., 2012; Costantino et al., 2012a-2012b; Filieri \& McLeay, 2014; Korfiatis \& Poulos, 2013; Kosar et al., 2014; Martínez María-Dolores et al., 2012; Plata-Alf, 2013; Yacouel \& Fleischer, 2012; Floris \& Campagna, 2014; Gutierrez Taño et al., 2014; Minazzi, 2015). Trenz y Berger (2013) en una interesante compilación de literatura científica sobre opiniones en Internet contribuyen a incentivar estas suposiciones citando a (Chaves et al., 2012) que asumen una escala de 1 a 10.

Sólo uno de los veinte artículos encontrados se refiere a la existencia de una puntuación mínima de 2,5 en las opiniones (Bjørkelund et al., 2012): "It seems that Booking.com does not have any reviews with scores below 2.5... scores are somewhat inflated toward the higher end of the scale...662,991 reviews from Booking.com, the lowest score from this set was $2.5^{\prime 8}$. Los autores tratan de explicar esta aparente anomalia: "It is therefore possible that Booking.com employ some sort of filtering mechanism, and ratings with all negative scores are regarded as spam."

Dividimos este capítulo en dos apartados diferenciados pero a la vez relacionados. En primer lugar aclaramos las dudas surgidas en torno al sistema de puntuaciones de Booking, llegando a la conclusión de que en realidad se utiliza una escala que va de 2,5 a 10 . Seguidamente, pasamos a cuantificar los efectos que esta peculiar y sorprendente escala tiene en las puntuaciones obtenidas por los hoteles, comparándolo con el sistema con escala de 1 a 10 que utiliza Priceline.

\footnotetext{
8 “Parece que Booking.com no alberga ninguna opinion por debajo del 2,5... las puntuaciones parecen infladas hacia la parte alta de la escala... de 662.991 opiniones en Booking.com la puntuación más baja era 2,5"

9 "Es probable que Booking.com use algún tipo de filtro que haga que las puntuaciones muy negativas sean consideradas como spam"
} 


\subsection{La escala 2,5 - 10 de Booking}

Para un análisis completo y fiable del sistema de opiniones y puntuaciones de Booking, se realizaron seis reservas reales en esta web. Se trata de estancias disfrutadas por el autor de la Tesis durante los meses de Octubre y Noviembre de 2011 en España y durante el mes de Agosto de 2013 en Canadá.

En cada caso, se recibió un e-mail, invitando a rellenar una encuesta de satisfacción online (Figura 19) y se completó todo el procedimiento, realizando "capturas de pantalla" de cada paso. Todo el proceso se encuentra documentado en el Anexo 1.

Figura 19. Email de Booking para rellenar encuesta.

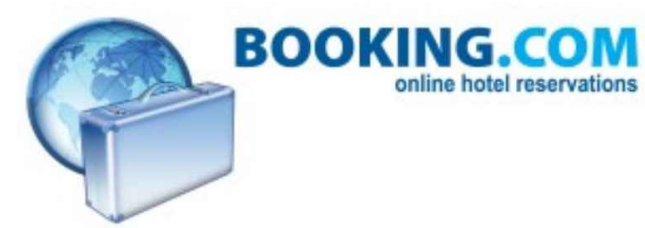

Estimado/a JUAN PEDRO MELLINAS,

Gracias por haber reservado en el Hotel Princesa Galiana a través de Booking.com. Nos gustaría saber cómo ha sido tu experiencia en el hotel para mejorar así nuestro servicio. Selecciona una de las siguientes opciones:

- Estuve en el hotel y quiero responder a 4 preguntas

- Estuve en el hotel pero no tengo tiempo para responder a las preguntas

- No estuve en el hotel

Gracias,

Booking.com

Fuente: Correo recibido tras realizar una reserva real.

Dado que Booking ofrece puntuaciones en una aparente escala convencional de 0 a 10 o de 1 a 10 , sería de esperar que la encuesta a rellenar se presentara en ese mismo formato, por ello planteamos la siguiente hipótesis:

$\mathrm{H}_{2}$. El cuestionario que Booking solicita rellenar a sus clientes, se presenta con puntuaciones que van de 0 a 10 o de 1 a 10. 
Al rellenar el cuestionario nos percatamos de que, en lugar de una escala numérica, el consumidor puede elegir entre cuatro calificaciones para cada parámetro: Mal, Regular, Bueno y Excelente (Figura 20).

Figura 20. Encuesta de valoración del hotel en Booking

2 ¿Cómo valorarías el Hotel Travelodge Montreal Centre en estos aspectos?

\begin{tabular}{|c|c|c|c|c|}
\hline & Mal & Regular & Bueno & Excelente \\
\hline Personal & ○ & (อ) & 0 & 0 \\
\hline Servicios & ○ & ○ & (e) & 0 \\
\hline Limpieza & 0 & ○ & 0 & (c) \\
\hline Confort & O & O & (2) & 0 \\
\hline Relación calidad / precio & O & 0 & O & (c) \\
\hline Ubicación & 0 & 0 & 0 & (c) \\
\hline
\end{tabular}

Fuente: Cuestionario de Booking

A continuación se solicitan datos adicionales y se da la posibilidad de escribir comentarios, a la vez que se pide la evaluación sobre el proceso de reserva con Booking. En la Tabla 20 se muestran las calificaciones asignadas a cada parámetro de los hoteles evaluados y la puntuación publicada por Booking.

Tabla 20. Resultados de las encuestas completadas en Booking

\begin{tabular}{|c|c|c|c|c|c|c|c|c|}
\hline FECHA & HOTEL & $\begin{array}{l}\frac{\mathbb{N}}{\mathrm{a}} \\
\frac{\mathrm{a}}{\mathrm{z}}\end{array}$ & $\begin{array}{l}\frac{5}{0} \\
0 \\
\frac{1}{2} \\
0 \\
0\end{array}$ & $\begin{array}{l}z \\
\text { 잉 } \\
\frac{0}{0} \\
\frac{0}{0}\end{array}$ & 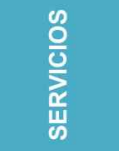 & $\begin{array}{l}\frac{1}{a} \\
\frac{2}{2} \\
0 \\
0 \\
\frac{1}{1} \\
\alpha\end{array}$ & 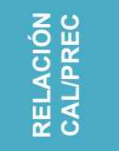 & $\begin{array}{l}80 \\
\frac{5}{2} \\
\frac{2}{2}\end{array}$ \\
\hline Oct'11 & $\begin{array}{c}\text { PRINCESA GALIANA } \\
\text { TOLEDO }\end{array}$ & Exc & Exc & Bueno & Bueno & Bueno & Exc & 8,8 \\
\hline Nov'11 & $\begin{array}{l}\text { VIK GRAN HOTEL COSTA } \\
\text { SOL }\end{array}$ & Malo & Regular & Bueno & Regular & Regular & Regular & 5 \\
\hline Ago'13 & $\begin{array}{l}\text { TRAVELODGE MONTREAL } \\
\text { CENTRE }\end{array}$ & Exc & Bueno & Exc & Bueno & Bueno & Bueno & 8,3 \\
\hline Ago'13 & $\begin{array}{l}\text { LAWRENCE COLLEGE } \\
\text { BROCKVILLE }\end{array}$ & Malo & Bueno & Regular & Regular & Bueno & Regular & 5,4 \\
\hline Ago'13 & $\begin{array}{l}\text { ALEXANDRA HOTEL } \\
\text { TORONTO }\end{array}$ & Bueno & Bueno & Bueno & Bueno & Bueno & Bueno & 7,5 \\
\hline Ago'13 & $\begin{array}{c}\text { DIPLOMAT INN NIAGARA } \\
\text { FALLS }\end{array}$ & Bueno & Bueno & Bueno & Bueno & Exc & Exc & 8,3 \\
\hline
\end{tabular}

Fuente: Elaboración propia a partir de las encuestas rellenadas en Booking 
La calificación global del hotel no la da el huésped, sino que se calcula automáticamente como una media aritmética de los seis aspectos evaluados ${ }^{10}$ (Costantino et al., 2012a; de Albornoz et al., 2011). Si inferimos las equivalencias numéricas de cada calificación obtenemos:

\section{Mal =2,5 Regular=5 Bueno=7,5 Excelente=10}

Para confirmar la exactitud de nuestras conclusiones, sería conveniente acceder a más valoraciones individuales de usuarios para observar así la puntuación asignada a cada categoría. Pero, dado que Booking únicamente muestra la puntuación media de todas las opiniones y existe un mínimo de 5 opiniones registradas para proceder a mostrar puntuaciones de un hotel, esta opción no resulta inicialmente viable. Sin embargo, podemos comprobar como también se muestra la puntuación media por tipo de viajero (Familias, Parejas, etc.). En los casos, en los que existe una única opinión de un tipo concreto de viajero (Figura 21), tenemos acceso a las valoraciones de dicha opinión.

No es frecuente que se dé esta circunstancia, pero centrándose en hoteles con menos de 30/40 opiniones registradas, es posible acceder a casos de este tipo que permiten verificar que la escala de Booking admite únicamente valores de 2,5 - 5 - 7,5 - 10. En el Anexo 2 mostramos una amplia variedad de casos que permiten comprobarlo.

Rechazamos por tanto la hipótesis $\mathrm{H}_{2}$ al comprobar que Booking no usa una escala tradicional de 0 a 10 o de 1 a 10 , sino que emplea una diferente, con cuatro valoraciones posibles, una puntuación mínima de 2,5 y máxima de 10.

En Diciembre de 2014 se realizó una nueva reserva a través de Booking, con la finalidad de verificar que el funcionamiento del sistema de valoraciones no había sufrido variaciones desde la última reserva, realizada en Agosto de 2013. Comprobamos que los criterios de puntuación permanecian invariables, pero observamos dos pequeñas novedades, que se pueden observar en la Figura 21.

\footnotetext{
${ }^{10}$ Desde Septiembre de 2014 comienzan a aparecer en las fichas de algunos hoteles dos nuevas categorías: Wifi y calidad del sueño.
} 
Figura 21. Nuevo cuestionario de Booking.

\section{¿Cómo valorarías el Hotel Restaurante el Horno en estos aspectos?}

\begin{tabular}{|c|c|c|c|c|}
\hline & Mal & Regular & Bueno & Excelente \\
\hline Personal & (c) & 0 & 0 & 0 \\
\hline Servicios & () & 0 & 0 & 0 \\
\hline Limpieza & (c) & 0 & 0 & 0 \\
\hline Confort & c) & 9 & 0 & 0 \\
\hline $\begin{array}{r}\text { Relación calidad/ } \\
\text { precio }\end{array}$ & (9) & 0 & 0 & 0 \\
\hline Ubicación & (c) & 0 & 0 & 0 \\
\hline
\end{tabular}

Tu opinión ayudará a otros viajeros a saber cómo es el alojamiento

\begin{tabular}{|c|c|c|c|c|}
\hline & Mal & Regular & Bueno & Excelente \\
\hline Comodidad de la cama & 0 & 0 & 0 & 0 \\
\hline Conexión WiFi gratuita & 0 & 0 & 0 & 0 \\
\hline
\end{tabular}

Fuente: Booking.com

Se comienza a solicitar la valoración sobre "Comodidad de la cama" y "Conexión WiFi gratuita", aunque estas puntuaciones no influyen en la puntuación global del hotel, que se sigue calculando como media aritmética de los seis aspectos señalados anteriormente.

Pero la principal novedad, la constituye el hecho de que se va mostrando la puntuación global que obtendrá el hotel en la parte superior a medida que se van realizando las valoraciones. Es posible ir cambiando las opciones elegidas y comprobar cómo, de forma automática, también cambia la puntuación global. En el ejemplo de la Figura 21, se puede observar como al valorar todos los aspectos como "Mal", la puntuación global es de 2,5. De haber existido esta nueva característica en fechas anteriores, no habría sido necesaria la realización de varias reservas para deducir los valores numéricos correspondientes a cada opción (Mal, regular, bueno, excelente). Habría bastado con realizar varias simulaciones, observando la puntuación que se asignaba en cada caso, antes de proceder a enviar el comentario. 


\subsection{Efectos de la escala del sistema de puntuaciones de Booking}

Tras conocer las peculiaridades de la escala de puntuaciones de Booking, se plantea la cuestión de los efectos que pudiera tener sobre las valoraciones que obtienen los hoteles. Tratamos de averiguar si este sistema provoca que se les otorguen puntuaciones superiores o inferiores, de las que tendrían si a los clientes se les pidera valorar su experiencia con una escala convencional de 1 a 10. Para ello comparamos los resultados que obtienen una serie de hoteles en Booking y Priceline, ya que esta web si cuenta con un sistema convencional que corresponde al que esperábamos para Booking.

\subsubsection{Priceline}

Priceline fue fundada en el estado de Connecticut en Estados Unidos en 1998, contando con 322.000 alojamientos en 170 países, pero solo está disponible en inglés. Así mismo tiene registradas más de 6 millones de opiniones de viajeros en su web. Además de hoteles, también ofrece servicios de venta de billetes de avión, alquiler de coches y paquetes vacacionales. En cuanto al aspecto de las webs, Booking parece tener un aspecto y navegación más sencillo y sobrio, mientras que Priceline presenta un aspecto más dinámico, apoyada en la imagen de dos celebridades como William Shatner ${ }^{11}$, que presta su imagen a la marca desde 1998 y Kaley Cuoco ${ }^{12}$, recientemente incorporada. Priceline también desarrolla sistemas específicos de venta con importantes descuentos como "Express Deals" o "Name your own Price" (Fay, 2004).

Como ya se indicó anteriormente, Booking es propiedad de Priceline desde 2005. La intención de la empresa es desarrollar "estrategias diferentes para cada una de las marcas, algo similar a lo que sucede con Expedia.com y Hotels.com". En palabras de Brian Ek, portavoz de Priceline, "Booking es el mayor servicio de reservas de hoteles del mundo, mientras que Priceline es el líder en servicios turísticos con descuento en Estados Unidos” (Levy, 2013).

\footnotetext{
${ }^{11}$ Conocido por su papel de captain Kirk en "Star Treck

${ }^{12}$ Conocida por su papel de Penny en la serie televisiva "The Big Bang Theory"
} 
En este contexto, se da la paradoja de que Booking tiene una dimensión mucho mayor que Priceline, aportando dos tercios de los ingresos al grupo empresarial. Dentro de su estrategia global, Booking ha potenciado su presencia en Estados Unidos a través de campañas televisivas a partir de Enero de 2013, lo que acentúa la competencia entre ambas marcas en el mercado Norteamericano.

A pesar de las ligeras diferencias en la forma de comercializar las reservas de hoteles, la presentación de los resultados de búsquedas no difiere demasiado entre ambas (Figura 22), como tampoco lo hace con respecto a otras agencias online. En cuanto a los sistemas de valoración, ambas muestran las estrellas del hotel y una puntuación en una aparente tradicional escala de 0 a 10 o de 1 a 10.

Figura 22. Presentación de la información de un hotel en Priceline y Booking

\section{priceline.com}

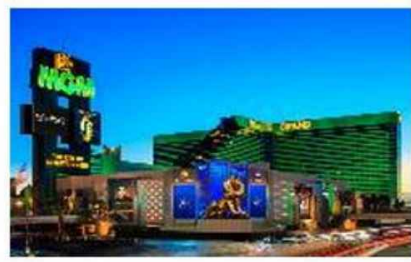

Mgm Grand Hotel Casino

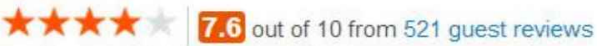

Las Vegas, NV (Las Vegas Strip)

$\$ 100$ /night

Freebies: $\curvearrowright$ P More Free Cancellation Available

\section{Booking.com}

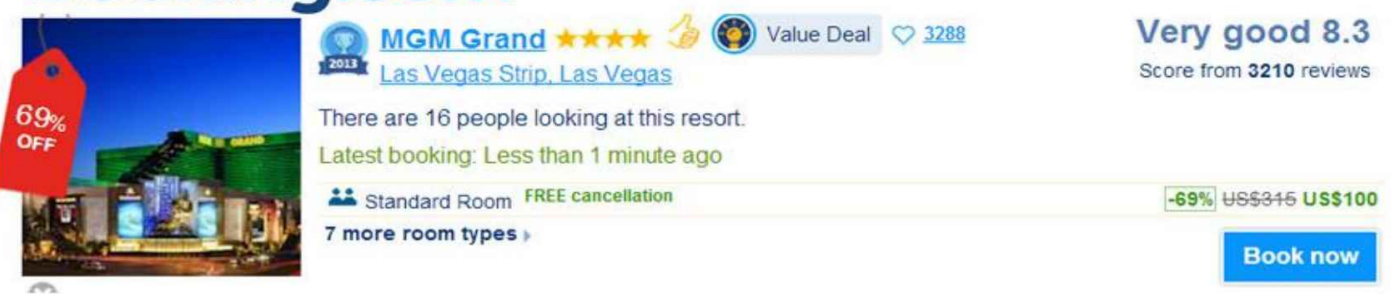

Fuente: Priceline y Booking

Para comprobar las características del sistema de puntuaciones de Priceline, realizamos una reserva en Agosto de 2013 en el "Extended Stay Hotel" de Ottawa. El procedimiento inicial es muy similar al de Booking y comienza con un email recibido varios días después de la estancia invitando a completar una encuesta (Figura 23). 
Figura 23. Email de Priceline para rellenar su encuesta.

\section{price fine.com' sian-in $\mid$ Check vour request \\ Fliahts | Hotels | Cars | Packanes I Cruises | Activities I PriceBreakers | Rewards I Last Minute Deals}

\section{Dear Juan, how was your trip?}

Thank you for your booking at Extended Stay Canada - Ottawa in Ottawa

Your first-hand experiences will help other travelers. Please take a few moments to complete a quick survey right away.

\section{begin your survey}

Thank you

Priceline.com

Fuente: Correo recibido tras realizar una reserva real.

Figura 24. Encuesta de valoración del hotel en Priceline

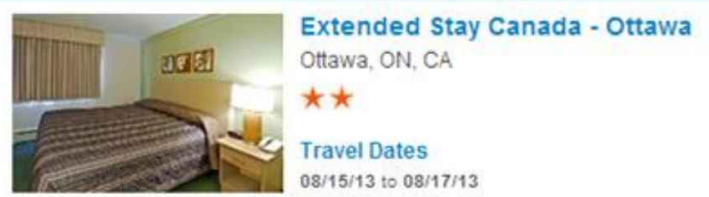

Tell us about this hotel

Roll over to indicate rating

Room
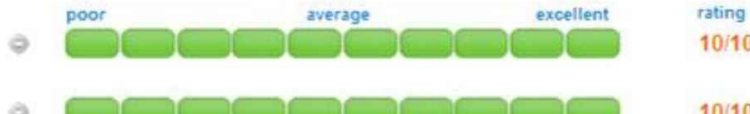

Cleanliness

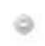

$10 / 10$

Staff

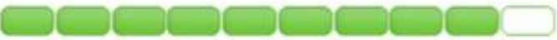

9/10

Location

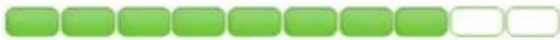

8110

Public Spaces
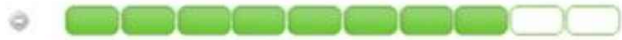

$8 / 10$

Overall Experience
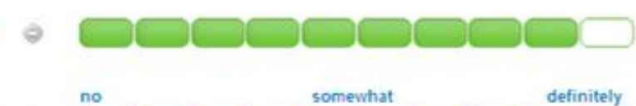

$9 / 10$

Did the hotel meet

your expectations for

the star level

Fuente: Encuesta en Priceline.com 
Al rellenar la encuesta de satisfacción observamos cómo, en este caso, si se ofrece la oportunidad de valorar cada aspecto del hotel de 1 a 10 (Figura 24). Además se solicita una valoración global de la estancia "Overall Experience" (también de 1 a 10), que es la que se acaba publicando junto a cada opinión. Esto indica que el sistema de Priceline si responde a lo que cabría esperar de un sistema basado en una escala de 1 a 10, por lo que resulta una referencia válida para su comparación con Booking.

Priceline conserva las opiniones durante 24 meses mientras, como ya se indicó, Booking borra las que tienen más de 14. Esta política contribuye a que la información proporcionada sea siempre relativamente reciente, en contraposición a otras webs, como por ejemplo TripAdvisor que mantienen opiniones con varios años de antigüedad.

\subsubsection{Objetivos y Metodología}

Creemos que la metodología óptima para comprobar si las puntuaciones están realmente infladas, debido al uso de una escala 2,5 a 10, es tomar una muestra de hoteles y ver si las valoraciones obtenidas en Booking son realmente mayores a las obtenidas en otras webs. Al realizar una búsqueda entre las webs más populares (Travelocity, Orbitz, Expedia, Hotels y TripAdvisor), observamos como todas muestran un sistema con una puntuación máxima de 5 (aparentemente en una escala de 1 a 5).

Consideramos que no es adecuado realizar una transformación de las puntuaciones para poder abordar una comparación con este tipo de sistemas. Si las transformamos (multiplicándolas por dos), se convertirían en una escala 2-10 y si transformamos las de Booking (dividiéndolas por dos) tendríamos una escala 1,25-5. Esto produciría ligeras distorsiones, que resultan inadmisibles cuando buscamos cierta precisión en los cálculos.

Por ello optamos por el sistema con escala de 1 a 10 de Priceline, cuyo funcionamiento corresponde con lo esperado por diversos investigadores que han utilizado Booking como base de datos en el pasado. Esta metodología nos permite establecer comparaciones precisas entre los valores reales en Booking 
y los que se hubieran obtenido de utilizar un sistema con escala de 1 a 10. Podemos así plantear la siguiente hipótesis:

$H_{3}$. Las puntuaciones de Booking son superiores a las de Priceline debido al peculiar sistema de puntuación que evita las valoraciones inferiores a 2,5.

Además trataremos de cuantificar de la forma más precisa posible esa distorsión. No nos limitamos a realizar una comparación de las puntuaciones medias en ambas webs, sino que realizamos un análisis más elaborado, que nos permite obtener información más precisa de las diferencias encontradas.

Por otra parte, investigamos si este sistema de puntuaciones proporciona a Booking algún tipo de ventaja competitiva, cuando su aplicación tiene como consecuencia obtener puntuaciones más altas de las que obtendría con un sistema convencional, lo que nos lleva al planteamiento de una nueva hipótesis al respecto:

$H_{4}$. Cuando un hotel obtiene una puntuación sustancialmente más alta en Booking que en Priceline, eso repercute en un mayor nivel de ventas a través de Booking.

Para validar $\mathrm{H}_{4}$, deberíamos conocer el número de reservas que se hacen en todos los hoteles de nuestra muestra con cada uno de los dos intermediarios utilizados, información de la que no disponemos. Por eso recurrimos a suponer la existencia de una correlación entre el número de opiniones y el número de reservas en cada web. Entendemos que la predisposición a colaborar en la realización de la encuesta de opinión, a la que invitan ambas webs, debe ser muy similar en los dos casos. Siendo así, el número de reservas realizadas a través de cada una de las webs será un factor ciertamente determinante para que un hotel tenga más opiniones registradas en una u otra web.

Esta metodología ya fue testada para el caso de un grupo de hoteles en China (Ye et al., 2008) utilizando las webs locales de Ctrip.com y Elong.com e información real de reservas realizadas. Los resultados mostraron una clara correlación positiva, con una $\mathrm{R}^{2}$ del $68 \%$, lo que sugiere una correlación de 
más del $80 \%$ entre número de opiniones y el número de reservas. Más tarde, el experimento se repitió con una muestra de hoteles mayor, obteniendo una $\mathrm{R}^{2}$ del 44\% (Ye et al., 2011).

En nuestro caso, existen factores que contribuirán a que esa correlación, aún siendo altamente significativa, no sea perfecta. Existen condicionantes adicionales que pueden determinar que un hotel tenga más opiniones de una web de que de otra:

- Que el hotel sea visitado principalmente por turistas europeos, donde Booking es más popular.

- Que el hotel participe en programas promocionales especiales en alguna de las webs, para mejorar sus ventas.

- Que el hotel no haya trabajado con alguna de las webs durante algún periodo de tiempo en los últimos meses.

Consideramos que, a igual precio, los consumidores tenderán a contratar hoteles con mejores valoraciones. En consecuencia, los hoteles que tengan una valoración sustancialmente mejor en Booking que en Priceline, tenderán a obtener mejores ventas en Booking. Entendemos que el efecto se diluirá cuando las diferencias sean muy reducidas. Por tanto, cuando las diferencias de puntuación sean altas (a favor de Booking) los clientes del hotel tenderán a contratar más a través de esta web y, en consecuencia, existirán más opiniones registradas.

\subsubsection{Muestra}

Aunque Priceline ofrece reservas de hoteles por todo el mundo, como se ha indicado anteriormente, dicha web se orienta principalmente al mercado de Estados Unidos. Por esta razón decidimos utilizar hoteles ubicados en ese país para la confección de la muestra objeto de estudio, de forma que podamos acceder a hoteles con un número suficiente de opiniones registradas.

Realizamos una selección de hoteles con un mínimo 100 opiniones registradas en ambas webs, algo que no resulta fácil, debido a la citada política de eliminación de opiniones antiguas. Optamos por realizar búsquedas 
aleatorias en las grandes ciudades y destinos turísticos del país, donde resulta más probable encontrar un número significativo de hoteles de gran tamaño, que cumplan con esta condición. Los datos fueron recogidos durante la primera semana de Mayo de 2014.

Seleccionamos así una muestra de 200 hoteles de 21 destinos diferentes, distribuidos de la siguiente forma:

- Las Vegas con 50 hoteles.

- 10 destinos con 10 hoteles: San Diego, Los Ángeles, San Francisco, Chicago, Atlanta, Orlando, Boston, Nueva York, Atlantic city y Washington D.C.

- 10 destinos con 5 hoteles: New Orleans, Philadelphia, Dallas, Houston, Phoenix, Miami, Memphis, Baltimore, Long Beach y Honolulu.

El hecho de que Las Vegas tenga 50 hoteles en la muestra se justifica por la cantidad de alojamientos de gran tamaño con los que cuenta. Señalar que 25 de los 50 mayores hoteles del mundo se encuentran ubicados en este destino turístico.

De esta selección se recogieron finalmente un total de 67.946 opiniones de Priceline y 130.306 de Booking. Para el caso de los hoteles de Priceline, todos a excepción de dos, tienen más de 200 opiniones, mientras que en el caso de Booking sólo 141 superan esta cifra. Este dato contrasta con el de los hoteles con más de 1.000 opiniones que son 38 en el caso de Booking y solo 1 en Priceline. En todo caso, tanto el tamaño de la muestra como el número de observaciones por hotel, nos garantizan obtener resultados bastante precisos.

Adicionalmente, también recurrimos a nuestra muestra de hoteles de costa españoles, para confirmar los datos observados en la distribución de las puntuaciones registradas en Booking. 


\subsubsection{Resultados de la comparación entre Booking y Priceline}

Al comparar las puntuaciones entre ambas webs observamos como existen valoraciones generalmente más altas en Booking que en Priceline, siendo la puntuación media en Booking de 7,99 mientras que en Priceline es de 7,52 . Además en el $78 \%$ de los hoteles la puntuación en Booking es mayor, el $5 \%$ obtiene una puntuación idéntica en ambas webs y sólo en un $17 \%$ de los casos la puntuación es mayor en Priceline.

Realizamos una representación gráfica de los resultados, reflejando en el eje de abscisas los valores obtenidos en Priceline y en el eje de ordenadas, la diferencia entre el valor en Booking y el de Priceline, para cada uno de los 200 hoteles, obteniendo así una nube de puntos representativa (Gráfico 9). En los casos que las puntuaciones de dos o tres hoteles coinciden, se incrementa el tamaño del punto. La nube de puntos obtenida, sugiere la presencia de una correlación lineal importante, por lo que realizamos la correspondiente regresión lineal, representada por la línea roja.

Gráfico 10. Diferencias de puntuaciones entre Priceline y Booking

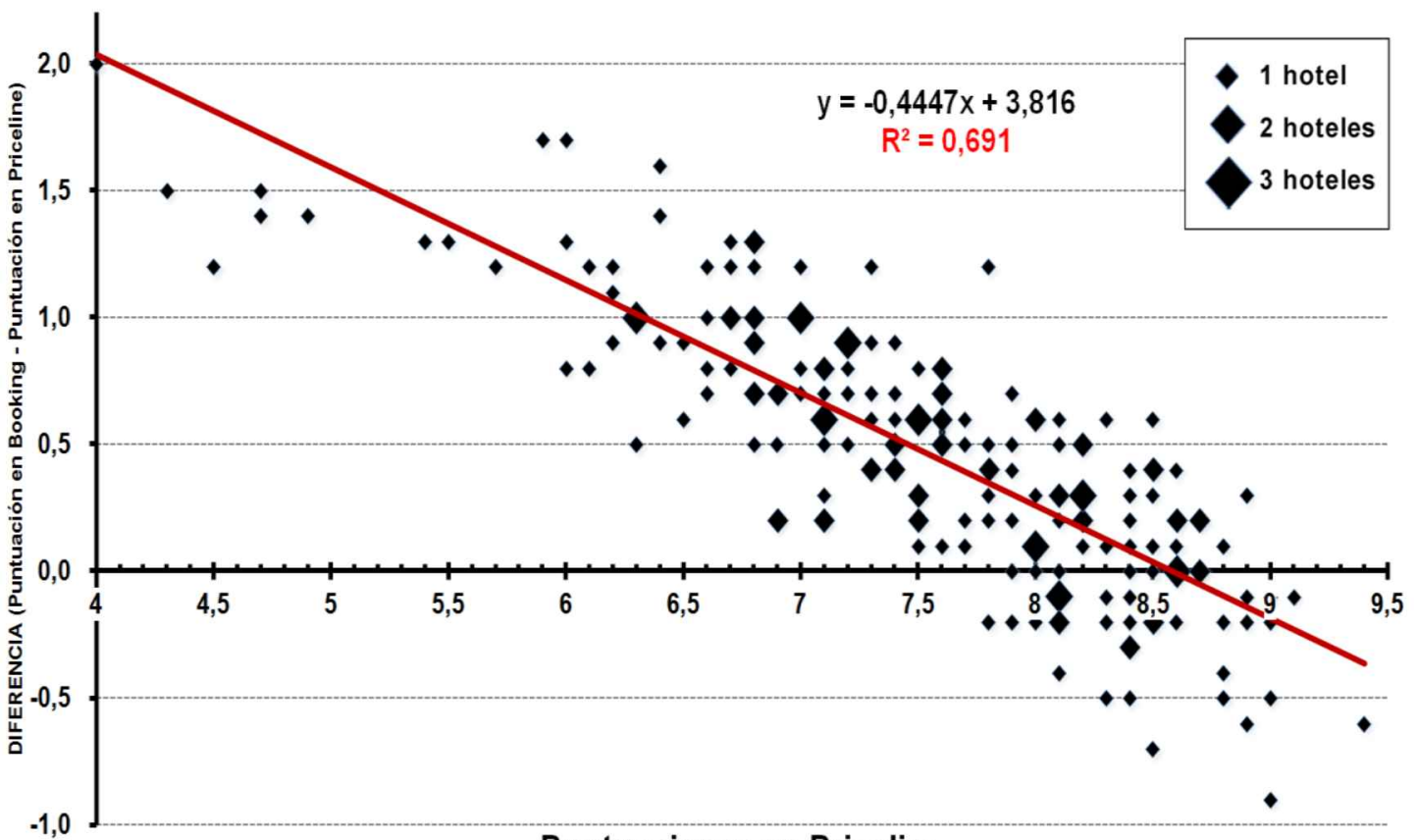

Puntuaciones en Priceline

Fuente: Elaboración propia a partir de datos de Priceline.com y Booking.com

$\mathrm{R}^{2}$ nos da un valor del $69,1 \%$, lo que confirma la existencia de correlación lineal entre el nivel de puntuación y las diferencias entre ambas webs. 
Observamos como las diferencias de puntuaciones son más acusadas en los hoteles con menor valoración, pasando a ser más reducidas a medida que aumenta la valoración de los mismos. De hecho, para hoteles con una muy alta valoración, detectamos que las puntuaciones en Priceline son ligeramente superiores a las de Booking. En el grupo de puntuaciones de menos de 8 en Priceline, Booking obtiene sistemáticamente mejores valoraciones, suponiendo este grupo de hoteles casi dos tercios de las muestra $(64,5 \%)$. Seguidamente hay un grupo de hoteles, que se encuentran entre un 8,1 y un 8,5 (22,5\% de la muestra), en los que no existe una definición clara de que web proporciona las mejores puntuaciones. Finalmente, en el tramo que va a partir de 8,6 y que representa únicamente el $13 \%$ de la muestra, las puntuaciones son mayoritariamente mejores en Priceline.

Analizados estos datos, podemos confirmar la hipótesis $\mathrm{H}_{3}$, ya que las puntuaciones en Booking son significativamente superiores a las de Priceline, a la vez que descubrimos que el efecto de "puntuaciones infladas" no es algo general para todos los hoteles, sino que varía en función de la puntuación del hotel. Podemos decir que existen diferencias muy significativas, a favor de Booking, para hoteles con puntuaciones bajas, diferencias reducidas para hoteles con puntuaciones medias y una práctica ausencia de diferencias para hoteles con puntuaciones altas. Solamente en los casos de hoteles con puntuaciones muy altas, podemos hablar de una mejor valoración en Priceline, con diferencias reducidas.

En el gráfico 10, representamos la distribución de frecuencias de los valores en ambas webs. Observamos como las puntuaciones de Booking se encuentran muy concentradas a partir de la puntuación de 7,3 ya que las inferiores a esta cifra únicamente representan el $8 \%$ de la muestra, mientras que representan el $36,5 \%$ para Priceline. El principal efecto que parece conseguir el sistema de puntuación de Booking es el de minimizar el número de hoteles con puntuaciones bajas, desplazándolos a una zona de puntuaciones medias. 
Gráfico 11. Distribución de frecuencias de la muestra de hoteles.

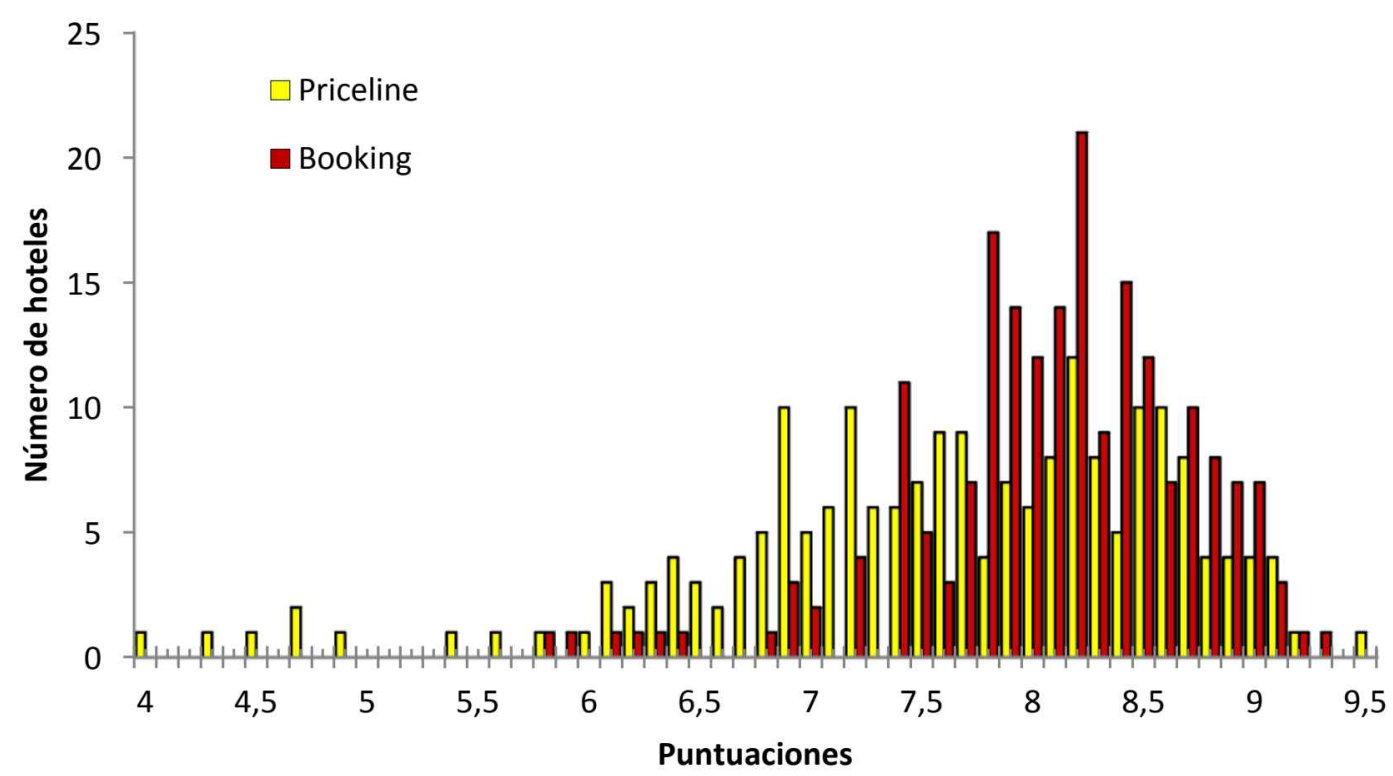

Fuente: Elaboración propia a partir de datos de Priceline.com y Booking.com

Para comprobar si esa concentración de puntuaciones a partir de una valoración de 7 es algo generalizado o una peculiaridad de esta muestra de hoteles en Estados Unidos, analizamos nuestra muestra de 1.440 hoteles de costa españoles, con datos de 2011, obteniendo los resultados indicados en la tabla 21 y representados en el gráfico 12.

Tabla 21. Distribución de la muestra por categorías

\begin{tabular}{|lccc|}
\hline Denominación & Puntuación & $\begin{array}{c}\text { No de } \\
\text { Hoteles }\end{array}$ & $\begin{array}{c}\% \\
\text { s/total }\end{array}$ \\
\hline Mal & $2.5-3.9$ & 0 & $0 \%$ \\
\hline Decepcionante & $4.0-4.9$ & 1 & $0.07 \%$ \\
\hline Aceptable & $5.0-5.5$ & 1 & $0.07 \%$ \\
\hline Agradable & $5.6-5.9$ & 6 & $0.42 \%$ \\
\hline OK & $6.0-6.9$ & 98 & $6.81 \%$ \\
\hline Bien & $7.0-7.9$ & 697 & $48.40 \%$ \\
\hline Muy Bien & $8.0-8.5$ & 476 & $33.06 \%$ \\
\hline Fabuloso & $8.6-8.9$ & 125 & $8.68 \%$ \\
\hline Fantástico & $9.0-9.4$ & 34 & $2.36 \%$ \\
\hline Excepcional & $9.5-10$ & 2 & $0.14 \%$ \\
\hline
\end{tabular}

Fuente: Booking 
Gráfico 12. Distribución de frecuencias de la muestra.

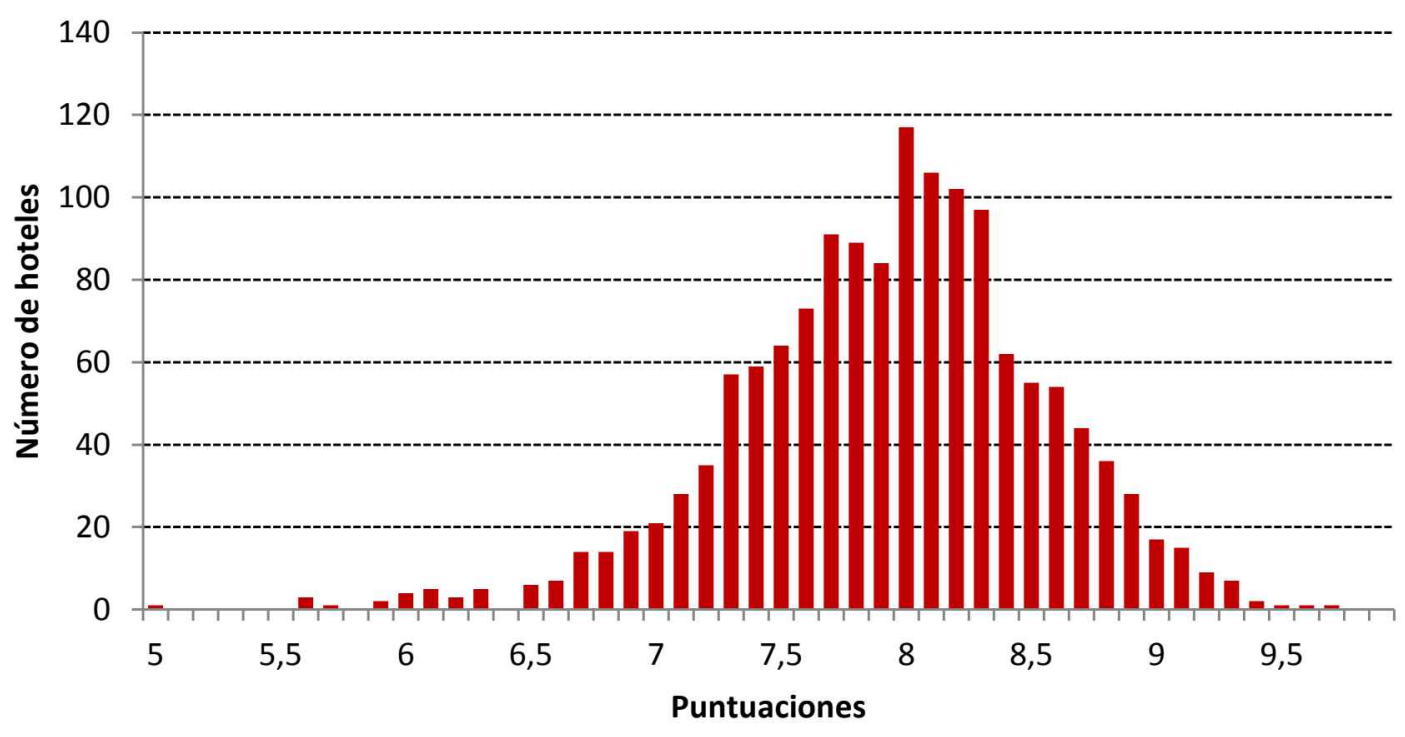

Fuente: Booking

Los datos obtenidos son similares, confirmando la tendencia de las puntuaciones obtenidas en Booking a concentrarse en valores por encima de los 7 puntos. Con este sistema de puntuaciones, prácticamente no aparecen hoteles con mala valoración. Más del 99\% tienen una calificación de "Agradable" o superior y el $93 \%$ tiene una nota igual o superior a 7 puntos, lo que comúnmente se conoce como "Notable" en una escala tradicional de 0 a 10. El $82 \%$ de las críticas están centradas en el rango de 7,0 a 8,5 , lo que dificulta seriamente el poder diferenciar claramente entre hoteles mejor o peor calificados. A modo de ejemplo, un hotel con una calificación de 7 , se sitúa dentro del grupo de los peores hoteles, ya que el $92 \%$ tienen una calificación superior. Sin embargo si la calificación es de 8 se sitúa dentro de los hoteles de calidad media-alta, ya que obtiene una puntuación superior al $55 \%$ de la muestra.

Cuando en 2014 volvemos a tomar datos de Booking, comprobamos que se había cambiado el sistema de denominación por puntuaciones. Aunque sigue ofreciendo la calificación numérica obtenida para cada uno de los hoteles que cuentan con un mínimo de cinco opiniones, sólo expresa una denominación concreta para aquellos que obtienen al menos una valoración de 7,1 (Figura 25). 
En la actualidad por tanto, nos encontramos que los hoteles con una puntuación inferior a 7,1 no tienen denominación, por lo que se evitan usar las correspondientes a "decepcionante", "aceptable" y "agradable". Este cambio parece tener cierta lógica, ya que no tenía sentido calificar como "aceptable" o "agradable" a hoteles que estaban entre el $8 \%$ de peores hoteles.

Figura 25. Denominaciones según puntuación.

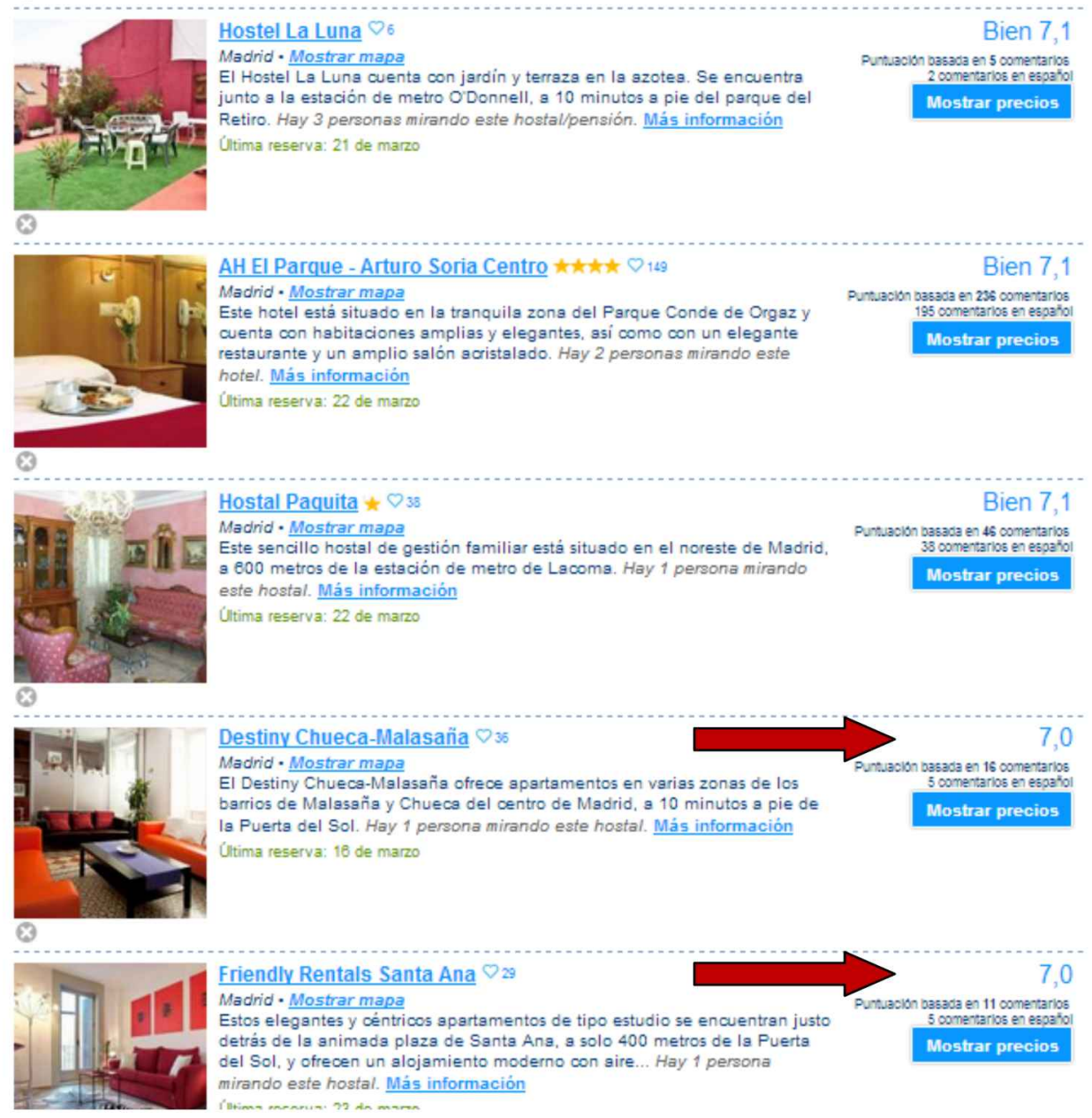

Fuente: Booking

En la muestra obtenida de 200 hoteles de Estados Unidos, en 108 de ellos (54\%) el número de opiniones registradas es mayor en Booking, mientras que en el $46 \%$ hay más opiniones registradas en Priceline. En el gráfico 13, se representa el número de hoteles que obtienen mejor puntuación en una u otra web. La escala del eje vertical muestra los valores que se obtienen al restar la puntuación de Priceline a la de Booking, de igual forma que se hacía en el Gráfico 10. Observamos que para diferencias negativas (mejores puntuaciones en Priceline) o ligeramente positivas, los hoteles con un número de opiniones 
es mayor en Priceline. Por el contrario, cuando las diferencias de puntuaciones son mayores, es generalmente en Booking donde existen más opiniones registradas. Los datos numéricos muestran que:

- En los 37 hoteles en que Booking obtiene una puntuación mayor que la de Priceline en un punto o más, 27 de ellos obtienen más opiniones en Booking (73\%).

- En los 44 casos de hoteles con idéntica puntuación en ambas webs o mejor en Priceline, 28 de ellos obtienen más opiniones en esta web (64\%).

- En los 119 hoteles en los que la diferencia a favor de Booking es menor que un punto, se mantiene una proporción más cercana a la media de la muestra, para 65 es superior en Booking (55\%) y en para Priceline los es en $54(45 \%)$.

Gráfico 13. Web con mayor número de opiniones

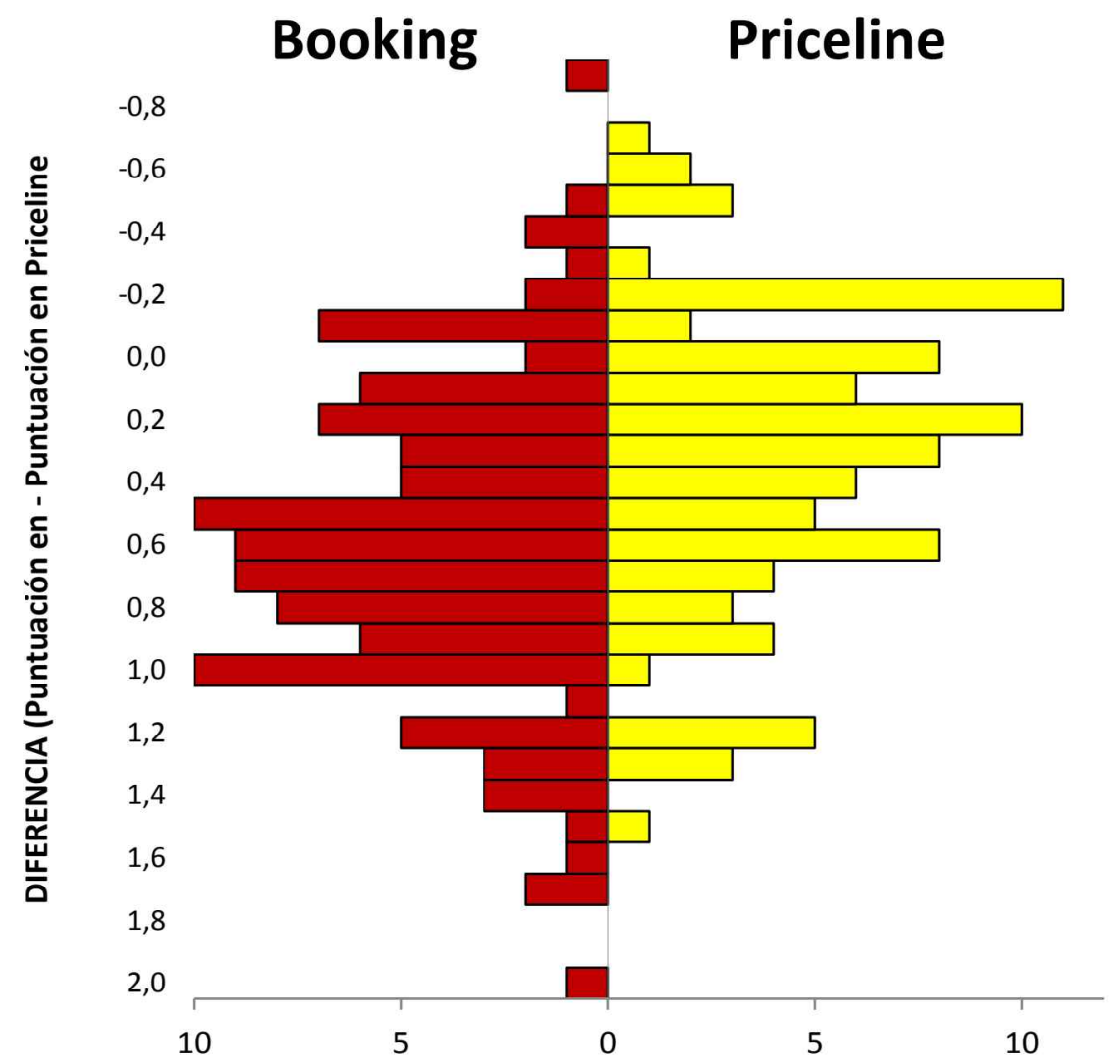

Fuente: Elaboración propia a partir de datos de Priceline y Booking 
Con estos datos podemos aceptar la hipótesis $\mathrm{H}_{4}$, sobre los efectos en el número de reservas que tienen las diferencias de puntuaciones entre ambas webs. Se pone de manifiesto que los hoteles con bajas puntuaciones, en los que los que las valoraciones de Booking son mucho mayores, obtienen más opiniones en esta web y consecuentemente más reservas. Por lo tanto, el efecto de "puntuaciones infladas" para hoteles con puntuaciones bajas y medias, que deriva del sistema de valoración de Booking, tiene un efecto positivo en las ventas para ese grupo de hoteles.

\subsubsection{El caso del Hotel Pennsylvania}

Sería interesante ejemplificar en un caso concreto, las consideraciones mencionadas en los apartados anteriores. Para ello escogemos uno de los casos extremos, donde la puntación del hotel es especialmente baja y los efectos detectados se pueden observar con gran claridad.

Para ello se ha seleccionado al Hotel Pennsylvania de Nueva York, que se encuentra en el mismo centro de Manhattan, junto al Madison Square Garden y el Empire State, muy cerca de Times Square, contando con 1.705 habitaciones. Los precios por noche suelen estar por encima de los $250 \$$, precio habitual en esta zona. Se trata de uno de los hoteles peor valorados del centro de esta ciudad con multitud de opiniones negativas, que se quejan de casi todo, a excepción de su ubicación, que está bien considerada (Figura 26).

En Agosto de 2014 tenía una valoración de 5 en Priceline (basada en 435 opiniones) y de 6,2 en Booking (basada en 9.159 opiniones). Es probable que las altas expectativas que se puedan crear los clientes, tras pagar más de $250 \$$ por una sola noche de hotel, expliquen parcialmente el alto número de clientes insatisfechos por no encontrar los estándares de calidad que esperaban. Pero, en todo caso, consideramos que constituye un buen ejemplo de hoteles con puntuaciones bajas, en los que se dan las mayores diferencias entre ambos sistemas. En este caso la puntuación se ve afectada, por un lado por el hecho de que las puntuaciones negativas no pueden ser inferiores a 2,5 en Booking y por otro el sistema de media aritmética para el cálculo de la puntuación final. 
Figura 26. Puntuaciones del Hotel Pensylvania en Priceline y Booking

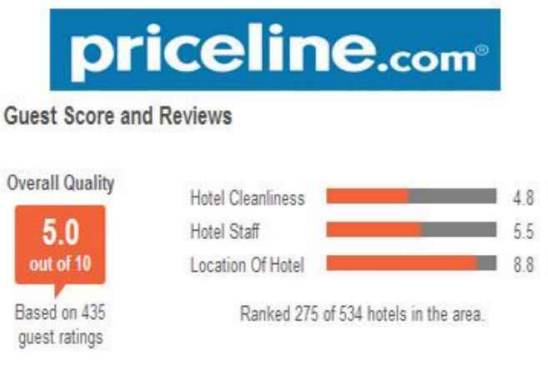

\section{Booking.com}

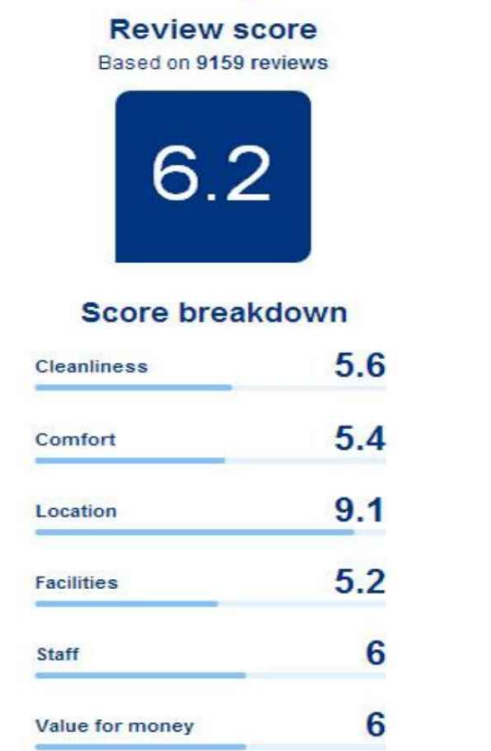

Fuente: Priceline y Booking

En el caso de Priceline, resulta bastante habitual encontrar entre las 30 últimas opiniones registradas varios casos de clientes totalmente insatisfechos que otorgan valoraciones de 1 o 2. Pero en el caso de Booking, este mismo tipo de clientes no tienen la oportunidad de otorgar puntuaciones tan bajas al hotel, ya que el mínimo es 2,5. Además, dada la magnífica ubicación física del hotel, los clientes acostumbran a otorgar una puntuación alta a este aspecto $(7,5$ o 10) lo que hace que las puntuaciones medias de los clientes totalmente insatisfechos suban ligeramente. Nos encontramos de esta forma que, en lugar de obtener valoraciones de 1 o 2 como en Priceline, se observan las siguientes puntuaciones:

- 3,3: Cuando 5 aspectos son valorados con el mínimo $(2,5)$ y uno con 7,5. Esto da una media de 3,33, que redondeando se convierte en 3,3. 
- 3,8: Cuando 5 aspectos son valorados con el mínimo $(2,5)$ y uno con el máximo (10). Esto da una media de 3,75 , que redondeando nos resulta 3,8 .

Como ya mencionamos anteriormente, las comparaciones entre sistemas con una puntuación máxima de 5 y de 10, puede derivar en imprecisiones al tratar de equiparar escalas. Creemos que resulta interesante mostrar también las puntuaciones obtenidas por este hotel en otras plataformas online, con una escala de puntuación máxima de 5 (Tabla 22)

Tabla 22. Puntuaciones del Hotel Pensylvania.

\begin{tabular}{|lcc|} 
Web & Puntuación & $\begin{array}{c}N^{0} \text { de } \\
\text { opiniones }\end{array}$ \\
\hline Travelocity & 2,7 & 332 \\
\hline Orbitz & 2,6 & 1.582 \\
\hline Expedia & 2,7 & 9.081 \\
\hline Hotels.com & 2,7 & 8.410 \\
\hline TripAdvisor & 2,5 & 7.342 \\
\hline
\end{tabular}

Fuente: Información disponible webs

Resulta evidente que un hotel con una puntuación de 6,2 en una escala con límite 10, resulta más atractivo que un hotel con 2,6 en una escala con límite 5. Esta última puntuación podría interpolarse a un 5,2 en una escala con límite 10. Así mismo, el 6,2 sería un 3,1 si lo pasamos a una escala con límite 5. Resulta evidente que la percepción de la calidad del hotel para el caso de Booking es siempre más favorable.

En el caso analizado existe una importante diferencia entre el número de opiniones registradas en cada web, lo que resulta un indicativo del número de reservas realizadas en cada uno. Parece obvio que es más complicado que un usuario realice una reserva en un hotel que apenas alcanza el "aprobado" como es el caso de la valoración obtenida en Priceline, mientras que un hotel con un 6,2 puede ser percibido como una puntuación "aceptable" por un mayor número de usuarios. 


\subsubsection{Conclusiones}

De la bibliografía consultada sólo una de la publicaciones (Bjørkelund et al., 2012) detecta algo extraño en la escala, pero no acierta a explicar por qué la valoración mínima de los hoteles es 2,5. En la mayor parte de los casos, estas diferencias no tienen una relevancia significativa en las conclusiones finales de los artículos citados. Pero cuando se usa Booking como base de datos, implementando análisis estadísticos basados en la suposición de una escala errónea, se pueden dar ligeras imprecisiones en los resultados y conclusiones finales del estudio. Un claro ejemplo se presenta en uno de los citados artículos (Chaves et al., 2012), al tratar de homogeneizar los datos de TripAdvisor y Booking:

"Because the assessment system was different on the two sites (TripAdvisor uses a scale from 1 to 5 and Booking.com from 1 to 10), we set the ratings of Booking.com to a scale of $1 e 5$ (i.e. from 1 to 2.4 is equivalent to a rating of 1 , from 2.5 to 4.4 is equivalent to a rating of 2 , etc.) $)^{n 13}$

Usando este sistema, parece como si Booking tratara de incrementar las valoraciones de los hoteles, garantizando que casi todos sean percibidos como hoteles de cierta calidad. Por ejemplo, un hotel con una calificación de 7 , normalmente será percibido como un hotel de calidad media o media-alta, cuando en realidad lo que esa puntuación significa es que el $90 \%$ de los hoteles son mejores que este. Para un consumidor medio, resulta complicado realizar un análisis comparativo de las opiniones y deducir que los hoteles valorados con un 7 en realidad son de los peores en comparación con el resto de esa web o que la puntuación media de los hoteles en esta web se encuentra cercana al 8.

\footnotetext{
${ }^{13}$ Debido a que el sistema de evaluación es diferente en los dos sitios (TripAdvisor utiliza una escala de 1 a 5 y Booking.com del 1 al 10), transformamos las puntuaciones de Booking.com a una escala de 1 a 5 (es decir, de 1 a 2,4 corresponde a una calificación de 1, de 2,5 a 4,4 corresponde a una calificación de 2 , etc.).
} 
Los datos obtenidos confirman que las puntuaciones de Booking están infladas respecto a Priceline, confirmándose así la hipótesis $\mathrm{H}_{3}$. Aunque según podemos concluir, los resultados aportan dos hallazgos adicionales:

a) Las diferencias entre las puntuaciones es claramente mayor en los hoteles con valoraciones más bajas, existiendo una correlación lineal evidente entre nivel de puntuación y diferencias de puntuación.

b) En los casos de hoteles con puntuaciones muy altas, el sistema de Booking, no solo no contribuye a inflar las puntuaciones, sino que hace que sean inferiores a las de un sistema convencional como el de PriceLine.

La primera de las conclusiones era ciertamente esperable, ya que una de las peculiaridades del sistema es que no permite asignar puntuaciones inferiores a 2,5 a ningún aspecto. Dado que la puntuación de cada hotel es la media aritmética de seis aspectos diferentes, basta con que algunos de ellos no sean calificados con la puntuación más baja, para que la resultante esté por encima de ese 2,5 en los casos de clientes totalmente insatisfechos, como se ha podido comprobar en el ejemplo del Hotel Pennsylvania. Al calcular la puntuación media del hotel, el hecho de que los clientes más insatisfechos otorguen puntuaciones de más de tres puntos, en lugar de uno o dos, contribuye sustancialmente a obtener valores medios más altos.

La segunda de las conclusiones nos ha resultado más sorprendente, pero entendemos que puede tener su explicación en el sistema de cálculo de la puntuación del hotel mediante una media de seis aspectos que, en este caso, no favorece la obtención de puntuaciones extremadamente altas. Para que un hotel obtenga la puntuación máxima de 10, es necesario que el cliente otorgue la máxima puntuación en cada uno de esos ítems, ya que de no ser así la media se vería reducida. Por el contrario, en el caso de Priceline, un cliente totalmente satisfecho puede otorgar un 9 o un 10 a una puntuación total, aunque no haya valorado los distintos aspectos por separado con la puntuación máxima. En todo caso, las diferencias resultan mínimas y no sobrepasan las tres décimas en casi ninguno de los casos. 
La hipótesis $\mathrm{H}_{4}$ se refería al posible aumento en las ventas que tendría Booking gracias a su sistema de puntuaciones. Efectivamente comprobamos como, en los casos en los que el sistema provoca incrementos de puntuaciones significativas, ese hecho redunda positivamente en el número de reservas en los hoteles afectados.

Debemos concluir que el sistema de puntuaciones de Booking provoca un incremento sustancial de las puntuaciones de un número importante de hoteles, lo que conlleva un incremento de su negocio. Se trata, por lo tanto, de una exitosa estrategia empresarial, que probablemente sea desconocida, tanto por sus competidores, como por los hoteleros y los clientes.

Consideramos que esta estrategia puede llegar a ser percibida como deshonesta por algunos clientes, en tanto en cuanto Booking está utilizando un sistema diferente al tradicional y esperado, que hace parecer a los hoteles mejores de lo que realmente son. Para averiguar si esto es así o no se debería realizar un estudio complementario que, a través de encuestas personales, determinara como perciben realmente los clientes estos hechos.

En el ámbito académico, creemos que la información acerca de las escalas utilizadas contribuirá a optimizar el tratamiento estadístico de los estudios que utilizan los datos numéricos proporcionados por Booking. Consideramos que futuras investigaciones deben ir orientadas a analizar cada uno de los seis aspectos de la valoración por separado, evitando la media aritmética que el sistema realiza de forma automática.

Somos conscientes y queremos ponerlo de manifiesto de que el análisis cuenta con ciertas limitaciones metodológicas relacionadas con la muestra, ya que si bien su tamaño y calidad son adecuadas, es cierto que está limitada a los hoteles de un país concreto y la comparación se hace con una sola web de reservas. Sería interesante realizar estudios similares con muestras de hoteles de otros países y con otras webs que utilicen un sistema de puntuaciones de 1 a 10 o de 0 a 10, para confirmar la extrapolación de los resultados a nivel global. 
Por último, cuando analizamos el impacto en las reservas que tienen las diferencias en las puntuaciones, utilizamos ciertas aproximaciones que, aunque su validez haya sido demostrada en otros estudios, no son estrictas. Sería interesante desarrollar un estudio con datos reales de reservas en hoteles, como los realizados por Ye et al. en China, para verificar como el peso de Booking en las reservas de un hotel es inversamente proporcional a la puntuación obtenida por el hotel. 


\section{EVOLUCIÓN DE LAS VALORACIONES DE LOS HOTELES ESPAÑOLES DE COSTA (2011-2014)}

La base de datos de opiniones de hoteles creada en 2011 nos permite detectar diferencias en la calidad percibida en las provincias analizadas. Además, una segunda recopilación de datos, realizada casi tres años después, posibilita realizar un análisis sobre la evolución de esas valoraciones.

\subsection{Introducción y Metodología}

Existe una percepción subjetiva sobre la calidad de los diferentes destinos de la costa española. Mientras unas provincias se identifican con un turismo de "alto standing" otras se asocian a un "turismo masivo" de poder adquisitivo medio-bajo. El primer grupo lo forman destinos como Málaga o Baleares, asociados a establecimientos de lujo, hecho al que ayuda el ser visitados por diversas celebridades nacionales e internacionales. En el segundo se situarían destinos como Benidorm o Lloret de Mar, tradicionalmente identificados con un turismo de bajo poder adquisitivo. En función de esto, planteamos la siguiente hipótesis de trabajo:

$H_{5}$ : Las provincias de Málaga y Baleares están entre las que tienen mayor valoración, mientras que las de Alicante y Girona son las peor valoradas por los huéspedes de hoteles.

El sector turístico español, parece haber sostenido su nivel de actividad en los últimos años, a pesar de la persistente crisis económica. Pero desconocemos si lo ha hecho a costa de una reducción en la calidad de los servicios, empujada por la creciente competencia en precios a nivel nacional e internacional. Un exceso en el control de los costes, ha podido derivar en un deterioro significativo del servicio, que se vería reflejado en las valoraciones de los consumidores. Teniendo en cuenta lo expuesto, planteamos la siguiente hipótesis:

$H_{6}$ : Las valoraciones de los hoteles se han reducido durante la crisis económica. 
Utilizamos la base de datos recogida sobre los hoteles de costa de 2011 y la de Marzo de 2014. Teniendo en cuenta que, como ya se ha referido, los datos que se reflejan en Booking corresponden a los 14 meses anteriores, esta metodología nos permite analizar las variaciones producidas entre el periodo de Septiembre 2010 a Noviembre de 2011 y desde Diciembre de 2012 a Marzo de 2014. Tenemos así la posibilidad de estudiar la existencia, o no, de variaciones en la puntuación de los hoteles durante un periodo de más de dos años.

\subsection{Resultados obtenidos}

Cuando tratamos de ver la puntuación media por provincia observamos como, debido a la alta concentración en el tramo de 7,0 a 8,5, estas no muestran variaciones significativas en las valoraciones, ya que la media nacional se encuentra en un 7,848 , que va del 7,752 de Barcelona y el 7,742 de Málaga al 7,982 de Canarias o el 7,969 de Cádiz (Tabla 23).

Para tratar de reflejar de una forma más clara las diferencias entre provincias, dividimos la serie de datos en cuartiles de un tamaño similar, en función de las puntuaciones obtenidas. En los dos cuartiles centrales quedarían los hoteles con una puntuación media, mientras que el inferior y superior reflejarían el porcentaje de hoteles con una puntuación alta o baja. En el gráfico 14 observamos cómo se aprecian diferencias significativas entre las provincias.

En Marzo de 2014 repetimos la búsqueda utilizando la misma metodología. De los 1.440 hoteles, logramos identificar 1.366, un 95\% que permanecen en la web de Booking y que además tienen un mínimo de cinco opiniones registradas. Ese $5 \%$ de hoteles desaparecidos se puede deber a diferentes factores, entre los que pueden figurar el cierre del hotel (definitivo o por reformas), el cambio en la denominación, que dificulta su identificación, o que el hotel haya dejado de vender sus servicios a través de Booking. 
Gráfico 14. Puntuaciones provinciales por cuartiles (2011).

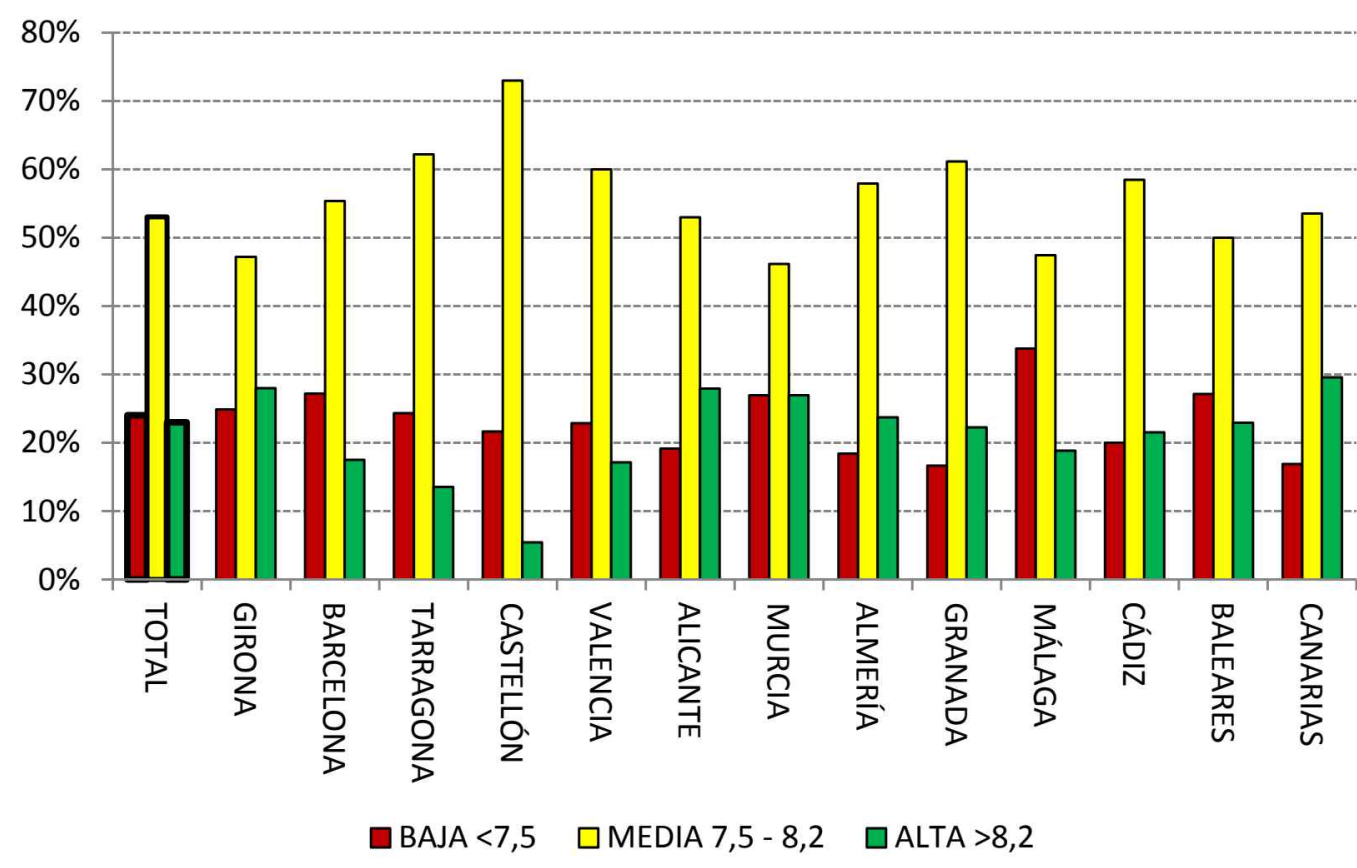

Fuente: Elaboración propia a partir de datos obtenidos de Booking.com

El número de opiniones registradas en esos 1.366 hoteles era de 180.851 en 2011 , pasando a 226.867 en 2014 , lo que supone un incremento del $25 \%$ de opiniones registradas. Este hecho puede estar ocasionado por obtener un mayor peso de las reservas a través de Booking, o bien a una mayor predisposición de los clientes a colaborar dando su opinión o a una combinación de ambos factores.

La variación en las puntuaciones medias de los hoteles son mínimas, por lo que debemos recurrir a un tercer decimal para expresar las cifras finales (Tabla 23). Partimos de una media de 7,848 en 2011 y pasamos a 7,883 en 2014. Esta diferencia mínima se explica por el hecho de que 168 hoteles obtienen exactamente la misma puntuación, mientras 676 mejoran y 522 empeoran. Otro dato reseñable es que 505 de los hoteles (37\%) mantienen la misma puntuación o la varían en una sola décima. 
Tabla 23. Puntuaciones de Hoteles por provincia.

\begin{tabular}{|llll|}
\hline PROVINCIA & 2011 & 2014 & DIFERENCIA \\
\hline GIRONA & 7,813 & 7,866 & 0,053 \\
\hline BARCELONA & 7,752 & 7,788 & 0,036 \\
\hline TARRAGONA & 7,760 & 7,784 & 0,023 \\
\hline CASTELLÓN & 7,792 & 7,875 & 0,083 \\
\hline VALENCIA & 7,811 & 7,783 & $-0,029$ \\
\hline ALICANTE & 7,916 & 7,946 & 0,030 \\
\hline MURCIA & 7,808 & 7,856 & 0,048 \\
\hline ALMERÍA & 7,951 & 7,940 & $-0,011$ \\
\hline GRANADA & 7,900 & 7,835 & $-0,065$ \\
\hline MALAGA & 7,742 & 7,806 & 0,065 \\
\hline CÁDIZ & 7,969 & 7,962 & $-0,007$ \\
\hline CANARIAS & 7,982 & 7,942 & $-0,040$ \\
\hline BALEARES & 7,826 & 7,906 & 0,080 \\
\hline
\end{tabular}

Fuente: Elaboración propia a partir de datos obtenidos de Booking

Buscamos la existencia de diferencias importantes por provincias, pero los datos siguen presentando una gran estabilidad, con diferencias que no llegan a una décima.

Repetimos el análisis basado en cuartiles por provincias, obteniendo resultados muy similares a los de 2011. Cabe destacar que existen ligeras mejoras en las puntuaciones medias de las provincias de Málaga y Baleares y que también se reflejan en mejoras en su distribución por cuartiles. Aunque en Málaga siguen predominando los hoteles con puntuaciones bajas, en el caso de Baleares la situación se revierte, destacando ahora los hoteles con puntuaciones altas. 
Gráfico 15. Puntuaciones provinciales por cuartiles (2014).

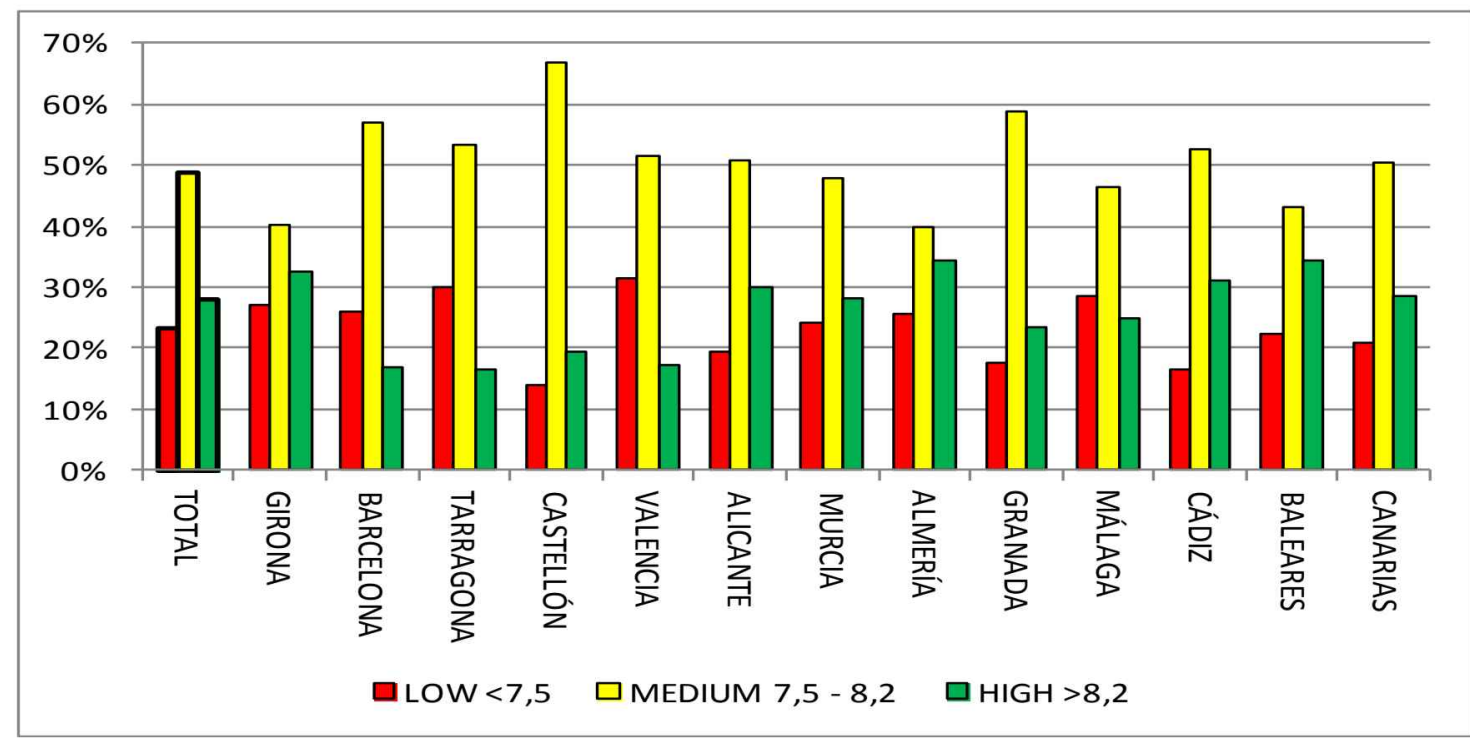

Fuente: Elaboración propia a partir de datos obtenidos de Booking.com

\subsection{Conclusiones}

A nivel general, se detecta una gran homogeneidad en las calificaciones medias de los hoteles de las provincias analizadas, existiendo diferencias mínimas en los periodos tratados. Para descubrir diferencias significativas, debemos recurrir a una división en cuartiles poniendo así de manifiesto ciertas variaciones entre provincias.

Nos centramos en el análisis de las seis principales zonas, es decir aquellas que acumulan más de 100 hoteles y que suponen el $80 \%$ del total de los establecimientos. Barcelona presenta en ambos periodos una proporción de hoteles con baja puntuación relativamente superior a la media, situación que se repite en el caso de Málaga, aunque la situación mejora algo en 2014.

En cuanto a los que presentan unas puntuaciones superiores, destacamos los de Alicante, Girona y Canarias. El caso de Baleares, resulta curioso, ya que ha cambiado su situación de 2011 a 2014, contando con varios hoteles que pasan de la zona de puntuación media a la de puntuación alta.

De estos resultados resulta llamativa la inclusión de Málaga dentro del grupo de provincias con hoteles peor valorados. Sin embargo, Alicante que se asocia con mucha frecuencia a un turismo de nivel medio o bajo, con lugares tales como Benidorm, obtiene una puntuación especialmente alta. Este mismo 
caso se repite en el caso de Girona, cuyo turismo en la Costa Brava, aparece muchas veces asociado a los bajos precios y calidades, con casos como el del "turismo de borrachera" en Lloret de Mar (Jiménez \& Prats, 2006).

Estos datos ponen de manifiesto que las ideas preconcebidas sobre la calidad de los hoteles según provincia, no responden exactamente a la realidad. Descartamos por tanto la hipótesis $\mathrm{H}_{5}$ ya que Málaga y Baleares no están entre las provincias con hoteles mejor valorados, ni Alicante y Girona entre los que obtienen peores puntuaciones.

No dudamos de que Málaga o Baleares cuenten con importantes establecimientos hoteleros de altísima calidad, pero junto a ellos, convive una oferta hotelera considerada en esta web de calidad media o media-baja, que provoca que el promedio de la valoración de sus establecimientos, no destaque sobre el de otras provincias.

En los casos de provincias con cierta imagen negativa, como Alicante y Girona (Jiménez \& Prats, 2006), tampoco podemos negar la existencia de establecimientos orientados a un turismo masivo que busca precios bajos. Pero los datos muestran que, junto a esos establecimientos, existe una importante planta hotelera que oferta servicios de alta calidad.

Los datos obtenidos también nos hacen rechazar la hipótesis $\mathrm{H}_{6}$, referida a las especulaciones sobre si la situación de crisis reinante en el país durante este periodo pudiera haber afectado la calidad del servicio. Las ligeras variaciones en la evolución de las valoraciones (mayormente positivas) durante estos años, indican una estabilidad en este sentido. Aunque este pueda ser un dato positivo, también pone de manifiesto la ausencia de la tan ansiada "reorientación hacia el turismo de calidad" del sector.

Entendemos que el seguimiento de la planta hotelera de una zona concreta, a través de las puntuaciones en sistemas como el de Booking u otros análogos, puede permitir, tanto a académicos como a instituciones, obtener una imagen real y objetiva de la percepción de los visitantes. El éxito de la implantación de políticas de mejora de calidad en los establecimientos hoteleros, puede medirse de forma sencilla con este tipo de metodologías. Este 
tipo de análisis temporal se puede realizar a través de herramientas de software $^{14}$ ya existentes o de desarrollo relativamente sencillo, que permiten la recopilación y estructuración de la información procedente de diferentes fuentes.

\footnotetext{
${ }^{14}$ Reviewpro, Revinate, HotelReporting , aboutmihotel , hotelmanager.
} 


\section{FACTORES QUE INFLUYEN EN LA PUNTUACIÓN DE LOS HOTELES}

Consideramos que existen factores medibles que influyen en las puntuaciones obtenidas por los hoteles, por lo que creemos interesante la realización de un análisis profundo a este respecto, usando para ello la muestra de hoteles de costa, con datos de Booking y TripAdvisor. Por esta razón nos planteamos cinco hipótesis y comprobaremos su validez a lo largo de este epígrafe:

$H_{7}$ : A mayor número de estrellas, los hoteles obtendrán mejor puntuación.

$H_{8}$ : A mayor tamaño de hotel, el número de estrellas también es mayor y el ratio habitaciones/empleado es menor.

$H_{9}$ : A mayor tamaño del hotel, el número de opiniones registradas también es mayor.

$H_{10}$ : A mayor número de estrellas del hotel, el número de opiniones registradas también es mayor.

$H_{11}$ : A mayor número de opiniones, los hoteles obtendrán mejor puntuación.

A raíz de los resultados obtenidos, proponemos un modelo que racionaliza el conjunto de relaciones detectadas.

\subsection{Relación entre número de estrellas y puntuación del hotel}

Usando las puntuaciones obtenidas en Booking, observamos como los hoteles de tres estrellas (733 en total) tienen una calificación de 7,7; los de cuatro estrellas (627 hoteles) de 7,9 y los de cinco estrellas (80 hoteles) un 8,5.

Efectivamente, los hoteles con mayor número de estrellas obtienen mejores puntuaciones, siendo especialmente importante la diferencia entre los de cinco estrellas y el resto, lo que confirma la hipótesis $\mathrm{H}_{7}$. Esto implica que provincias con un porcentaje de hoteles de cuatro y cinco estrellas superior a la media, deberían de obtener puntuaciones medias mayores y viceversa. En la 
Tabla 24 se refleja el porcentaje medio de los hoteles de la muestra y los porcentajes para cada una de las provincias.

Tabla 24. Porcentaje de hoteles por provincia según número de estrellas

\begin{tabular}{|c|c|c|c|c|c|c|c|c|c|c|c|c|c|c|}
\hline$\frac{\infty}{\frac{\infty}{4}}$ & $\frac{1}{6}$ & $\frac{\pi}{\frac{1}{0}}$ & $\begin{array}{l}\frac{1}{2} \\
\frac{0}{0} \\
\frac{c}{0}\end{array}$ & $\frac{\frac{\pi}{2}}{\frac{0}{0}} \frac{1}{\frac{1}{\alpha}}$ & $\frac{\text { WI }}{\frac{E}{2}}$ & $\frac{2}{0}$ & $\frac{\frac{4}{3}}{\frac{3}{2}}$ & $\frac{\frac{1}{0}}{\frac{0}{2}}$ & $\frac{\frac{4}{n}}{\frac{11}{2}}$ & $\frac{\mathbf{N}}{\frac{1}{0}}$ & $\frac{\frac{1}{4}}{\frac{2}{4}}$ & $\frac{1}{4}$ & 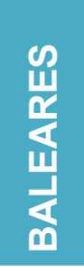 & $\frac{\frac{\infty}{4}}{\frac{n}{4}}$ \\
\hline 3 & $51 \%$ & $55 \%$ & $66 \%$ & $54 \%$ & $60 \%$ & $49 \%$ & $57 \%$ & $46 \%$ & $26 \%$ & $54 \%$ & $50 \%$ & $42 \%$ & $58 \%$ & $28 \%$ \\
\hline 4 & $44 \%$ & $42 \%$ & $29 \%$ & $43 \%$ & $38 \%$ & $49 \%$ & $37 \%$ & $54 \%$ & $71 \%$ & $42 \%$ & $50 \%$ & $50 \%$ & $37 \%$ & $60 \%$ \\
\hline 5 & $6 \%$ & $3 \%$ & $4 \%$ & $3 \%$ & $2 \%$ & $3 \%$ & $6 \%$ & $0 \%$ & $3 \%$ & $5 \%$ & $0 \%$ & $8 \%$ & $5 \%$ & $12 \%$ \\
\hline
\end{tabular}

Fuente: Elaboración propia a partir de datos obtenidos de Booking

Barcelona presenta una distribución de hoteles en la que los de tres estrellas tienen un mayor peso frente a los de cuatro y cinco, si los comparamos con la media. Aunque las diferencias son mínimas, pueden explicar en parte su valoración final. El caso de Baleares es similar, lo que hace pensar que sus valoraciones medias estarían condicionadas por la apuesta del sector hotelero de la zona por los establecimientos de tres estrellas, en detrimento de los de cuatro.

Sin embargo, en el caso de Málaga las malas puntuaciones recibidas no se justifican por las estrellas de sus hoteles. El porcentaje de hoteles de cuatro y cinco estrellas es superior al de la media nacional y, aún así obtienen las peores calificaciones entre los destinos principales.

Girona, a pesar de ser la zona cuyos hoteles tienen un nivel de estrellas más bajo, obtiene puntuaciones algo más altas a las de la media. En el caso de Canarias, que cuenta con una planta hotelera con un peso sustancialmente mayor en hoteles de cuatro y cinco estrellas, puede explicar así sus buenas calificaciones. En Alicante los hoteles de tres estrellas tienen mucho peso, en menoscabo de los de cuatro y cinco, sin embargo obtiene unas calificaciones a destacar por ser muy altas. 


\subsection{Relación entre el tamaño del hotel y su número de estrellas y empleados}

Existe también una relación entre las estrellas de un hotel y su tamaño según ponen de manifiesto los datos del INE (INE, 2014). Si exceptuamos los hoteles de cinco estrellas, que representan únicamente el 1,6\% de la planta hotelera nacional, el resto de hoteles presentan una clara relación entre el número de plazas por hotel, el número de estrellas y el número de habitaciones por empleado (Tabla 25).

Tabla 25. Plazas por hotel y habitaciones por empleado

\begin{tabular}{|cccccc|} 
Estrellas & Hoteles & Plazas & $\begin{array}{c}\text { Personal } \\
\text { empleado }\end{array}$ & $\begin{array}{c}\text { Plazas por } \\
\text { hotel }\end{array}$ & $\begin{array}{c}\text { Habit. por } \\
\text { empleado }\end{array}$ \\
\hline TOTAL & 16.419 & 1.731 .431 & 227.190 & 105 & 7,62 \\
\hline Cinco & 269 & 83.245 & 24.811 & 309 & 3,36 \\
\hline Cuatro & 2.298 & 716.764 & 105.559 & 312 & 6,79 \\
\hline Tres & 2.971 & 541.608 & 64.425 & 182 & 8,41 \\
\hline Dos & 2.098 & 138.735 & 12.305 & 66 & 11,27 \\
\hline Una & 1.299 & 55.538 & 4.722 & 43 & 11,76 \\
\hline
\end{tabular}

Fuente: INE. Encuesta de ocupación hotelera (2014)

Se confirma así la hipótesis $\mathrm{H}_{8}$, ya que observamos que a mayor número de estrellas, corresponde un mayor número de plazas por hotel y un menor ratio de habitaciones por empleado.

Las estrellas que se otorgan a un hotel según los diferentes sistemas de clasificación, están en parte supeditadas a la prestación de una serie de servicios. Para un hotel de mayor tamaño, cumplir estos requisitos supone un menor coste relativo por habitación. La existencia de estas "economías de escala"15 propicia que los hoteles de cuatro estrellas tengan un tamaño medio mayor que los de tres estrellas.

Además de los servicios obligatorios según categoría, es normal que los hoteles con mayor número de estrellas presten servicios adicionales y que la calidad del servicio sea, por lo general, mayor. Esta circunstancia se refleja

\footnotetext{
${ }^{15}$ Situación de producción en la que el coste por unidad producida disminuye a medida que aumenta el número de unidades producidas
} 
claramente en el número de habitaciones por empleado, que es menor cuando el número de estrellas es mayor.

\subsection{Relación entre el tamaño de un hotel y el número de opiniones}

La hipótesis $\mathrm{H}_{9}$ sostiene que lo que hace que un hotel tenga más opiniones es su mayor capacidad, es decir, el número de habitaciones de que dispone. Esta relación parece obvia, pero para confirmarla usamos en este caso los datos de TripAdvisor, tomando los hoteles con al menos 50 opiniones, de las cuatro provincias con mayor número de hoteles de nuestra muestra. Los resultados muestran una clara correlación entre ambos factores, por lo que también confirmamos la hipótesis $\mathrm{H}_{9}$ (Tabla 26).

Tabla 26. Número de opiniones en función del número de habitaciones

\begin{tabular}{|c|c|c|c|c|c|c|c|c|c|c|}
\hline & \multicolumn{2}{|c|}{ ALICANTE } & \multicolumn{3}{c|}{ BALEARES } & \multicolumn{2}{c|}{ CANARIAS } & \multicolumn{2}{c|}{ MALAGA } & \multicolumn{2}{|c|}{ TOTAL } \\
\hline $\begin{array}{c}N^{\circ} \text { de } \\
\text { habitaciones }\end{array}$ & $\begin{array}{c}\mathrm{n}^{\circ} \\
\text { hot. }\end{array}$ & $\begin{array}{c}\text { media } \\
\text { op. }\end{array}$ & $\begin{array}{c}\mathrm{n}^{\circ} \\
\text { hot. }\end{array}$ & $\begin{array}{c}\text { media } \\
\text { op. }\end{array}$ & $\begin{array}{c}\mathrm{n}^{\circ} \\
\text { hot. }\end{array}$ & $\begin{array}{c}\text { media } \\
\text { op. }\end{array}$ & $\begin{array}{c}\mathrm{n}^{\circ} \\
\text { hot. }\end{array}$ & $\begin{array}{c}\text { media } \\
\text { op. }\end{array}$ & $\begin{array}{c}\mathrm{n}^{\circ} \\
\text { hot. }\end{array}$ & $\begin{array}{c}\text { media } \\
\text { op. }\end{array}$ \\
\hline $0-100$ & 9 & 113,22 & 32 & 101,25 & 11 & 86,27 & 16 & 128,56 & 68 & 106,84 \\
\hline $101-200$ & 23 & 165,60 & 55 & 162,62 & 29 & 168,65 & 33 & 165,76 & 140 & 165,10 \\
\hline $201-300$ & 20 & 202,70 & 37 & 200,08 & 34 & 287,38 & 24 & 238,46 & 115 & 234,36 \\
\hline Más de 300 & 9 & 347,00 & 20 & 315,50 & 56 & 522,07 & 20 & 348,30 & 105 & 434,62 \\
\hline
\end{tabular}

Fuente: Elaboración propia a partir de datos de TripAdvisor

\subsection{Relación entre el número de estrellas y el número de opiniones de un hotel}

Estudiamos también la relación entre el número de estrellas de un hotel y el número de críticas que recibe en Booking y TripAdvisor, mostrando los resultados en la tabla 27 . La hipótesis $\mathrm{H}_{10}$ sostiene que los hoteles con mayor número de estrellas tendrán registradas más opiniones, quedando confirmada a tenor de los datos. La excepción vuelve a ser la reducida parte de la muestra conformada por los hoteles de cinco estrellas. 
Tabla 27. Numero de estrellas y número de opiniones registradas

\begin{tabular}{|ccccc|} 
Estrellas & $\begin{array}{c}\text { Media } \\
\text { Booking }\end{array}$ & $\begin{array}{c}\text { Media } \\
\text { TripAdvisor }\end{array}$ & $\begin{array}{c}\text { Mediana } \\
\text { Booking }\end{array}$ & $\begin{array}{c}\text { Mediana } \\
\text { TripAdvisor }\end{array}$ \\
\hline $\mathbf{3}$ & 117 & 104 & 77 & 48 \\
\hline $\mathbf{4}$ & 143 & 182 & 93 & 126 \\
\hline $\mathbf{5}$ & 129 & 228 & 77 & 146 \\
\hline
\end{tabular}

Fuente: Elaboración propia a partir de datos de TripAdvisor y Booking

\subsection{Relación entre el número de opiniones y las puntuaciones de un} hotel

Según un estudio realizado en Marzo de 2010 sobre datos de TripAdvisor (Melián-González et al., 2013), sobre una base de 16.680 hoteles en dicha web de opiniones, existe una relación directa entre el número de opiniones de un hotel y la puntuación obtenida por el hotel, tal y como indica claramente su título: "Online Customer Reviews of Hotels: As Participation Increases, Better Evaluation Is Obtained"16.

Por otra parte, TripAdvisor aconseja a los hoteleros invitar a los clientes a escribir opiniones, tal y como se indicaba en apartados anteriores. El que exista un estudio científico que demuestre que seguir el consejo de TripAdvisor es beneficioso para los hoteleros, resulta muy positivo para sus intereses. Indudablemente, el crecimiento de la comunidad de TripAdvisor, el número de visitas y el número de opiniones registradas en su web, es algo sumamente beneficioso para la marca. Por ello se hace eco de este estudio científico en su web, destacando como fuente la Cornell University (Tripadvisor for business, 2013). Queremos señalar que la comunicación de TripAdvisor comete un error al citar como fuente dicha universidad, en lugar de hablar de tres investigadores de la Universidad de Las Palmas, que han visto su trabajo publicado en la revista científica que edita la Cornell University.

Los datos del citado estudio resultan concluyentes y parecen no dejar lugar a duda sobre la existencia de una efectiva relación estadística al respecto (Tabla 28)

\footnotetext{
${ }^{16}$ Opiniones online de clientes de hoteles: Al incrementar el número de opiniones, la puntuación del hotel mejora
} 
Tabla 28. Puntuaciones en función de las opiniones.

\begin{tabular}{|lcc|}
\hline No de opiniones & Hoteles & $\begin{array}{c}\text { Puntuación } \\
\text { Media }\end{array}$ \\
\hline Entre $\mathbf{1 1}$ y $\mathbf{2 0}$ & 3.461 & 3,515 \\
\hline Entre $\mathbf{2 1}$ y $\mathbf{3 0}$ & 2.351 & 3,572 \\
\hline Entre $\mathbf{3 1}$ y $\mathbf{4 0}$ & 1.699 & 3,64 \\
\hline Entre $\mathbf{4 1}$ y $\mathbf{5 0}$ & 1.333 & 3,707 \\
\hline Entre $\mathbf{5 1}$ y $\mathbf{1 0 0}$ & 3.853 & 3,725 \\
\hline Mas de $\mathbf{1 0 0}$ & 3.983 & 3,9 \\
\hline TOTAL & $\mathbf{1 6 . 6 8 0}$ & $\mathbf{3 , 6 9 1}$ \\
\hline
\end{tabular}

Fuente: Melian-González et al., 2013

Siguiendo una metodología similar a la utilizada en dicho estudio (MeliánGonzález et al., 2013), analizamos nuestra muestra y tomamos los datos de los hoteles con al menos 10 opiniones. Utilizamos los datos de Booking y TripAdvisor, representándolos en las tablas 29 y 30 .

Tabla 29. Puntuaciones en función de las opiniones (Booking)

\section{No de opiniones Hoteles Puntuación Media}

\begin{tabular}{|l|c|c|}
\hline Entre $\mathbf{1 1}$ y $\mathbf{2 0}$ & 102 & $\mathbf{7 , 6 6}$ \\
\hline Entre $\mathbf{2 1}$ y $\mathbf{3 0}$ & 104 & $\mathbf{7 , 6 7}$ \\
\hline Entre $\mathbf{3 1}$ y $\mathbf{4 0}$ & 104 & $\mathbf{7 , 7 7}$ \\
\hline Entre $\mathbf{4 1}$ y $\mathbf{5 0}$ & 87 & 7,82 \\
\hline Entre $\mathbf{5 1}$ y $\mathbf{1 0 0}$ & 357 & 7,87 \\
\hline Entre $\mathbf{1 0 1}$ y 200 & 350 & 7,88 \\
\hline Más de 200 & 269 & 7,94 \\
\hline TOTAL & $\mathbf{1 3 7 3}$ & $\mathbf{7 , 8 4}$ \\
\hline
\end{tabular}

Fuente: Elaboración propia a partir de datos de Booking 
Tabla 30. Puntuaciones en función de las opiniones (TripAdvisor)

\begin{tabular}{|l|c|c|}
\hline No de opiniones & Hoteles & Puntuación Media \\
\hline Entre $\mathbf{1 1}$ y $\mathbf{2 0}$ & 133 & 3,7068 \\
\hline Entre $\mathbf{2 1}$ y $\mathbf{3 0}$ & 103 & 3,6408 \\
\hline Entre $\mathbf{3 1}$ y $\mathbf{4 0}$ & 99 & 3,5253 \\
\hline Entre $\mathbf{4 1}$ y $\mathbf{5 0}$ & 82 & 3,622 \\
\hline Entre $\mathbf{5 1}$ y $\mathbf{1 0 0}$ & 242 & 3,7459 \\
\hline Más de $\mathbf{1 0 0}$ & 616 & 3,8506 \\
\hline TOTAL & $\mathbf{1 . 2 7 5}$ & $\mathbf{3 , 7 4 6 6}$ \\
\hline
\end{tabular}

Fuente: Elaboración propia a partir de datos de TripAdvisor

La hipótesis $\mathrm{H}_{11}$ plantea la existencia de una relación positiva entre el número de opiniones que tiene registradas un hotel y su valoración. En el caso de Booking esa relación se mantiene exactamente, pero para el caso de TripAdvisor existen ligeras diferencias. Entendemos que en esta muestra de 1.275 hoteles deberían reproducirse los resultados obtenidos sobre 16.680 establecimientos del citado estudio, pero las puntuaciones de los grupos de hoteles con menor número de opiniones son mayores de lo esperado. Los datos nos hacen aceptar la hipótesis $\mathrm{H}_{11}$ planteada, pero también nos muestran que esa relación no tiene la consistencia esperada.

7.6. Conclusiones sobre los factores que influyen en las puntuaciones

En este apartado hemos comprobado la relación entre el número de estrellas de un hotel y la puntuación obtenida en las webs de opiniones, observando que existen zonas dónde los hoteles de cuatro y cinco estrellas superan en número a los de tres y en consecuencia las puntuaciones medias de la zona son mayores. En el caso de nuestra muestra de hoteles, la escasa diferencia entre las puntuaciones de los hoteles de tres y cuatro estrellas $(7,7 \mathrm{y}$ 7,9 respectivamente), hace que este factor no aparezca siempre como determinante.

Los datos oficiales del INE, muestran claramente una relación positiva entre el tamaño del hotel y su número de estrellas. Los hoteles de mayor 
tamaño son los que tienden a tener un mayor número de estrellas. Además también poseen un ratio de habitaciones por empleado menor, lo que favorece la prestación de un mejor servicio. Por tanto, parece lógico pensar que ante dos hoteles similares, obtendrá más opiniones aquel que cuente con mayor número de habitaciones y, por lo tanto, mayor número de clientes.

Se detecta también una importante relación entre el número de estrellas de un hotel y el número de opiniones registradas en el mismo. Resulta algo lógico, una vez constatado que existe cierta relación entre el tamaño de un hotel y su número de estrellas, así como entre el tamaño del hotel y el número de opiniones. Los hoteles más grandes tienden a tener más estrellas y también más clientes, por lo que genera más opiniones.

Se observa como existe una relación directa entre el número de estrellas de un hotel, su número de habitaciones, su número de opiniones y su calificación. En el caso del número de críticas de los hoteles de cinco estrellas, esta relación no se cumple, probablemente debido a la mayor edad de los usuarios y su menor uso de Internet. En todo caso este tipo de hoteles únicamente representan el $6 \%$ de nuestra muestra y el $1,6 \%$ de la planta hotelera nacional.

Por otro lado, los hoteles con mayor capacidad, generan volúmenes de negocio que les obligan a contar con una plantilla de personal mayor que los hoteles de menor tamaño. Este factor también hace más probable la contratación de personal con mayor cualificación para la dirección de grandes equipos humanos y contar con un mayor presupuesto. Como consecuencia inmediata, resulta más probable que de esta forma se preste un mejor servicio, que se refleje en mejores valoraciones.

Hay ciertos servicios que suponen unos gastos fijos, por lo que los costes por habitación pueden ser muy altos si no se tiene un volumen mínimo de plazas. Así sucede por ejemplo con los servicios de animación, Spa o guardería. En este sentido resulta más probable que los hoteles de mayor tamaño puedan afrontar la prestación de esos servicios, cuyo coste relativo les 
resulta menor, lo que a su vez también favorece que obtengan valoraciones más positivas.

En relación a este mismo aspecto, las estrellas que se otorgan a un hotel según los diferentes sistemas de clasificación, están en parte supeditadas a la prestación de una serie de servicios. Para un hotel de mayor tamaño, cumplir con dichos requisitos supone un menor coste relativo por habitación. La existencia de "economías de escala" propicia que los hoteles de cuatro estrellas tengan un tamaño medio mayor que los de tres estrellas. Además, la prestación de más servicios y de una mayor calidad, requiere que el ratio de personal asignado por huésped aumente al aumentar el número de estrellas del hotel.

Por lo tanto, un hotel de mayor tamaño tenderá a tener una mayor variedad de servicios y de mejor calidad a un coste relativamente menor, lo que hará más probable que obtenga las cuatro estrellas. Un alto número de habitaciones propiciará un alto número de críticas y la variedad y calidad de sus servicios hará que sus valoraciones sean mejores. Este planteamiento se recoge de forma gráfica en la figura 27.

Mediante flechas negras se representa lo que entendemos como relaciones directas causa-efecto, que derivan del tamaño del hotel, mientras que las flechas blancas indican relaciones existentes que entendemos son aparentes. El mayor tamaño de un hotel favorece el aumento de 3 magnitudes diferentes (estrellas, puntuaciones y críticas), por lo que el hecho de que a mayor número de críticas o estrellas existan mejores puntuaciones no significa que estos dos factores incidan en las puntuaciones, sino que los tres dependen del tamaño del hotel y aumentan o disminuyen en función de ese factor principal. 
Figura 27. Relación Componentes vs Puntuación

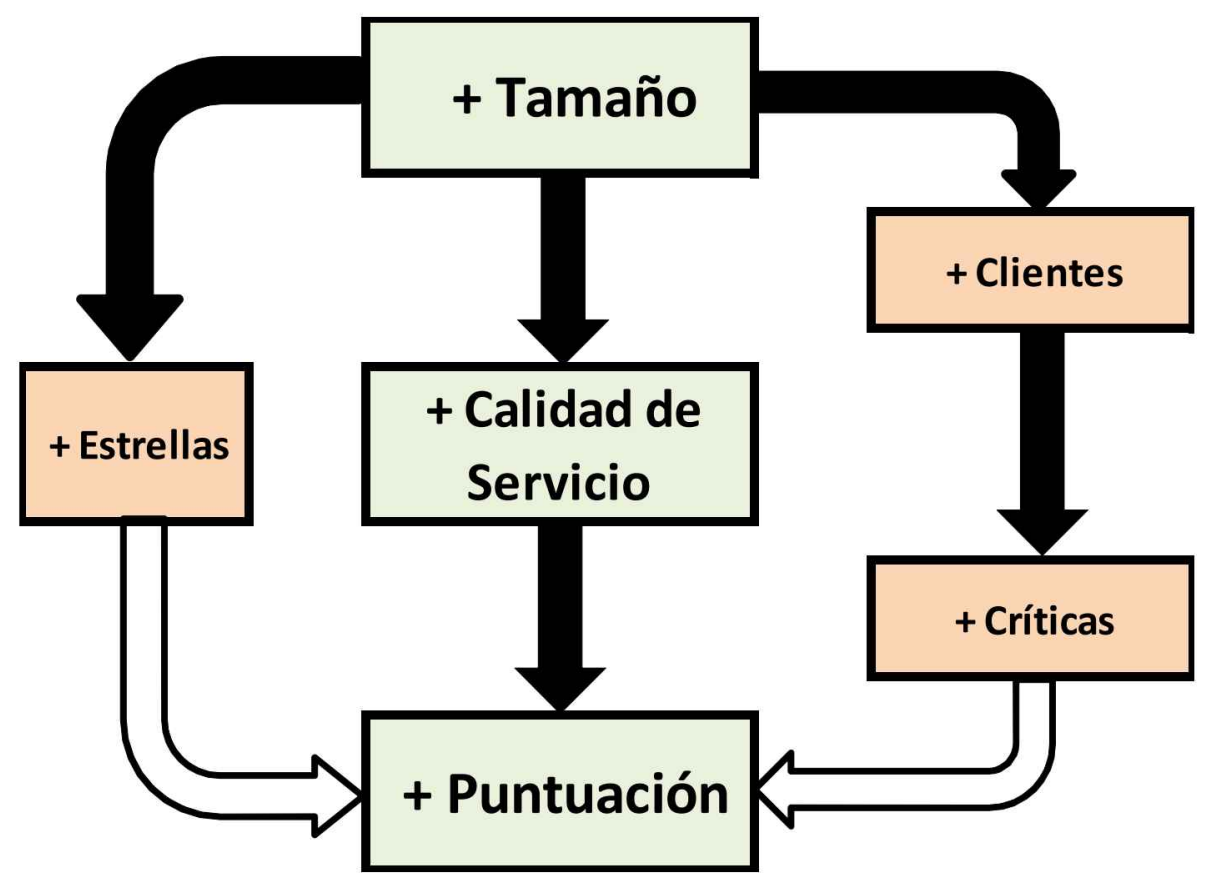

Fuente: Elaboración propia.

En este sentido, las conclusiones que extraemos de lo anteriormente expuesto difieren ligeramente de las propuestas por el estudio que destacaba el aumento del número de opiniones como factor favorecedor de la mejora de las puntuaciones de un hotel (Melián-González et al., 2013), por lo que resultará conveniente analizar algunas de las conclusiones a las que llegaron dichos autores, contrastándolas con los resultados obtenidos con nuestros datos.

Este análisis argumentaba que, cuantas más opiniones existan, más precisa será la valoración del hotel y se verá menos afectado por opiniones extremas en su puntuación global. Esto no es más que un reflejo del concepto de población y muestra, que resulta evidente y lógico. Es cierto que varias opiniones inusualmente negativas en un hotel con pocas opiniones puede bajar su puntuación media ostensiblemente, diluyéndose ese efecto con el aumento del número de opiniones. Aunque también ocurre que en la situación contraria, es decir, varias opiniones especialmente positivas podrian causar el efecto contrario, que se diluiría con el paso del tiempo, al añadirse puntuaciones más de acorde a la realidad del hotel. 
También se argumentaba que un mayor número de opiniones, ayuda al hotel a conocer mejor las necesidades de sus clientes y mejorar sus servicios, razonamiento en el que coincidimos, aunque no sabemos si realmente el enriquecimiento de la información de que el hotel dispone, al aumentar el número de opiniones, repercute significativamente en la mejora de sus servicios y en las puntuaciones finales obtenidas. Sin embargo, sí que existe una tendencia generalizada a una ligera mejora en las puntuaciones medias de los hoteles, lo que hace que las opiniones más recientes de un hotel resulten mejores que las más antiguas. Así lo sugieren los datos obtenidos en nuestra muestra de hoteles, usando las puntuaciones obtenidas en Booking, con una diferencia de 2 años y medio, según se refleja en el capítulo 6 de esta Tesis.

Por lo tanto, aunque se aprecia una relación entre el número opiniones de un hotel y la puntuación obtenida por este, parece no tener sentido argumentar que se trata de una relación real de causa-efecto. No es especialmente recomendable sugerir sistemáticamente a los clientes que compartan sus opiniones sobre el hotel en TripAdvisor, ya que, en circunstancias normales, el incremento del número de opiniones no tiene porque mejorar la valoración del hotel. Aunque en el caso de que se tenga la percepción de que agentes malintencionados están escribiendo opiniones negativas sobre el hotel, si puede ser aconsejable seguir ese tipo de procedimiento. 


\section{USO DE LAS REDES SOCIALES POR LOS HOTELES}

\subsection{Introducción}

Actualmente asistimos a un proceso de incorporación de los hoteles a las redes sociales, que guarda bastantes similitudes con el sufrido a finales del pasado siglo, cuando los hoteles se debatían entre la necesidad o no de crear una página web. Finalmente parece que todos los hoteles han ido entendiendo la importancia de tener una web y ahora, se trata de decidir si se ha de estar en Facebook, Twitter o YouTube o Flickr. Nos hemos centrado en estas cuatro herramientas por ser las que han alcanzado un mayor número de usuarios y popularidad, pero somos conscientes que la lista se podría ampliar mediante el análisis y seguimiento de los mismos en Google+, Pinterest, FourSquare, Picasa, Linkedin, Tuenti, Instagram y otros.

Estudios realizados sobre el sector hotelero español (Mota, 2011) indican un alto nivel de implantación de las redes sociales, ya que un $73 \%$ hacen uso de ellas. Este estudio, publicado en la revista HostelMarket utilizó una muestra de 351 establecimientos hoteleros de todo el país, con la metodología indicada en la Figura 28.

Figura 28. Ficha técnica del estudio de HostelMarket

\section{FICHA TÉCNICA}

La presente encuesta ha sido realizada en octubre de 2011 y contestada por 351 establecimientos de toda España. Estos se clasifican, por tipología, como vacacionales $(41,31 \%)$, urbanos $(33,33 \%)$, rurales $(17,66 \%)$ y otros (7,70\%); por categoría, de 5E-5EGL (5,41\%), 4E-4LL (30,78\%), 3E-3LL (36,75\%), 2E-2LL (19,94\%) y 1E-1LL (7,12\%); finalmente, por pertenencia, Independiente $(66,10 \%)$ e Integrado en Grupo/Cadena $(33,90 \%)$.

(7) Sobre 232 respuestas. (8) Sobre 131 respuestas. (9) Sobre 147 respuestas

Fuente: HostelMarket

Los resultados globales muestran un alto nivel de participación en redes sociales de un número importante de hoteles, junto con una importante 
predisposición a incorporar el uso de estas herramientas por parte de aquellos que todavía no lo hacen (Figura 29).

Figura 29. Principales resultados del estudio de Hostelmarket

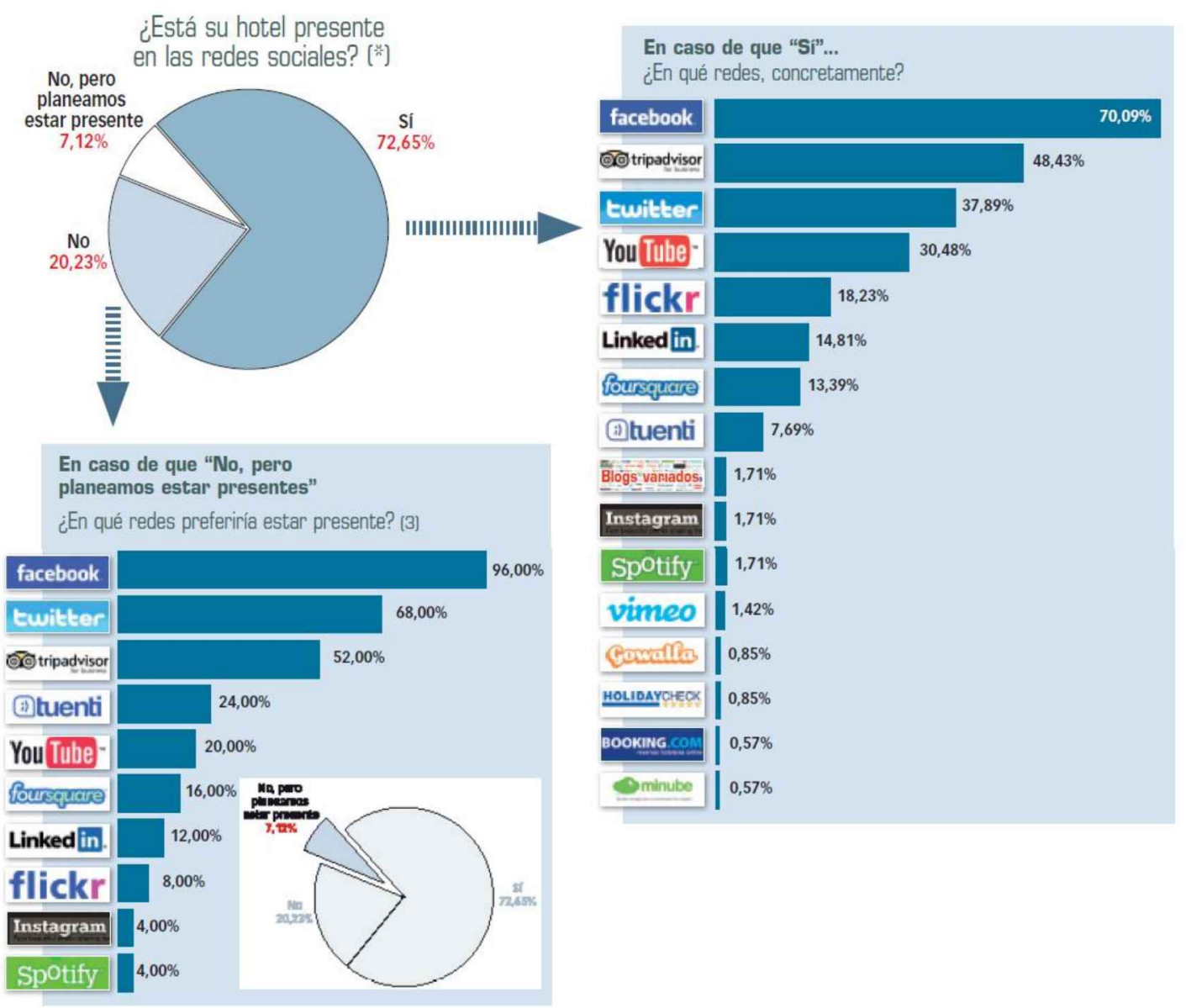

Fuente: HostelMarket

Pero un primer acercamiento al estudio de las redes sociales por los hoteles, nos deja la impresión subjetiva de que existen muchos establecimientos que gestionan de forma deficiente estas herramientas. Esas anomalías parecen darse especialmente en hoteles que no pertenecen a grandes cadenas, cometiendo, a nuestro parecer, claros errores de gestión.

En base a esto se decidió profundizar en el tema empleando una muestra de hoteles suficientemente amplia y una metodología que nos permitiera identificar, de forma objetiva, aquellos establecimientos que no cumplieran unos parámetros mínimos de uso eficiente de las redes sociales. 


\subsection{Metodología}

Utilizamos nuestra muestra de hoteles de costa, de los que se seleccionan los 1.282 que cuentan con al menos 10 opiniones de usuarios en Booking. De esta forma se evita la inclusión de hoteles de reciente apertura o de tamaño especialmente reducido. Los datos fueron obtenidos entre los meses de Marzo y Mayo de 2012.

Se clasifican los hoteles en 3 categorías dependiendo de su pertenencia a cadenas hoteleras:

- Independientes: Hoteles que no pertenecen a ninguna cadena hotelera (484 hoteles)

- Pequeña cadena: Hoteles pertenecientes a pequeñas cadenas hoteleras con menos de 10 hoteles (357 hoteles)

- Gran cadena: Hoteles pertenecientes a cadenas hoteleras con 10 hoteles o más (441 hoteles)

Se observa que la gran mayoría de las "grandes cadenas" hoteleras usan las redes sociales más relevantes y tienen una política definida de actuación, sin cometer errores de gestión evidentes. Entendemos que la actividad en redes sociales de este tipo de hoteles merece un análisis separado, por lo que los excluimos de la presente muestra.

Por este motivo nos centramos en analizar los hoteles "independientes" y de "pequeña cadena". De esta forma, la base de datos elaborada queda configurada finalmente con un total de 841 hoteles, de los que el $53 \%$ son de 3 estrellas, el $42 \%$ de 4 estrellas y el $5 \%$ de 5 estrellas. En principio se observa como muchos no usan redes sociales y, los que las emplean, lo hacen en ocasiones de manera inadecuada.

Planteamos las siguientes hipótesis de trabajo:

$H_{12}$ : Los datos sobre uso de redes sociales de la muestra de hoteles de costa españoles, coinciden con los publicados en otros estudios. 
$H_{13}:$ Un alto porcentaje de los hoteles que hacen uso de redes sociales, lo hace de forma inadecuada.

El primer paso en la realización de este estudio consiste en buscar la web del hotel y observar si, en su página principal, tiene enlaces a Facebook, Twitter, YouTube o Flickr. Para aquellos hoteles que no tienen enlaces, ni referencia alguna a redes sociales en su web, se realizan búsquedas adicionales en Google del tipo "hotel xxx facebook" o "hotel xxx twitter", para tratar de detectar su presencia en estas redes sociales.

Creemos que resulta muy complicado encontrar parámetros objetivos para determinar si una red social se gestiona o no de la forma más adecuada. Pero es posible identificar al menos tres errores que son medibles y que nos indican, cuando los encontramos, de una forma objetiva y fácilmente detectable, que un perfil en Facebook o Twitter no se gestiona correctamente. Estos errores son:

1) No tener enlaces a redes sociales en la web del hotel (Oculto): El uso de redes sociales por cualquier empresa, debe incluir la integración de estas en la web corporativa, ya sea a través de pequeños iconos o mediante "plugins específicos"17 que las redes sociales ofrecen.

2) No aportar contenidos con cierta frecuencia (Sin actualizar): No existe un número considerado óptimo de actualizaciones para una página de Facebook, ya que depende del tipo de negocio del que se trate. Hay cierto consenso sobre que una página de Facebook debe actualizarse de forma continua, con un mínimo de 2 veces por semana, aunque resulta más adecuado hacerlo la mayor parte de los días. Para esta investigación, observamos las 9 semanas de Enero y Febrero de 2012, considerando que aquellas páginas de Facebook o Twitter que no han aportado al menos 9 actualizaciones en ese periodo, están cometiendo un error.

3) Utilizar un perfil personal en lugar de un perfil de empresa (Amigos): Actuar de esta forma supone una violación de las condiciones

\footnotetext{
${ }^{17}$ Complemento que permite insertar enlaces o contenidos de diferentes redes sociales en una web.
} 
de uso propias de Facebook, por lo que en cualquier momento esta red social podría cerrar la página del hotel. Twitter, por el contrario, no tiene estas limitaciones.

\subsection{Resultados}

Presentamos los datos diferenciados entre hoteles "independientes" y de "pequeña cadena", según la definición del apartado anterior (Gráfico 16). Como era de esperar, en la mayor parte de los casos existen importantes diferencias entre ambas categorias, existiendo un mayor nivel de uso de redes sociales en las "pequeñas cadenas".

Gráfico 16. Uso de redes sociales por los hoteles

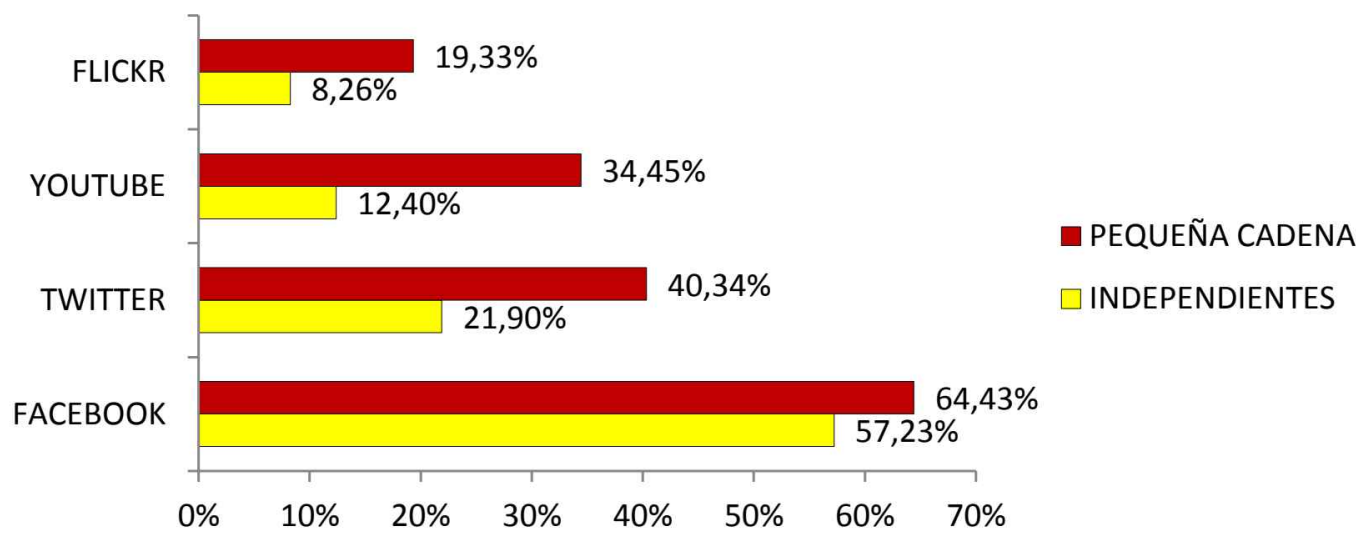

Fuente: Elaboración propia

El mencionado estudio de HostelMarket (Mota, 2011) utiliza un tamaño muestral inferior y una metodología diferente. En lugar de observar lo que hacen hoteles en las redes sociales (dato público), envían una encuesta a una serie de dichos establecimientos y trabajan con los datos obtenidos de los establecimientos que se prestan a colaborar. Los datos obtenidos en ese estudio para la categoría de "hoteles Independientes", son similares a los aquí hallados para Facebook (65,52\%), y en YouTube $(24,14 \%)$, pero divergen bastante para Flickr $(43,10 \%)$ y Twitter $(13,36 \%)$, lo que nos lleva a confirmar parcialmente la hipótesis $\mathrm{H}_{12}$, referida a la coincidencia entre los datos de nuestra muestra y los de otros estudios sobre esta misma temática. En todo caso, las cifras son ciertamente alentadoras, observándose un importante nivel de adopción de estas nuevas herramientas por parte de los hoteles. 
Sin embargo, comienzan a convertirse en cifras preocupantes, cuando se analiza más en profundidad la gestión de la principal red social: Facebook (Gráfico 17). Indicamos "Correcto" cuando el hotel no comete ninguno de los tres errores descritos en la gestión de redes sociales y "No tiene" cuando no utiliza redes sociales. Siguiendo la metodología y definiciones descritas en el apartado anterior, se obtienen los siguientes resultados.

\section{Gráfico 17. Uso de Facebook por los hoteles}

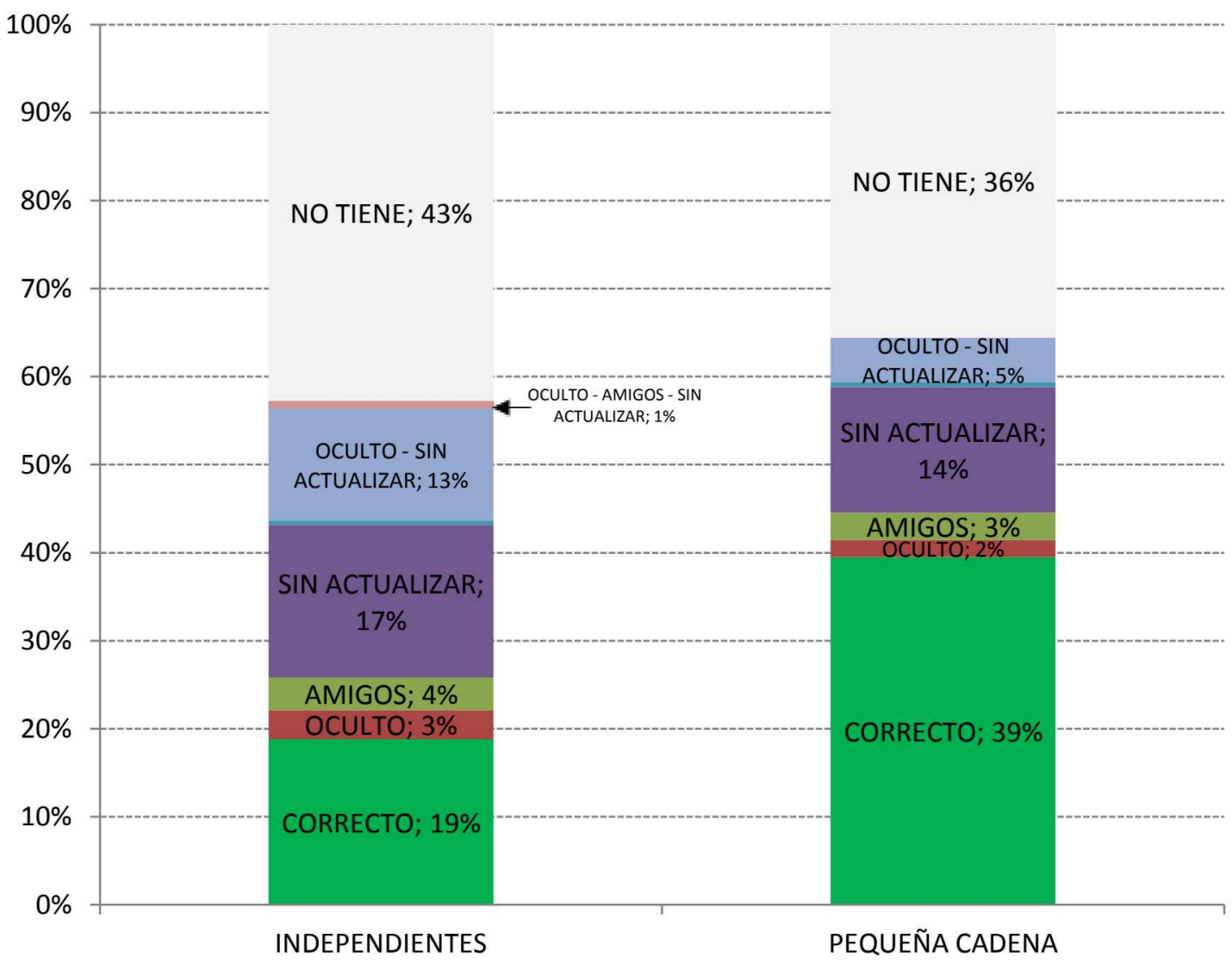

Fuente: Elaboración propia

En el caso de los hoteles independientes, el uso aparente de Facebook es del $57 \%$, pero si profundizamos en cómo gestionan esta herramienta observamos como la mayoría de los hoteles comete algunos errores evidentes en su gestión. De hecho el número de los que utilizan Facebook de forma deficiente $(38 \%)$ es el doble del que los que lo hacen de una forma aparentemente adecuada (19\%).

En los hoteles de pequeñas cadenas, el nivel de uso de Facebook es mayor $(64 \%)$ y, en este caso, la mayor parte de los hoteles que usan Facebook 
lo hacen de forma aparentemente adecuada. Aún así resulta llamativo que el $39 \%$ de los hoteles de pequeñas cadenas que usan Facebook lo hagan cometiendo errores básicos de gestión.

En un análisis más detallado, añadiendo como factor el número de estrellas de los hoteles, muestra resultados previsibles: Los hoteles con mayor número de estrellas tienden a usar Facebook con mayor frecuencia y además lo hacen de una forma más adecuada (Gráfico 18). Entendemos que un hotel utiliza Facebook "Mal" cuando comete uno o varios de los errores descritos, "Bien" cuando no hay errores e indicamos "Sin" cuando no utiliza esta red social.

Gráfico 18. Uso de Facebook según el número de estrellas

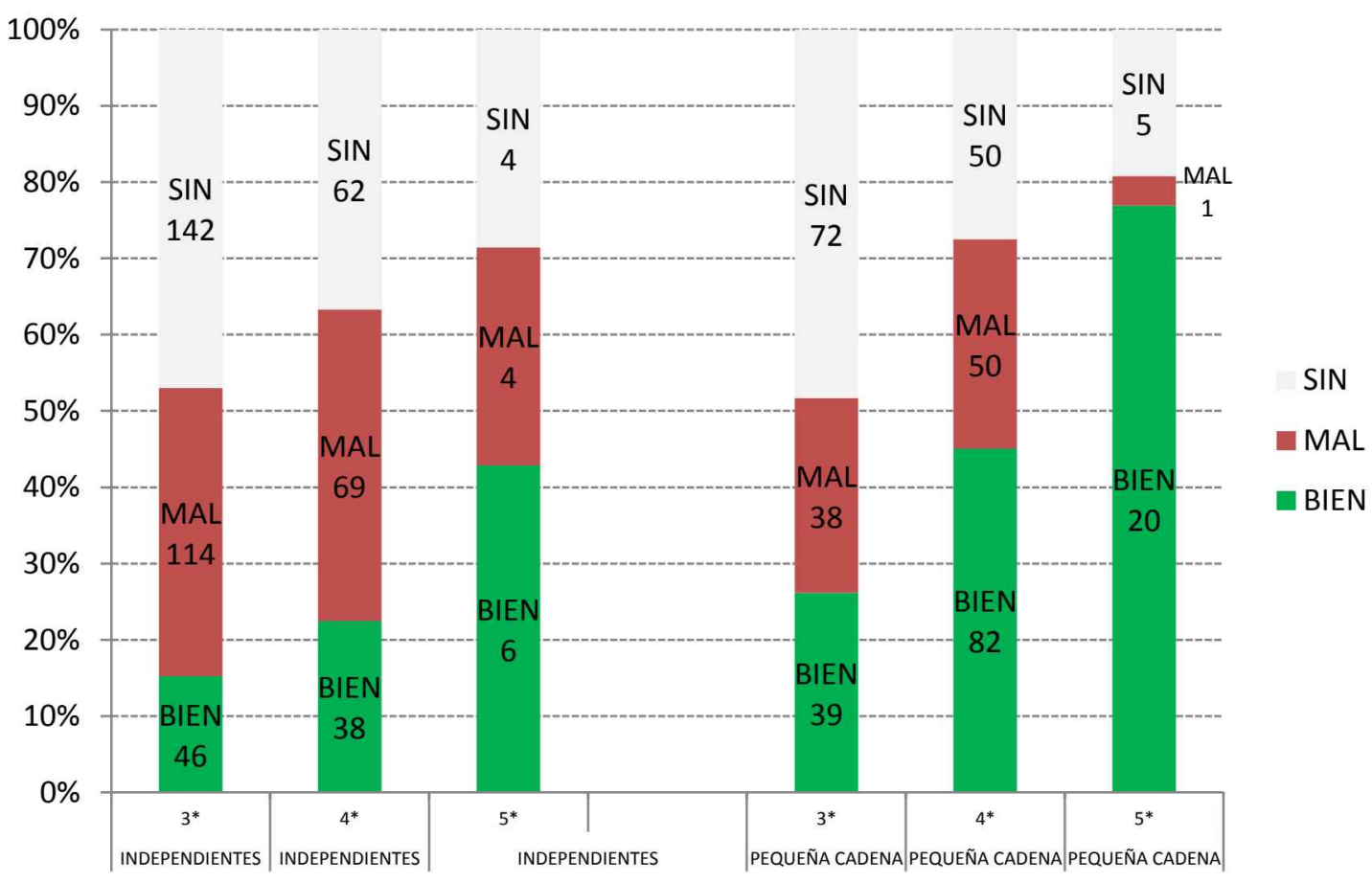

Fuente: Elaboración propia

En el caso de Twitter se obtienen resultados igualmente reveladores sobre la gestión de esta red social. En este caso el error principal es no actualizar convenientemente y con la frecuencia mínima aconsejable (Gráfico 19). 
Gráfico 19. Uso de Twitter por los hoteles

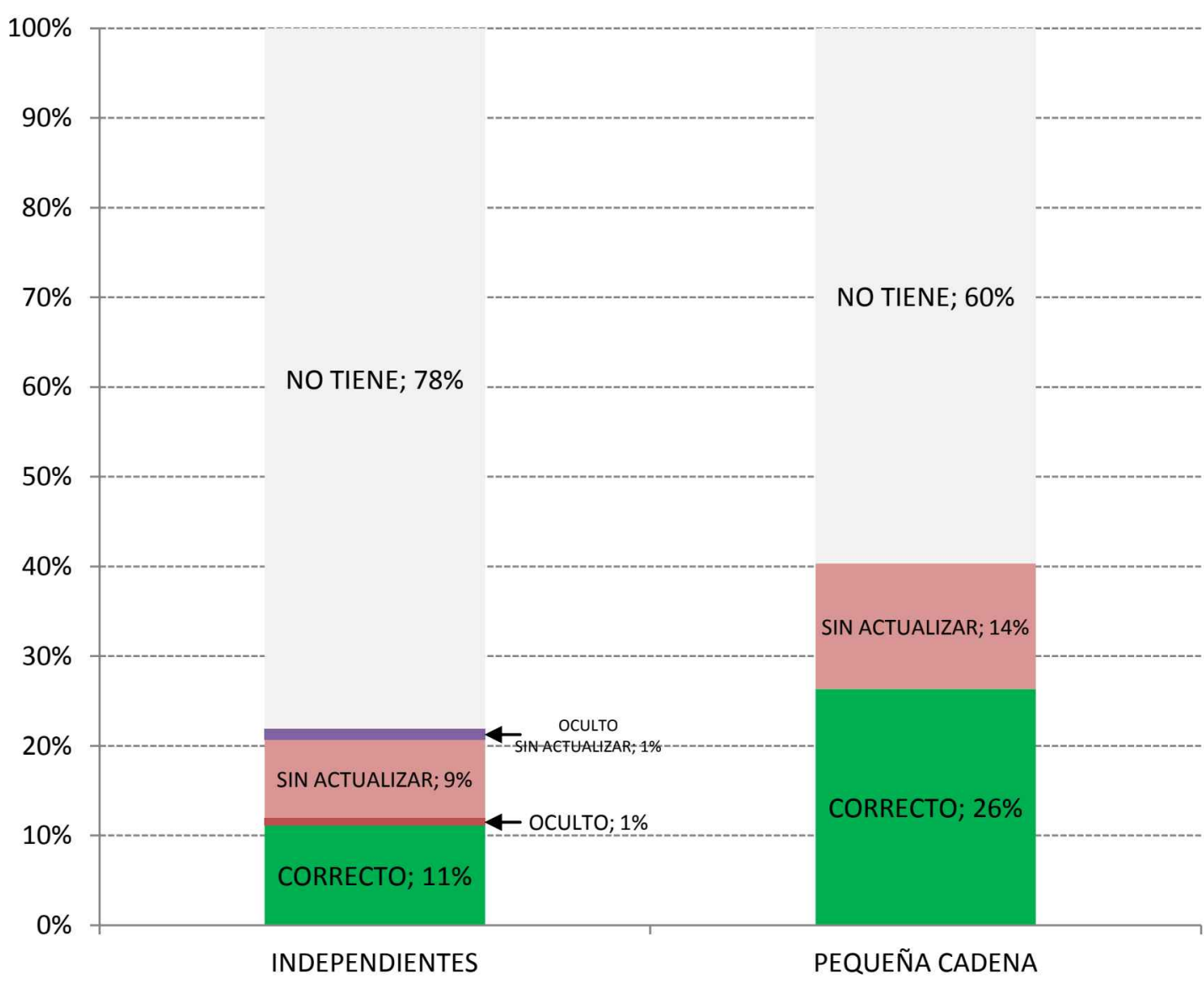

Fuente: Elaboración propia

En el caso de los hoteles independientes, la mitad de los que usan Twitter no lo actualizan y/o no lo muestran en su web. Por otra parte, el $35 \%$ de los hoteles de pequeñas cadenas que usan Twitter, no actualiza regularmente sus contenidos.

Si nos centramos ahora en el análisis del uso de Twitter, teniendo en cuenta el número de estrellas de los hoteles, se repite la misma correlación observada en el caso de Facebook: los hoteles con mayor número de estrellas, tienden a usar con mayor frecuencia Twitter y lo hacen cometiendo menos errores (Gráfico 6). 
Gráfico 20. Uso de Twitter según el número de estrellas

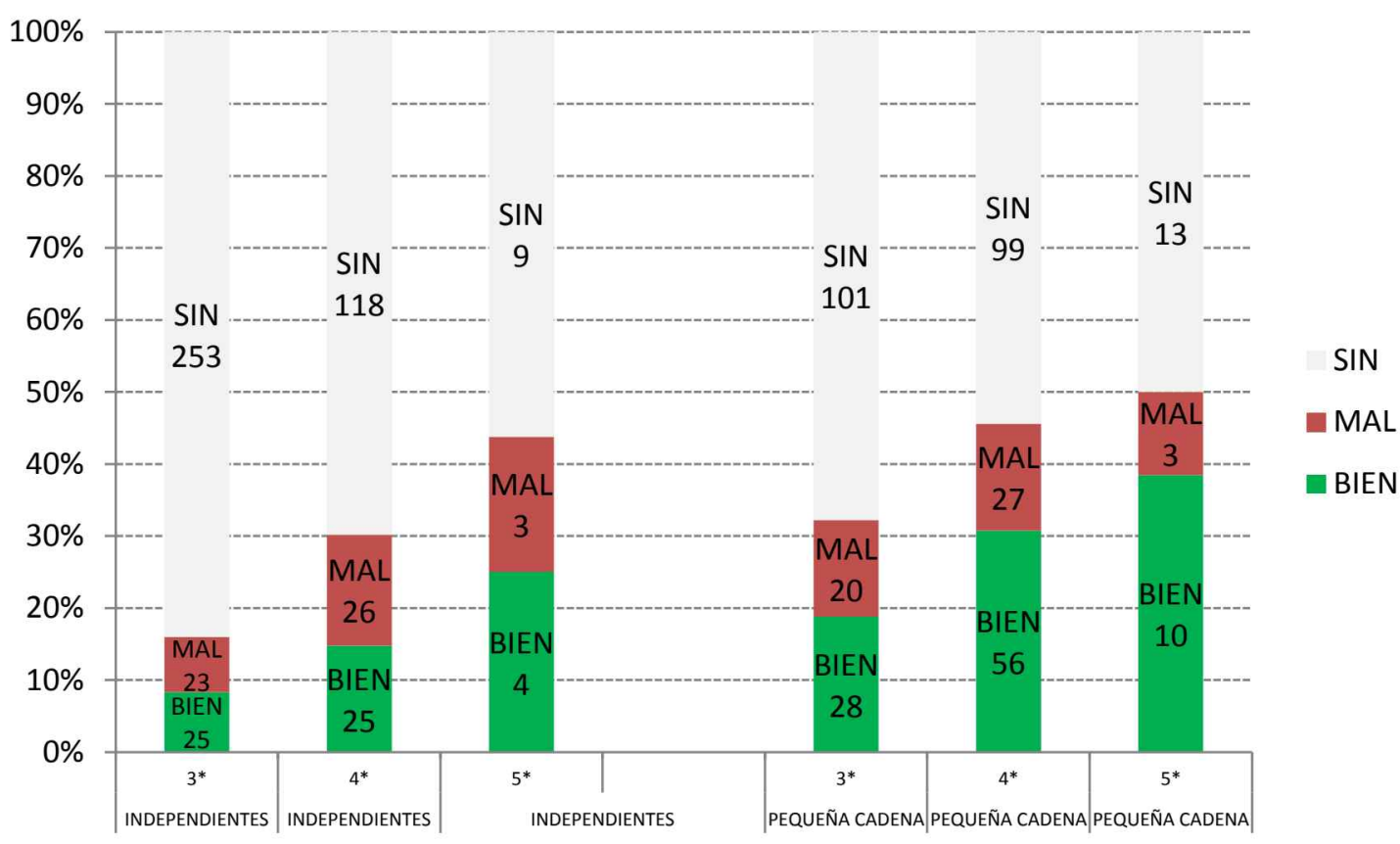

Fuente: Elaboración propia

Un estudio adicional del uso de YouTube por parte de los establecimientos hoteleros, nos vuelve a mostrar una relación directa entre el número de estrellas y el uso de esta herramienta. La excepción la constituyen los hoteles independientes de 5 estrellas, pero hemos de señalar que en nuestro estudio contamos con un reducido tamaño muestral para esta tipología (14 hoteles).

Gráfico 21. Uso de YouTube por los hoteles

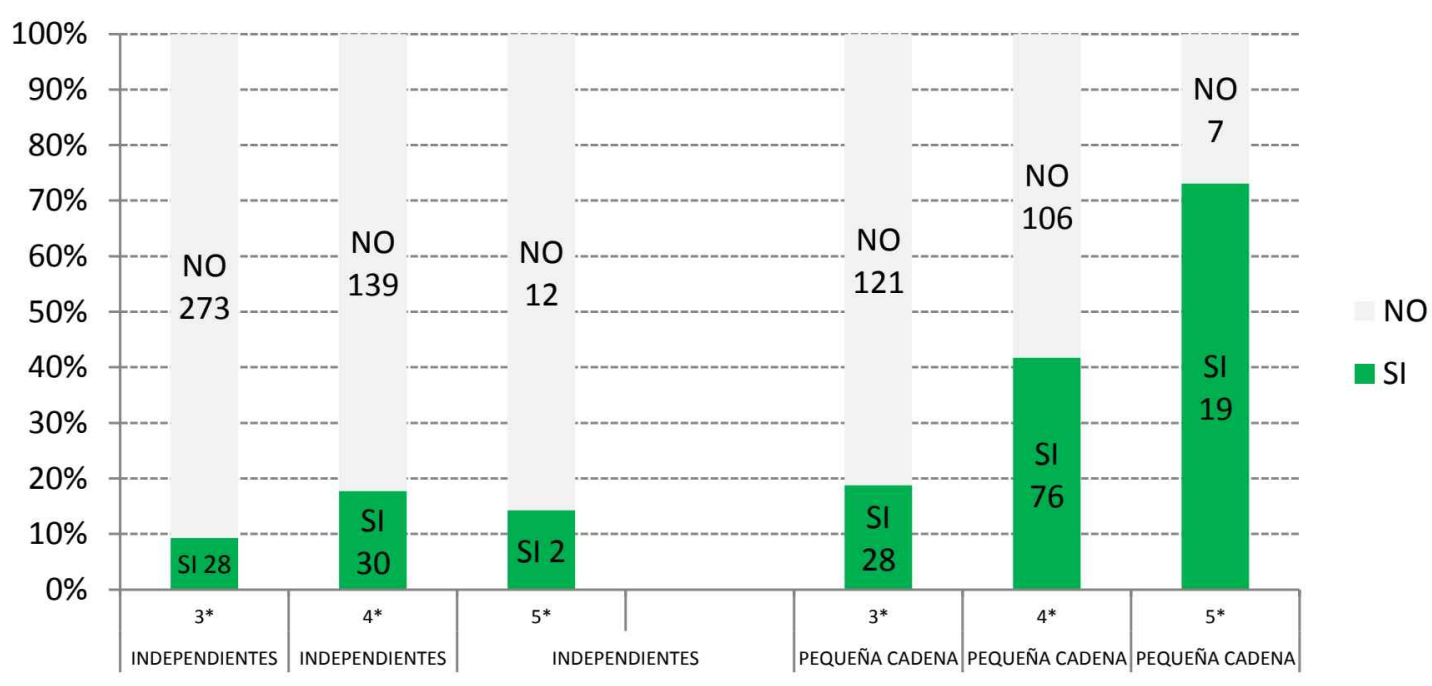

Fuente: Elaboración propia 
Los datos de Flickr resultan similares a los de Twitter y YouTube. Existe una relación, aunque tiene la excepción de nuevo en los hoteles independientes de 5 estrellas.

Gráfico 22. Uso de Flickr

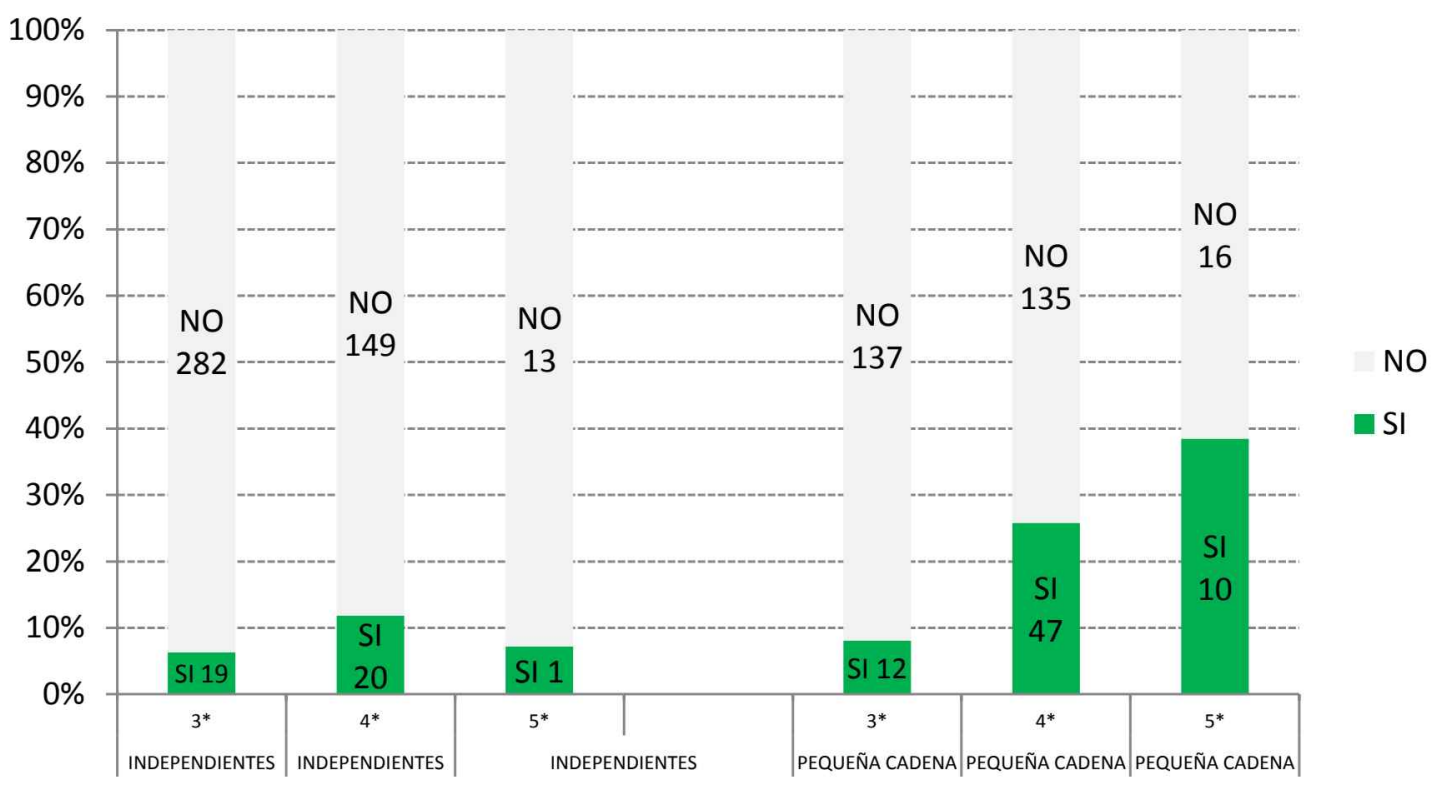

Fuente: Elaboración propia

\subsection{Conclusiones}

Se ha descrito la gran relevancia que tiene Internet en la sociedad actual y la importancia de las redes sociales en el uso que hacen los internautas de la web. En lo relativo al turismo, la interrelación con esta nueva realidad online, es mayor que en cualquier otro sector económico, lo que debería tener consecuencias inmediatas en la incorporación de los hoteles a las redes sociales. Estas evidencias hacen que la mayoría de los hoteles entiendan que resulta recomendable estar en las redes sociales, igual que en su momento entendieron que resultaba imprescindible tener una página web. Las grandes cadenas hoteleras han asumido esta realidad en su inmensa mayoría, pero aproximadamente un tercio del resto de hoteles no acaban de incorporarse a las redes sociales.

Mediante el uso de tres criterios objetivos y medibles, que detectan errores evidentes en la gestión de redes sociales, se ha logrado identificar 
aquellos que hacen un uso inadecuado de las mismas. El hecho de que la presencia en éstas sea básicamente gratuita y que su manejo sea relativamente sencillo, hace más fácil que esta incorporación se produzca de forma rápida y masiva. Pero observamos como también provoca que la presencia de hoteles independientes y de pequeñas cadenas en redes sociales presente graves deficiencias, siendo especialmente alto el porcentaje de uso inadecuado en el caso de los hoteles independientes. Ambos datos confirman la hipótesis $\mathrm{H}_{13}$ sobre el alto porcentaje de hoteles que hacen un uso inadecuado de las redes sociales.

No cometer ninguno de esos tres errores no significa necesariamente que el hotel no cometa otros también importantes, aunque más difíciles de medir. Si cada uno de los hoteles que, según los criterios utilizados en este estudio actúan de manera adecuada en redes sociales, fuera sometido al juicio de expertos, probablemente las cifras de uso correcto de estas, por parte de los mismos, sería sensiblemente inferior.

Se detectó también que los hoteles con mayor número de estrellas tienden a usar en mayor proporción redes sociales. Además el porcentaje de establecimientos con deficiencias en la gestión de redes sociales (según los criterios establecidos) resulta menor en los hoteles con mayor número de estrellas.

Para un hotel resulta fácil estar en redes sociales de forma muy básica, pero observamos cómo algunos hacen que ese proceso sea aún más fácil, realizando su incorporación sin planificación ni formación alguna en este campo. Además, en demasiadas ocasiones, su trabajo carece de la continuidad necesaria en estas tareas, denotándose un abandono evidente de la actividad en redes sociales, transcurrido un tiempo. Para realizar una gestión en redes sociales mínimamente racional, se debe elegir al personal adecuado, adquirir unos conocimientos básicos y observar lo que hacen otros hoteles.

Los estudios citados sobre el uso de las redes sociales por parte de los hoteles españoles resultan esperanzadores y tremendamente positivos. HostelMarket utiliza el titular "Los Hoteles se enganchan a las Redes Sociales" 
mientras que Europa Press destaca, basándose en el informe ePyme 2011 (Fundetec, 2012), "Las pymes hoteleras son las empresas españolas más activas en redes sociales" (Europa Press, 2012). Este optimismo disminuye con los resultados del presente estudio, que pone de manifiesto, que si bien es cierta dicha presencia, el problema de la falta de rigor en la incorporación de los hoteles independientes y de pequeñas cadenas a las redes sociales es claro.

Entendemos que estos hoteles deben empezar a tomar conciencia de que más de la mitad de sus clientes utiliza Internet para tomar su decisión de compra y que la mayoría de esos clientes internautas son también usuarios de redes sociales. En buena lógica, eso debería conducir a los responsables comerciales de estos establecimientos a ser usuarios avanzados de las herramientas y aplicaciones más populares de la web.

La metodología empleada para la contabilización de empresas que usan redes sociales y la detección de errores en la gestión de páginas de Facebook y Twitter de empresas, también puede ser utilizada en estudios sobre otros sectores económicos. Entendemos que el procedimiento tradicional de envío de encuestas utilizado en los análisis de HostelMarket y ePyme resulta costoso y tedioso ya que, en casos como este, en el que los datos son públicos y de fácil acceso, se pueden obtener de forma rápida y sencilla. Además así se evitan posibles sesgos y se agiliza este tipo de investigaciones. 


\section{RELACIÓN ENTRE EL USO DE REDES SOCIALES Y LA PUNTUACIÓN DE LOS HOTELES}

\subsection{Introducción}

En el capítulo 8, se analizaba como un gran porcentaje de estos establecimientos realiza un uso inadecuado de las principales redes sociales. Partimos en este capítulo, de la hipótesis de que el uso adecuado de estas nuevas herramientas para la promoción de un hotel denota una gestión eficiente. Por el contrario, ignorar esta nueva realidad o implementar su adopción de forma inadecuada, implica ciertas carencias en la gestión del establecimiento hotelero. Consideramos que esa mayor o menor capacidad de gestión del negocio, puesta de manifiesto en el uso de redes sociales, se podría reflejar en la valoración otorgada por los usuarios en sitios web como Booking y TripAdvisor. Estas puntuaciones miden el nivel de satisfacción de los clientes que, principalmente, viene determinada por el correcto desempeño de sus gestores. Teniendo en cuenta esto, se plantea la siguiente hipótesis:

$H_{14}$ : Los hoteles que utilizan redes sociales de forma adecuada son mejor valorados que los que lo hacen de forma deficiente, que a su vez son mejor valorados que los que no hacen uso de estas herramientas.

Nuestro planteamiento no se basa en la idea de que los hoteles, por utilizar redes sociales, consiguen alcanzar una mejor valoración por parte de sus clientes. Exploramos la hipótesis de si optar por no usar redes sociales o no prestar la atención adecuada a su uso, es un reflejo de ciertas carencias en el área de Marketing, sustanciadas en el rechazo o la baja predisposición hacia la adopción de estas nuevas tecnologías.

\subsection{Metodología}

Partimos de la muestra y la base de datos definida en el capítulo 8, de los que ya tenemos tanto sus cifras acerca del uso de redes sociales, como sus puntuaciones en Booking y TripAdvisor. 
Decidimos contrastar esta hipótesis $\mathrm{H}_{14}$, no solo para la globalidad de la muestra seleccionada, sino que utilizamos seis perfiles diferenciados de hoteles, en función del número de estrellas (3, 4 ó 5) y de si son hoteles independientes o pertenecen a una pequeña cadena hotelera. Descartamos los hoteles con menos de 10 opiniones en Booking y TripAdvisor, con lo que la base de datos elaborada queda configurada finalmente por un total de 841 hoteles, de los que 450 son de 3 estrellas, 351 de 4 estrellas y 40 de 5 estrellas. Recopilamos un total de 208.392 opiniones en ambas plataformas, con una media de 124 por hotel en TripAdvisor y 136 en Booking. Repetimos así nuestro análisis en las cuatro redes sociales ya analizadas en el capítulo 8.

\subsection{Resultados}

El análisis inicial de la muestra obtenida, nos da seis grupos de hoteles con un número significativo de observaciones en los grupos de hoteles de 3 y 4 estrellas, que van de 163 a 287 para los hoteles (Tabla 1). Aunque el número mínimo de opiniones por hotel es de 10 (Op.TA y Op.BK), la media en todos los casos está por encima de las 80. En cuanto a las puntuaciones medias obtenidas por cada grupo de hoteles, ha de señalarse que TripAdvisor funciona con un sistema con una puntuación máxima de 5 , mientras en el caso de Booking es 10.

Tabla 31. Distribución de la muestra.

\begin{tabular}{|c|c|c|c|c|c|c|}
\hline \multicolumn{5}{|c|}{} & \multicolumn{5}{c|}{ MEDIA } \\
\hline Agrup. & Estr. & Total & Pt.TA & Cr.TA & Pt.BK & Cr.BK \\
\hline Indep. & $3^{*}$ & 287 & 3,74 & 88,92 & 7,89 & 128,78 \\
\hline Indep. & $4^{*}$ & 174 & 3,76 & 97,70 & 7,88 & 150,56 \\
\hline Indep. & $5^{*}$ & 23 & 3,67 & 100,78 & 7,91 & 130,91 \\
\hline P.cad. & $3^{*}$ & 163 & 3,70 & 146,36 & 7,77 & 155,66 \\
\hline P.cad. & $4^{*}$ & 177 & 3,80 & 187,41 & 7,86 & 115,05 \\
\hline P.cad. & $5^{*}$ & 17 & 4,00 & 191,76 & 8,21 & 126,94 \\
\hline \multicolumn{2}{|c|}{ TOTAL } & $\mathbf{8 4 1}$ & $\mathbf{3 , 7 5}$ & $\mathbf{1 2 5 , 0 4}$ & $\mathbf{7 , 8 6}$ & $\mathbf{1 3 5 , 6 3}$ \\
\hline
\end{tabular}

Fuente: Elaboración propia a partir de datos de TripAdvisor y Booking.

Se observan como las variaciones de puntuaciones entre los diferentes grupos, son aparentemente ínfimas, existiendo cierta tendencia a una mejor 
puntuación cuando el hotel tiene 4 estrellas, en contraposición a cuando tiene 3. No queda tan clara la influencia que tiene en las puntuaciones el pertenecer a una pequeña cadena o ser un hotel independiente.

Observamos como existe una alta concentración de valores (3,5 y 4$)$ en TripAdvisor, obteniendo estas puntuaciones casi dos tercios de los hoteles (Gráfico 1). Este dato es relevante para entender la razón por la que en los grupos de hoteles analizados las puntuaciones medias se encuentran siempre entre estas 2 cifras.

Gráfico 23. Distribución de la muestra en TripAdvisor.

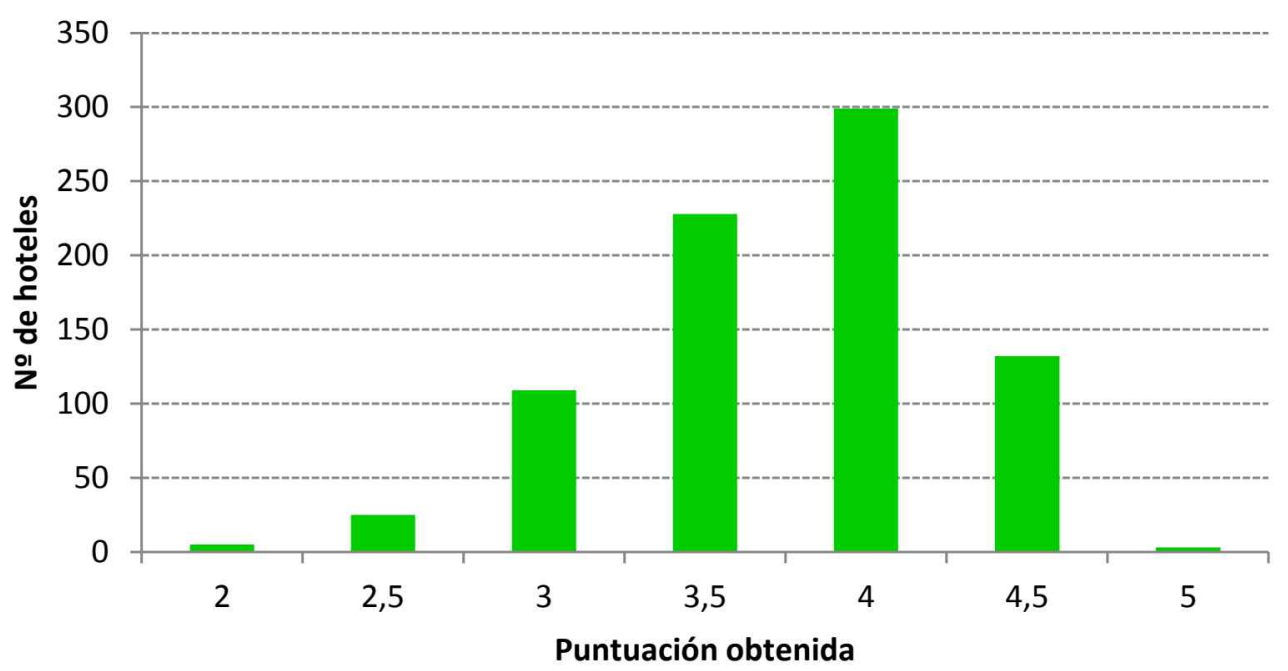

Fuente: Elaboración propia a partir de datos de TripAdvisor

Sucede algo similar con las puntuaciones de Booking, que se concentran en el tramo 7 a 8,5 , que agrupa el $80 \%$ de los hoteles de la muestra (Gráfico 24). De forma análoga al caso de TripAdvisor, esta circunstancia explica que todos los datos medios obtenidos se encuadren en el rango de 7,6 a 8,15. Las diferencias entre las submuestras, aparentemente son mínimas, al existir variaciones de solo unas centésimas. Pero ante las concentraciones descritas en las puntuaciones, esas centésimas pueden significar diferencias sustanciales. 
Gráfico 24. Distribución de la muestra en Booking.

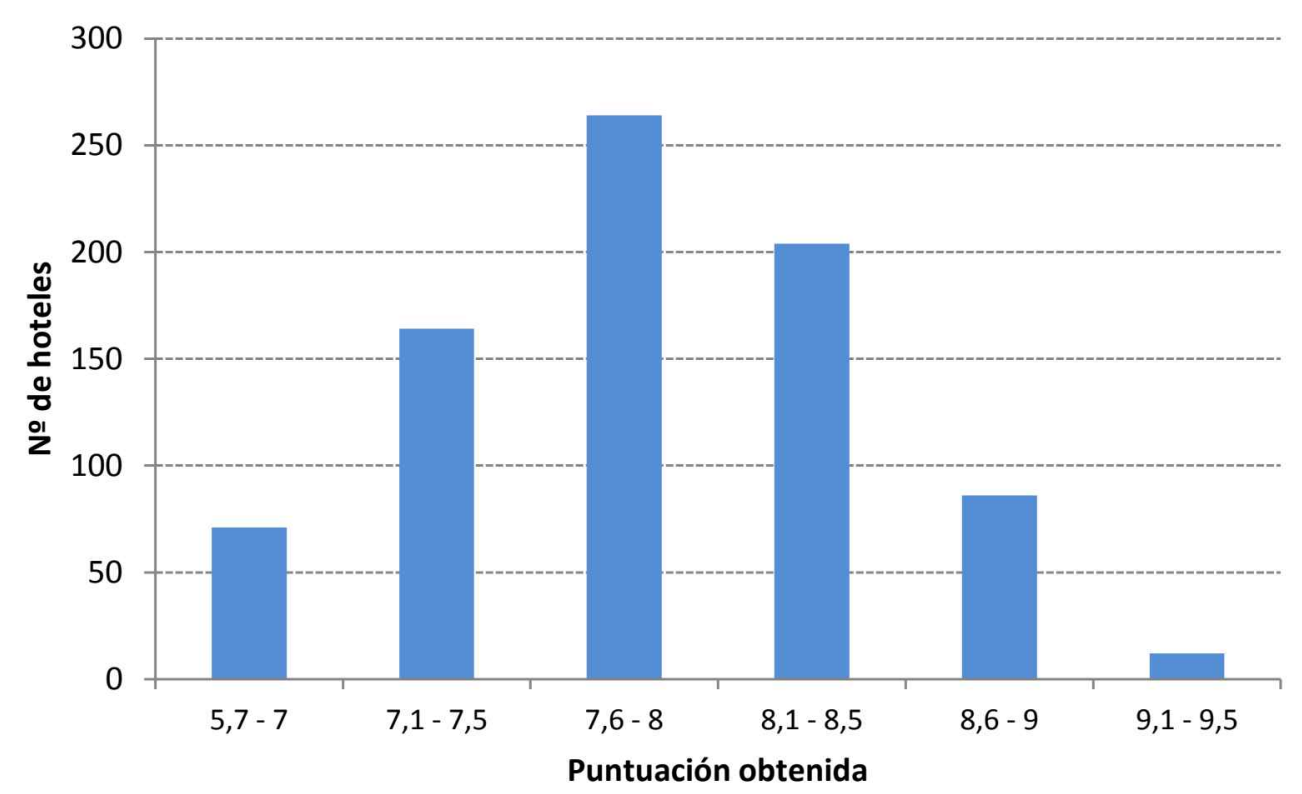

Fuente: Elaboración propia a partir de datos de Booking

En el caso de Facebook (Tabla 32) las diferencias son claras y evidentes entre los hoteles que hacen un uso adecuado de esta red social y los que han decidido no usar esta herramienta. Las diferencias con los datos de Booking son de 28 centésimas, mientras que para TripAdvisor son de 22. En cuanto a las diferencias, cuando se introduce el factor de los hoteles que realizan un uso inadecuado de esta red social, aunque se cumple esta relación de forma global, en los casos de los hoteles independientes, hay dos alteraciones mínimas cuando se usan los datos de TripAdvisor, señaladas en rojo.

Tabla 32. Uso de Facebook por los hoteles.

\begin{tabular}{|c|c|c|c|c|c|c|c|c|c|c|c|}
\hline \multicolumn{10}{|c|}{} & \multicolumn{10}{|c|}{ FACEBOOK } \\
\hline Total & Estr. & Agrup. & $\begin{array}{c}\text { No } \\
\text { usa }\end{array}$ & $\begin{array}{c}\text { Ptos. } \\
\text { BK }\end{array}$ & $\begin{array}{c}\text { Ptos. } \\
\text { TA }\end{array}$ & $\begin{array}{c}\text { Usa } \\
\text { mal }\end{array}$ & $\begin{array}{c}\text { Ptos. } \\
\text { BK }\end{array}$ & $\begin{array}{c}\text { Ptos. } \\
\text { TA }\end{array}$ & $\begin{array}{c}\text { Usa } \\
\text { bien }\end{array}$ & $\begin{array}{c}\text { Ptos. } \\
\text { BK }\end{array}$ & $\begin{array}{c}\text { Ptos. } \\
\text { TA }\end{array}$ \\
\hline 287 & $3^{*}$ & Indep. & 141 & 7,8 & 3,67 & 106 & 7,93 & 3,8 & 40 & 8 & 3,79 \\
\hline 174 & $4^{*}$ & Indep. & 63 & 7,63 & 3,58 & 69 & 7,96 & 3,9 & 42 & 8,1 & 3,81 \\
\hline 23 & $5^{*}$ & Indep. & 3 & 7,73 & 3,5 & 11 & 8,07 & 3,64 & 9 & 7,78 & 3,778 \\
\hline 163 & $3^{*}$ & P.cad. & 71 & 7,6 & 3,56 & 34 & 7,79 & 3,71 & 58 & 7,98 & 3,87 \\
\hline 177 & $4^{*}$ & P.cad. & 53 & 7,73 & 3,66 & 52 & 7,85 & 3,83 & 72 & 7,96 & 3,87 \\
\hline 17 & $5^{*}$ & P.cad. & 3 & 8,63 & 4,33 & 3 & 8,1 & 3,83 & 11 & 8,13 & 3,95 \\
\hline & \multicolumn{2}{|c|}{ TOTAL } & $\mathbf{3 3 4}$ & $\mathbf{7 , 7 2}$ & $\mathbf{3 , 6 3}$ & $\mathbf{2 7 5}$ & $\mathbf{7 , 9 1}$ & $\mathbf{3 , 8 1}$ & $\mathbf{2 3 2}$ & $\mathbf{8 , 0 0}$ & $\mathbf{3 , 8 5}$ \\
\hline
\end{tabular}

Fuente: Elaboración propia. 
Observamos un nivel de consistencia similar en el caso de Twitter, aunque menos pronunciado (Tabla 33). Las diferencias globales entre los hoteles que usan y no usan esta red social es de 17 centésimas para Booking y 12 para TripAdvisor. En los casos de uso inadecuado, también existe una clara relación global, con ligeras anomalías (señaladas en rojo) en dos de los grupos.

Tabla 33. Uso de Twitter por los hoteles.

\begin{tabular}{|c|c|l|c|c|c|c|c|c|c|c|c|}
\hline \multicolumn{10}{|c|}{} & \multicolumn{10}{|c|}{ Thal } \\
\hline Total & Estr. & Agrup. & $\begin{array}{c}\text { No } \\
\text { usa }\end{array}$ & $\begin{array}{c}\text { Ptos. } \\
\text { BK }\end{array}$ & $\begin{array}{c}\text { Ptos. } \\
\text { TA }\end{array}$ & $\begin{array}{c}\text { Usa } \\
\text { mal }\end{array}$ & $\begin{array}{c}\text { Ptos. } \\
\text { BK }\end{array}$ & $\begin{array}{c}\text { Ptos. } \\
\text { TA }\end{array}$ & $\begin{array}{c}\text { Usa } \\
\text { bien }\end{array}$ & $\begin{array}{c}\text { Ptos. } \\
\text { BK }\end{array}$ & $\begin{array}{c}\text { Ptos. } \\
\text { TA }\end{array}$ \\
\hline 287 & $3^{*}$ & Indep. & 241 & 7,86 & 3,72 & 23 & 8,04 & 3,83 & 23 & 8 & 3,76 \\
\hline 174 & $4^{*}$ & Indep. & 122 & 7,78 & 3,69 & 22 & 8,05 & 3,93 & 30 & 8,13 & 3,92 \\
\hline 23 & $5^{*}$ & Indep. & 14 & 7,84 & 3,64 & 7 & 7,96 & 3,64 & 2 & 8,25 & 4 \\
\hline 163 & $3^{*}$ & P.cad. & 103 & 7,7 & 3,67 & 19 & 7,67 & 3,58 & 41 & 7,95 & 3,84 \\
\hline 177 & $4^{*}$ & P.cad. & 103 & 7,82 & 3,79 & 26 & 7,85 & 3,79 & 48 & 7,92 & 3,82 \\
\hline 17 & $5^{*}$ & P.cad. & 7 & 8,49 & 4,07 & 5 & 8,16 & 3,9 & 5 & 7,88 & 4 \\
\hline \multicolumn{2}{|c|}{ TOTAL } & $\mathbf{5 9 0}$ & $\mathbf{7 , 8 2}$ & $\mathbf{3 , 7 2}$ & $\mathbf{1 0 2}$ & $\mathbf{7 , 9 3}$ & $\mathbf{3 , 7 9}$ & $\mathbf{1 4 9}$ & $\mathbf{7 , 9 9}$ & $\mathbf{3 , 8 4}$ \\
\hline
\end{tabular}

Fuente: Elaboración propia.

Tanto para YouTube como para Flickr, vuelven a repetirse datos muy similares (Tablas 34 y 35), con diferencias medias en Booking de 15 y 19 centésimas respectivamente y de 14 y 16 en TripAdvisor. En este caso no se establecen criterios para detectar un mal uso de estas herramientas.

Tabla 34. Uso de YouTube por los hoteles

\begin{tabular}{|c|c|l|c|c|c|c|c|c|}
\hline \multicolumn{1}{|c|}{} & \multicolumn{1}{c|}{ YOUTUBE } \\
\hline Total & Estr. & Agrup. & $\begin{array}{c}\text { No } \\
\text { usa }\end{array}$ & $\begin{array}{c}\text { Ptos. } \\
\text { BK }\end{array}$ & $\begin{array}{c}\text { Ptos. } \\
\text { TA }\end{array}$ & $\begin{array}{c}\text { Usa } \\
\text { bien }\end{array}$ & $\begin{array}{c}\text { Ptos. } \\
\text { BK }\end{array}$ & $\begin{array}{c}\text { Ptos. } \\
\text { TA }\end{array}$ \\
\hline 287 & $3^{*}$ & Indep. & 270 & 7,9 & 3,72 & 17 & 8,15 & 3,97 \\
\hline 174 & $4^{*}$ & Indep. & 140 & 7,85 & 3,74 & 34 & 7,97 & 3,87 \\
\hline 23 & $5^{*}$ & Indep. & 13 & 7,89 & 3,65 & 10 & 7,94 & 3,7 \\
\hline 163 & $3^{*}$ & P.cad. & 121 & 7,71 & 3,69 & 42 & 7,94 & 3,74 \\
\hline 177 & $4^{*}$ & P.cad. & 106 & 7,78 & 3,73 & 71 & 7,97 & 3,9 \\
\hline 17 & $5^{*}$ & P.cad. & 7 & 8,29 & 3,93 & 10 & 8,16 & 4,05 \\
\hline \multicolumn{2}{|c|}{ TOTAL } & $\mathbf{6 5 7}$ & $\mathbf{7 , 8 4}$ & $\mathbf{3 , 7 2}$ & $\mathbf{1 8 4}$ & $\mathbf{7 , 9 9}$ & $\mathbf{3 , 8 6}$ \\
\hline
\end{tabular}

Fuente: Elaboración propia. 
Tabla 35. Uso de Flickr por los hoteles

\begin{tabular}{|c|c|l|c|c|c|c|c|c|}
\hline \multicolumn{10}{|c|}{} & \multicolumn{10}{c|}{ FLICKR } \\
\hline Total & Estr. & Agrup. & $\begin{array}{c}\text { No } \\
\text { usa }\end{array}$ & $\begin{array}{c}\text { Ptos. } \\
\text { BK }\end{array}$ & $\begin{array}{c}\text { Ptos. } \\
\text { TA }\end{array}$ & $\begin{array}{c}\text { Usa } \\
\text { bien }\end{array}$ & $\begin{array}{c}\text { Ptos. } \\
\text { BK }\end{array}$ & $\begin{array}{c}\text { Ptos. } \\
\text { TA }\end{array}$ \\
\hline 287 & $3^{*}$ & Indep. & 268 & 7,88 & 3,72 & 19 & 8,06 & 3,92 \\
\hline 174 & $4^{*}$ & Indep. & 153 & 7,84 & 3,75 & 21 & 8,11 & 3,81 \\
\hline 23 & $5^{*}$ & Indep. & 21 & 7,88 & 3,64 & 2 & 8,3 & 4 \\
\hline 163 & $3^{*}$ & P.cad. & 140 & 7,75 & 3,69 & 23 & 7,91 & 3,78 \\
\hline 177 & $4^{*}$ & P.cad. & 139 & 7,8 & 3,75 & 38 & 8,05 & 3,95 \\
\hline 17 & $5^{*}$ & P.cad. & 9 & 8,4 & 4 & 8 & 8 & 4 \\
\hline & \multicolumn{2}{|c|}{ TOTAL } & $\mathbf{7 3 0}$ & $\mathbf{7 , 8 4}$ & $\mathbf{3 , 7 3}$ & $\mathbf{1 1 1}$ & $\mathbf{8 , 0 3}$ & $\mathbf{3 , 8 9}$ \\
\hline
\end{tabular}

Fuente: Elaboración propia.

Las puntuaciones globales indican, una relación significativa entre el uso correcto de redes sociales y las puntuaciones obtenidas en Booking y TripAdvisor. Los hoteles que menor puntuación media obtienen son los que no usan redes sociales, en los cuatro tipos estudiados, seguidos de los que hacen un uso deficiente, siendo los hoteles que hacen un uso correcto los que obtienen las mejores puntuaciones. De los 80 datos mostrados, únicamente 6 no siguen esta pauta (señalados en rojo), aunque la diferencia no va más allá de las 9 centésimas en ningún caso. Además esas faltas de concordancia puntuales, se refieren a diferencias relacionadas con el uso inadecuado de redes sociales. Pero en todos los casos, se cumple estrictamente la relación entre los hoteles que hacen un uso adecuado de estos sistemas y los que los ignoran.

Al diferenciar entre hoteles independientes y de pequeña cadena, junto al número de estrellas, las conclusiones se repiten en todas las redes sociales para los hoteles de 3, 4 y 5 estrellas, tanto en hoteles independientes como de pequeña cadena, aunque la muestra de los de 5 estrellas es bastante reducida. Cabe destacar que las diferencias entre hoteles, en función de su uso de redes sociales son siempre mayores que las que existen en función de su número de estrellas o su afiliación a un grupo hotelero. 


\subsection{Conclusiones}

Queda por tanto demostrada la relación entre el uso de redes sociales y las puntuaciones obtenidas por los hoteles, por lo que se confirma la hipótesis $\mathrm{H}_{14}$, tanto a nivel global como en cada uno de los grupos de hoteles y redes sociales. La clara correlación entre el uso de cualquiera de estas redes sociales y las valoraciones que obtiene de sus clientes podría venir dada por la capacidad económica de cada establecimiento, con lo que a mayores recursos se tendría mayor facilidad para la implantación de estas tecnologías y podrían prestar servicios de forma más adecuada. Pero entendemos que este planteamiento resulta poco consistente, teniendo en cuenta que, al contrario de lo que sucede con una página web, el uso básico de redes sociales es gratuito y no son necesarios conocimientos de programación informática. Para su uso a nivel empresarial básico, basta con tener unos conocimientos medios como usuario, que se deben complementar con cierta formación fácil de adquirir.

A tenor de los resultados, la interpretación inmediata de los datos podría implicar la conclusión de que el uso de redes sociales incrementa el nivel de satisfacción de los huéspedes. Pero, aunque los números pudieran dar verosimilitud a esa afirmación, la lógica indica que no resulta un razonamiento tan sencillo. Evidentemente, los clientes no van a mostrar mayor satisfacción sobre su estancia en el hotel acerca del nivel de limpieza o amabilidad de los empleados, por el hecho de que éste tenga Facebook o vídeos en YouTube. El uso de las redes sociales resulta de utilidad para la captación de clientes y/o para su fidelización, pero difícilmente contribuirá a variar la percepción de la experiencia real vivida por el huésped durante su estancia.

Consideramos que el uso de redes sociales, más aun cuando se hace de forma adecuada, denota una gestión eficiente de un establecimiento hotelero. El aprovechamiento de estas nuevas herramientas tecnológicas resulta especialmente aconsejable en el sector hotelero, más aún cuando su implementación no requiere de grandes inversiones económicas. Aquellos hoteleros que hacen uso de ellas, muestran una capacidad de adaptación a los cambios en los sistemas de promoción de sus establecimientos, una formación 
mínima en las nuevas tecnologías y una predisposición abierta a los cambios y a la mejora continua.

Por el contrario, aquellos hoteleros que, a pesar de las evidencias, se resisten al uso de las redes sociales, muestran cierta aversión al cambio y una clara apuesta por las fórmulas tradicionales de gestión de sus establecimientos. Este comportamiento puede deberse a una falta de formación de la gerencia o a una escasez de recursos económicos para invertir en la misma.

Generalmente un alto nivel de formación, tanto de la gerencia de la empresa como del personal, junto a una mentalidad abierta a los cambios, utilizando las nuevas herramientas que la tecnología pone en sus manos, favorece una mejora en el servicio. Pero una escasa formación o la aversión a los cambios por parte de un gestor empresarial, suele ir en detrimento de la calidad del mismo. Ambos modelos de gestión se ven reflejados en el uso de redes sociales y obtienen su premio o castigo en las valoraciones que los usuarios hacen en Internet.

Este tipo de análisis es susceptible de ser realizado de forma análoga tomando como factor definitorio de la gestión eficiente de un establecimiento hotelero, otros indicadores tecnológicos alternativos. La existencia de una web correctamente adaptada a los dispositivos móviles, el número de seguidores en Facebook o la prestación de un servicio wifi de conexión a Internet (gratuito o de pago), podrían ser indicativos de una gestión adecuada de un hotel. 


\section{INDICIOS DE ALGUNAS ANOMALÍAS EN LAS PUNTUACIONES DE HOTELES EN TRIPADVISOR}

\subsection{Introducción}

TripAdvisor manifiesta contar con métodos de control que evitan la inclusión de contenido fraudulento, basadas en controles automatizados y manuales de las opiniones que entran en el portal. Pero los métodos de control que pueda imponer, simplemente consiguen dificultar la inclusión de opiniones falsas o limitar su número, no evitarlas totalmente.

En el caso de Booking, su procedimiento de captación de opiniones dificulta la inclusión de opiniones fraudulentas, ya que sólo aquellos clientes que se han alojado y han pagado su estancia pueden aportar contenidos. Tomando los datos de Booking como fiables y comparándolos con los obtenidos para una serie de hoteles en TripAdvisor, es posible realizar un acercamiento cuantitativo a la problemática de las opiniones manipuladas. Los hoteles cuyas puntuaciones no sean similares en ambas webs, quedarían automáticamente señalados. Si esta circunstancia se repitiera con una alta frecuencia podríamos cuestionar la fiabilidad del sistema en su conjunto.

\subsection{Metodología y muestra}

Partimos de un artículo (Mayzlin et al., 2012) en el que sus autores comparaban las puntuaciones obtenidas en TripAdvisor y Expedia para un grupo de 2.931 hoteles de Estados Unidos. El estudio incide en la dificultad para introducir opiniones falsas en un sistema como el de Expedia, frente a la relativa facilidad para hacerlo en sistemas como el de TripAdvisor. En base a esto, utilizan el sistema de Expedia como referencia fiable asumiendo que, de no existir manipulación en TripAdvisor, las puntuaciones en ambas webs deben ser similares. En este caso, son capaces de detectar que los hoteles independientes o de pequeñas cadenas, así como los que tienen otros establecimientos cercanos, son más propensos a generar opiniones manipuladas. Estos hoteles tienen mayor número de puntuaciones extremadamente positivas en TripAdvisor que en Expedia. De igual forma los 
hoteles cercanos tienen mayor número de puntuaciones extremadamente negativas en TripAdvisor.

Expedia utiliza un sistema de opiniones verificadas, similar al de Booking. Como se ha indicado anteriormente, resulta más recomendable el uso de Booking para este tipo de estudios en el mercado europeo, debido al volumen de opiniones que registra. HotelReporting es una empresa especializada en gestionar comentarios de los huéspedes de hoteles, que en Septiembre de 2012 publicó los resultados de un estudio (HotelReporting, 2012) en el que comparaba las puntuaciones obtenidas por 230 hoteles de 4 estrellas, con más de 100 opiniones cada uno, en Booking y TripAdvisor. Los resultados indicaron que no existían diferencias significativas entre uno y otro sistema con solamente un $1,87 \%$ de diferencia entre ambos. Aunque las conclusiones obtenidas son ciertamente interesantes, este tipo de metodología no permite detectar que opiniones concretas son manipuladas, ni tan si quiera establecer un porcentaje hoteles con puntuaciones anómalas, simplemente pone de manifiesto las escasa diferencias entre ambos sistemas, cuando analizamos hoteles con un volumen de opiniones alto.

Entendemos que el uso de este tipo de metodologías, puede ayudar a aportar luz sobre un tema, alrededor del cual hay tantas dudas y sospechas. Nuestro enfoque, aunque basado en los mismos principios, se centra más en detectar aquellos valores en las puntuaciones que indican que se ha podido desarrollar una efectiva estrategia de generación artificial de opiniones positivas por parte del hotel o si ha sido víctima de una campaña de opiniones negativas falsas.

Ni TripAdvisor tiene un sistema infalible de detección del fraude, ni los estudios realizados al respecto son capaces de concluir que opiniones concretas son fiables, ni tan siquiera aportar una cifra concreta del porcentaje de opiniones manipuladas existentes. La metodología empleada en este estudio tampoco pretende obtener conclusiones definitivas al respecto, simplemente aportar una visión alternativa que propicie una mejor comprensión de la cuestión. 
Nuestras consideraciones iniciales son similares en su planteamiento a las del estudio del citado estudio (Mayzlin et al., 2012), pero usando como referencia Booking en lugar de Expedia. Utilizamos nuestra base de datos de hoteles de costa españoles y seleccionamos aquellos hoteles que cuentan con un mínimo de 50 opiniones registradas en Booking, para seguidamente realizar una búsqueda de estos hoteles en TripAdvisor, seleccionando únicamente aquellos que también cuentan con un mínimo de 50 opiniones. De esta forma obtenemos una muestra de 660 hoteles con al menos 50 opiniones en ambas webs. Para el caso de TripAdvisor el sistema de puntuación, aunque permite 9 puntuaciones distintas (de 1 a 5 puntos), concentra el $96 \%$ de las puntuaciones en sólo 4, para el caso de nuestra muestra (Gráfico 25). Sin embargo, en el caso de Booking, encontramos puntuaciones que van de 5,6 a 9,4, aunque el $80 \%$ se concentren en el tramo de 7 a 8,5 .

Gráfico 25. Distribución de la muestra en TripAdvisor

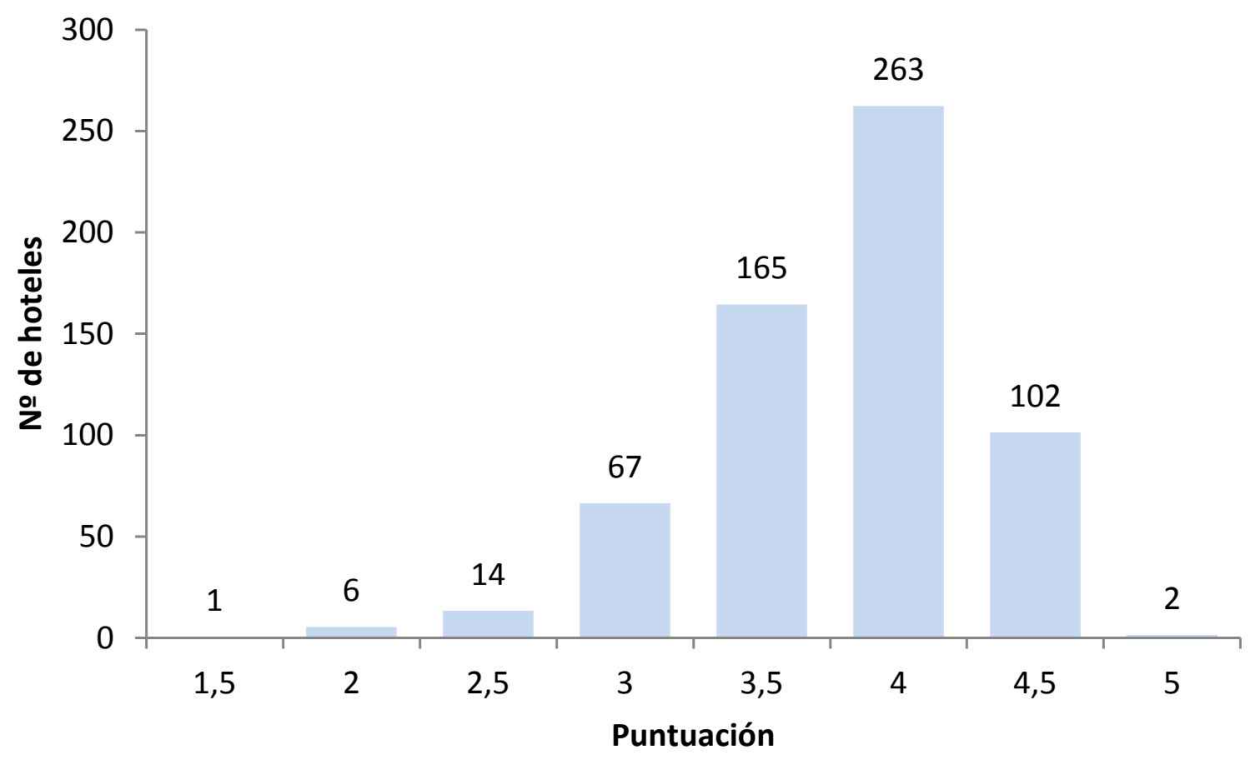

Fuente: Elaboración propia

Resulta evidente que para cada puntuación de TripAdvisor, debería corresponder un rango de puntuaciones en Booking. A mayores puntuaciones en TripAdvisor, corresponderán mayores puntuaciones en Booking, por lo que cualquier valor que no siguiera esta correspondencia, podría indicar la 
posibilidad de un fraude en el sistema. Basándose en este razonamiento, formulamos la siguiente hipótesis:

$\mathrm{H}_{15}$ : Existe un número significativo de hoteles que generan opiniones positivas o reciben negativas a través de prácticas irregulares en TripAdvisor.

Analizamos las distribuciones de frecuencias de los hoteles de los cuatro grupos de puntuaciones en TripAdvisor que representan el 96\% de la muestra. Estos cuatro grupos cuentan con un número mínimo de hoteles, que pueden hacer cada una de las submuestras mínimamente significativas. Realizamos una representación gráfica de la distribución de frecuencias para cada uno de ellos y calculamos una serie de variables estadísticas, que nos permitirán valorar los datos obtenidos.

La representación gráfica de la distribución de frecuencias sugiere que los datos son compatibles con una distribución normal para los citados cuatro grupos, por lo que calculamos la distribución normal teórica resultante y realizamos el correspondiente test de normalidad para medir el nivel de ajuste real. Planteamos que la existencia de fraude o manipulación generalizada, junto a datos reales, no sería compatible con una distribución normal, ya que existirian un gran número de valores que no se ajustarían a este modelo. Los casos de puntuaciones manipuladas aparecerían en los extremos de las distribuciones de frecuencias, en un número tal, que no podríamos hablar de una distribución normal.

\subsection{Resultados}

En los gráficos 26, 27, 28 y 29 se muestran las distribuciones de frecuencias de los resultados obtenidos en cada caso, añadiendo la representación de la distribución normal teórica en cada uno de ellos. 


\section{Gráfico 26. Hoteles con 3 estrellas en TripAdvisor}

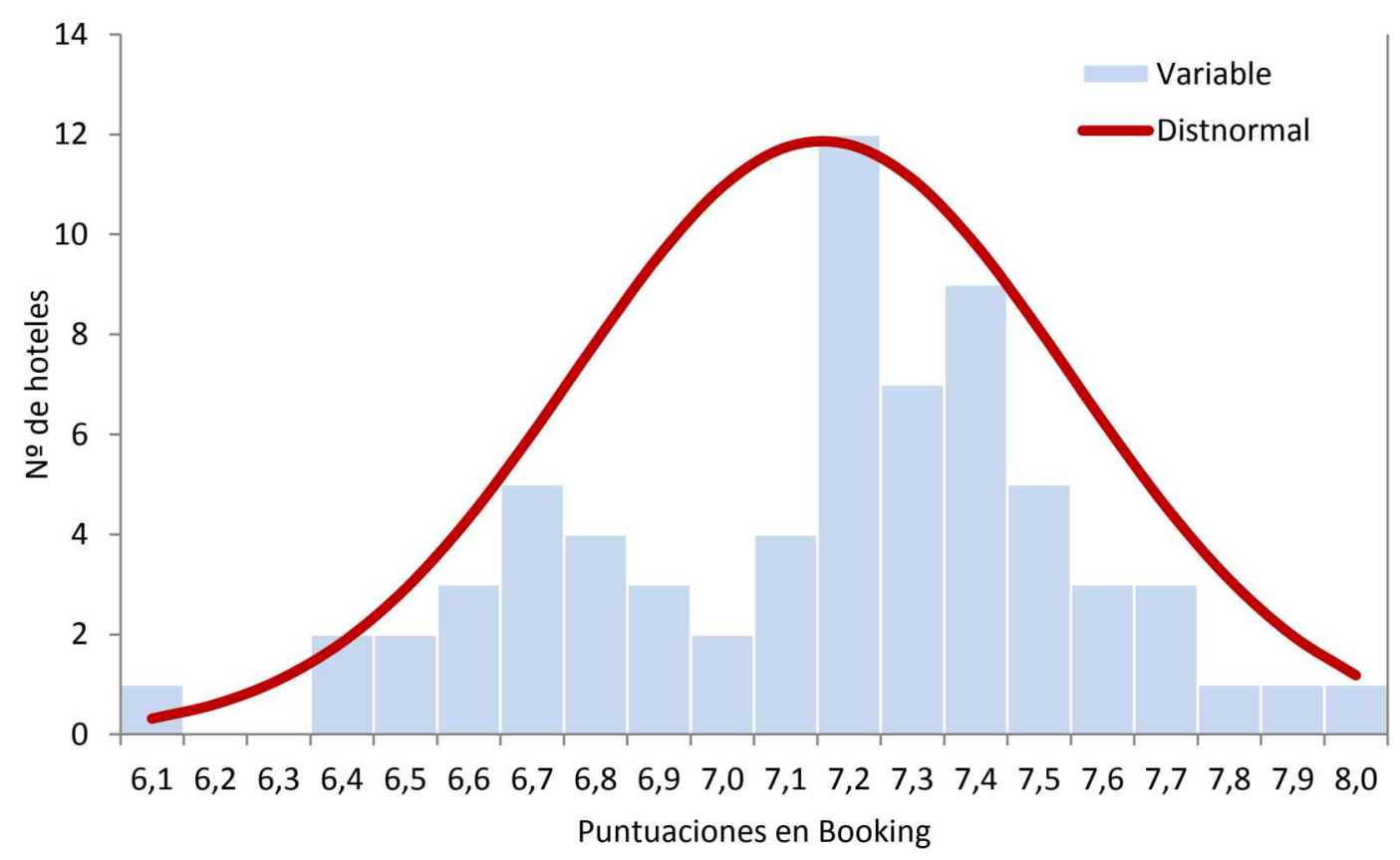

Fuente: Elaboración propia

Gráfico 27. Hoteles con 3,5 estrellas en TripAdvisor

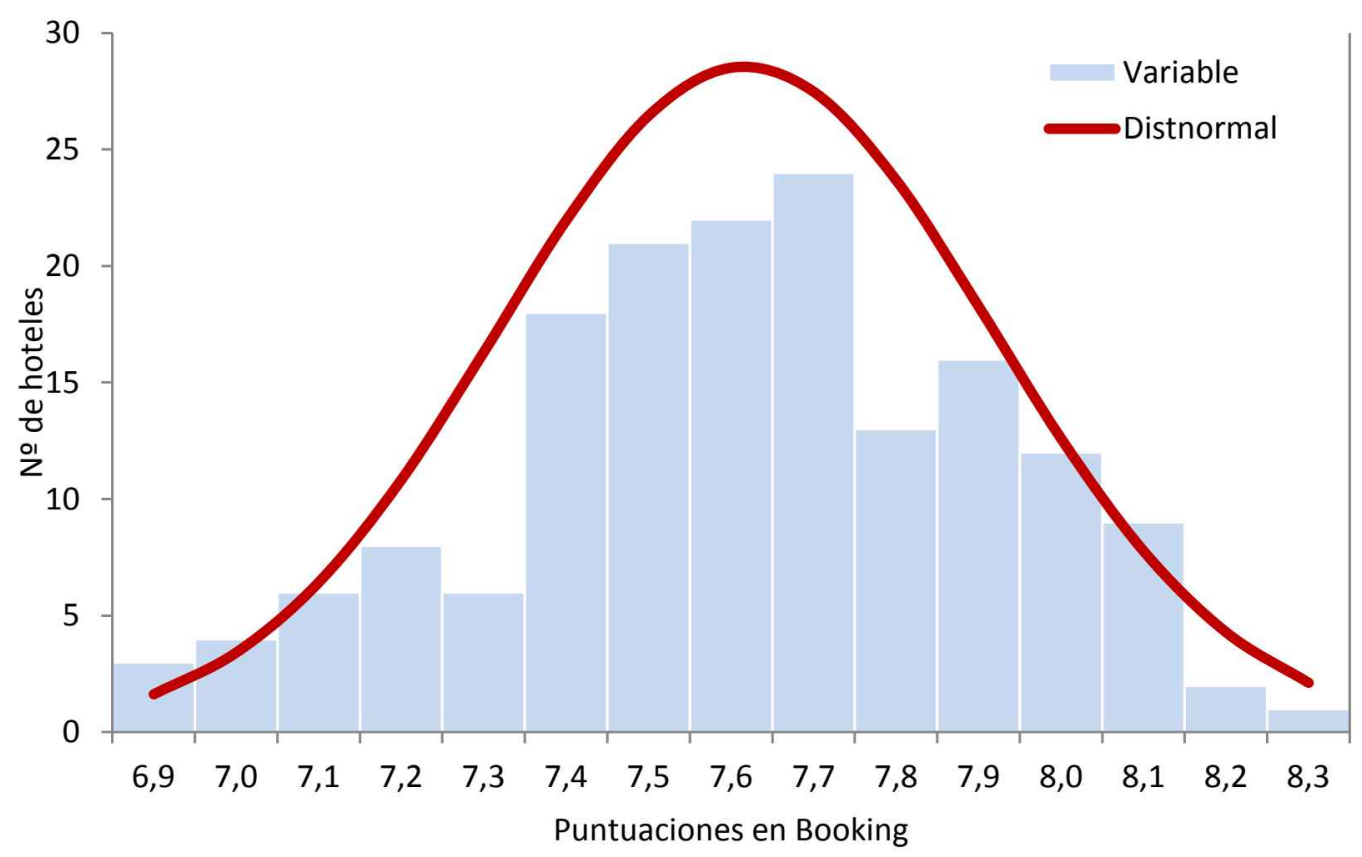

Fuente: Elaboración propia 


\section{Gráfico 28. Hoteles con 4 estrellas en TripAdvisor}

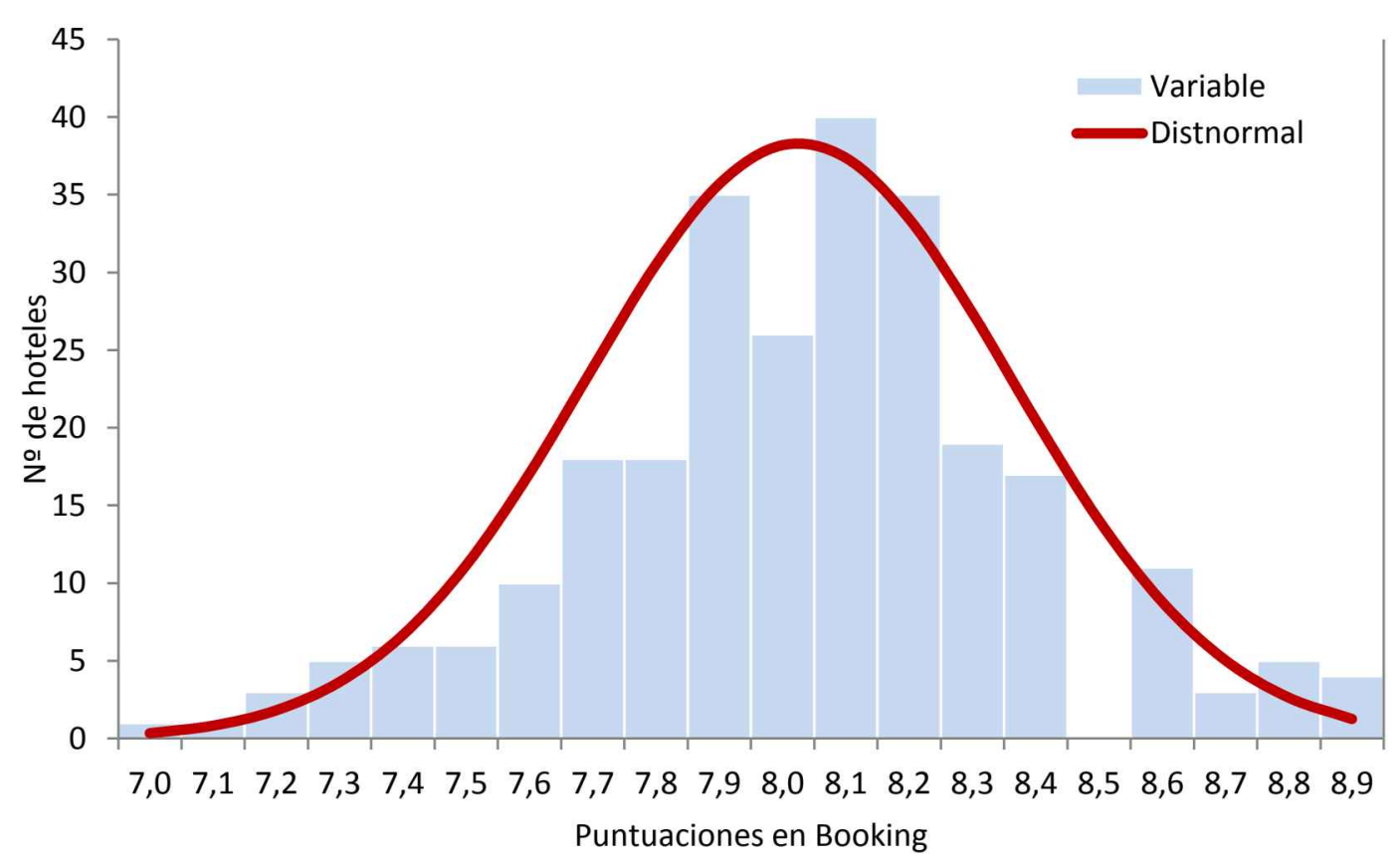

Fuente: Elaboración propia

Gráfico 29. Hoteles con 4,5 estrellas en TripAdvisor

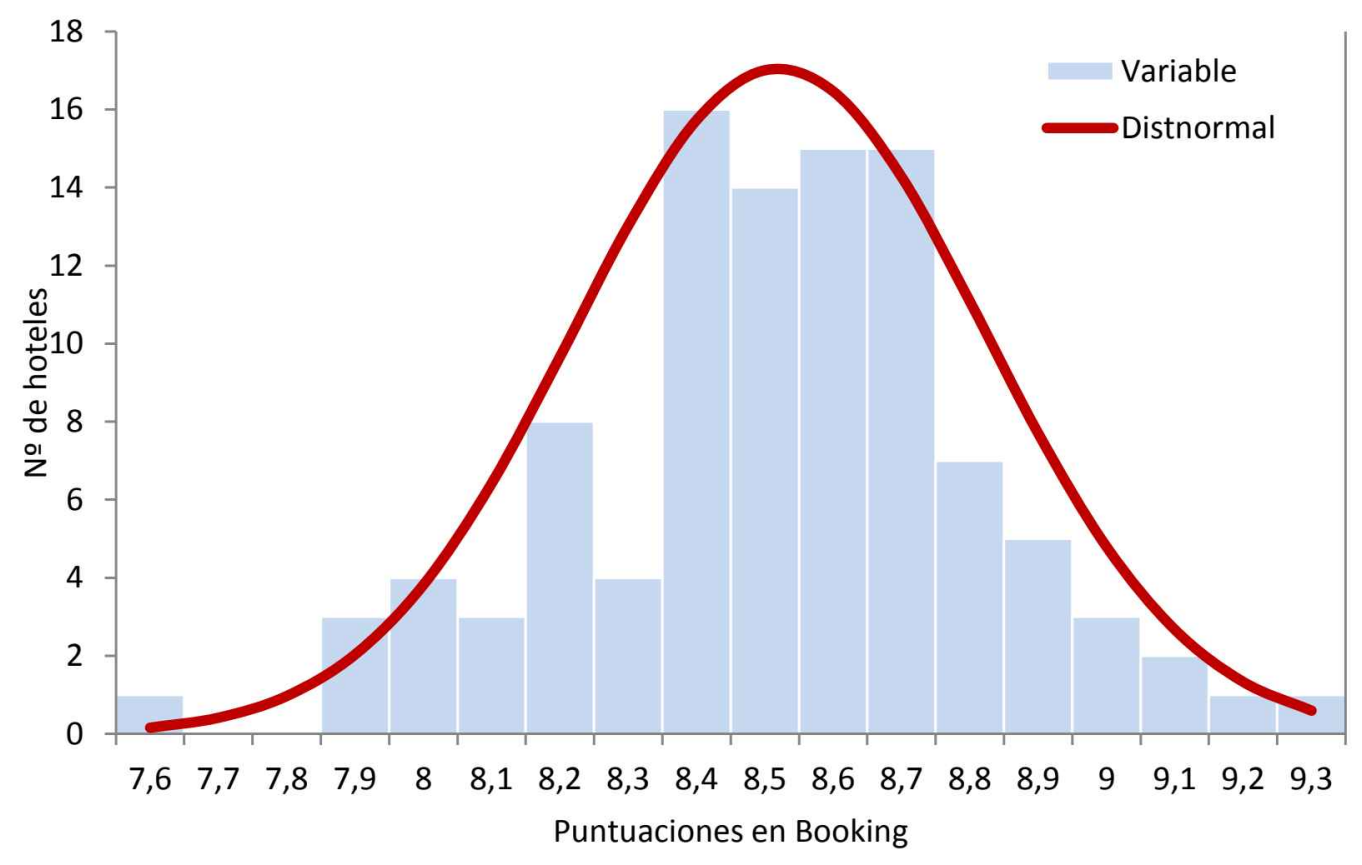

Fuente: Elaboración propia 
Observamos que para la misma puntuación en Booking, puede existir una correspondencia con 2, 3 o incluso 4 categorías diferentes en TripAdvisor. Para una valoración de 8,4 en Booking, relativamente alta, tenemos prácticamente la misma cantidad de hoteles con 4 y con 4,5 en TripAdvisor. Un hotel con un 7,7 de puntuación en Booking, resulta bastante probable que tenga una valoración de 3,5 o 4 en TripAdvisor, aunque también encontramos casos, poco frecuentes, en los que tiene una valoración de 3. Para puntuaciones de 7,9 y 8 , encontramos hoteles con las 4 diferentes puntuaciones de TripAdvisor analizadas, aunque la correspondencia más frecuente es la de 3,5 o 4.

Nos planteamos realizar el test de normalidad para contrastar la hipótesis nula $\left(\mathrm{H}_{0}\right)$ de normalidad de la población en los cuatro tipos de hoteles. Calculamos el estadístico de Prueba de Kolmogorov-Smirnov (KS), y lo comparamos con los valores críticos $D(n, \alpha)$ de este estadístico que están tabulados en la tabla correspondiente y comprobamos que se no se puede rechazar la hipótesis de normalidad en todos los casos, con un nivel de significación del $20 \%$ en tres de ellos. (Tabla 36 ).

Tabla 36. Datos estadísticos de las distribuciones

\begin{tabular}{|ccccccccc|} 
& Media & Desviación & Asimetria & $\begin{array}{c}\text { Dmáx } \\
\text { (KS) }\end{array}$ & $n$ & a & Dn, a & $\mathrm{H}_{0}$ \\
\hline $\mathbf{3 , 0}$ * & 7,157 & 0,392 & $-0,384$ & 0,06939011 & 68 & 0,2 & 0,12975656 & $\mathrm{SI}$ \\
\hline $\mathbf{3 , 5}$ & 7,617 & 0,299 & $-0,231$ & 0,06952327 & 165 & 0,2 & 0,08329939 & $\mathrm{SI}$ \\
\hline $\mathbf{4 , 0} *$ & 8,034 & 0,349 & $-0,253$ & 0,0927112 & 263 & 0,02 & 0,09372722 & $\mathrm{SI}$ \\
\hline $\mathbf{4 , 5} *$ & 8,521 & 0,301 & $-0,220$ & 0,08925278 & 102 & 0,2 & 0,10594579 & $\mathrm{SI}$ \\
\hline
\end{tabular}

Fuente: Elaboración propia

A modo de ejemplo se adjunta el gráfico donde se aprecia de forma visual el resultado positivo del test de normalidad de Kolmogorov-Smirnov (Gráfico 30). 
Gráfico 30. Test de Kolmogorov-Smirnov para hoteles con 3 estrellas

\section{Puntuaciones en Booking}

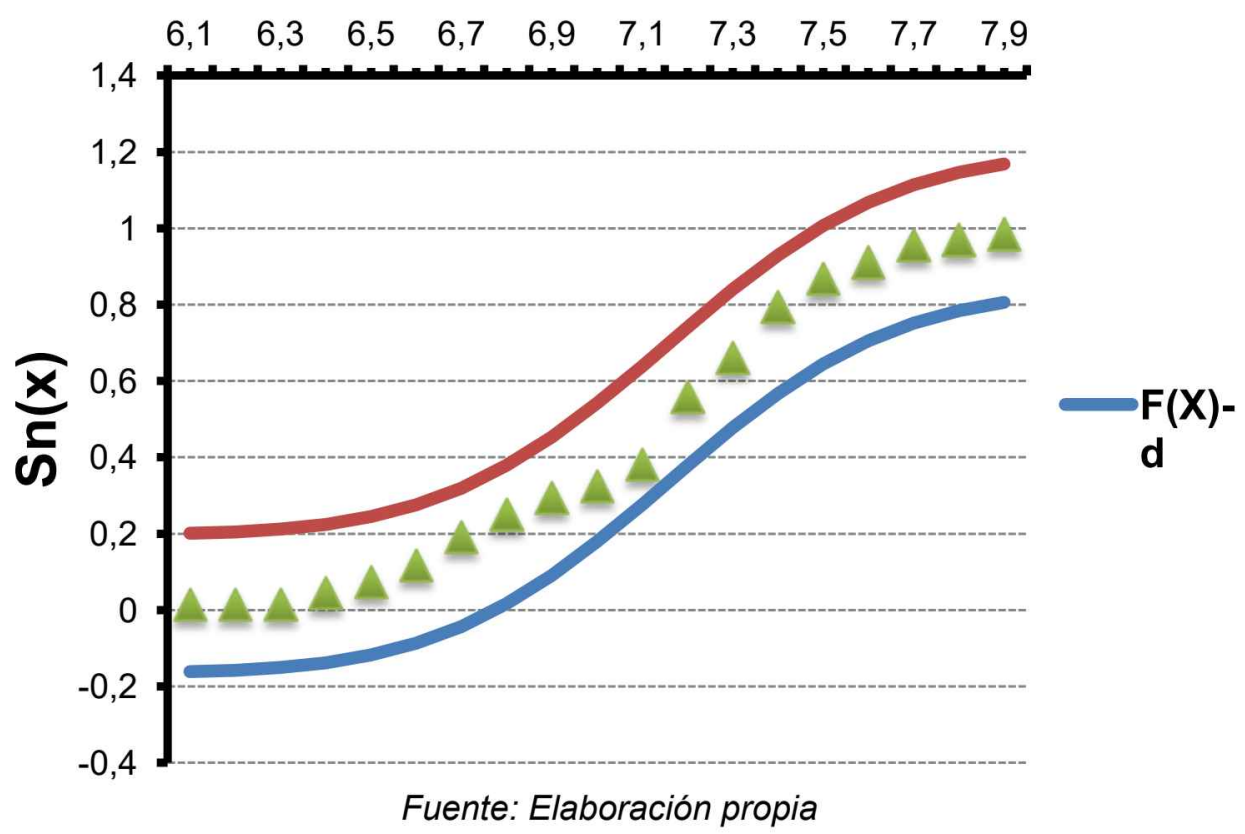

La representación gráfica de los datos no indica una clara asimetria en ningún sentido, pero la aplicación del coeficiente de asimetría, indica una orientación de los datos hacia el lado izquierdo (valores negativos) en los 4 grupos. En todo caso, la observación de las propias gráficas, pone de manifiesto que se trata de una asimetría poco pronunciada.

\subsection{Interpretación de los resultados}

Estos resultados nos permiten elaborar una estrategia que facilite la determinación de los niveles de fraude existentes. Un hotel que genera opiniones positivas contraviniendo la política de TripAdvisor, obtendrá una puntuación media más alta de lo normal. Por ejemplo, un hotel con un 7,2 de puntuación en Booking, actuando de forma correcta hubiera obtenido una puntuación de 3,5 , pero si realiza acciones fraudulentas de forma exitosa deberían proporcionarle puntuaciones de 4 o 4,5.

Por el contrario, si un hotel recibe opiniones negativas generadas de forma irregular, obtendrá una puntuación sensiblemente más baja de lo normal en TripAdvisor si esas opiniones negativas son suficientes y la estrategia de difamación tiene realmente éxito. Un hotel, con un 7,7 en Booking, al que le 
correspondería una puntuación de 4 si no existiesen irregularidades, podría ver como baja su valoración a 3,5 o 3 .

Entendemos que si un hotel ha defraudado en TripAdvisor o ha sufrido un ataque, eso se verá reflejado en la relación de puntuaciones entre TripAdvisor y Booking. Así, los hoteles con éxito en su estrategia fraudulenta, aparecerán en el extremo izquierdo de la distribución de frecuencias para una puntuación concreta en TripAdvisor. Son hoteles que consiguen la misma puntuación que otros en TripAdvisor, pero partiendo de una puntuación mucho más baja que el resto en Booking. En este caso, la mayor parte de los hoteles con una puntuación similar en Booking, están una o dos categorías por debajo en TripAdvisor.

Si por el contrario, el hotel es víctima de una campaña de opiniones negativas fraudulentas, aparecerá en el extremo derecho de la distribución de frecuencias para su puntuación en TripAdvisor. Son hoteles que obtienen menor valoración en TripAdvisor de lo que se podría pensar por su puntuación en Booking.

Estos valores serían los llamados outliers en cada distribución, valores en los extremos de la distribución que pueden indicar la existencia de una irregularidad. Pero al observar las representaciones gráficas, parece que no existen tales outliers, si no valores esperados en los extremos de una distribución normal. De existir un número medianamente significativo de hoteles con prácticas fraudulentas, según se plantea en la hipótesis $H_{15}$, deberían aparecer picos, como los señalados en amarillo en el gráfico 31. Pero al observar las representaciones gráficas, parece que no existen tales valores atípicos, si no valores esperados en los extremos de una distribución normal, lo que supone el rechazo de la hipótesis $\mathrm{H}_{15}$ planteada. 
Gráfico 31. Ejemplo de situación con hoteles sospechosos

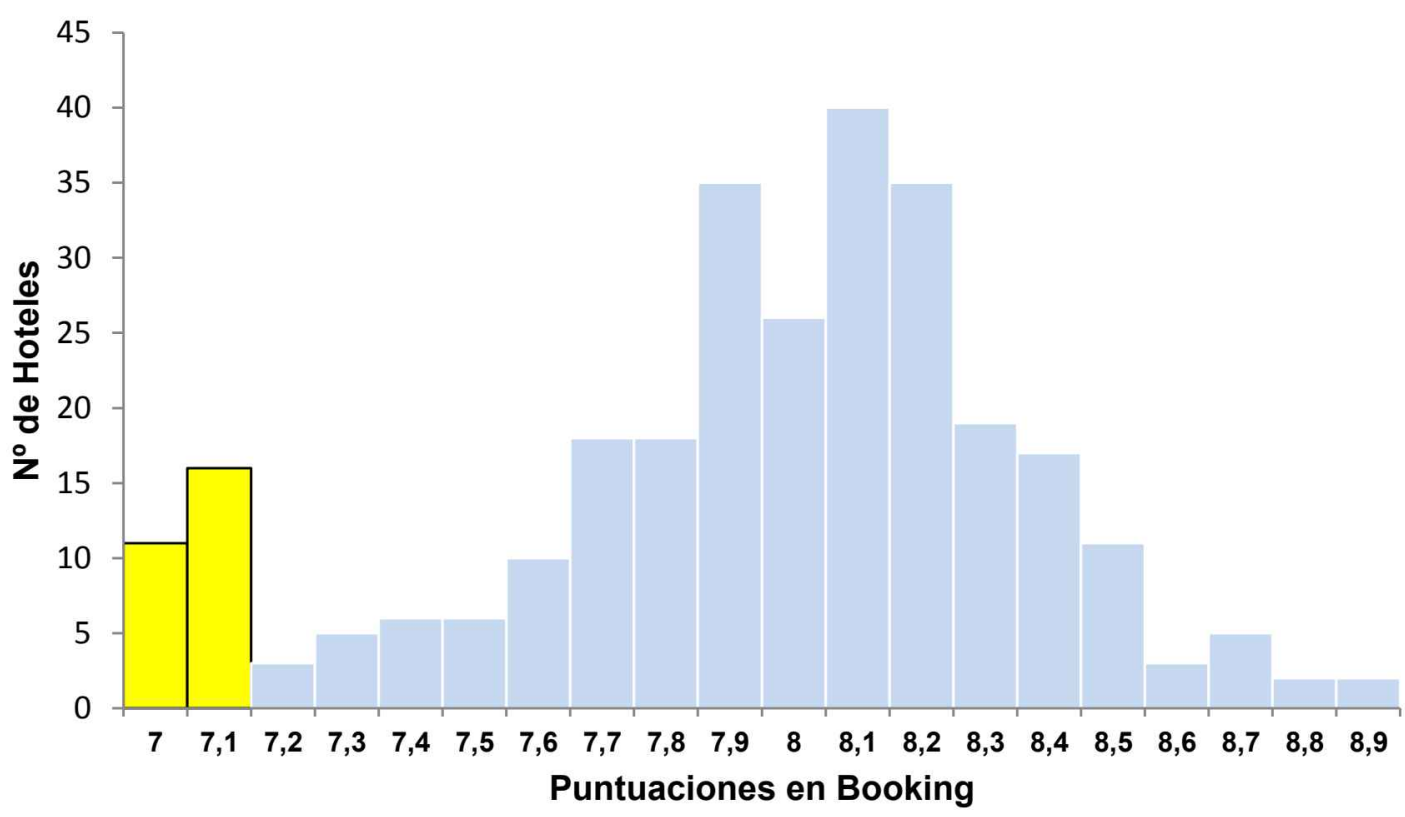

Fuente: Elaboración propia

Consideramos lógico pensar que el posible fraude existente, corresponde principalmente a hoteles que utilizan estrategias irregulares para mejorar sus puntuaciones. Los casos de hoteles que sufren ataques de opiniones negativas por parte de la competencia o de otros agentes malintencionados deberían de ser menos frecuentes, sobre todo porque es más sencillo generar contenido positivo del propio hotel que contenido negativo de varios hoteles de la competencia. Resulta más beneficioso para un hotel generar 10 opiniones positivas sobre su establecimiento, que generar una opinión negativa en cada uno de los 10 competidores directos que tiene. Esta circunstancia, aunque de manera muy débil, parece ponerse de manifiesto en la asimetría detectada para los cuatro grupos analizados.

Teniendo en cuenta todas las alternativas posibles, podriamos considerar que los valores situados en los extremos de cada gráfica no correspondieran a los esperados en una "distribución normal", sino que fueran casos reales de fraude. Pero, aún tomando aquellos casos que están en esos extremos y cuya puntuación en Booking es más propia de una categoría superior o inferior en TripAdvisor, su porcentaje sería mínimo, ya que no irían más allá del 5 o 10\% del total de los hoteles. 
Esta metodología no sirve, de por sí, para identificar los hoteles defraudadores o víctimas de ataques, pero resulta perfectamente válida para descartar sospechas en ambos sentidos. Si las opiniones de un hotel presentan un patrón sospechoso de opiniones positivas, pero su valoración en TripAdvisor es coherente con la obtenida en Booking, habría que descartar la existencia de fraude 0 , al menos, la existencia de un número suficiente de opiniones manipuladas que afecten significativamente su calificación en TripAdvisor. Si un hotel argumenta ser víctima de una campaña de difamación, pero tiene una puntuación en TripAdvisor, que coincide con la mayor parte de los hoteles de su misma puntuación en Booking, podríamos descartar las sospechas de un fraude masivo. El hotel ha podido sufrir de algunas opiniones negativas malintencionadas, pero quedaría demostrado que su escaso número, no ha afectado significativamente a su puntuación en TripAdvisor. Por ejemplo, un hotel con un 7,5 en Booking y con una valoración de 3,5 en TripAdvisor, difícilmente puede ser acusado de generar opiniones fraudulentas de forma generalizada o de ser víctima de ataques de opiniones negativas.

Este mismo procedimiento resulta válido para identificar como "sospechosos" a los hoteles que se sitúan en los extremos de la gráfica. En nuestra muestra, encontramos dos ejemplos claros, que podrían corresponder a este tipo de hoteles. Es el caso de un hotel que con un 6,1 en Booking obtiene una puntuación de 3 en TripAdvisor y de otro que con un 7,6 en Booking, obtiene un 4,5 en TripAdvisor. En todo caso, habria que utilizar un criterio subjetivo, para determinar la amplitud del segmento de hoteles que se podrían etiquetar de esta forma.

Hay que señalar el hecho de que los hoteles de nuestra muestra tienen un mínimo de 50 opiniones registradas, estando la media por encima de las 100, lo que puede contribuir decisivamente a que no se detecte una cantidad apreciable de posibles casos de fraude, ante divergencias entre las puntuaciones de Booking y TripAdvisor. A mayor número de opiniones naturales que tenga un hotel, mayor número de opiniones manipuladas se deben generar para que se produzca un efecto real y palpable en sus valoraciones. El trabajo que esto supone y la posibilidad creciente de ser 
detectado y castigado por TripAdvisor, puede contribuir a que los hoteles eviten estas conductas.

También observamos que, cuando un hotel tiene una puntuación relativamente baja, el efecto de incluir opiniones muy positivas, con un valor de 5 puntos, tiene un mayor efecto que cuando el hotel ya tiene una puntuación alta. En la Figura 30 observamos un ejemplo de cuatro hoteles con puntuaciones diferentes. Insertar diez opiniones de 5 puntos en el caso del hotel de 3 puntos, le llevará probablemente a alcanzar una puntuación de 3,5 o incluso 4. Pero en el caso del hotel con 4 puntos, si inserta el mismo número de opiniones manipuladas, es probable que no sea suficiente para alcanzar los 4,5 de valoración.

Figura 30. Ejemplos de puntuaciones en TripAdvisor

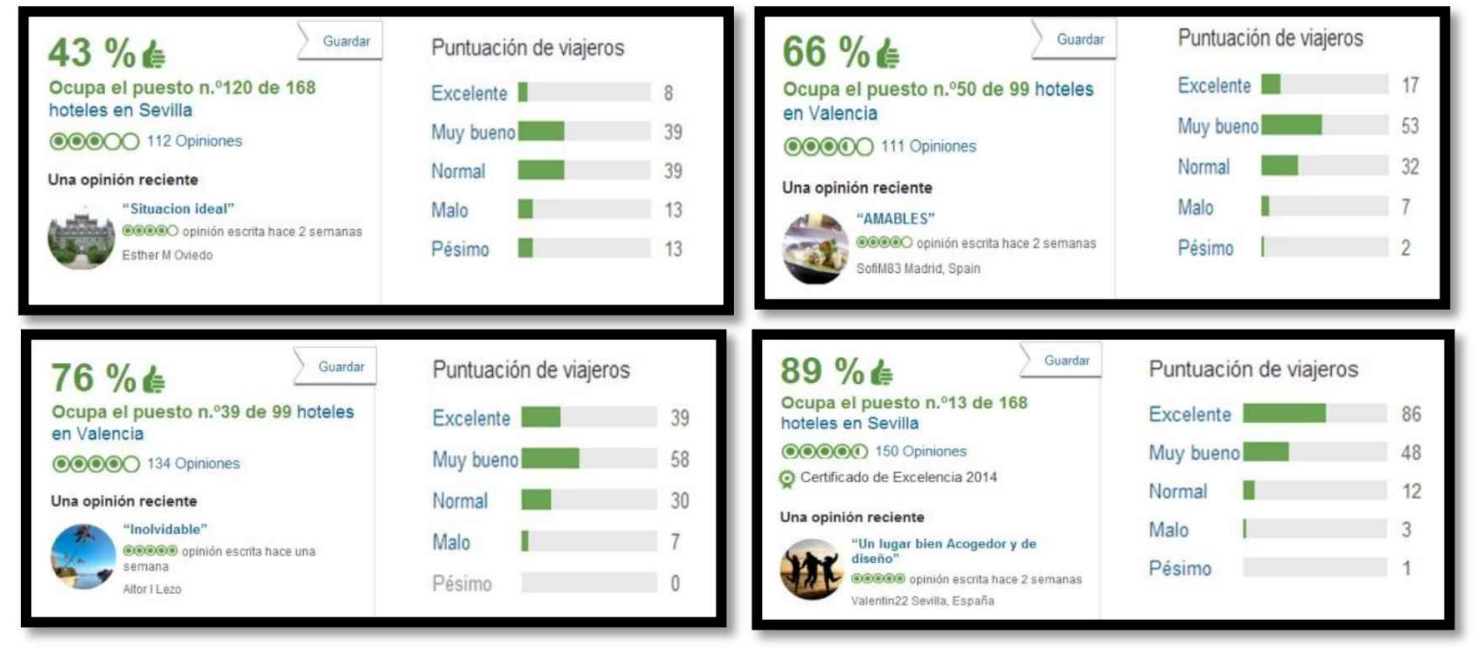

Fuente: Capturas de pantalla de TripAdvisor

\subsection{Conclusiones e implicaciones para el sector hotelero}

La observación e interpretación de los datos obtenidos nos lleva a concluir que, aunque hay indicios de casos de opiniones manipuladas en TripAdvisor, los hoteles con una valoración sustancialmente alterada por esta razón parecen ser muy escasos.

Esta conclusión se limita a hoteles con una cantidad mínima de opiniones registradas, lo que dificulta y hace poco atractivo establecer sistemas de manipulación. En los casos de hoteles con pocas opiniones, en los que la inclusión de un número reducido de opiniones extremadamente positivas, 
puede tener un efecto sustancial, la tentación de actuar de forma irregular puede resultar mucho mayor.

Cuando hablamos de una "valoración sustancialmente alterada" nos referimos a hoteles cuya puntuación es mucho mayor o menor en TripAdvisor de lo que sería si no actuara irregularmente. Los datos nos hacen descartar, casi por completo, los casos de hoteles que debieran tener 3 puntos de valoración y obtienen 4 o 4,5, así como los de hoteles que ven hundida su puntuación por ataques de opiniones manipuladas, con variaciones de un punto o más. Pero estos datos no descartan la existencia de hoteles que, actuando contrariamente a las reglas, aumentan mínimamente su puntuación, como sugiere la ligera asimetría detectada. Nos referimos a hoteles que deberían tener un 3,5 y obtienen un 4 o la de hoteles que por recibir opiniones negativas manipuladas bajan su puntuación también en medio punto.

Por lo tanto no descartamos la existencia de un alto porcentaje de hoteles que pueda actuar de forma inadecuada, simplemente constatamos que, debido al alto número de opiniones registradas, los efectos sobre la valoración final de un establecimiento es mínima. Un usuario de esta web, puede tener cierta seguridad de que un hotel con una alta valoración, en realidad no es un hotel mediocre, que "haciendo trampas", ha conseguido una puntuación excelente. Así mismo los responsables de un hotel con una baja valoración, difícilmente pueden argumentar que esa situación es debida a ataques recibidos por agentes malintencionados.

Es probable que TripAdvisor, dentro de su política de detección de fraude utilice un sistema parecido, que le facilite la identificación de hoteles que deberían ser investigados. En todo caso, esta metodología puede servir como base para aquellos investigadores que, en el ámbito académico, pretendan encaminar sus estudios en este campo. Identificando los hoteles que se encuentran en los extremos de cada distribución de frecuencias, sería posible acotar grupos de hoteles susceptibles de estar generando o recibiendo contenido manipulado. 
Entendemos que para los hoteleros, este análisis puede servir para alcanzar un mayor conocimiento acerca de un tema sobre el que existen muchos "rumores y sospechas" y pocos datos fiables. La utilización de esta metodología, incluso de los datos mostrados, puede ayudar a disipar dudas sobre dos conjeturas recurrentes en el sector, cuando se habla de TripAdvisor:

1) Creer que el hotel propio no obtiene una mejor puntuación global porque una parte de las opiniones negativas recibidas provienen de agentes malintencionados.

2) Creer que los hoteles de la competencia obtienen mejor puntuación que el propio, no por satisfacer de mejor manera a los clientes, sino porque utilizan técnicas contrarias a las normas de TripAdvisor para incrementar artificialmente sus valoraciones.

Para un hotelero, ignorar la información que proporciona TripAdvisor, argumentando la falta de autenticidad de gran parte de los contenidos que aparecen en esta web, no tiene sentido a la vista de estos datos. 


\section{APROXIMACIÓN CUALITATIVA AL PROBLEMA DE LA FIABILIDAD EN TRIPADVISOR}

Se consideró pertinente dedicar un capítulo a profundizar sobre la diversa casuística en torno a la polémica sobre la existencia de contenido manipulado en TripAdvisor. En este caso, abordamos el problema desde un enfoque descriptivo y principalmente cualitativo.

Los repetidos intentos de pervertir el sistema, que son descritos a lo largo de este capítulo, son un claro reflejo de la importancia que los hosteleros dan a la imagen que se proyecta sobre los establecimientos en esta web. Así mismo, la difusión que se da en los más destacados medios de comunicación a estos asuntos, evidencia la magnitud del problema, que ha pasado de ser algo meramente anecdótico dentro del sector hostelero a convertirse en un tema de preocupación en el mismo.

\subsection{Introducción}

La aparición de la Web 2.0 ha revolucionado la forma de entender Internet, proporcionando a los usuarios la posibilidad de participar activamente en la red, mediante la aportación de contenidos. Las marcas se ven afectadas por esta nueva realidad, ya que su reputación depende en gran medida de la difusión, de forma incontrolada, de información a través de webs, foros, blogs o redes sociales. A la combinación de la información plasmada por las marcas en la red, junto al contenido generado por usuarios ajenos a la empresa es lo que se conoce como reputación online.

Paralelamente a la popularización de la Web 2.0 ha surgido el problema de la aportación de opiniones falsas sobre bienes y servicios. Algunas marcas pretenden mejorar dicha reputación online mediante la aportación de opiniones favorables sobre sus productos y/o negativas sobre los de la competencia. En otros casos, usuarios con diversas motivaciones, emprenden campañas de desprestigio a través de críticas negativas masivas. En todos los casos, los que emplean este tipo de técnicas tratan de defraudar al resto de miembros de la comunidad, adoptando diferentes identidades falsas que les permiten 
permanecer en el anonimato. Es un problema tratado ampliamente por la literatura científica en los últimos años y que recogimos en el apartado 3.2.3, que abarca diversos sectores, entre los que destaca el turístico.

Según la información proporcionada en su propia web, TripAdvisor es "la web de viajes más grande del mundo" y "proporciona consejos fiables de viajeros reales". No existen dudas sobre su relevancia dentro del mundo de los viajes según indican sus cifras (TripAdvisor, 2014b). Pero no resulta tan clara la fiabilidad de la totalidad del contenido generado por sus usuarios, ya que cualquier internauta puede registrarse en esta web y aportar información veraz o falsa sobre hoteles en los que ha podido estar alojado o sin haberlo hecho. TripAdvisor dice usar sofisticados métodos de control del contenido fraudulento, pero esas medidas simplemente dificultan y limitan la inclusión de opiniones falsas, no las evitan totalmente.

Se pone de manifiesto como los sofisticados métodos de detección de fraude de TripAdvisor no incluyen la lectura por parte de personal cualificado de cada opinión publicada. Así mismo, se describe someramente el procedimiento para escribir opiniones sin ser detectado y se muestran algunos ejemplos de empresas especializadas en este tipo de prácticas irregulares.

Pero lo que TripAdvisor considera "fraude" va más allá de la obvia inclusión de opiniones falsas, detallando una serie de comportamientos que violan su normativa (TripAdvisor, 2011). Analizamos en profundidad dos de estas infracciones:

- Ofrecer incentivos, premios o participación en sorteos a los clientes que den su opinión en TripAdvisor.

- La solicitud de opiniones de forma selectiva únicamente de aquellos huéspedes que tuvieron una experiencia positiva.

En los últimos años han aparecido diversas noticias sobre casos de fraude en TripAdvisor en los medios de comunicación de amplia difusión. Pero desconocemos si se trata de casos "excepcionales" o si, por el contrario, es más habitual en esta web de lo que aparenta y son muchos los hoteles que recurren a estas prácticas. Una búsqueda a través de la web, usando 
básicamente Google, nos ayuda a detectar algunos casos que ilustran esta situación. En base a ello, analizamos hasta qué punto la difusión de esta información negativa puede afectar a la reputación de TripAdvisor.

\subsection{Opiniones incentivadas en TripAdvisor}

\subsubsection{Introducción}

En ocasiones, hoteles o cadenas hoteleras, tratan de aumentar el número de críticas ofreciendo algún tipo de premio o incentivo, contraviniendo las normas generales sobre fraude de TripAdvisor (TripAdvisor, 2011). Además, su propia web cuenta con un apartado específico sobre este asunto titulado "Política de incentivos de TripAdvisor: Por qué premiar las opiniones de los viajeros va en contra de las reglas" (TripAdvisor Insights, 2014).

Aunque TripAdvisor aconseja a los hosteleros animar a los clientes a participar con su opinión, prohíbe expresamente que se ofrezca ningún tipo de regalo o incentivo para conseguirlo. Este tipo de acciones, aunque menos palmarias, también son consideradas como fraude. Nos centramos en esta práctica irregular, especialmente en la realización de sorteos entre clientes que opinan sobre un establecimiento, detectando diversos casos. A modo de ejemplo, se identifican dos hoteles que realizan sorteos de regalos entre los clientes que opinan sobre ellos, solicitando la inclusión de un código específico dentro del comentario realizado, para participar en el concurso. Esta excepcional circunstancia nos permite saber qué opiniones son realizadas para participar en el sorteo.

\subsubsection{Metodología}

Como ya se ha mencionado, planteamos la investigación desde un punto de vista cualitativo principalmente, mostrando diferentes casos en los que hoteles recurren a ofrecer incentivos por escribir opiniones sobre su establecimiento en TripAdvisor. Pero añadimos un enfoque cuantitativo al encontrar dos casos de hoteles en los que es posible saber las opiniones que se han escrito de forma incentivada. 
Para la búsqueda de casos de concursos o promociones utilizamos los buscadores de Google y Twitter. Unimos a la palabra "TripAdvisor" términos como "concurso", "premio", "rifa" o "regalo", repitiendo la operación con sus equivalentes en inglés. Se trata de una metodología sencilla y básica, pero que permite la identificación de varias decenas de casos evidentes, de lo que TripAdvisor considera fraude.

Aunque la normativa de TripAdvisor parece clara, nos sorprende la cantidad de casos evidentes de irregularidades detectados, por lo que creemos oportuno solicitar una confirmación al respecto. Para ello recurrimos a la cuenta oficial de TripAdvisor en Twitter, lo que nos permite obtener una respuesta oficial y pública, que no deja lugar a dudas sobre la interpretación de su normativa.

Detectamos que la mecánica de los concursos consiste básicamente en un sorteo entre todas las opiniones escritas en TripAdvisor. En otros casos se solicita a aquellos usuarios, que hayan escrito una opinión y deseen participar en el sorteo, que envíen por email el enlace de la opinión escrita. Pero en dos de los casos (Hotel Tempo y Beech Hill Hotel), se solicita a los usuarios que introduzcan un código al escribir su opinión (Figura 31). El Hotel Tempo de Bucarest (Rumanía) requiere que los usuarios coloquen el código "THPD" en su opinión. En el caso del Hotel Beech Hill de Windermere (Reino Unido) se solicita colocar el número de reserva en el comentario. 
Figura 31. Códigos para participar en concurso

\section{"great hotel in great area" \\ OOOOO Reviewed January 20, 2011}

Brilliant hospitality throughout, nothing to much trouble for staff. Made welcome on arrival, even offered free new year drinks. Rooms immaculately clean,linen changed daily and breakfast served with a smile. Hotel perfectly situated in centre of town. A LITTLE GEM!! "THPD"

\section{"Comfortable, friendly hotel with stunning views" OOOOO Reviewed 17 September 2013}

We stayed here for 4 nights in Sept 2013 (booking.com ref 961268546) and loved it. It's about 5 mins outside of Bowness so lovely and quiet and away from the main town. There is plenty of free parking - we never had a problem finding space

Fuente: Capturas de pantalla de TripAdvisor

Una vez recopiladas las opiniones incentivadas, las comparamos con el resto de opiniones de cada hotel para comprobar si existen diferencias en sus puntuaciones medias. Aunque las bases de los concursos no especifican que las opiniones deben ser positivas, consideramos que la pérdida de anonimato provocará un sesgo hacia las opiniones más positivas. En base a esto, formulamos la siguiente hipótesis:

$\mathrm{H}_{16}$ : Los usuarios que reciben incentivos por opinar en TripAdvisor escriben opiniones más positivas que el resto de usuarios.

\subsubsection{Casos detectados}

Mediante la mencionada metodología de búsquedas a través de Google y Twitter, detectamos decenas de casos, entre los que destacamos los pertenecientes a cadenas hoteleras, por entenderlos más relevantes que los que corresponden a hoteles o restaurantes independientes. 
La cadena hotelera "Ciutat Hotels" ${ }^{18}$ de Barcelona muestra, tanto en su web como en su página de Facebook, una promoción (Ciutat Hotels, 2014) que consiste en el sorteo de una estancia entre los clientes que escriban una opinión en TripAdvisor. La promoción estuvo vigente al menos hasta Abril de 2014 e incluye un sorteo cada mes. La cadena de hoteles Oasis ${ }^{19}$ (Oasis hotels, 2012) de México, sorteaba entre los huéspedes de sus hoteles, que opinan en TripAdvisor un iPad. En la promoción difundida por Facebook, se muestra el sorteo realizado, que incluye la asistencia de azafatas, ejecutivos y un notario.

La cadena hotelera Dunas ${ }^{20}$ (Dunas Hotels, 2014) ofrece en su web 100 puntos de su programa de fidelización a aquellos clientes que escriban una opinión en TripAdvisor y otras webs. El mismo procedimiento es utilizado por la cadena Playa Senator ${ }^{21}$ (Playa Senator, 2011), que utiliza su página de Facebook y su web para dar a conocer esta promoción.

Por su parte, el complejo hotelero Marina D'or ${ }^{22}$ de Oropesa del Mar en Castellón, creó en 2014 una promoción que premiaba a las agencias de viaje intermediarias que aportasen comentarios en diferentes sitios web, entre los que se encontraba TripAdvisor (Marina D'or, 2014). En este caso existe un ejemplo evidente de un usuario que se identifica como una agencia de viajes, que hace comentarios con la máxima puntuación de tres hoteles del complejo en cuatro días (Figura 32).

\footnotetext{
${ }^{18}$ www.ciutathotels.com: Cuenta con 4 hoteles y un alojamiento de apartamentos en la provincia de Barcelona.

${ }^{19}$ www.oasishotels.com: Cadena con 7 hoteles en Cancún y 2 en Riviera Maya.

${ }^{20}$ www.hotelesdunas.com: Cuenta con 4 hoteles en Gran Canaria.

${ }^{21}$ www.playasenator.com: Cuenta con 30 hoteles en Península y Canarias.

${ }^{22}$ www.marinador.com: Complejo de ocio con 5 hoteles y alquiler de apartamentos.
} 
Figura 32. Ejemplo de participación en concurso de Marina D'Or

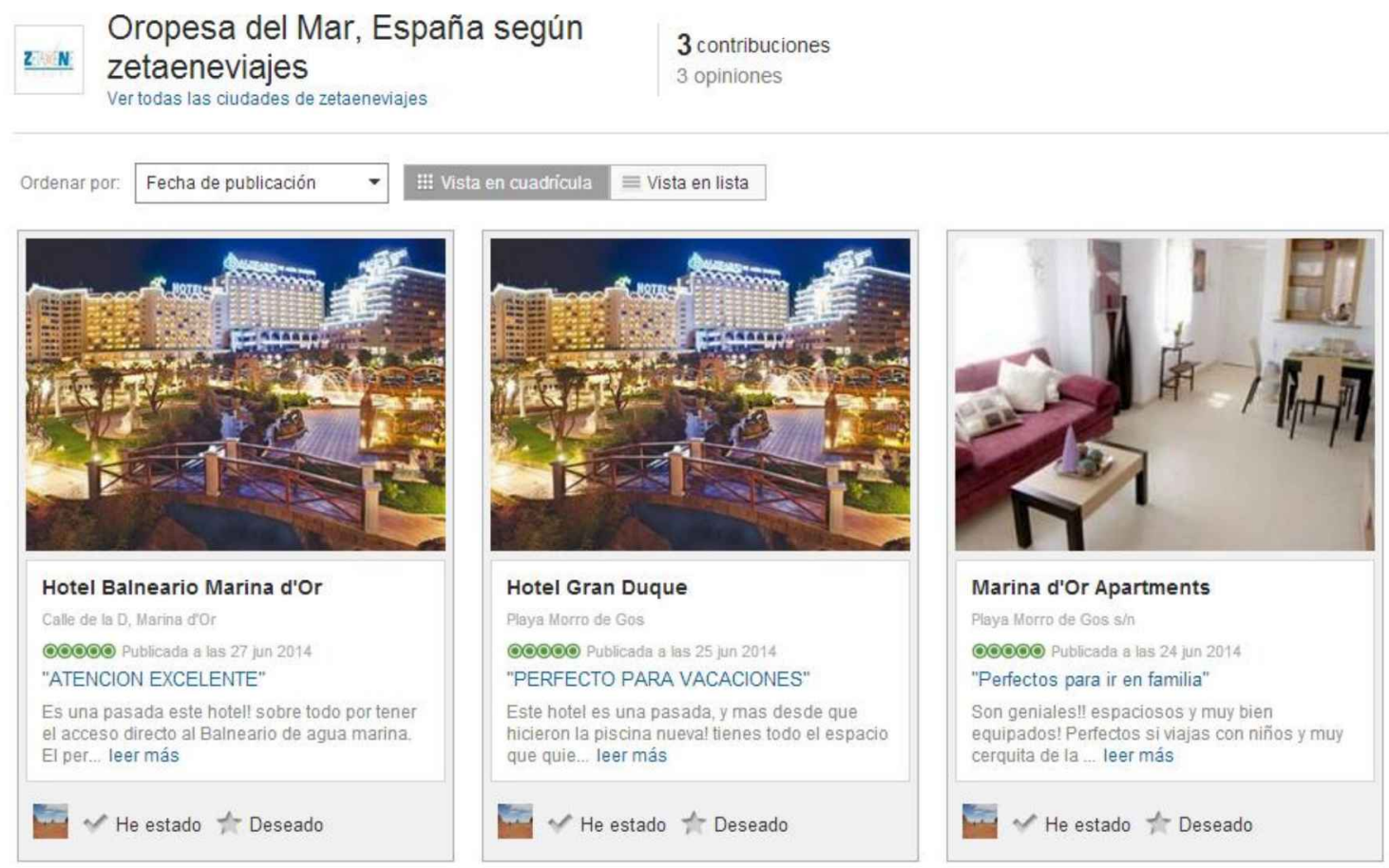

Fuente: http://www.tripadvisor.es/members-citypage/zetaeneviajes/g1025029

El Holiday Inn ${ }^{23}$ Hotel \& Suites Raleigh - Cary (Holiday Inn, 2011) de Carolina del Norte (EE.UU), distribuyó una tarjeta entre sus clientes invitándoles a escribir en TripAdvisor a cambio de 1.000 puntos de su programa de fidelización de clientes. En este caso, un viajero realizó un fotografía (de baja calidad) y explicó su experiencia al respecto en su comentario sobre el hotel en cuestión: "...Also they have a neat little flyer bribing people for 1000 points to leave positive reviews on this website..."24. El Renaissance Dallas Hotel $^{25}$ (EE.UU.) también ofrecía 5.000 puntos en el programa de fidelización de Marriott por el mismo concepto (Renaissance, 2011). La opinión del usuario que subió la foto a su comentario de TripAdvisor también muestra su disconformidad al respecto "Didn't like the bribe in the lounge on the computer to get guests to "enhance" the Tripadvisor rating, not playing fair."26

\footnotetext{
${ }^{23}$ www.holidayinn.com: Esta cadena hotelera cuenta con más de 3.000 hoteles en todo el mundo.

24 "También tiene un pequeño folleto para "sobornar" a la gente, a cambio de 1.000 puntos, por escribir opiniones positivas."

${ }^{25}$ renaissance-hotels.marriott.com: Cadena de hoteles, perteneciente al grupo Marriott, que cuenta con más de 100 hoteles en el mundo.

26 "No me gustó la hoja tratando de sobornar junto a los ordenadores de la planta principal, tratando de mejorar sus puntuaciones, no juegan limpio"
} 
Otro ejemplo similar lo encontramos en el hotel Howard Johnson ${ }^{27}$ Inn and Suites Central de San Antonio (Texas). El usuario explica claramente en su comentario de TripAdvisor el malestar que le causa la tarjeta en la que se le ofrece un descuento por escribir una opinión: "They apparently are offering discounts for people who give them good reviews on Trip Advisor. I can't say that ALL of the "perfect scores" people have given them here are a direct result of that, but if they are.....be prepared to be disappointed."28 (Howard Johnson, 2013). El InterContinental ${ }^{29}$ Hotel de Toronto (Canadá) ofrecía a sus clientes una habitación de mayor categoría a la contratada en su próxima estancia, si dejaban un comentario en TripAdvisor (Gilbreath, 2010).

Otros hoteles, en este caso independientes, repiten prácticas similares en diversos países. EI LX boutique hotel (LX, 2014) de Lisboa, sorteaba estancias de dos noches entre los clientes que escriben sobre el establecimiento, a través de una promoción en Twitter y Facebook. El hotel Villa Gesell (Villa Gesell, 2013) de Argentina sorteaba una estancia de fin de semana, también usando Facebook y Twitter como vías de difusión. El hotel Mariscal Robledo (Mariscal Robledo, 2013) de Santa Fé de Antioquía en Colombia sorteaba cada mes 3 magníficos premios entre los clientes que les siguen en redes sociales y además escriben en TripAdvisor sobre el establecimiento. El hotel Las Cumbres (Las Cumbres, 2014) de Punta del Este en Uruguay ofrecía diversos premios a los que juzga como mejores comentarios en TripAdvisor. El hotel Marina Suites (Marina suites, 2012) de Gran Canaria sorteaba entre los clientes que escriben opiniones en TripAdvisor y Google Maps, una estancia de 5 noches, difundiendo la promoción en su web y redes sociales.

Encontramos 70 casos más, en los que distintos establecimientos ofrecen algún tipo de obsequio o la posibilidad de entrar en un sorteo a los clientes que escriban en TripAdvisor. En el Anexo 3 se muestran las entradas en Twitter (tweets) de cada uno de los casos, facilitando de esta forma el acceso a los detalles de cada una de las promociones.

\footnotetext{
${ }^{27}$ www.hojo.com: Cadena hotelera que cuenta con más de 100 moteles y hoteles en todo el mundo.

28 "Al parecer, están ofreciendo descuentos para las personas que les dan buenas críticas en Tripadvisor. No puedo decir que todas las "puntuaciones perfectas" la gente les ha dado son por esto, pero si son ..... prepárate para la decepción"

${ }^{29}$ www.ihg.com: Cadena de hoteles de lujo, con más de 200 establecimientos en todo el mundo.
} 


\subsubsection{Verificaciones a través de Twitter}

Según plantea su propia normativa, resulta bastante evidente que los casi 100 casos descritos, corresponden a lo que TripAdvisor describe como fraude cuando dice "...Ofreciendo incentivos como descuentos, mejoras en la categoría de las habitaciones o cualquier otro trato especial a cambio de opiniones..." (TripAdvisor, 2011). Ante tal cantidad de incidencias, cuya detección no es muy difícil, resulta extraño que la empresa no actúe de acuerdo a su política de "tolerancia cero" ante cualquier tipo de situación irregular.

Por esta razón nos pusimos en contacto con TripAdvisor, a través de su cuenta oficial de Twitter en España y pusimos en su conocimiento dos casos de diferente tipología. En el primero un hotel ofrece una ventaja (Wifi gratis) a aquellos clientes que dan su opinión en TripAdvisor y el segundo caso un restaurante ofrece participar en el sorteo de una cena, a cambio de una opinión.

En la Figura 33 podemos observar la promoción publicada en la página de Facebook y Twitter de la cadena hotelera Poseidón ${ }^{30}$ en Agosto de 2012.

Figura 33. Promoción de Poseidón Hoteles publicada en Facebook y Twitter

Hoteles Poseidon@hotelesposeidon.2 de ago.de 2012

Si haces un comentario en TripAdvisor de unos de nuestros hoteles, durante tu estancia te REGALAMOS 3 HORAS DE... fb.me/1R0E0KY1Q Abrir

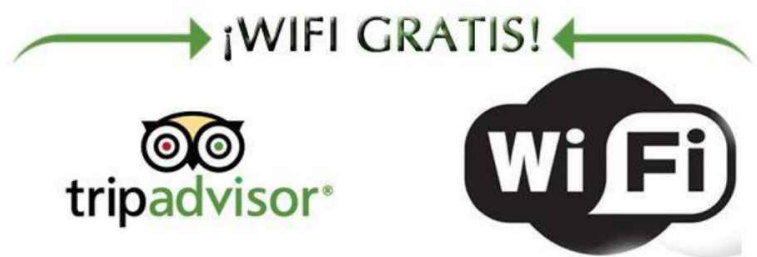

SI DAS TU OPINIÓN EN TRIPADVISOR DE NUESTROS HOTELES, ESCRÍBENOS UN MENSAJE CON EL ENLACE DE TU COMENTARIO Y TE REGALAMOS 3 HORAS DE WIFI.

en Complejo Poseidón, Poseidón Playa y Playas de Guardamar.

Fuente: Twitter (@hotelesposeidon)

\footnotetext{
${ }^{30}$ www.hotelesposeidon.com: Cadena hotelera con 6 establecimientos en la provincia de Alicante.
} 
Conociendo las normas de TripAdvisor, procedimos a ponerlo en su conocimiento y así comprobar "de primera mano" cómo actúa TripAdvisor ante violaciones de sus normas por parte de hoteles. De esta forma se comunicó (vía Twitter) la incidencia (Figura 34).

Figura 34. Conversación en Twitter con TripAdvisor

Juan Pedro Mellinas@eljuanpedro.8 de ago.de 2012

@TripAdvisorES ¿Es esto correcto?... Yo creo que va en contra de los principios y reglas de TripAdvisor. pic.twitter.com/nULpwK9s

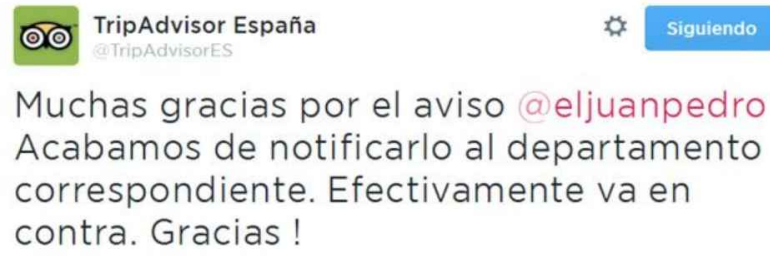

Fuente: Twitter (@eljuanpedro)

La respuesta fue rápida $y$, efectivamente, el grupo hotelero estaba actuando de forma inadecuada. La promoción se publicó el 2 de Agosto de 2012 en Facebook y Twitter. TripAdvisor tuvo conocimiento el día 8 de Agosto. Pasados dieciocho días desde la violación de las normas de TripAdvisor y doce desde que la empresa tuvo conocimiento del asunto, la promoción no se había retirado y se seguían publicando opiniones en TripAdvisor sobre alguno de los hoteles. Días después, se retiró en Facebook, pero el tweet no se borró, aunque resultara finalmente inservible al enlazar a una foto de Facebook ya borrada.

En Abril de 2014 repetimos la operación, en este caso se trata del Lancaster Beach Restaurant de Barcelona, que ofrece la promoción en sus perfiles de Twitter y Facebook (Figura 35). 
Figura 35. Promoción de Lancaster y conversación con TripAdvisor

Juan Pedro Mellinas @eljuanpedro.11 de abr

@TripAdvisorES Hola, ¿Esto sería correcto o va en contra de vuestras normas?

回 Ver foto

hasad LancasterBeachClub @LancasterBeach - 8 de abr.

Tu opinión cuenta mucho para nosotros. Por este motivo, premiamos tu

participación en Trip Advisor con un sorteo... fb.me/6vbf1L21

\section{lancaster beach restaurant}

¿Te ha qustado nuestro restaurante?

Sorteamos 2 cenas entre los que opinéis en

๑ఠtripadvisor

Sólo hasta el 30 de abril de 2014

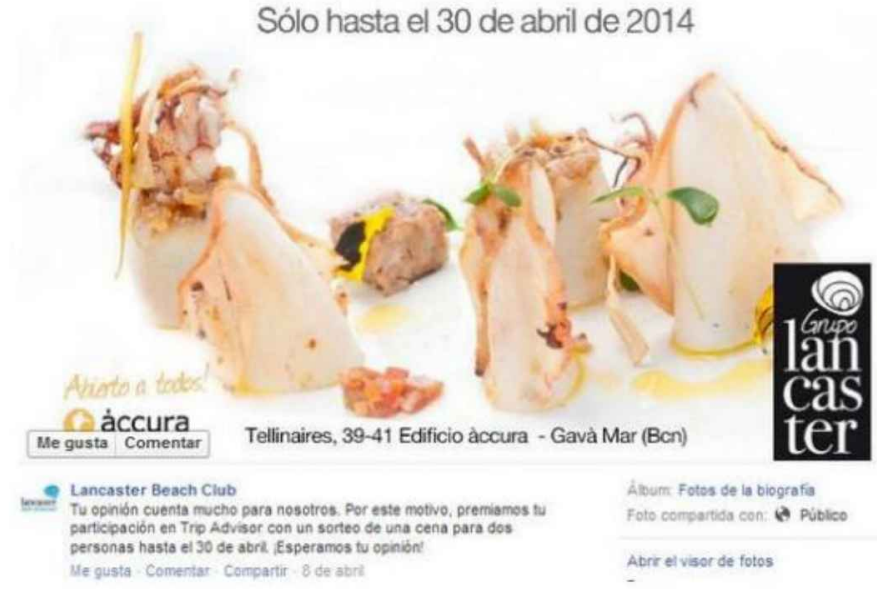

$8: 13$ - 11 de abr. de 2014

Reportar archivo

TripAdvisor España @TripAdvisorES - 11 de abr

()

@eljuanpedro Esto no está permitido. Gracias por avisarnos, notificamos

al departamento correspondiente. Saludos!

Fuente: Twitter (@eljuanpedro)

La respuesta fue, otra vez, rápida y clara. Pero en este caso, TripAdvisor no consiguió que el restaurante retirara la promoción de sus cuentas de Facebook y TripAdvisor. Para Noviembre de 2014, todavía no se había borrado y TripAdvisor tampoco había tomado alguna de las medidas sancionadoras que tiene previstas para estos casos. 


\subsubsection{Cuantificación del efecto causado al incentivar las opiniones}

El Beech Hill Hotel presentaba 11 opiniones participantes en su concurso, desarrollado desde 2013, todas ellas con la puntuación máxima de 5 puntos. Teniendo en cuenta que sólo el $39 \%$ de las opiniones generadas en este hotel le otorgan esta máxima calificación (Gráfico 32), existe un sesgo generado extremadamente positivo.

Gráfico 32. Opiniones no condicionadas (Beech Hill Hotel)

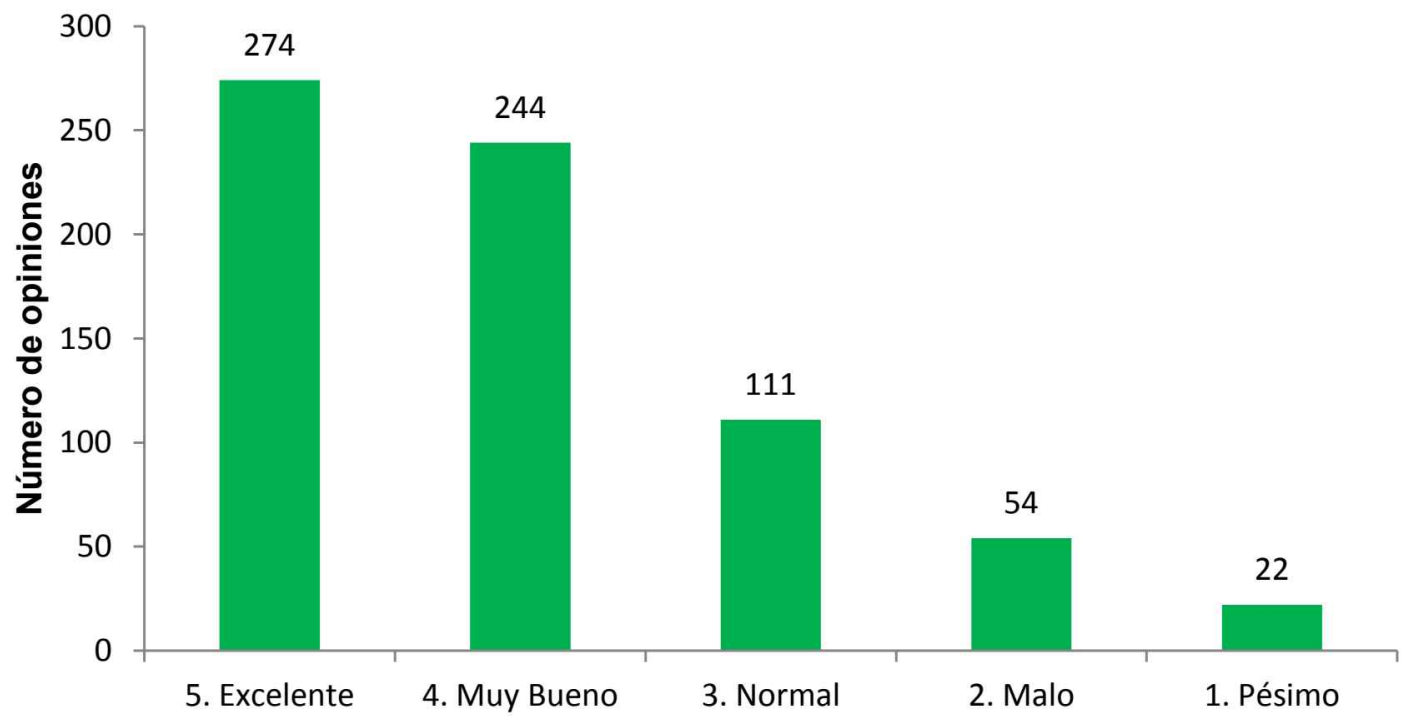

Fuente: Elaboración propia a partir de datos de TripAdvisor

En el caso del Tempo Hotel, la promoción se remonta a 2011 y, desde entonces, se detectaron 12 opiniones de participantes en su concurso, ocho de ellas con 5 puntos y cuatro con 4 puntos. Para las opiniones no condicionadas, observamos cómo el 53\% obtienen la puntuación máxima de 5 puntos (Gráfico $33)$, frente al $66 \%$ en las incentivadas. 
Gráfico 33. Opiniones no condicionadas (Tempo Hotel)

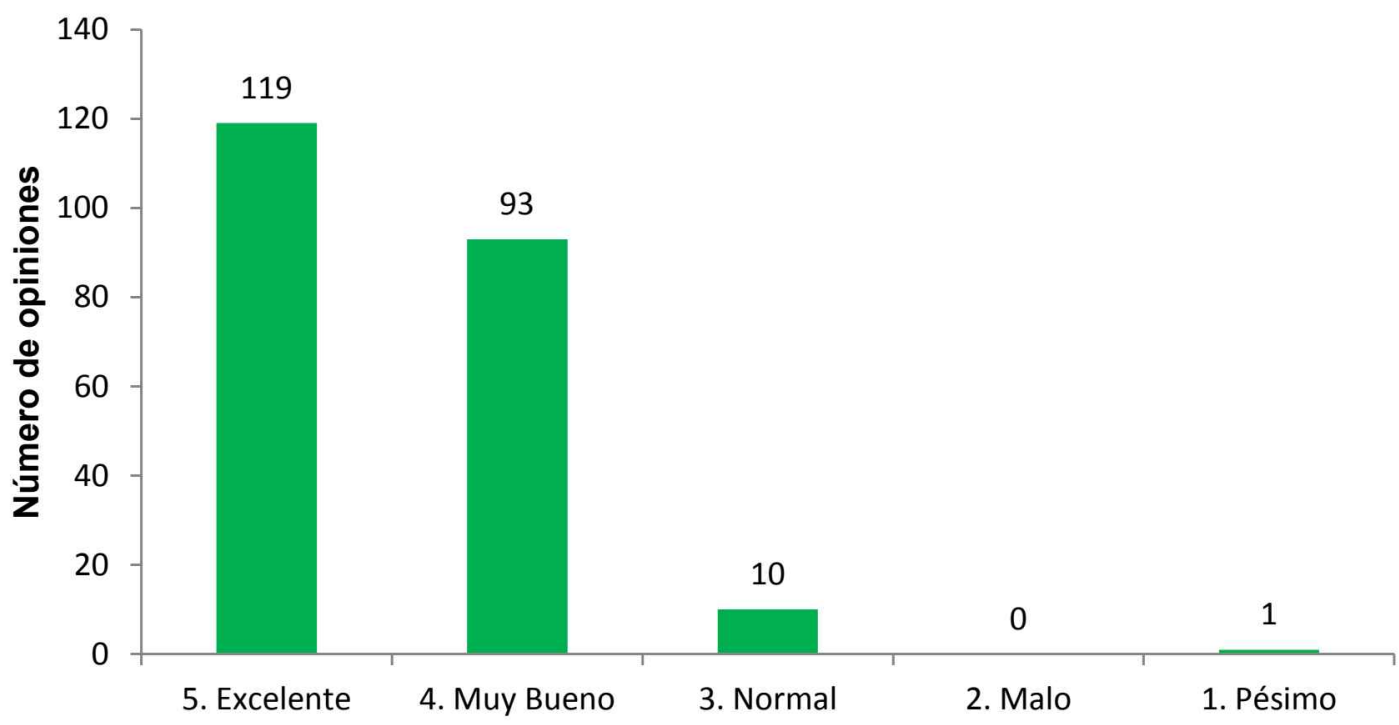

Fuente: Elaboración propia a partir de datos de TripAdvisor

Los resultados de ambos casos, confirman nuestra hipótesis $\mathrm{H}_{16}$ que planteaba un sesgo positivo en las opiniones incentivadas, pero lo hacen de formas muy diferentes. Mientras que en el caso del Tempo hotel, se pone de manifiesto cierto sesgo, en el caso del Beech Hill Hotel, el condicionamiento observado es total, con el $100 \%$ de opiniones obteniendo la máxima puntuación.

\subsection{Tarjetas invitando a opinar en TripAdvisor}

TripAdvisor recomienda a los hoteles solicitar a sus clientes la aportación de opiniones sobre su estancia. Para ello ofrece, a los establecimientos registrados en su web, unas tarjetas personalizadas para entregar a los clientes a su salida (El blog de TripAdvisor, 2010), aunque algunos hoteles prefieren realizar sus propios diseños, solicitar la colaboración vía email o de forma verbal. Algunos internautas fotografían estas tarjetas y las difunden a través de la red, lo que nos ha permitido acceder a varios ejemplos (Figura 36). 
Figura 36. Ejemplos de tarjetas que invitan a opinar a los clientes

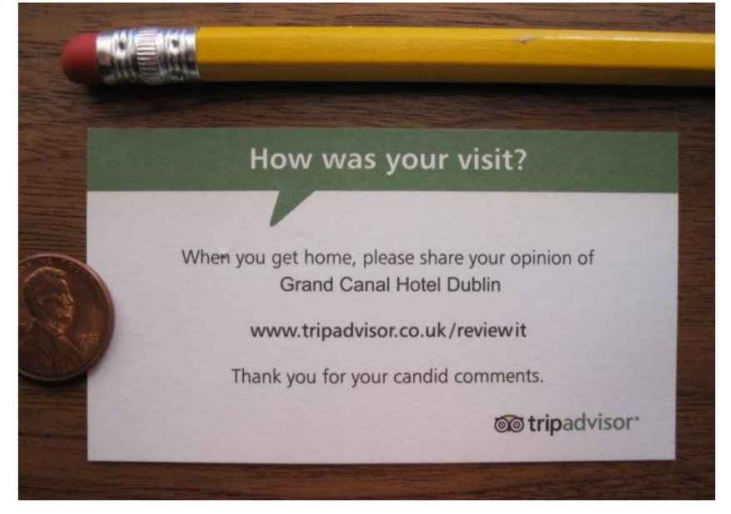

http://www.reviewtrackers.com/8-terrific-tripadvisor-tipsbusinesses/

roses are red

violets are blue

will you be a peach

and write us a review?

www.tripadvisor.com

search for $\Rightarrow$ "Value Place Lexington"

http://affordablehotelblog.com/category/tripadvisor/

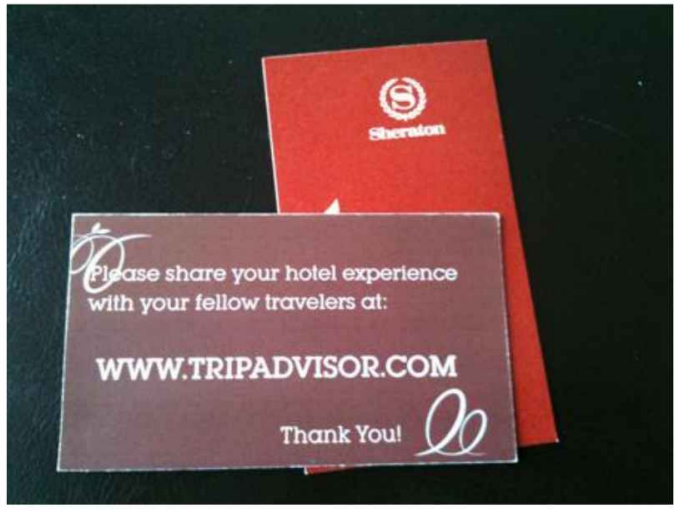

http://www.wilhelmus.ca/2010/07/sheraton-tripadvisorcards.html

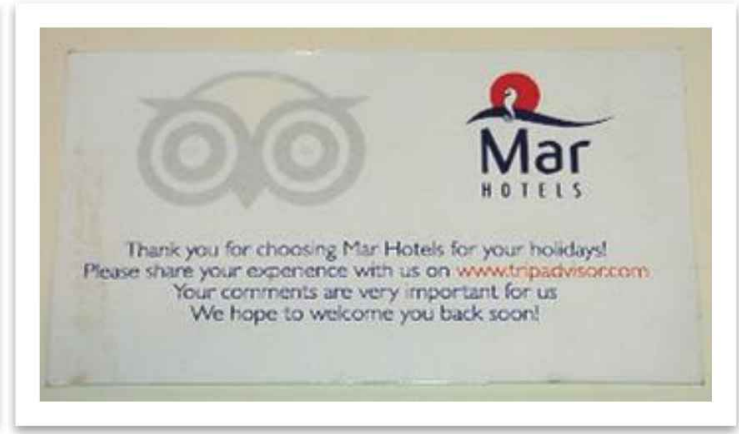

http://www.nickburcher.com/2012/08/how-to-createearned-media-advocacy-ask.html

Fuente: Webs indicadas en cada caso

En el caso del Hotel Extended Stay America ${ }^{31}$ de Renton-Seattle (Figura 37), la tarjeta incluye instrucciones precisas de como actuar durante todo el proceso, indicando incluso como dar la máxima puntuación de satisfacción al hotel (Give us your "5 Circle" review). Por supuesto, esto contraviene las normas de publicación (TripAdvisor, 2011) pero resulta difícil de detectar si no se difunde en Internet y ningún "inspector" de TripAdvisor visita el hotel. En este caso, ha sido un cliente el que ha proporcionado una evidencia de posible irregularidad por parte del hotel, ya que, además de incluir la fotografía, explica

\footnotetext{
${ }^{31}$ www.extendedstayamerica.com: Cadena con hoteles en EE.UU. y Canadá, con casi 700 establecimientos.
} 
en los comentarios de TripAdvisor el caso de la existencia de una tarjeta indicándole cómo valorar al hotel con la puntuación máxima.

Figura 37. Tarjeta del Hotel Extended Stay America Renton

\section{Extended Stay America - Seattle - Renton Photo: Card asking for a perfect rating on TripAdvisor!}

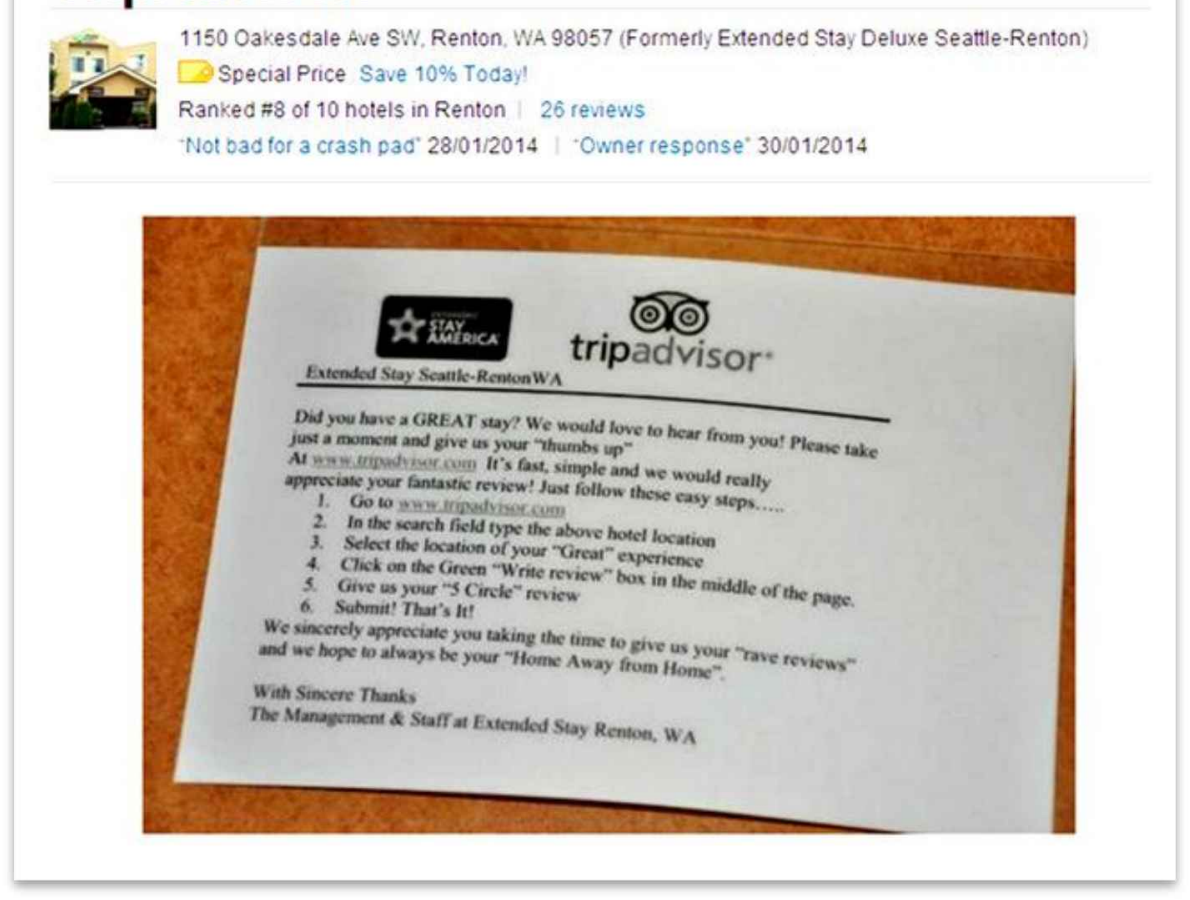

Fuente: http://www.tripadvisor.co.uk/LocationPhotoDirectLink-g58704-d226231i55782601-Extended_Stay_America_Seattle_Renton-Renton_Washington.html

Si en lugar de recomendar a todos sus clientes que utilicen TripAdvisor, un hotel se centra en solicitarlo exclusivamente a aquellos clientes que han quedado muy satisfechos con su estancia, probablemente las puntuaciones medias obtenidas también serían mucho más altas. Se trataría de influir sobre clientes que repiten su estancia año tras año y/o clientes que acuden por primera vez, pero que manifiestan claramente su satisfacción al personal del hotel.

Si un hotel se encuentra plagado de críticas especialmente positivas, obtenidas de esta forma, su valoración no será nada útil para un potencial cliente, ya que estará sobrevalorado frente a otros que no influencian a sus clientes más satisfechos para que realicen críticas. Un hotel tendrá mejor puntuación que otro de similares características, no por prestar mejores 
servicios, sino por preocuparse de detectar a los clientes más satisfechos y convencerles para que escriban en TripAdvisor.

Por todo ello, TripAdvisor considera una práctica fraudulenta "La solicitud de opiniones de forma selectiva únicamente de aquellos huéspedes que tuvieron una experiencia positiva", según recoge en sus normas (TripAdvisor, 2011). Pero para los hoteleros españoles las prácticas anteriormente descritas son totalmente adecuadas y recomendables, considerándolas una importante herramienta para la mejora de la reputación online de sus establecimientos, según la Confederación Española de Hoteleros y Alojamientos Turísticos ${ }^{32}$ (CEHAT) de la que depende el Instituto Tecnológico Hotelero ${ }^{33}$ (ITH). Por ello editaron una guía de 8 páginas, que ofrecían en su web para instruir a los hoteleros y a su personal en la correcta utilización de estas técnicas. Básicamente se trataba de animar a que escribieran opiniones sobre el hotel, únicamente a aquellos clientes que creyeran realmente satisfechos (Figura 38). Para ello utilizan como soporte unas tarjetas, similares a las mencionadas anteriormente.

Esta guía, disponible en la red hasta Marzo de 2014, se creó el 10 de Junio de 2009 y se incluye en el Anexo 4. Sopesamos la posibilidad de que el citado aspecto de la normativa de TripAdvisor fuera de una fecha posterior a la creación de la guía. Para confirmar la información nos dirigimos (vía Twitter) a la delegación de España de TripAdvisor en 2014, que nos confirma que "estas son nuestras directrices desde siempre" (Figura 39).

\footnotetext{
${ }^{32}$ www.cehat.com: 14.000 establecimientos y 1.500 .000 plazas, agrupadas en 64 asociaciones.

${ }^{33}$ www.ithotelero.com
} 
Figura 38. Extracto de las instrucciones del manual del ITH

\section{3. ¿A quien le damos las tarjetas?}

Con el fin de asegurarnos que los comentarios que dejen sobre nuestro hotel sean positivos, es fundamental entregar la tarjeta únicamente a aquellos clientes habituales del hotel, aquellos que tengan un alto grado de repetición., o que hayan transmitido al personal del hotel, sin dejar lugar a dudlas, su satisfacción con los servicios disfrutados y el trato recibido.

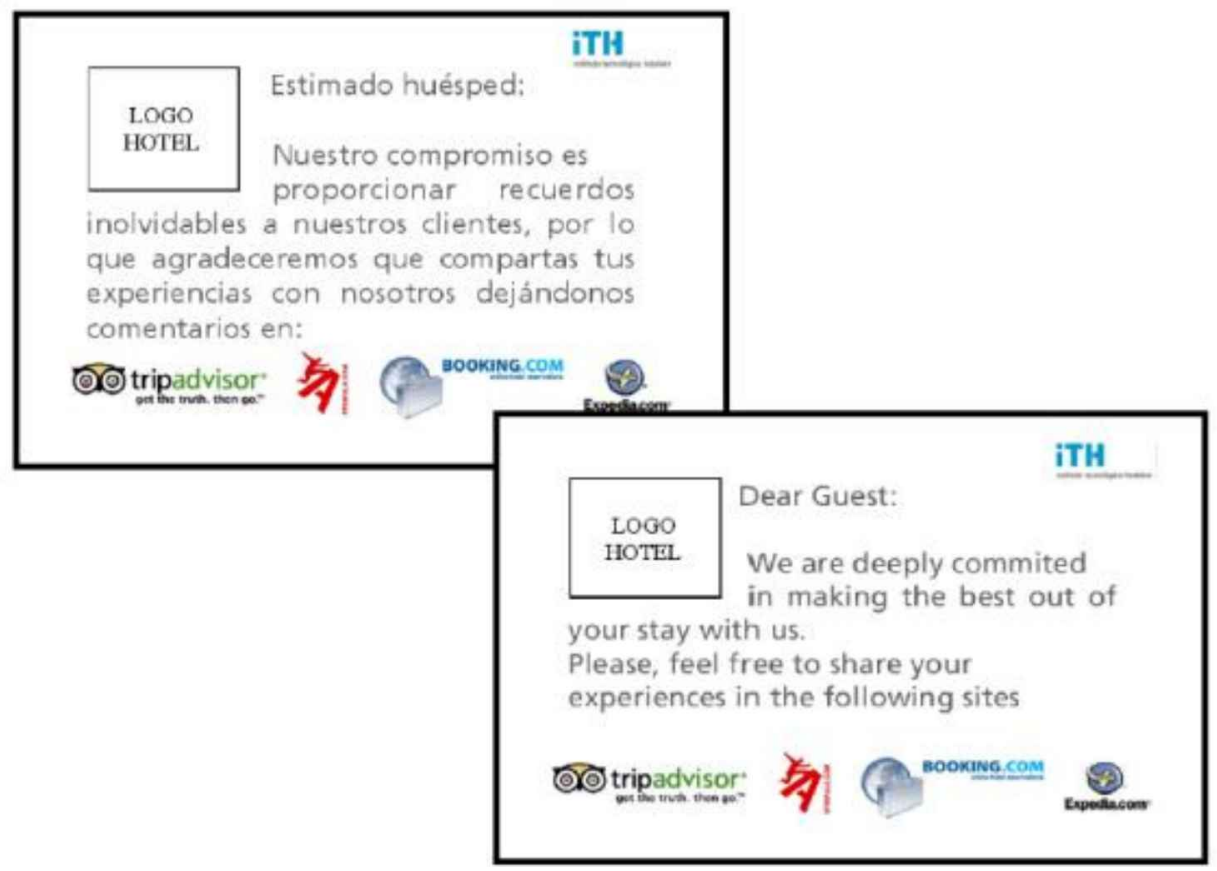

Fuente: ITH. Guía reputación online (Anexo 4)

Seguidamente, TripAdvisor procedío a ponerse en contacto con el Instituto Tecnológico Hotelero, casi 5 años después de la difusión del documento que ha estado recomendando a los empresarios del sector la realización de acciones inapropiadas para mejorar su valoración. Por su parte, el Instituto Tecnológico Hotelero, al ser requerido por TripAdvisor, procedió a la retirada de la citada guía de su web (Anexo 4). 
Figura 39. Conversación por Twitter con TripAdvisor y el ITH

Juan Pedro Mellinas @eljuanpedro - 3 de mar.

@TripAdvisorES Es fraude? "Solicitud de opiniones de forma selectiva

únicamente de aquellos huespedes que tuvieron una experiencia positiva"

Abrir

Juan Pedro Mellinas (c)eljuanpedro 3 de mar

@TripAdvisorES Lo he visto aqui pero lo desconocia, desde cuando pasa

esto? tripadvisor.es/vpages/review_.

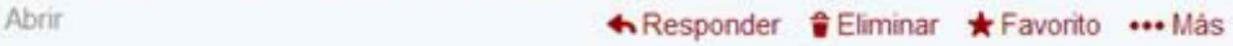

TripAdvisor España @itripAdvisorES - 3 de mar.

(๐)@eljuanpedro Hola Juan Pedro, estas son nuestras directrices de publicación desde siempre...

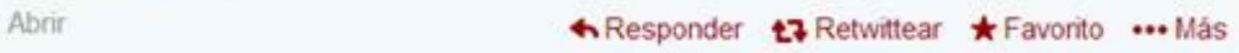

Juan Pedro Mellinas @eljuanpedro - 3 de mar.

@TripAdvisorES Entonces, mirar esta guia del Instituto Tecnológico Hotelero y

decirme que os parece ithotelero.com/wp-content/upl... @ithotelero
Abrir
h Responder
- Eliminar
$\star$ Favorito $\cdots$ Más

TripAdvisor España @TripAdvisorES - 3 de mar.

@eljuanpedro Nos hemos puesto en contacto con ellos. Gracias Juan Pedro cc @ithotelero
- Ocultar conversación
4 Responder
ใ7 Retwittear

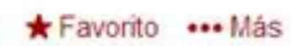

10-46 - 3 de mar de 2014 - Detalles

Juan Pedro Mellinas @eljuanpedro - $2 \mathrm{~h}$

@TripAdvisorES Pensaba que @ithotelero os pediria disculpas y lo retirarian de inmediato, pero 3 dias después sigue igual ¿harán algo?

Abrit

น Responder 合 Eliminar ^ Favorito ... Más

iTH

ITH @ithotelero : $48 \mathrm{~min}$

Hola@eljuanpedro! Ya hablamos c/@TripAdvisorES,lo retiramos hace 3 dias. Igual lo tienes en cache! Gracias por seguirnos y estar pendiente!

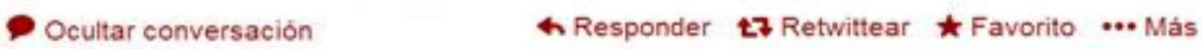

Fuente: Twitter (@eljuanpedro)

Desconocemos el número de hoteleros que han llevado a cabo acciones de este tipo, sin ser conscientes de que, al menos, no son éticas, confiando en las indicaciones del ITH. En todo caso, resulta reseñable que TripAdvisor no fue capaz de detectar la presencia de esta guía hasta que no le fue expresamente comunicado vía Twitter. También es sorprendente que TripAdvisor no detectara a ningún hotel utilizando esta metodología y éste le aclarase que seguía las recomendaciones del ITH. 
ReviewPro ${ }^{34}$ es una empresa multinacional que desarrolla un software específico para la monitorización de la reputación online de los hoteles, recopilando información de webs como TripAdvisor. Es destacable que en su web aparece un sello, con el logo de TripAdvisor, dónde indica "Approved by TripAdvisor", además de ser "colaborador certificado" de TripAdvisor (ReviewPro, 2013). En 2013 editó una guía de 23 páginas sobre “Cómo pueden los hoteles incrementar el volumen de opiniones" (ReviewPro, 2012), en la que se realizan recomendaciones similares a las del ITH. En las páginas 7, 8 y 9 de esta guía se encuentran frases como:

"...Si el cliente ha tenido una fantástica estancia sin problemas, no dudes en pedírsela. Si, por el contrario, la experiencia vivida por el cliente ha sido negativa, asegúrate de que habéis hecho todo en vuestra mano para corregir el problema antes de considerar la posibilidad de solicitar una opinión..."

“...Durante el check-out vuestros empleados pueden preguntar al cliente si ha tenido una buena experiencia en vuestro hotel. Y si es así, animar a los clientes a que compartan su opinión en el sitio web que prefieran..."

"...Como en muchos hoteles, el personal de citizenM, llamados Embajadores, preguntan a los clientes si disfrutaron de su estancia durante el check-out. Si éstos les informan de algún problema, se lo comunican directamente a un gerente para que lo resuelva rápidamente. Pero si la persona tuvo una buena experiencia, se le pide que comparta su opinión online..."

En este caso no se ha puesto el contenido de esta guía en conocimiento de TripAdvisor, pero deducimos que dada la similitud de las recomendaciones con las del ITH, resultan igualmente inadecuadas, incumpliendo también las directrices de esta web.

\footnotetext{
${ }^{34}$ www.reviewpro.com
} 


\subsection{Generación de opiniones falsas en TripAdvisor}

En ocasiones son los propios hoteleros, sus empleados o personas que por alguna razón les quieren favorecer, quienes escriben comentarios positivos sobre sus establecimientos. Aunque TripAdvisor señala que pone todos los medios para detectar este tipo de fraude, no resulta eficiente al $100 \%$. Presentamos los comentarios de un foro de TripAdvisor (Figura 40), en el que se hablaba sobre un establecimiento de alquiler de alojamientos rurales.

Aunque no se trata de la ficha de un establecimiento hotelero, estos comentarios reúnen las principales características que deberían hacer sospechar a cualquier usuario y a TripAdvisor de que pueden ser falsos:

- Los comentarios son todos ellos extremadamente positivos, sin destacar ningún tipo de inconveniente o desventaja del establecimiento.

- Todos los comentarios son publicados en un reducido periodo de tiempo (algo menos de media hora). Este es el tiempo medio necesario para que una persona pueda dar de alta 5 usuarios nuevos y escribir a su vez los comentarios.

- El nombre de tres de los cinco usuarios tiene la misma estructura (país+año).

- Todos los usuarios tienen un único post en la fecha indicada de 2011 y para 2014 no había ningún registro de otra actividad en la web. Esto indica que los usuarios se han creado específicamente para realizar este comentario. 


\section{Figura 40. Estracto del Foro de TripAdvisor}

\begin{tabular}{|c|c|}
\hline \multirow{5}{*}{$\begin{array}{l}\text { inction } \\
\text { Traveller70s } \\
\text { Cartagena... } \\
\text { posts: } 1\end{array}$} & $\begin{array}{l}66 \text { Villa Eulalia Eco Village Resort, a place for Rest } \\
\text { and Enjoy } 5 y \\
\text { Jul } 02,2011,7: 16 \text { PM }\end{array}$ \\
\hline & \multirow[b]{2}{*}{$\begin{array}{l}\text { We have spent some wonderful days of tranquility at villa } \\
\text { Eulalia, and we have been treated so well. The environment of } \\
\text { the eco village is very nice and we have done several hiking } \\
\text { trails as well as enjoy the various beaches that are relatively } \\
\text { close. At the same time we have also enjoyed being able to } \\
\text { eat fruit freshly picked from the trees in the orchard. It is a } \\
\text { unique experience and I would highly recommend the place. } \\
\text { Thanks for everything. }\end{array}$} \\
\hline & \\
\hline & Reply \\
\hline & $\Delta$ Report inappropriate content \\
\hline \multirow[t]{2}{*}{4 replies } & Expand view 1 \\
\hline & $\begin{array}{l}\text { 1. Re: Villa Eulalia Eco Village Resort, a place for Rest } \\
\text { and Enjoy } \\
\text { Jul } 02,2011,7: 22 \text { PM }\end{array}$ \\
\hline $\begin{array}{l}\text { Sexylady1955 } \\
\text { Madrid, Spain } \\
\text { posts: } 1\end{array}$ & $\begin{array}{l}\text { The house is located in a rural eco village estate Villa Eulalia. } \\
\text { It is very comfortable and very well equipped. The pool is } \\
\text { great for cooling down. It's an ideal place for the country } \\
\text { lover, as it is very quiet and there is no noise. Señora } \\
\text { Feliciana has treated us so well and made us feel as if we } \\
\text { were family. Thank you very much for everything again. }\end{array}$ \\
\hline & Reply \\
\hline & $\Delta$ Report inappropriate content \\
\hline
\end{tabular}

2. Re: Villa Eulalia Eco Village Resort, a place for Rest and Enjoy

Jul 02, 2011, 7:25 PM

What we liked most of Villa Eulalia was the tranquility that reigns here. In general, we loved everything! It was such a pleasure being there, we may make it a summer get-away this year. Thank you very much for everything. Sincerely, Michael

australian7

Perth...

3. Re: Villa Eulalia Eco Village Resort, a place for Rest
and Enjoy
Jul 02, 2011, 7:35 PM
We had a very pleasant stay at Villa Eulalia eco village resort.
The bungalow is very nice. The fans are suitable during the
day, there is no need for them during the night, as it's quite
cool. There is a large garden in front of the bungalow and fruit
picking can also be done.
It's a very nice home, quiet, close to beautiful beaches and
beautiful walks. We will definitely return.

Fuente: http://www.tripadvisor.com/ShowTopic-g1087589-i16362-k4610406-

Villa_Eulalia_Eco_Village_Resort_a_place_for_Rest_and_Enjoy-

Fuente_Alamo.html 
En la red podemos encontrar diversas webs, foros y blogs, en los que se trata sobre la cuestión de las opiniones falsas en TripAdvisor. Algunos dan indicaciones sobre cómo escribir sin ser detectado, como en el ejemplo de la web TripAdvisorWatch.com que se muestra en la Figura 41. Seguimos sin conocer exactamente la metodología de detección que usa TripAdvisor. En todo caso, se tratan de sospechas que tienen un valor meramente anecdótico, ya que no existen estudios fiables al respecto.

Figura 41. Consejos para escribir opiniones en TripAdvisor sin ser detectado

10 TIPS WE RECEIVED THAT MIGHT ALLOW HOSPITALITY PROFESSIONALS TO PROLIFICALLY WRITE THEIR OWN REVIEWS AND POTENTIALLY WRITE REVIEWS ON COMPETITOR PAGES...

From the hundreds of anonymous tips we received we've evaluated the ones below as being the most effective at exploiting the weaknesses in TripAdvisors' security. So shocked are we at the ease with which these tips work, we're wondering whether we're the last to find out about them. We aren't recommending you use these tips, we're just letting you know what other people seem to be doing freely. Which is a great shame. We hope that by sharing this list Tripadvisor will close the loop holes that unscrupulous professionals are exploiting. We do not condone the use of these tips in any way.

1. Download an IP Changer (Google Easy-Hide IP) and select different cities as your location at will.

2. Develop multiple email aliases using hotmail, gmail, or other generic domains.

3. Vary your browser. Use Firefox, Chrome or Safari but do so in incognito mode.

4. Access Trip Adwisor only after clearing your Internet cache.

5. Develop your email aliases before you use them to avoid just positing 1 review repeatedly. This takes time but is worth doing.

6. Research post codes properly when signing in, especially if writing a review from a foreign country.

7. Don't bombard the site. Build up your reviews over weeks and months.

8. Change your writing style and vocabulary. Make the review an interesting story for either good or bad reviews.

9. Remember to alternate your star ratings as if you're evaluating your business from a different perspective each time.

10. Be careful. Be methodical. If you get caught you'll be red flagged, as some hotels have.

Fuente: $h$ ttp://tripadvisorwatch.wordpress.com/2011/11/08/how-people-fake-tripadvisor-reviews/

TripAdvisor admite y denuncia la existencia de organizaciones dedicadas a ofrecer opiniones manipuladas a sus clientes, a cambio de dinero. En Marzo de 2013, señalaba la web www.TripAdvisorSuccess.com como ejemplo de empresa dedicada a este tipo de fraude (TripAdvisor Insights, 2013d), aunque en su web no hablan explícitamente de opiniones falsas. 
Un caso similar es el www.reputationcrafting.com, que ofrece la inclusión de opiniones en diversas webs, entre las que se encuentra TripAdvisor. A nivel nacional, encontramos el caso de www.comentaok.com, que ofrece un servicio similar (Figura 42).

Figura 42. Detalle de la web Comentaok

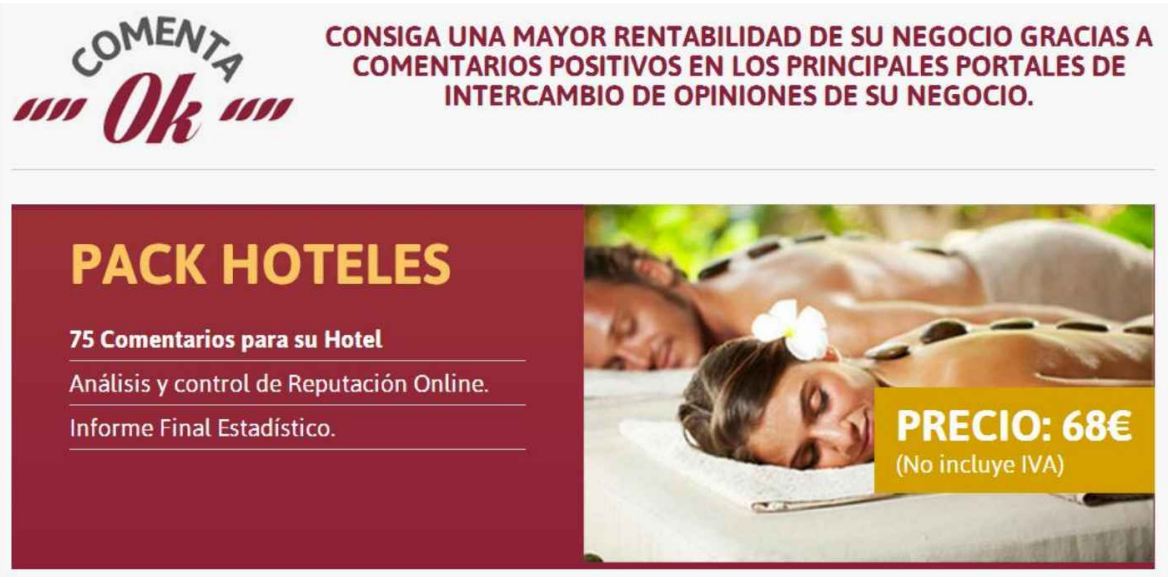

Fuente: www.comentaok.com

Otra situación relacionada, es la de la contratación de autónomos independientes por parte de hoteles, para que realicen críticas sin ser detectados por TripAdvisor. Una búsqueda a través de foros especializados, proporciona resultados sobre individuos ofreciendo sus servicios y entidades que a su vez los solicitan. En el Anexo 5 se recogen una serie de ejemplos ilustrativos.

En Julio de 2011, The New York Times (Streitfeld, 2011), realizó una profunda investigación sobre este tema que incluye a TripAdvisor (Figura 43). El artículo resultante muestra la existencia de un creciente mercado de empresas e individuos que, cada vez más, recurren a las opiniones falsas para mejorar la reputación de sus negocios. 
Figura 43. Artículo New York Times

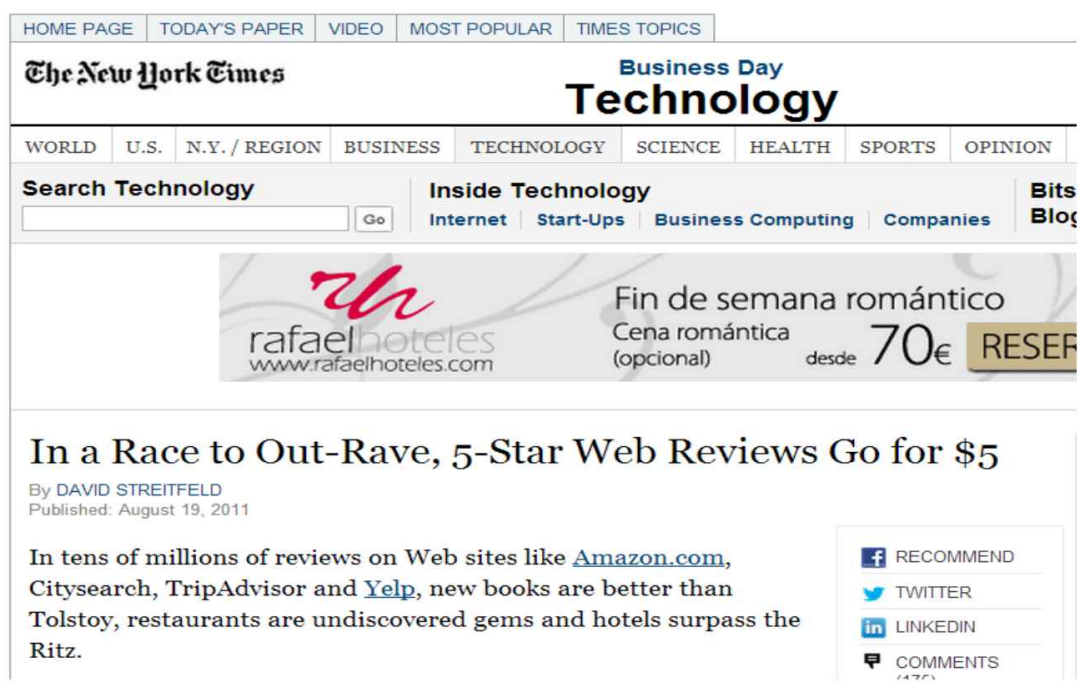

Fuente: http://www.nytimes.com/2011/08/20/technology/finding-fakereviews-online.html?_r $=0$

\subsection{Verificación humana de las opiniones en TripAdvisor}

Una de la condiciones para escribir una opinión en TripAdvisor es haber estado efectivamente en el lugar de que se habla (Hotel, Restaurante, Museo, etc.). Esto queda muy claro en su normativa (TripAdvisor, 2011). Concretamente uno de los requisitos es "estar escritas por viajeros reales: aceptamos opiniones que detallen experiencias de primera mano con las instalaciones o servicios de un establecimiento".

Por si quedara alguna duda, la web especifica qué se entiende exactamente por "opinión de viajero de primera mano" (TripAdvisor, 2013b). Dentro de las condiciones requeridas se explica que "No se admitirá información no recabada personalmente o testimonios de oídas (información sin verificar, rumores o citas de otras fuentes, o bien supuestos comentarios o experiencias de otras personas)".

El efectivo cumplimiento de esta normativa requiere de un sistema de verificación humano de las opiniones, es decir, que alguien en TripAdvisor lea cada una de las opiniones enviadas por los usuarios antes de su publicación. Parece una medida lógica y evidente, para tratar de evitar esta y otras irregularidades. En función de ello planteamos la siguiente hipótesis: 
$H_{17}$ : Todas las opiniones de TripAdvisor son leídas y aprobadas por un empleado de la empresa antes de su publicación.

Evidentemente, la mayoría de los usuarios no leen al detalle las normas de publicación de esta web, por lo que puede considerarse normal que algunos las infrinjan sin mala intención. Para TripAdvisor resulta difícil saber si un comentario se realiza en función de una experiencia "de primera mano" o si la persona nunca estuvo en ese lugar. Pero si el viajero especificara claramente en su comentario que nunca ha estado en el lugar sobre el que ha escrito, eso sí permitiría evitar la publicación de ese tipo de opiniones.

La lectura de una entrada de un blog sobre viajes (Eime, 2013) nos ilustra sobre la existencia de opiniones de viajeros que manifiestan claramente no haber estado en el lugar del que hablan, contraviniendo la normativa de TripAdvisor. A partir de esa información desarrollamos una pequeña investigación al respecto a través de búsquedas usando Google como herramienta. Utilizamos frases similares a las encontradas en el referido blog, lo que nos permitió ampliar el número de casos. Los resultados se muestran en el Anexo 6, en el que podemos observar opiniones publicadas, a pesar de contener frases como:

"Never been there but know..."

"Never been there but worth a try!"

"I've never been there, but it's one of the most famous restaurants in Vienna"

"I have never stayed here"

Que TripAdvisor permita estos comentarios, contraviene de forma clara su propia normativa, convirtiéndose en el primer indicio de ausencia del referido control humano de contenidos. Una profunda búsqueda, tanto en la página de TripAdvisor, como en diversas webs y noticias no nos aporta una aclaración al respecto.

Una investigación de la autoridad de la defensa de la competencia en Italia concluyó en Diciembre de 2014 con una multa de 500.000 euros a TripAdvisor, por no hacer lo suficiente para evitar la inclusión de comentarios 
falsos y afirmar que el contenido de su web está basado en opiniones reales (AGCM, 2014). De la amplia resolución, destacamos dentro de lo que dicha autoridad considera como hechos probados, los siguientes extractos:

"Peraltro la verifica manuale previa alla pubblicazione si attiva solo quando il sistema di filtraggio considera che la recensione sia falsa o sospetta. '35

"Va inoltre osservato che le risorse umane che TripAdvisor destina allo svolgimento di tale attività sono molto limitate, in quanto per l'Europa il gruppo di investigazione è composto da 5 dipendenti, dei quali solo 1 conosce l'italiano. ${ }^{\text {'36 }}$

En un interesante artículo de Hannah Koban (Koban, 2013), escrito en el blog del curso sobre redes sociales que se imparte en el Boston College's Carroll School of Management ${ }^{37}$. Destacamos el párrafo en el que explica cómo se actúa con las opiniones de TripAdvisor que no han sido detectadas inicialmente como "sospechosas" por el sistema (traduciendo al español):

"Si una opinión es aceptada por nuestro algoritmo, pasa al equipo de "Integridad de Contenido". Este equipo está formado por antiguos agentes de la ley y de la C.I.A., que tienen como única tarea leer cada opinión antes de ser publicada en TripAdvisor. Una vez más, estos moderadores comprueban que cada opinión cumple las normas y buscan potenciales casos de opiniones fraudulentas. Solamente después de que la opinión es leída y aprobada por un miembro del equipo de "Integridad de Contenido" es publicada en TripAdvisor."

Aunque Hannah no es una portavoz oficial de TripAdvisor, este procedimiento parece totalmente razonable y coincide con lo planteado en la hipótesis $\mathrm{H}_{17}$ y con lo que se podría esperar cuando TripAdvisor se refiere a los

\footnotetext{
${ }^{35}$ Por otra parte, la verificación manual de las opiniones, antes de su publicación, sólo se activa cuando el sistema de filtración considera que la opinión es falsa o sospechosa.

${ }^{36}$ También hay que señalar que los recursos humanos que TripAdvisor asigna a la verificación de las opiniones son muy limitados, ya que el equipo de investigación para Europa consta de cinco empleados, de los cuales sólo uno habla italiano.

${ }^{37}$ Hannah es empleada en la sede central de TripAdvisor en Massachusetts y escribe sobre algo que conoce, titulando "Crowsourcing, TripAdvisor \& the problem of bogus reviews"
} 
grandes esfuerzos y recursos que dedica a la detección del fraude. Pero entra en contradicción con lo observado en la serie de opiniones del Anexo 6.

Ante estos datos, estimamos conveniente realizar una comprobación, de forma que se pudiera clarificar el procedimiento real que siguen. Para ello se realizó un comentario sobre un hotel, en el que indicamos claramente que nunca nos habíamos alojado. El elegido fue el hotel Beberly Wilshire Beberly Hills, actualmente gestionado por la cadena Four Seasons. ${ }^{38}$

Tratamos de facilitar que cualquier revisor de TripAdvisor, que realmente leyera el comentario, detectara que no cumplía sus parámetros. Para ello lo titulamos "El hotel que me gustaría visitar", dando a entender desde el principio que no hemos estado nunca en el hotel. Dentro del contenido, especificamos claramente “...Nunca he estado en el hotel...”. Además, en el breve comentario que realizamos se incluyeron frases un tanto ridículas (Figura 44).

Figura 44. Opinión real, aceptada y publicada en TripAdvisor

\section{"El hotel que me gustaría visitar" \\ OOOOO Opinión escrita hace 3 semanas}

Este es el hotel de la película Pretty Woman de Julia Roberts y Richard Geere. Desde que la vi, siempre he querido ir a este maravilloso hotel. Espero que el recepcionista tan amable que había en la película esté todavía allí para atendernos. Además aprovecharé para visitar las tiendas de Rodeo Drive y que algún amable señor pague mis compras en esas tiendas de lujo.

Nunca he estado en el hotel, ni en Estados Unidos, pero espero cumpliar algún día mi sueño de visitarlo y vivir una experiencia de película.

\section{Se aloió el Febrero de 2014. viaió en Dareia}

Fuente: http://www.tripadvisor.es/Hotel_Review-g32070-d125138-Reviews-

Beverly_Wilshire_Beverly_Hills_A_Four_Seasons_Hotel-Beverly_Hills_California.html

El usuario que creamos era totalmente nuevo, lo que podría suponer un elemento de sospecha para los revisores. Además se da una puntuación

\footnotetext{
${ }^{38}$ Este hotel es famoso por ser el de la película "Pretty Woman", con Richard Geere y Julia Roberts, lo que le ha dotado de gran fama a nivel mundial.
} 
extremadamente buena, tratando que el propio hotel (que probablemente si leyera el comentario) no lo denunciara por inadecuado. La opinión tardó entre 12 y 24 horas en ser publicada. Parece evidente que nadie procedió a su lectura, por lo que no sabemos porque no se publicó de forma casi inmediata, una vez pasados los controles automáticos que pueda tener el sistema.

Seguidamente tratamos de averiguar si este procedimiento es exclusivo de TripAdvisor o es similar al de otras comunidades de viajeros. La asociación Hotrec $^{39}$, muestra desde 2007, preocupación por la proliferación de webs que recogen opiniones de viajeros, sin que exista un control sobre sus contenidos. En base a ello creó en 2010 un decálogo de principios a seguir por este tipo de organizaciones (Hotrec, 2010). Resulta especialmente relevante el primer punto, referido al "control editorial" de las opiniones:

"Guest reviews should only be published after verification by qualified editorial staff of the authenticity and reliability of the entry. ${ }^{\wedge 0}$

Seguidamente, Hotrec trasladó a las entidades involucradas este decálogo, para que cada una de ellas pudiera explicar de qué forma cumplen cada uno de los puntos. Las respuestas están publicadas en su web (Hotrec, 2011) y vamos destacar las afirmaciones de tres de las comunidades de viajeros más importantes que hacen sobre el primer punto del decálogo:

\section{Holidaycheck:}

"Every hotel review on HolidayCheck has to pass a quality check prior to its publication on the website. This quality check consists of a technical scan and an additional manual revision. If the technical scan detects distinctive features and also randomly, hotel reviews are screened manually by trained professional employees from the content quality assurance team. ${ }^{3.11}$

\footnotetext{
${ }^{39}$ Hotrec.eu: Se define como la asociación paragüas europea, que agrupa a asociaciones hosteleras nacionales.

40 "Las opiniones de los huéspedes sólo deben ser publicadas después de la verificación por personas cualificadas de la autenticidad y fiabilidad de la entrada."

41 "Cada opinión en HolidayCheck tiene que pasar un control de calidad antes de su publicación en esta web. Este control de calidad consiste en un análisis técnico y una revisión manual adicional. Si la
} 


\section{Zoover:}

"Zoover has a team of moderators. They verify every new review, photo and video. Our system also has some technical control functions. ${ }^{, 42}$

\section{TripAdvisor:}

"Travelers put their trust in TripAdvisor's reviews and we take the responsibility of earning and maintaining that trust very seriously. We have a zero tolerance policy for fraud, and work constantly and diligently to maintain the high integrity that travelers expect from our content.

TripAdvisor employs a team of moderators that examine questionable reviews. We also use automated tools on the site that help flag questionable content for review, and our large and passionate community of millions of travelers are an invaluable resource in helping to detect anomalies and maintain our high standards.

However, with tens of millions of reviews and more than one million hotels, restaurants and attractions on TripAdvisor; it would be almost impossible to conclusively fact check each of the details of every review submitted millions of travelers. Travelers add an average of 21 reviews and opinions to TripAdvisor every minute and we believe that the sheer volume of reviews allows travelers to get the facts, spot trends among reviews and determine whether a property is right for them.",33

\footnotetext{
exploración técnica detecta en las opiniones características distintivas y también al azar, son examinados manualmente por empleados profesionales capacitados del equipo de control de calidad de contenido."

42 "Zoover cuenta con un equipo de moderadores. Verifican cada nueva opinión, foto y video. Nuestro sistema también tiene algunas funciones de control técnico"

43 "Los viajeros ponen su confianza en las opiniones de TripAdvisor y nos tomamos la responsabilidad de ganar y mantener esa confianza muy en serio. Tenemos una política de tolerancia cero ante el fraude, y trabajamos constantemente $y$ diligentemente para mantener la alta integridad que los viajeros esperan de nuestro contenido.

TripAdvisor emplea un equipo de moderadores que examinan opiniones sospechosas. También utilizamos herramientas automatizadas que ayudan a marcar el contenido sospechoso para su revisión, y nuestra gran y apasionada comunidad de millones de viajeros son un recurso muy valioso para ayudar a detectar anomalías y mantener nuestros altos estándares.

Sin embargo, con decenas de millones de críticas y más de un millón de hoteles, restaurantes y lugares de interés en TripAdvisor; sería casi imposible verificar de manera concluyente cada uno de los detalles de cada opinión de las enviadas por millones de viajeros. Los viajeros añaden un promedio de 21 comentarios y opiniones a TripAdvisor cada minuto y creemos que la gran cantidad de comentarios
} 
La respuesta de HolidayCheck parece indicar la existencia de un sistema de verificación humano, mientras que la de Zoover lo explica con total claridad. Sin embargo, la respuesta de TripAdvisor, aunque es más extensa, no responde a la cuestión planteada, evitando pronunciarse sobre si un equipo humano verifica cada opinión antes de su publicación.

La suma de todos estos indicios vuelve a hacer sospechar que la existencia del conjunto de comentarios encontrados (Anexo 6) no responde a errores puntuales en el sistema de verificación de TripAdvisor, sino que obedecen a un procedimiento establecido que no pasa por la lectura de todas las opiniones antes de ser publicadas. Para confirmarlo, en Marzo de 2014 volvemos a recurrir a la cuenta oficial de TripAdvisor en España, que tan amablemente había atendido nuestros requerimientos en anteriores ocasiones (Figura 45).

Figura 45. Pregunta en Twitter al perfil oficial TripAdvisor en España

邹

Juan Pedro Mellinas @eljuanpedro.12 de mar.

@TripAdvisorES ¿Se leen todas las opiniones antes de publicarlas o sólo las que el sistema automático detecta como "sospechosas"?

Fuente:Twitter (@eljuanpedro)

Pasados 12 días sin obtener respuesta a nuestra consulta, recurrimos a la cuenta oficial de TripAdvisor a nivel internacional que también dejó sin respuesta nuestra consulta (Figura 46)

Figura 46. Pregunta en Twitter al perfil oficial TripAdvisor Internacional

\section{Juan Pedro Mellinas @eljuanpedro.24 de mar. \\ @ TripAdvisor Does any human read every review or just those the system detected as "suspicious"?}

Fuente: Twitter (@eljuanpedro)

Ante la acumulación de indicios, el paso siguiente podría pasar por repetir, un número significativo de veces, la operación de escribir opiniones similares a las del Beberly Wilshire Beberly Hills y comprobar que cantidad de ellas acaban siendo publicadas. Entendemos que la realización de este tipo de 
experimentos, sin el consentimiento explícito de TripAdvisor, podría ser éticamente reprobable. En todo caso, con las pruebas obtenidas, tenemos que rechazar definitivamente la hipótesis $\mathrm{H}_{17}$, que planteaba la revisión por personal cualificado de cada opinión antes de su publicación.

\subsection{La reputación de TripAdvisor ante la difusión de noticias} negativas

\subsubsection{Introducción}

Internet está abierto a la difusión de todo tipo de informaciones y opiniones de una manera sencilla y anónima, de forma que son millones de usuarios los que aportan contenidos a la red. Esa libertad y falta de control, permite que algunos individuos incluyan críticas falsas sobre hoteles en TripAdvisor, sin que la web pueda evitarlo, pero también permite que miles de individuos se dediquen a criticar a TripAdvisor de forma anónima.

En la mayoría de los casos se trata de opiniones que inciden en su falta de rigor en el control de las opiniones, en el gran número de opiniones falsas registradas y en como esto perjudica gravemente a los hoteleros. Resulta difícil saber qué contenidos son veraces y cuales son informaciones proporcionadas por partes interesadas, tales como hoteles perjudicados por TripAdvisor o incluso webs competidoras que tratan de magnificar artificialmente el problema de las críticas falsas (HolidayCheck, 2012). Proporcionamos, a modo de ejemplos ilustrativos sobre este tipo de webs, dos direcciones: tripadvisorwarning.com, tripadvisorwatch.wordpress.com. Los contenidos de estas y otras webs, vienen acompañados de un llamativo grafismo, que se incluye en el Anexo 7.

Aunque la credibilidad de estos contenidos debe ser puesta siempre en cuestión, creemos que resultan interesantes en cuanto a su utilidad como recopilatorio de noticias publicadas en medios de comunicación veraces. Además proporcionan información complementaria sobre diferentes aspectos técnicos, que pueden servir de base para la realización de posteriores estudios sobre esta cuestión. Hacen referencia a técnicas para generar contenido falso 
sin ser detectado por TripAdvisor, cómo suplantar la identidad de un propietario de hotel, cómo funcionan los procedimientos de chantajes a hoteles, etc.

En muchas ocasiones esos comentarios trascienden más allá, y se habla de TripAdvisor en los medios de comunicación en relación a la existencia de opiniones falsas en su web. En algunos casos se trata de hechos anecdóticos, centrados en hoteles concretos, que no deberían tener consecuencias económicas directas graves para la compañía. El problema es que la difusión de estos incidentes en los medios de comunicación puede perjudicar gravemente su imagen. Esa difusión no se limita a medios de comunicación especializados en el sector hotelero o turístico, medios locales o medios de baja difusión, si no que se extiende a destacables medios a nivel internacional. A modo de ejemplo, citamos The New York Times, The Wall Street Journal, Forbes, NBC News, ABC News, FOX News, The Times, The Guardian, The Telegraph, The DailyMail, BBC news, etc.

Nos pareció interesante realizar un acercamiento, de carácter cualitativo y descriptivo a esta problemática. Realizamos una recopilación de los diversos incidentes que afectan la reputación de TripAdvisor, de forma que se pueda obtener una imagen clara de la magnitud del problema. Además analizamos la posible repercusión en la valoración de las acciones de la compañía que los incidentes descritos han podido tener.

\subsubsection{Metodología}

La metodología de investigación utilizada es el estudio del caso. Se trata de una investigación de tipo cualitativo, que tiene como objetivo la interpretación y la comprensión de los fenómenos analizados. Este enfoque cualitativo pretende alcanzar es una perspectiva fenomenológica que ayude a proporcionar los datos del análisis a través de la interpretación del investigador, desde un punto de vista holístico (Yin, 2011).

El estudio de caso consiste en la recopilación de informaciones sobre una organización, un grupo o personas en un periodo de tiempo, con el fin de realizar un análisis en profundidad en un contexto determinado. La 
organización es TripAdvisor y el periodo de tiempo comienza en el año 2010 y finaliza en 2014.

Generalmente se diferencia entre tres tipos de estudio de caso (Yin, 2011):

- Explicativos: Establecen relaciones de causa efecto.

- Descriptivos: Relatan las características que definen el caso.

- Exploratorios: Se producen en áreas del conocimiento donde el tema es poco conocido con el objetivo de obtener más información.

En este análisis, el estudio desarrollado es principalmente de carácter descriptivo y exploratorio, en tanto en cuanto se detallan las características de la problemática de la reputación de TripAdvisor en relación a las noticias aparecidas en prensa, siendo éste un asunto no tratado de forma tan profunda por la literatura científica. Añadimos un aspecto explicativo a la investigación cuando relacionamos los diferentes incidentes con la cotización en bolsa de la compañía.

Nos basamos en la búsqueda de noticias relacionadas con TripAdvisor en Internet, utilizando diversos sistemas y palabras clave. Utilizamos el idioma inglés como principal vía para su búsqueda. Posteriormente realizamos una clasificación temática de cada uno de los asuntos por los cuales TripAdvisor está siendo noticia desde 2010, siempre relacionados con la existencia de opiniones falsas albergadas en su web.

El acceso a noticias en medios como la televisión, la radio o la prensa en papel es muy limitado, por lo que nos centramos en los medios con presencia en Internet. En muchas ocasiones la misma noticia o incidente es reproducido por decenas de medios de comunicación en el mundo. Nos hemos limitado a realizar una recopilación de los medios de comunicación más relevantes que se han hecho eco de cada uno de los problemas de reputación detectados, mostrando una tabla resumen en cada uno de los apartados.

TripAdvisor comenzó a cotizar en bolsa en Diciembre de 2011. Tras unos primeros meses de subida general de la acción, durante la segunda mitad de 
2012, sufrió un descenso en su cotización hasta situarse en valores cercanos a los de su salida a Bolsa. En ese contexto la revista Forbes (Forbes, 2012) publicó un artículo con el título “TripAdvisor's \$35 Fair Value Could Suffer From Fake Review Concerns", en el que hace referencia a la forma en la que la reputación de TripAdvisor se estaba viendo afectada por la publicación de noticias sobre la cantidad de críticas falsas presentes en su web. Según el autor, esta circunstancia podría afectar muy negativamente a la cotización de la compañía.

La evolución posterior en la cotización las acciones, parece invalidar la hipótesis planteada por Forbes. Pero, aun sabiendo que existe una tendencia claramente positiva en las cotizaciones, planteamos la siguiente hipótesis:

$H_{18}$ : En los días posteriores a la publicación de noticias negativas sobre la fiabilidad de las opiniones en TripAdvisor, la cotización de sus acciones sufre depreciaciones apreciables.

Si la difusión de estas noticias, pone en cuestión la fiabilidad de la información contenida en TripAdvisor, ese hecho debería tener algún tipo de impacto medible, lo que corroboraría parcialmente el análisis de Forbes.

Hemos obtenido información completa sobre la cotización de sus acciones desde Diciembre de 2011, cuando la compañía comenzó a cotizar en bolsa. Usamos una metodología similar a la utilizada en otros sectores (Rhee \& Haunschild, 2006; Telang \& Wattal, 2005) para comprobar si las noticias negativas que afectan a la reputación de la compañia tienen su reflejo en su cotización en bolsa.

Para cada caso, desde Enero de 2012, mostramos una gráfica con su cotización durante tres meses, incluyendo el mes anterior al incidente y los dos meses posteriores. Además, mostramos la respuesta oficial dada por TripAdvisor, información que obtenemos de las propias noticias.

\subsubsection{TripAdvisor designa al "hotel más sucio de América"}

En Junio de 2011, TripAdvisor publicó un listado con los hoteles más sucios del mundo, basándose en los comentarios y puntuaciones de los 
usuarios de la comunidad. En lo referente a Estados Unidos, el Grand Resort Hotel and Convention Center de Tennessee, fue nombrado como el "Hotel más sucio de América".

Dado que la clasificación de hoteles de TripAdvisor está basada en críticas de viajeros, que no prueban haber estado realmente en el hotel, y que la inclusión del hotel en esta lista les ha perjudicado gravemente, su propietario decidió emprender acciones legales contra TripAdvisor (Figura 47).

Figura 47. Artículo de USA Today

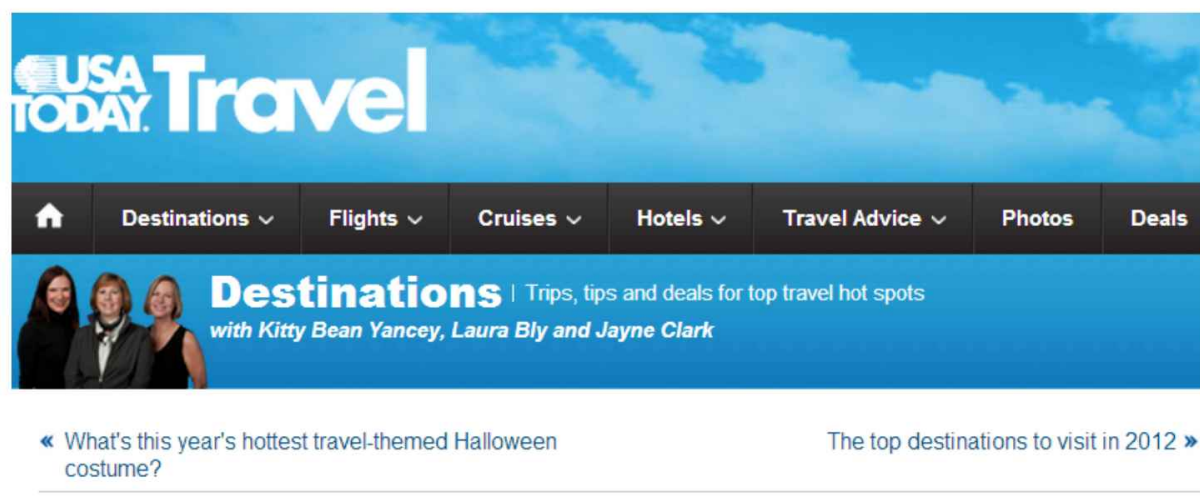

Does TripAdvisor play dirty with hotel reviews?

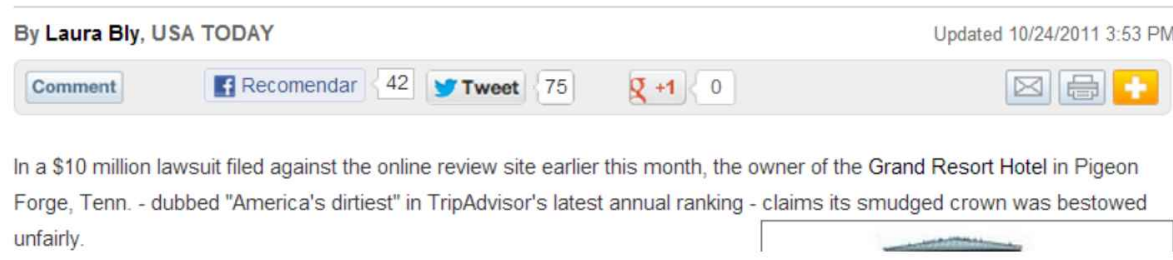

Fuente: http://travel.usatoday.com/destinations/dispatches/post/2011/10/does-

TripAdvisor-play-dirty-with-hotel-reviews/557148/1

Tabla 37. El hotel "más sucio" de América

THE DAILY TELEGRAPH - Tennessee hotel sues TripAdvisor for being declared 'dirtiest in US' (21/10/2011)

http://www.telegraph.co.uk/travel/travelnews/8841579/Tennessee-hotel-sues-TripAdvisor-for-being-declared-dirtiestin-US.html

USA TODAY - Does TripAdvisor play dirty with hotel reviews? (24/10/2011)

http://travel.usatoday.com/destinations/dispatches/post/2011/10/does-TripAdvisor-play-dirty-with-hotel-

reviews/557148/1

WBIR TV - Internet reviewers say Pigeon Forge hotel is the dirtiest in América (24/10/2011)

http://www.wbir.com/video/761334337001/0/Internet-reviewers-say-Pigeon-Forge-hotel-is-the-dirtiest-in

BUSINESS INSIDER - A Tennessee Resort Is Suing TripAdvisor For Calling It The 'Dirtiest Hotel In America' (28/10/2011)

http://www.businessinsider.com/pigeon-forge-hotel-suing-tripadvisor-dirtiest-2011-10

Fuente: Elaboración propia 
La demanda por un total de 10 millones de dólares, por los daños causados a la imagen del hotel no tuvo éxito. En Agosto de 2012, la sentencia dio la razón a TripAdvisor, al considerar que no se estaba difamando la reputación del hotel (Figura 48).

Figura 48. Noticia sobre sentencia del hotel más sucio de América

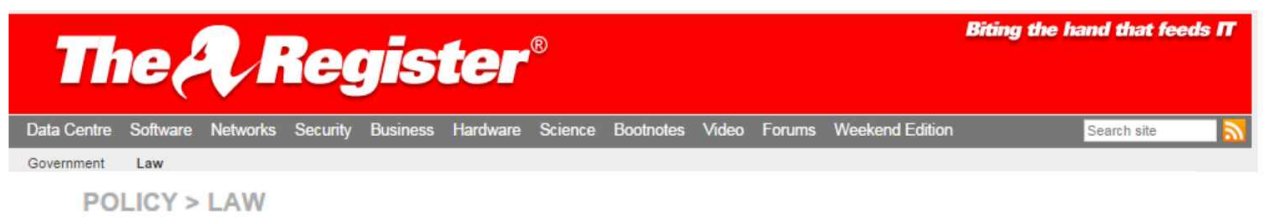

TripAdvisor didn't defame hotel by putting it on 'top 10 dirtiest' list

\footnotetext{
Unverified user review ranking: It's a diss, but it's not defamatory judge

BY OUT-LAW.COM, 3 Sep 2012
}

Fuente: http://www.theregister.co.uk/2012/09/03/tripadvisor_reviews_vs_hotel_ruling/

\subsubsection{Demanda judicial por el "Cuadro Rojo"}

Como se ha indicado anteriormente, TripAdvisor coloca un llamativo cuadrado rojo, en las fichas de los hoteles que sospecha están introduciendo críticas falsas sobre su establecimiento, advirtiendo sobre la manipulación que al parecer se está realizando. La aparición de esta advertencia supone un castigo para el hotel, perjudicando así su imagen frente a los consumidores.

Para que TripAdvisor considere que un hotel está siguiendo estas prácticas, debe detectar una gran cantidad de críticas positivas, recogidas en un corto periodo de tiempo, con un lenguaje sospechoso, con una misma ubicación o IP, etc. En principio se trataría de acciones del propio hotel para mejorar su imagen, aumentando el número de opiniones positivas, lo que mejoraría su puntuación y ranking. Pero si alguien desea que el hotel aparezca con el "cuadro rojo" y que su imagen se vea perjudicada, podría también introducir masivamente críticas positivas hasta que TripAdvisor pusiera la llamativa advertencia. Sería el caso de un competidor, pero también el de un ex-empleado o cliente que busca perjudicar al hotel en cuestión.

El Riverside Hotel and Restaurant de Evesham (Reino Unido), que fue víctima de un cuadro rojo de advertencia, con la consecuente pérdida de 
prestigio, decidió demandar a TripAdvisor en Septiembre de 2011. El hotel argumenta que cualquiera podría haber escrito esas opiniones, con el único fin de perjudicarles.

Tabla 38. Demanda judicial por el "cuadro rojo"

AOL (AMERICA ON LINE) - High-end hotel faces ruin thanks to TripAdvisor 'red flag' $(02 / 10 / 2011)$

http://travel.aol.co.uk/2011/10/02/high-end-hotel-faces-ruin-thanks-to-TripAdvisor-red-flag/

THE INDEPENDENT - Hotelier's business collapses after 'good' reviews on website $(30 / 09 / 2011)$

http://www.independent.co.uk/travel/news-and-advice/hoteliers-business-collapses-after-good-reviews-on-website2363191.html

THE INQUIRER - Glowing review ruins a hotel's business (30/09/2011)

http://www.theinquirer.net/inquirer/news/2113545/glowing-review-ruins-hotels-business

THE TELEGRAPH - TripAdvisor: upmarket hotelier faces ruin after website 'red flags hotel' $(30 / 09 / 2011)$

http://www.telegraph.co.uk/travel/travelnews/8798854/TripAdvisor-upmarket-hotelier-faces-ruin-after-website-red-

flags-hotel.html

THE DAILY MAIL - Hotelier sues TripAdvisor after accusations she wrote fake positive reviews causes revenue to plummet by $75 \%(25 / 10 / 2011)$

http://www.dailymail.co.uk/news/article-2053221/Hotelier-sues-TripAdvisor-accusations-wrote-fake-positive-reviews-

causes-revenue-plummet-75.html

THE HUFFINGTON POST - TripAdvisor Red Flag Kills Hotel's Bookings (03/10/2011)

http://www.huffingtonpost.co.uk/2011/10/03/tripadvisor-red-flag-kill_n_991779.html

THE TIMES - Hotelier damned by TripAdvisor for 'fake praise' sues for thousands in lost business $(25 / 10 / 2011)$

http://www.thetimes.co.uk/tto/law/article3205017.ece

Fuente: Elaboración propia

Figura 49. Artículo en The Telegraph

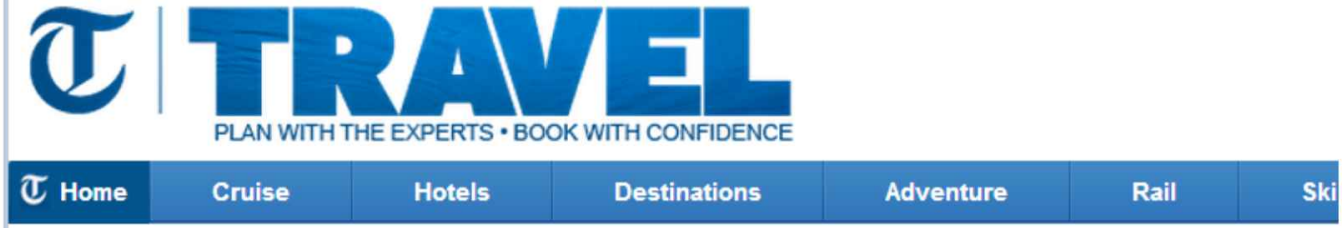

HOME " TRAVEL » TRAVEL NEWS

TripAdvisor: upmarket hotelier faces ruin after website 'red flags hotel'

A businesswoman who operates a high-end hotel is facing financial ruin after a customer's positive online review on TripAdvisor was suspected of being written by management.

Fuente: http://www.telegraph.co.uk/travel/travelnews/8798854/TripAdvisor-upmarkethotelier-faces-ruin-after-website-red-flags-hotel.html

\subsubsection{Presiones a hoteleros}

Desde 2011 aparecieron denuncias en diferentes medios de comunicación sobre chantajes a los propietarios de los hoteles. Estos 
denuncian que algunos clientes solicitan descuentos en la factura a pagar, servicios gratuitos o que les mejoren la categoría de la habitación, amenazando con realizar una o varias críticas negativas sobre el hotel, si no se atienden sus peticiones (Figura 50).

Figura 50. Artículo en The Times

\section{THE 通得TIMES \\ Travel News and Debate}

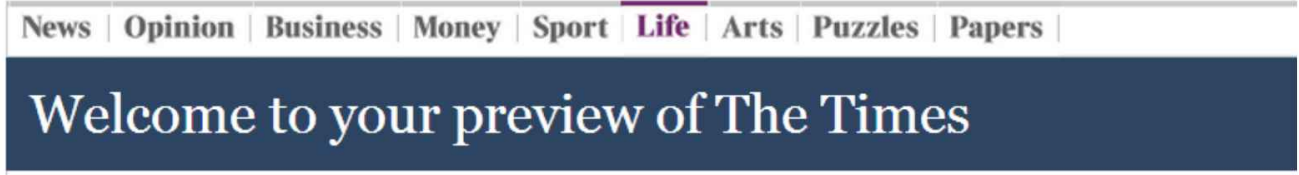

\section{Pay up or get a bad review: unscrupulous guests blackmail hotels with TripAdvisor}

Fuente: www.thetimes.co.uk/tto/travel/news/article3234171.ece

Tabla 39. Presiones a hoteleros

THE TIMES - Pay up or get a bad review: unscrupulous guests blackmail hotels with TripAdvisor (22/11/2011)

www.thetimes.co.uk/tto/travel/news/article3234171.ece

AOL (AMERICA ON LINE) - Hoteliers claim they're being 'blackmailed' by TripAdvisor reviewers $(22 / 11 / 2011)$

http://travel.aol.co.uk/2011/11/22/hoteliers-claim-theyre-being-blackmailed-by-TripAdvisor-reviewers/

THE DAILY MAIL - The holidaymakers' blackmail: Hotel guests using threat of poor TripAdvisor reviews to demand free upgrades and refunds $(23 / 11 / 2011)$

http://www.dailymail.co.uk/news/article-2064616/TripAdvisor-reviews-used-holidaymakers-blackmail-hotels.html

PR FIRE - Gay travel group to sue TripAdvisor (30/08/2011)

http://www.prfire.co.uk/travel-tourism/gay-travel-group-to-sue-TripAdvisor-71477.html

THE TELEGRAPH - Companies must learn from Qantas Twitter gaffe and TripAdvisor blackmails $(27 / 11 / 2011)$

http://www.telegraph.co.uk/technology/social-media/8912701/Companies-must-learn-from-Qantas-Twitter-gaffe-andTripAdvisor-blackmails.html

Fuente: Elaboración propia

Estas prácticas abren la puerta a otro tipo de chantajes (blackmail) en los que no es necesario haber estado alojado en el hotel. Bastaría con mandarles un email reclamándoles una cantidad de dinero si no quieren que su hotel se vea plagado de críticas falsas.

Después de meses de polémicas, en Enero de 2013, TripAdvisor establece un sistema de denuncia de posibles chantajes por parte de clientes 
(TripAdvisor Insights, 2013c). Los hoteles deben facilitar a TripAdvisor información de la persona que piensa que va a escribir una crítica malintencionada para que, de esta forma, pueda actuar no publicando dicha crítica

TripAdvisor, finalmente reconoció la existencia de un problema importante y tomó medidas para evitarlo, implementando un sistema que parece adecuado. Aunque la LOPD (Ley Orgánica 15/1999, de 13 de diciembre, de Protección de Datos de Carácter Personal), hace complicada la implantación de ese sistema en España, ya que exige el facilitar datos de carácter personal a un tercero (TripAdvisor) sin autorización del cliente.

\subsubsection{Hoteles con descuentos por escribir opiniones positivas}

Una situación, relacionada con la problemática ya descrita en el punto 11.2, ha sido el ofrecimiento por parte de los hoteles de descuentos o servicios gratuitos a los clientes que escriban críticas positivas sobre sus establecimientos. Este es el caso de The Cove Hotel in Cornwall (Reino Unido), cuyas ofertas especiales por escribir opiniones positivas en TripAdvisor (Figura 51), fueron recogidas en diversos medios de comunicación durante Julio de 2011.

Figura 51. Artículo en The Mirror

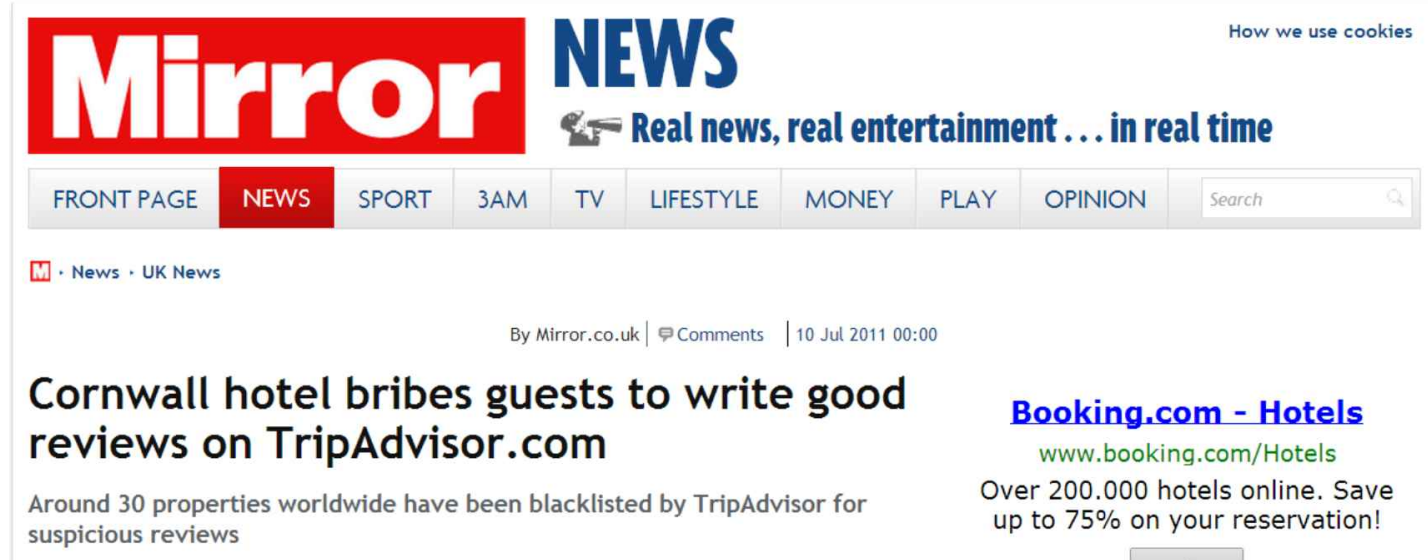

Fuente: http://www.mirror.co.uk/news/uk-news/cornwall-hotel-bribes-guests-to-write-140593 
Tabla 40. Hoteles con descuentos por escribir opiniones positivas

THE MIRROR - Cornwall hotel bribes guests to write good reviews on TripAdvisor.com $(07 / 10 / 2011)$

http://www.mirror.co.uk/news/uk-news/cornwall-hotel-bribes-guests-to-write-140593

THE DAILY MAIL - TripAdvisor bribes: Hotel owners offer free rooms in return for glowing reviews $(07 / 11 / 2011)$

http://www.dailymail.co.uk/travel/article-2013391/TripAdvisor-Hotel-owners-bribe-guests-return-good-reviews.html

THE TELEGRAPH - How to spot a fake hotel review (22/08/2011)

http://www.telegraph.co.uk/travel/travelnews/8716786/How-to-spot-a-fake-hotel-review.html

Fuente: Elaboración propia

El hotel, hasta Julio de 2011 recibió 26 críticas durante ese año, otorgándole 24 de ellas la máxima puntuación de 5. En Diciembre de 2011 el hotel seguía teniendo una valoración especialmente alta (4,5 sobre 5$)$, sin que hubiera aparecido el temido "cartel rojo". En Septiembre de 2014, aparecían 175 opiniones de las cuales 100 otorgaban esa máxima puntuación y la puntuación media había bajado a 4. Estas cifras parecen confirmar las sospechas que en su momento tuvo TripAdvisor sobre prácticas inadecuadas que mejoraban sus puntuaciones.

\subsubsection{Investigación de la Advertising Standards Authority}

Desde 2010 se ha puesto de manifiesto el descontento y preocupación de muchos hoteleros con el sistema de críticas de TripAdvisor en Reino Unido, liderados por empresarios como Duncan Bannatyne ${ }^{44}$ (Figura 52).

Figura 52. Artículo en Daily Mail

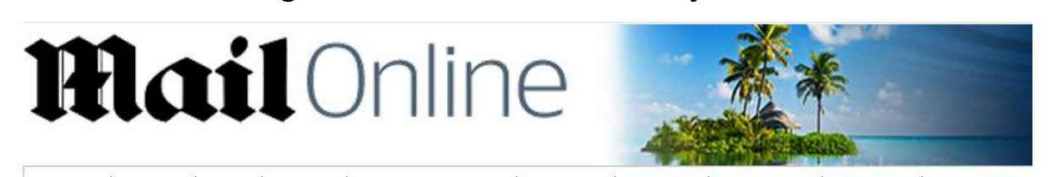

Home | News | U.S. | Sport | TV\&Showbiz | Femail | Health | Science | Money | RightMin Travel Home | Destinations | Holiday Types | Expert Reviews | Mail Travel | Travel Boards | Travel Blog | Cele

Duncan Bannatyne launches
$\begin{aligned} & \text { War of words against } \\ & \text { Expats }\end{aligned}$

Fuente: http://www.dailymail.co.uk/travel/article-1350025/TripAdvisor-

feels-wrath-Dragons-Den-star-Duncan-Bannatyne.html

\footnotetext{
${ }^{44}$ Empresario escocés, dedicado a diversas actividades entre las que se encuentran los centros de salud, spas y hoteles. Famoso en Reino Unido por su aparición en el programa de la BBC Dragons' Den.
} 
Pero es en Septiembre de 2010, cuando la consultora KwikChex ${ }^{45}$ manifiesta públicamente su intención de emprender acciones legales contra TripAdvisor, por las críticas falsas a hoteles y restaurantes, en representación de 400 establecimientos del Reino Unido. El 1 de Septiembre de 2011 la Advertising Standards Authority (ASA) confirma el comienzo de una investigación formal ante las quejas de los hoteles representados por KwikChex (Figura 53). En ese momento eran 2.000 los hosteleros representados por esta empresa.

Figura 53. Artículo en BBC news

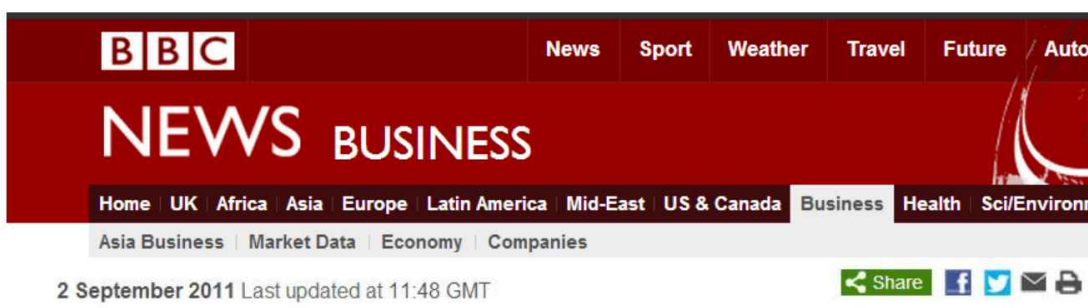

\section{ASA probes TripAdvisor's reviews}
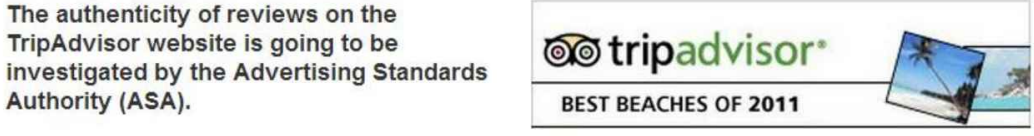

Fuente: http://www.bbc.co.uk/news/business-14764016

Tabla 41. Investigación de la Advertising Standards Authority

FORBES - Expedia: U.K. Launches Probe Of Fake Reviews On TripAdvisor (02/09/2011)

http://www.forbes.com/sites/ericsavitz/2011/09/02/expedia-u-k-launches-probe-of-fake-reviews-on-TripAdvisor/

THE GUARDIAN - TripAdvisor faces ASA investigation after review complaints (02/09/2011)

http://www.guardian.co.uk/media/2011/sep/02/TripAdvisor-asa-investigation-reviews

CNN - TripAdvisor scolded by UK ad regulator for 'trust' claims (01/02/2012)

http://www.cnn.com/2012/02/01/travel/tripadvisor-advertising-uk/

BBC News - TripAdvisor rebuked over 'trust' claims on review site (01/02/2012)

http://www.bbc.com/news/technology-16823012

SKY NEWS - TripAdvisor Faces 'Fake' Reviews Claims (01/02/2012)

http://news.sky.com/home/business/article/16160689

FINANCIAL TIMES - TripAdvisor censured over 'trusted reviews' (01/02/2012)

http://www.ft.com/intl/cms/s/0/d5dbfb92-4cc7-11e1-8b08-00144feabdc0.html\#axzz3AI0GEZaD

THE ECONOMIST - Tripped up (01/02/2012)

http://www.economist.com/blogs/gulliver/2012/02/tripadvisor

CBS NEWS - TripAdvisor can't claim UK reviews are reliable (01/02/2012)

http://www.cbsnews.com/8301-505245_162-57369669/TripAdvisor-cant-claim-uk-reviews-are-reliable/

Fuente: Elaboración propia

\footnotetext{
${ }^{45}$ www.kwikchex.com: Consultura especializada en reputación online.
} 
A finales de 2011 TripAdvisor cambió su slogan "reviews you can trust" por el de "reviews from our community". Según TripAdvisor ese cambio no tuvo relación alguna con la investigación de la ASA. En Diciembre de 2011 TripAdvisor había retirado su slogan en las páginas de Reino Unido y Estados Unidos, mientras para el resto de países del mundo utilizaba "The world largest travelsite".

El 1 de Febrero de 2012, ASA emitió su veredicto al respecto (ASA, 2012), dando la razón a los hoteles demandantes liderados por KwikChex (Figura 54). La resolución concluye de la siguiente forma:

"The ad must not appear again in its current form. We told TripAdvisor not to claim or imply that all the reviews that appeared on the website were from real travellers, or were honest, real or trusted. ${ }^{146}$

La respuesta official de TripAdvisor fue:

"We have confidence that the 50 million users who come to our site every month trust the reviews they read on TripAdvisor, which is why they keep coming back to us in increasingly larger numbers to plan and have the perfect trip ${ }^{377}$

Figura 54. Artículo en BBC News

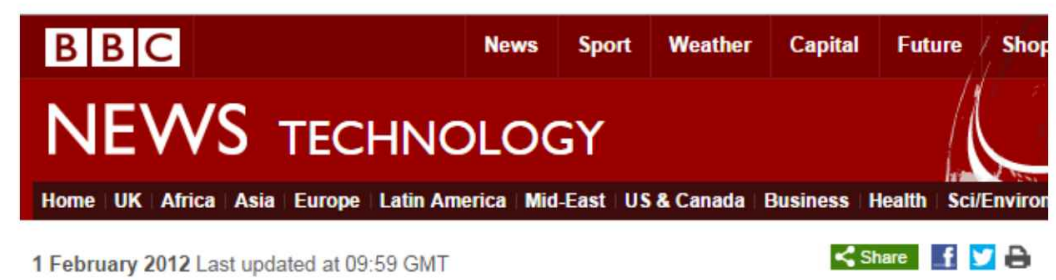

\section{TripAdvisor rebuked over 'trust' claims on review site}

TripAdvisor has been ordered to rewrite some of its marketing claims by the UK's Advertising Standards Authority.

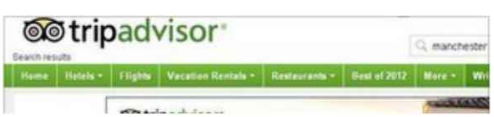

Fuente: http://www.bbc.com/news/technology-16823012

\footnotetext{
46 “El anuncio no debe aparecer de nuevo en su forma actual. Ordenamos a TripAdvisor no reclamar o implicar que todas las críticas que aparecen en el sitio web son de viajeros reales, que son honestas, verdaderas o fiables."

47 "Tenemos confianza en que los 50 millones de usuarios que visitan nuestra web cada mes la confían en los comentarios que leen en TripAdvisor, por eso que nos siguen visitando en cada vez más, para planificar y tener el viaje perfecto."
} 


\section{Gráfico 34. Valor de la acción Enero-Abril 2012}

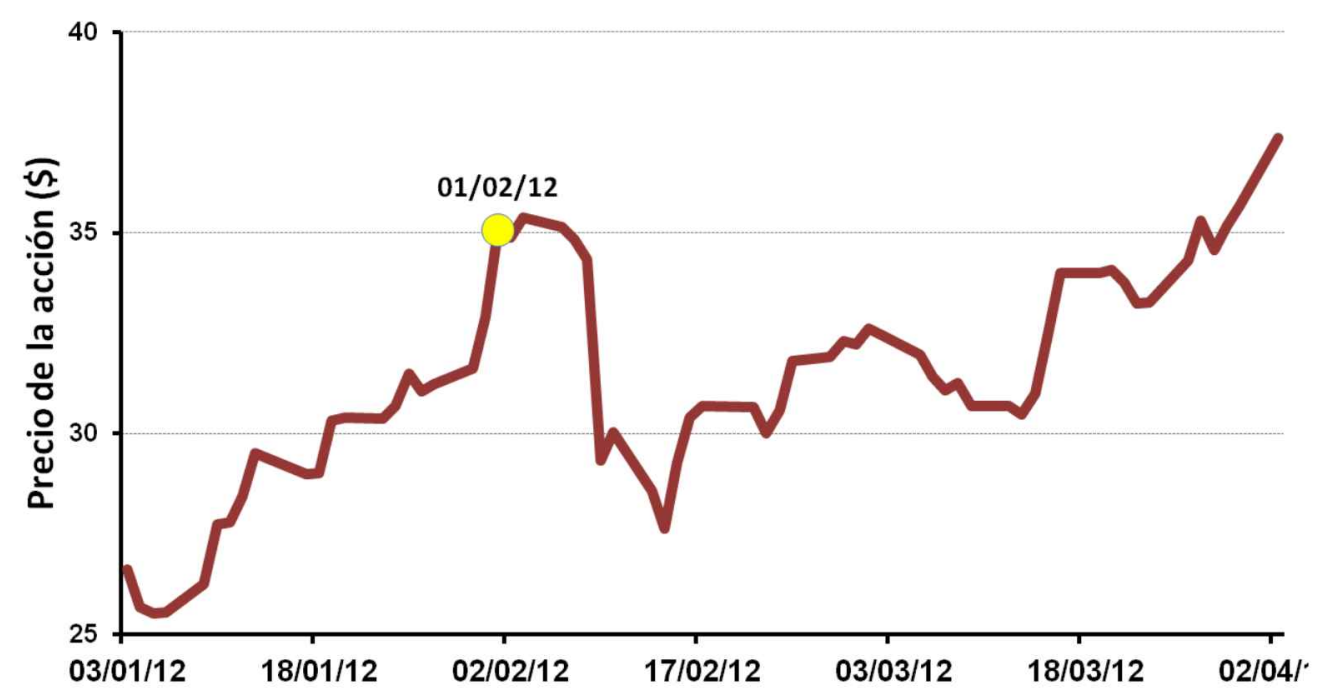

Fuente: Elaboración propia con datos de Nasdaq

En el Gráfico 34 observamos una importante caída en la cotización de las acciones, tras la resolución contraria a TripAdvisor. Pero resulta sorprendente que el supuesto efecto, en lugar de ser inmediato, tardara varios días en producirse. En todo caso, a las pocas semanas, el valor de la acción se recuperó por completo.

\subsubsection{El grupo Carlton y las opiniones de sus empleados}

Según distintos autores, las buenas calificaciones de un hotel propician un incremento en las ventas y/o un aumento de los precios que los viajeros están dispuestos a pagar (Melnik \& Alm, 2002; Yacouel \& Fleischer, 2012). Resulta, por lo tanto razonable que los hoteles procuren un incremento de sus valoraciones en webs como TripAdvisor. En algunos casos, esas opiniones también son un importante elemento para evaluar la gestión que realizan los responsables de los hoteles. Un ejemplo es la iniciativa que en 2010 tomó la cadena Meliá, que fue recogida en diversos medios de comunicación nacionales. El diario Expansión (Expansión, 2010) titulaba de esta forma la noticia: "Sol Meliá vincula los salarios a la opinión de los clientes en Internet. Los directores de los 350 establecimientos de la cadena española empiezan a tener hasta un $20 \%$ de su retribución variable ligada al ranking de hoteles de TripAdvisor". Este tipo de iniciativas, pueden suponer un estímulo adicional 
para que los gestores de los hoteles promuevan la inclusión de opiniones falsas.

TripAdvisor no hace públicos los casos concretos en los que se detectan fraudes de este tipo, limitándose a incorporar el "cuadro rojo" cuando lo estima oportuno. Pero en algunos casos, estos incidentes han sido difundidos por medios de comunicación, lo que contribuye a socavar la credibilidad de TripAdvisor. En este apartado y en los dos siguientes, mostramos los casos difundidos internacionalmente.

En Julio de 2010 la dirección del grupo hotelero Carlton en Irlanda, envió un email a 10 hoteles de la cadena para que creasen equipos de 5 personas, dedicadas a escribir opiniones positivas de sus hoteles en TripAdvisor. Según los hoteles implicados, el plan nunca se llevó a cabo y no se llegaron a escribir opiniones (Figura 55).

Figura 55. Artículo en NBC News

\section{三 DBNBCNEWS HOME LATEST SEARCH Q \\ TRAVEL}

\section{DISCUSS AS: I Sign in . \\ Report: Irish hotel chain sought to game TripAdvisor's system}

Tuesday Jan 31, 2012 12:08 PM

Fuente: http://overheadbin.nbcnews.com/_news/2012/01/31/10280803-reportirish-hotel-chain-sought-to-game-tripadvisors-system

Tabla 42. El grupo Carlton y las opiniones de sus empleados

THE HUFFINGTON POST - TripAdvisor's Fake Review Problem (02/16/12)

http://www.huffingtonpost.co.uk/peter-mcguire/tripadvisors-fake-review-problem b_1243907.html

NBC NEWS - Report: Irish hotel chain sought to game TripAdvisor's system (01/31/2012)

http://overheadbin.nbcnews.com/_news/2012/01/31/10280803-report-irish-hotel-chain-sought-to-game-tripadvisorssystem

TNOOZ - Irish hotel group denies employees told to post positive reviews (01/31/2012)

http://www.tnooz.com/article/irish-hotel-group-denies-employees-told-to-post-positive-reviews/

Fuente: Elaboración propia

La noticia se difundió en los medios de comunicación un día antes del citado veredicto de la ASA. Por lo tanto, el gráfico 34 muestra las cotizaciones 
en bolsa para esos dias. La respuesta oficial de TripAdvisor ante este incidente fue:

"Attempts to manipulate TripAdvisor are extremely rare as the vast majority of hoteliers understand the tremendous risk to their reputation and their business if they attempt to do this. We take serious steps to penalise businesses who are caught attempting to game the system. Posting fraudulent material is both a violation of our terms of use and against the law in many countries.",48

\title{
11.6.9. Ramada Hotel de Glasgow haciendo que sus empleados
}

\section{escriban opiniones}

En Octubre de 2012, el director del Ramada Glasgow Airport Hotel, fue acusado por uno de sus empleados de enviar emails al personal, animándoles a escribir opiniones positivas sobre el establecimiento. Frank Long, negó tal circunstancia, tal y como parece que había anunciado en los emails distribuidos. El hecho tuvo cierta repercusión en medios de comunicación, especialmente británicos (Figura 56), sin aparecer publicaciones posteriores sobre los resultados de la investigación que (supuestamente) se iba a abrir al respecto.

Figura 56. Artículo en Daily Mail

\section{mail Online}

\begin{abstract}
Home News U.S. | Sport | TV\&Showbiz | Australia | Femail | Health | Science | Money | Video | Travel | Fashion Finder
News Home | Arts | Headlines | Pictures | Most read | News Board | Wires $\quad$ Login

'Dear staff. We could do with some positive $\overbrace{}^{-5 \text { te } O \text { wet }}$ Enter your search Q Search comments': Hotel boss is caught telling his workers to post fake reviews on TripAdvisor

Fuente: http://www.dailymail.co.uk/news/article-2214974/Hotel-boss-caught-

telling-workers-post-fake-reviews-TripAdvisor.html
\end{abstract}

\footnotetext{
48 “Los intentos de manipular TripAdvisor son extremadamente raros debido a que la gran mayoría de los hoteleros entienden el tremendo riesgo que existe para su reputación y su negocio si intentan hacerlo. Tomamos medidas serias para penalizar a las empresas que son descubiertos tratando de infringir las normas del sistema. Publicar contenidos falsos es una violación de nuestros términos de uso y además es contrario a la ley en muchos países."
} 
Tabla 43. Ramada Hotel de Glasgow haciendo que sus empleados escriban opiniones

THE MIRROR - Hotel boss tells staff: Post glowing reviews on TripAdvisor by pretending to be guests who stayed here (09/10/2012)

http://www.mirror.co.uk/news/uk-news/tripadvisor-ramada-glasgow-airport-hotel-1368292

THE DAILY MAIL - 'Dear staff. We could do with some positive comments': Hotel boss is caught telling his workers to post fake reviews on TripAdvisor (09/10/2012)

http://www.dailymail.co.uk/news/article-2214974/Hotel-boss-caught-telling-workers-post-fake-reviews-TripAdvisor.html

THE DAILY RECORD - Hotel boss tells staff to write fake reviews, then vows to 'deny everything' if caught $(09 / 10 / 2012)$

http://www.dailyrecord.co.uk/news/scottish-news/hotel-boss-tells-staff-to-write-1368462

Fuente: Elaboración propia

La noticia fue publicada por "Daily Mail” el 9 de Octubre de 2012 y de ahí se ha sacado la captura de pantalla de la ficha del hotel en TripAdvisor, donde aparecen sus valoraciones en aquella fecha. Repetimos la operación el 2 de Marzo de 2014, visitando el perfil del hotel en esa fecha (Figura 57).

Figura 57. Valoraciones del hotel en TripAdvisor

\section{Ramada Glasgow Airport Hotel}

\section{Octubre 2012}

\section{Traveller rating}

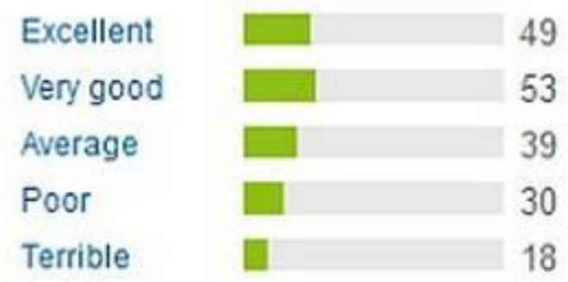

Total opiniones: 189
Marzo 2014

Traveller rating

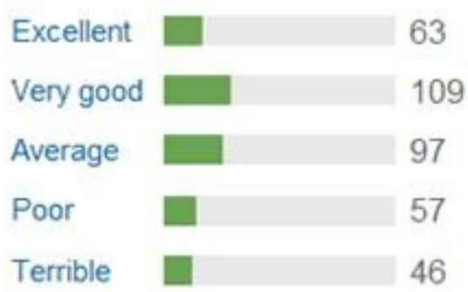

Total opiniones: $372(+97 \%)$

Fuente: TripAdvisor

Tras año y medio, el número de opiniones registradas casi se había duplicado (+97\%), pero encontramos diferencias significativas en las puntuaciones obtenidas. Las opiniones otorgando la puntuación máxima (excellent) sólo habían aumentado en un $28 \%$, en lugar de duplicarse como en el resto de categorias. Es decir, las opiniones extremadamente positivas de este hotel, han pasado de suponer un $26 \%$ hasta la denuncia, a ser el $8 \%$ desde entonces. 
Tras la publicación de la noticia, Frank Long dejo de ser el director del hotel, tras 5 años en el cargo, para regentar otro establecimiento hotelero, según indica su perfil de Linkedin ${ }^{49}$.

La respuesta oficial de TripAdvisor ante este incidente fue:

"Our content integrity team are investigating as a matter of urgency and if the hotel has been attempting to manipulate the TripAdvisor system, they will be penalised accordingly. Review fraud is also a violation of the law in many countries."

"The vast majority of property owners and managers understand the tremendous risk to their reputation and business if they attempt to post fraudulent information on review sites."

"We employ a number of methods of penalisation for businesses that attempt to manipulate our system, including affecting their popularity rating on the site and posting public warning notices on hotels that have made attempts to manipulate their rating. ${ }^{350}$

Gráfico 35. Valor de la acción Septiembre-Diciembre 2012

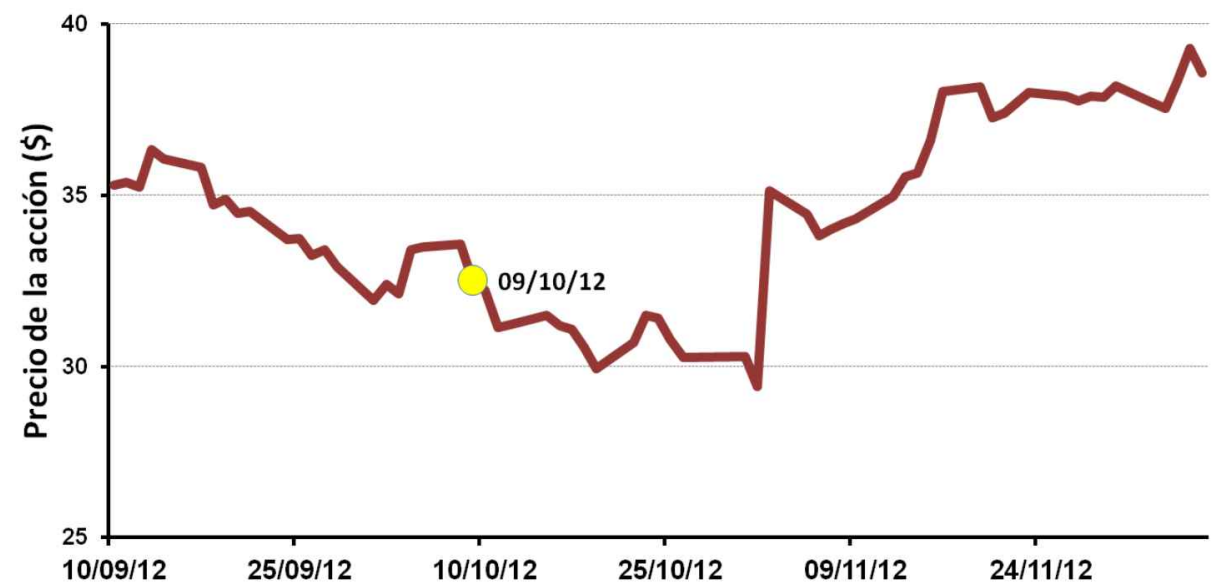

Fuente: Elaboración propia con datos de Nasdaq

\footnotetext{
${ }^{49}$ http://www.linkedin.com/pub/frank-long/59/ba1/7a0

50 "Nuestro equipo de la integridad del contenido están investigando con carácter de urgencia el asunto y si el hotel ha estado tratando de manipular el sistema de TripAdvisor, será sancionado en consecuencia. El fraude en las opiniones es también una violación de la ley en muchos países.

La gran mayoría de los propietarios y gerentes comprenden el tremendo riesgo para su reputación y negocio si intentan publicar información fraudulenta en webs de opiniones.

Contamos con métodos de penalización a las empresas que tratan de manipular nuestro sistema, incluyendo afectar su índice de popularidad en la web y la publicación de avisos de advertencia públicos en hoteles que han hecho intentos de manipular su puntuación."
} 
Parece que podría existir un pequeño impacto en las valoraciones tras el incidente, pero lo cierto es que las cotizaciones ya arrastraban una tendencia negativa durante el mes de Septiembre, que continuó hasta final de Octubre (Gráfico 35). En la primera semana de Noviembre todas esas pérdidas se habían recuperado y para finales de ese mes la cotización ya era un $20 \%$ superior a la del día del incidente.

\subsubsection{Un ejecutivo de Accor escribiendo opiniones}

Peter Hook, director de relaciones públicas en la cadena hotelera Accor para Asia y Pacífico, fue sorprendido en Mayo de 2013, escribiendo opiniones sobre hoteles de su compañía y de la competencia (Figura 58). Peter utilizaba un seudónimo, pero fue detectado al usar la aplicación para Facebook de TripAdvisor, en la que aparecía su foto. Aunque el autor siempre mantuvo que sus opiniones eran honestas, abandonó la compañía al mes siguiente, tras 18 años de servicio.

Figura 58. Artículo en The Telegraph

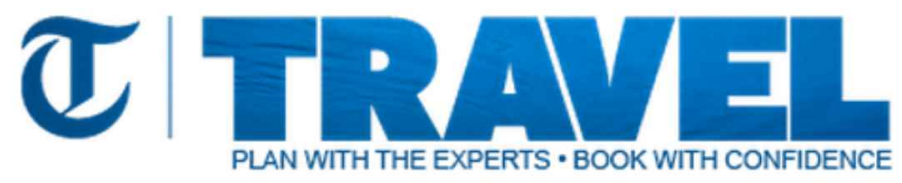

\begin{tabular}{|l|l|l|l|l|l|l|}
\hline$\widetilde{C}$ Home & Hotels & Destinations & Cruise & USA & Family & \\
\hline
\end{tabular}

HOME " TRAVEL " TRAVEL NEWS

TripAdvisor reviewer exposed as hotel executive

A senior executive at one of the world's largest hotel groups has admitted breaching TripAdvisor's rules by posting dozens of glowing reviews about the firm's properties.

Fuente: http://www.telegraph.co.uk/travel/travelnews/10076753/TripAdvisor-reviewerexposed-as-hotel-executive.html

Tabla 44. Ejecutivo de Accor escribiendo opiniones

THE NEW YORK TIMES - With Everyone a Critic, Hoteliers Struggle to Cope (27/05/2013) http://www.nytimes.com/2013/05/28/business/hotel-industry-deals-with-its-online-critics.html?_r=0

THE TELEGRAPH - TripAdvisor reviewer exposed as hotel executive (24/05/2013) http://www.telegraph.co.uk/travel/travelnews/10076753/TripAdvisor-reviewer-exposed-as-hotel-executive.html

TRAVEL WEEKLY - Accor suspends exec who posted fake reviews (04/06/2013) http://www.travelweekly.com/Travel-News/Hotel-News/Accor-suspends-exec-who-posted-fake-reviews/

Fuente: Elaboración propia 
La respuesta oficial de TripAdvisor fue:

"It would clearly be inappropriate for a senior executive of a hotel company to review hotels within their own company. All hotel reviews posted by this member are being removed pending investigation."

"As well as all reviews being screened by our world-class tools for fraud, we also benefit from a large and passionate community of more than 200 million monthly visitors who let us know if something is potentially amiss, as in this case. ${ }^{151}$

Gráfico 36. Valores de la acción Abril-Julio 2013

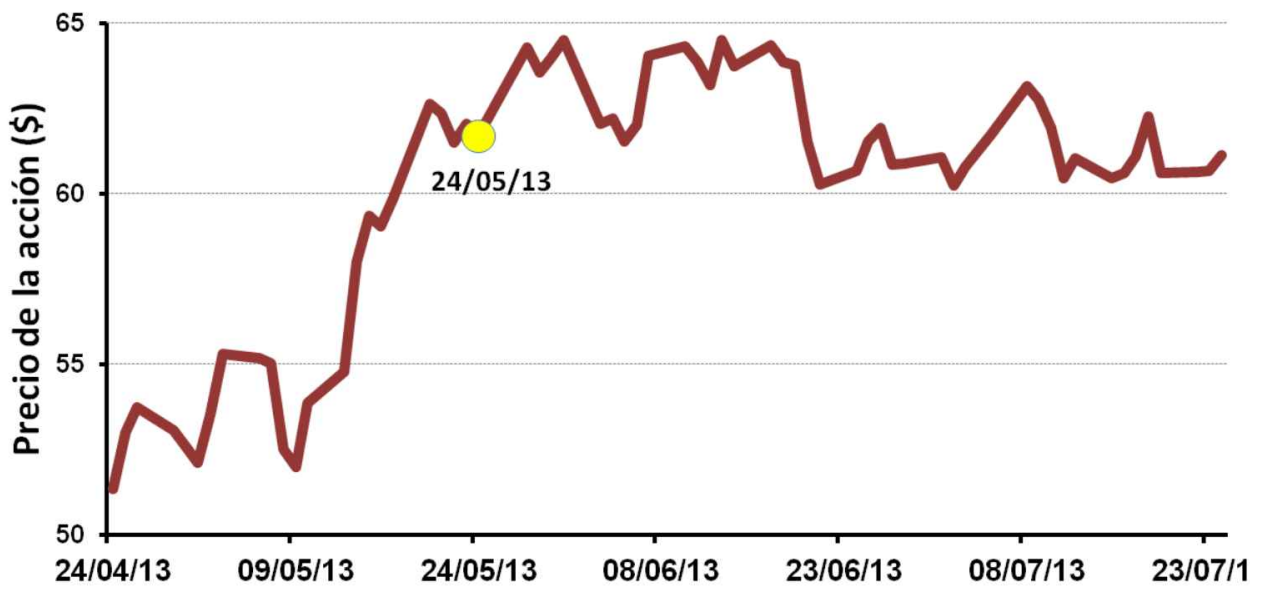

Fuente: Elaboración propia con datos de Nasdaq

Como se muestra en el Gráfico 36, el valor de la acción sugiere que no hubo ningún tipo de efecto negativo tras la publicación de la noticia.

\subsubsection{1. "Albergue de vagabundos" en Glasgow}

Una forma de demostrar la falta de control en TripAdvisor y la posibilidad de introducir información fraudulenta sin ser detectado, sería generando contenido falso, lo que pondría en evidencia al portal web. Esta podría ser una buena opción para el desarrollo de una investigación, pero su práctica

\footnotetext{
51 "Sería claramente inapropiado para un alto ejecutivo de una empresa hotelera escribir opiniones de los hoteles de su propia empresa. Todos los comentarios de los huéspedes publicados por este usuario, se están eliminando y queda pendiente de investigación.

Además todas las críticas son revisadas mediante nuestras magníficas herramientas de detección de fraude, que también se benefician de una comunidad grande y apasionada de más de 200 millones de visitantes mensuales que nos permiten saber si algo es potencialmente incorrecto, como en este caso."
} 
contravendría la política de uso de TripAdvisor y, probablemente, cierta legislación.

Algunos individuos, amparándose en el anonimato, han puesto en práctica esta metodología. Creemos interesante describir los casos en los que se ha llevado a cabo esta práctica, teniendo importante repercusión en medios de comunicación, dedicando este apartado y los dos siguientes a este tipo de casuística. Si bien éstos hechos no pueden ser usados como elementos de medida de la fiabilidad de TripAdvisor, son factores adicionales que socaban su credibilidad.

En Abril de 2013, un grupo de "bromistas" situó un albergue para vagabundos de Glasgow (Bellgrove Hotel) entre los 100 mejores hoteles del Reino Unido, sin ser detectados por TripAdvisor (Figura 59). Finalmente, la dirección del albergue, hartos de llamadas de personas queriendo hacer reservas en el establecimiento, contactó con TripAdvisor y se borró todo rastro del albergue en su web. Se logró acceder al caché de Google y recuperar una imagen como prueba (Figura 60).

Figura 59. Artículo en The Independent

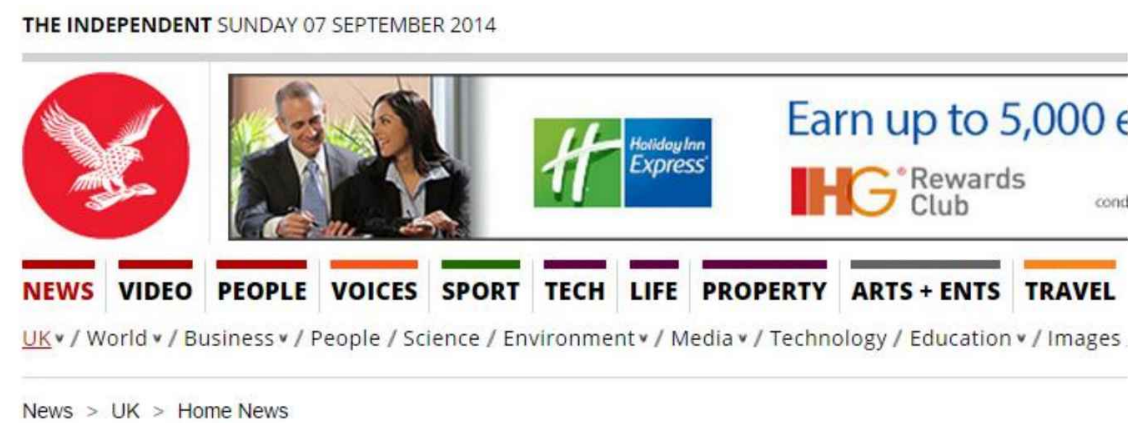

\section{Glasgow homeless hostel makes Tripadvisor's top 100 UK hotels after 'jokers' post comedy reviews}

Fuente: http://www.independent.co.uk/news/uk/homenews/glasgow-homeless-hostel-makes-tripadvisors-top-100-ukhotels-after-jokers-post-comedy-reviews-8588432.html 
Figura 60. Perfil eliminado del Bellgrove Hotel

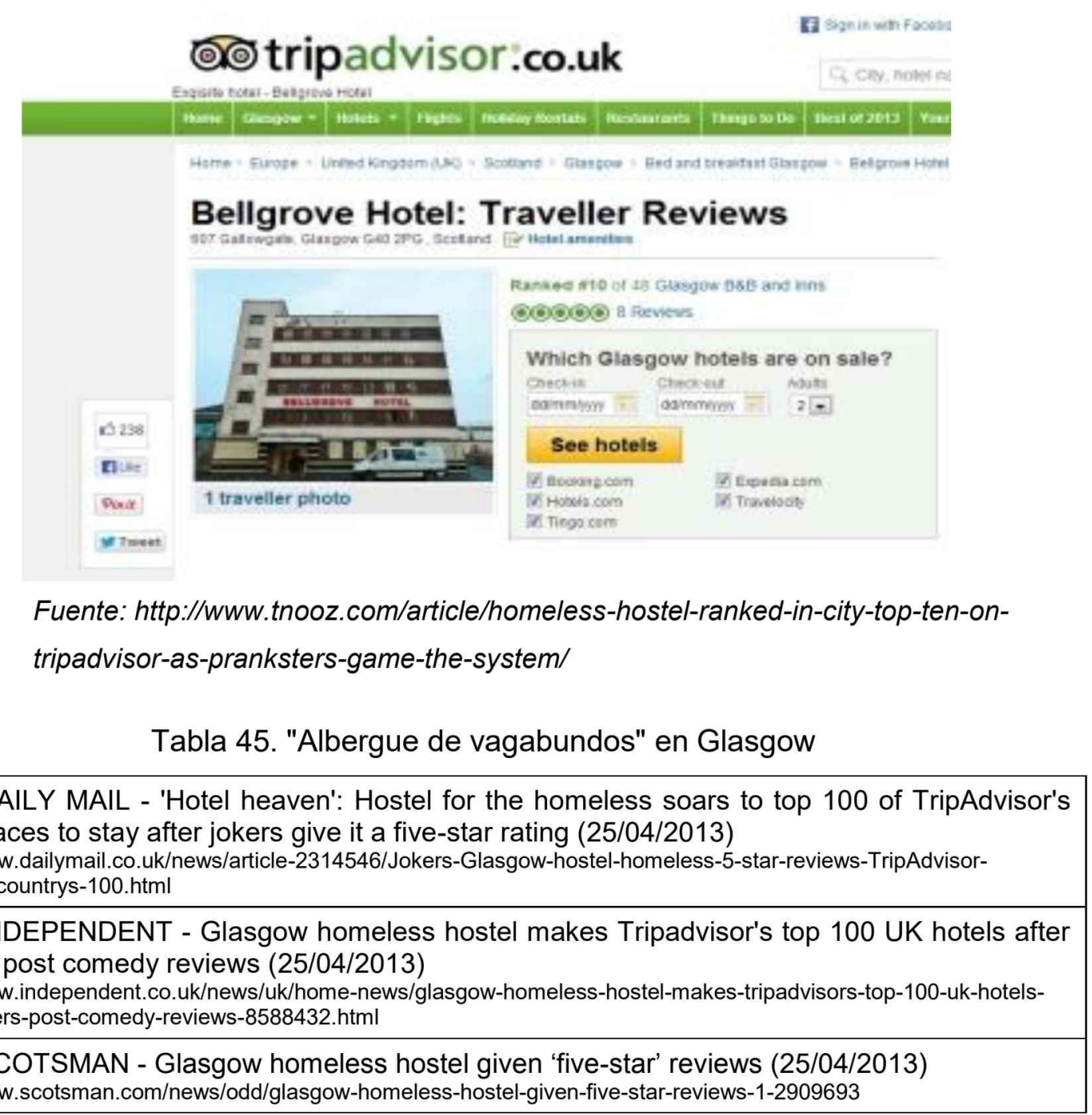

THE DAILY MAIL - 'Hotel heaven': Hostel for the homeless soars to top 100 of TripAdvisor's best places to stay after jokers give it a five-star rating (25/04/2013)

http://www.dailymail.co.uk/news/article-2314546/Jokers-Glasgow-hostel-homeless-5-star-reviews-TripAdvisor-

sending-countrys-100.htm

THE INDEPENDENT - Glasgow homeless hostel makes Tripadvisor's top 100 UK hotels after 'jokers' post comedy reviews $(25 / 04 / 2013)$

http://www.independent.co.uk/news/uk/home-news/glasgow-homeless-hostel-makes-tripadvisors-top-100-uk-hotelsafter-jokers-post-comedy-reviews-8588432.html

THE SCOTSMAN - Glasgow homeless hostel given 'five-star' reviews (25/04/2013)

http://www.scotsman.com/news/odd/glasgow-homeless-hostel-given-five-star-reviews-1-2909693

Fuente: Elaboración propia

La respuesta oficial de TripAdvisor fue:

"Thank you for alerting us to this. As this property is a homeless shelter, and therefore doesn't meet our listing guidelines, the listing itself is being removed from TripAdvisor."

"With over 60 pieces of content coming in every minute, occasionally a review or business that does not meet TripAdvisor's guidelines may slip 
through the cracks, and in these rare cases, our members can report the material to us, helping maintain the high quality content of our site. ${ }^{352}$

El valor de las acciones no parece que se viera afectado negativamente por este incidente (Gráfico 37).

Gráfico 37. Valores de la acción Marzo-Junio 2013

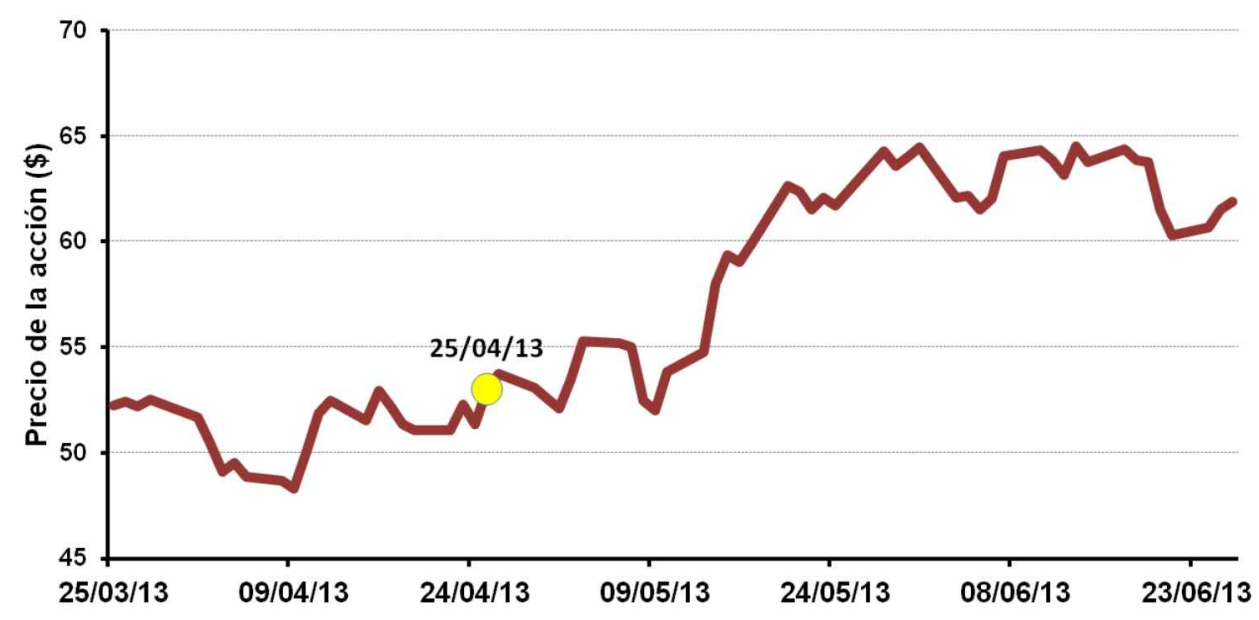

Fuente: Elaboración propia con datos de Nasdaq

\subsubsection{Un Restaurante inexistente}

Otro "bromista", actuando bajo el seudónimo de Oscar Parrot, creó en el verano de 2013 un restaurante ficticio en la localidad británica de Brixham (Figura 61). En pocas semanas consiguió, con la ayuda de colaboradores, escribir varias críticas extremadamente positivas, situando el establecimiento entre los mejores valorados en el ranking de TripAdvisor. La experiencia completa se narra en un libro publicado al efecto (Meeson \& Parrot, 2013). objetivo del autor no era otro que demostrar la vulnerabilidad de TripAdvisor y dar difusión a la historia en los medios.

\footnotetext{
52 “Gracias por alertarnos sobre esto. Como esta propiedad es un refugio para desamparados, y por lo tanto no cumple con nuestras directrices anuncio, la ficha del establecimiento está siendo retirada de TripAdvisor.

Con más de 60 opiniones cada minuto, de vez en cuando una opinión o negocio que no cumplen con las directrices de TripAdvisor pueden colarse, y en estos casos raros, nuestros usuarios pueden comunicarnos el incidente, ayudando a mantener el contenido de alta calidad de nuestro sitio web."
} 
Figura 61. Artículo en Fox News

- FOXNaWs

\section{Fake restaurant on TripAdvisor sends diners to alley filled with garbage cans}

Published July 29, 2013 - FoxNews.com

Fuente: http://www.foxnews.com/leisure/2013/07/29/fake-restaurant-ontripadvisor-sends-diners-to-alley-filled-with-garbage-cans/

Tabla 46. Un Restaurante inexistente

BBC NEWS - TripAdvisor removes fake Brixham restaurant Oscar's (30/07/2013)

http://www.bbc.com/news/uk-england-devon-23504081

THE TIMES - TripAdvisor fooled by fake 'floating' restaurant where staff don scuba gear to catch fish $(30 / 07 / 2013)$

http://www.thetimes.co.uk/tto/technology/internet/article3828886.ece

FOX NEWS - Fake restaurant on TripAdvisor sends diners to alley filled with garbage cans $(29 / 07 / 2013)$

http://www.foxnews.com/leisure/2013/07/29/fake-restaurant-on-tripadvisor-sends-diners-to-alley-filled-with-garbagecans/

FORBES - Fake Nautical Restaurant On Tripadvisor Gets Glowing Reviews (29/07/2013)

http://www.forbes.com/sites/grantmartin/2013/07/29/fake-restaurant-on-tripadvisor-gets-glowing-reviews/

Fuente: Elaboración propia

La respuesta oficial de TripAdvisor fue:

"With over 70 pieces of content coming in every minute covering more than 2.7 million properties around the world, occasionally a review or business that does not meet TripAdvisor's guidelines may slip through the cracks, and in these rare cases, our members can report the material to us, helping maintain the high quality content of our site. ${ }^{253}$

\footnotetext{
${ }^{53}$ Con más de 70 opiniones cada minuto y más de 2,7 millones de propiedades en el mundo, de vez en cuando una opinión o negocio que no cumplen con las directrices de TripAdvisor pueden colarse, y en estos casos raros, nuestros usuarios pueden comunicarnos el incidente, ayudando a mantener el contenido de alta calidad de nuestro sitio web
} 
Gráfico 38. Valores de la acción Junio-Septiembre 2013

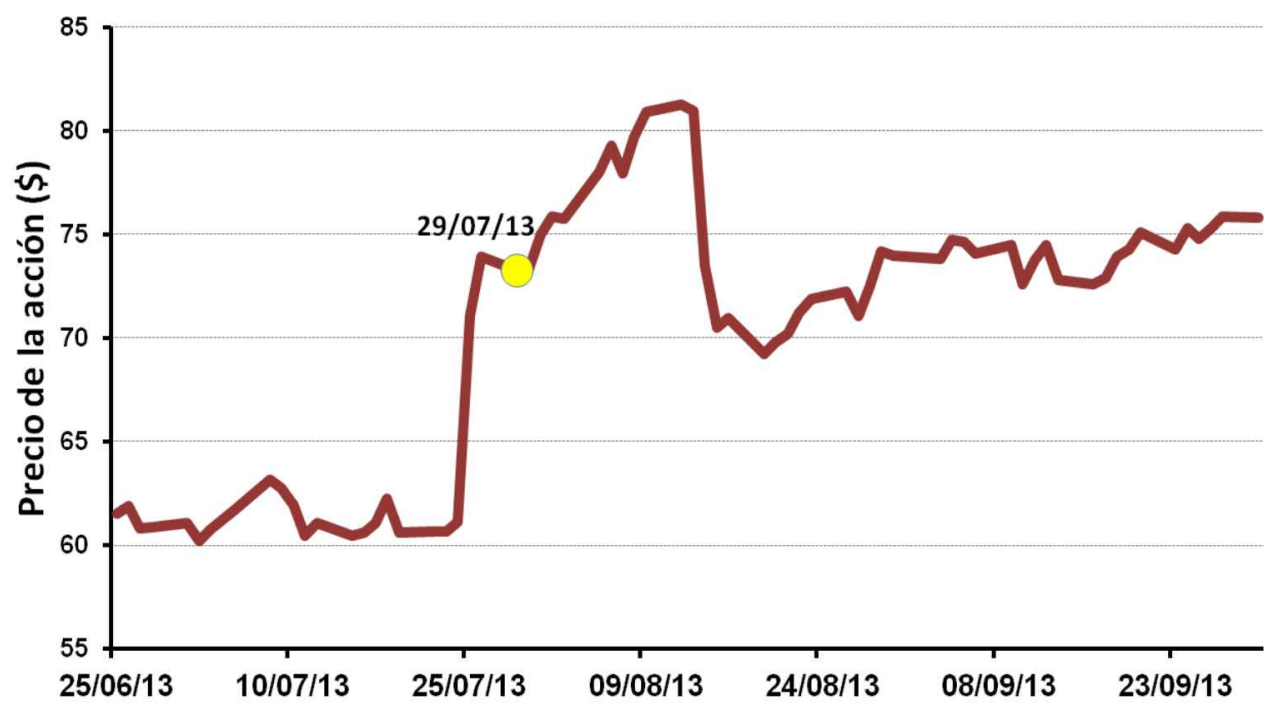

Fuente: Elaboración propia con datos de Nasdaq

El incidente no tuvo efectos negativos en la cotización de las acciones, sino que marca el comienzo de una racha alcista que incrementó el valor de las mismas en un $20 \%$ en un plazo inferior a un mes (Gráfico 38 ).

\subsubsection{Una señora escocesa clasificada como atracción turística}

En Febrero de 2014 sucedió algo similar en la ciudad de Glasgow, pero esta vez no se trató de un hotel o restaurante, sino que fue una atracción local, sobre las que TripAdvisor también permite escribir opiniones y puntuar. La atracción en cuestión era una señora de 60 años, Mary Johnston, víctima de otro fraude premeditado, que tardó varios días en ser detectado por TripAdvisor (Figura 62). Durante ese tiempo, logró situarse como la atracción número 87 de las 163 que se encuentran catalogadas en el ranking de TripAdvisor para Glasgow.

Figura 62. Artículo en Metro

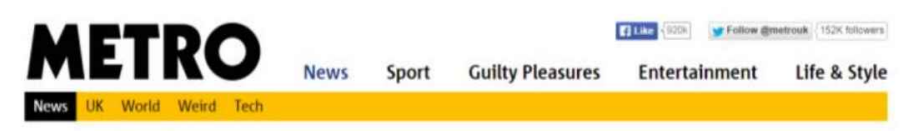

\section{Woman inadvertently becomes 87 th best Glasgow attraction after TripAdvisor mistake}

Fuente: http://metro.co.uk/2014/02/27/woman-inadvertently-becomes-

87th-best-glasgow-attraction-after-tripadvisor-mistake-4325826/ 
Tabla 47. Una señora escocesa clasificada como atracción turística

THE DAILY MAIL - Mary, 60, is voted Glasgow's 87 th most popular tourist destination after accidentally signing herself up on TripAdvisor (27/02/2014)

http://www.dailymail.co.uk/news/article-2569352/Mary-60-voted-Glasgows-87th-popular-tourist-destination-

accidentally-signing-TripAdvisorMary-XX-voted-Glasgows-87th-popular-tourist-destination-accidentally-signing-

TripAdvisor.html

METRO - Woman inadvertently becomes 87th best Glasgow attraction after TripAdvisor mistake $(27 / 02 / 2014)$

http://metro.co.uk/2014/02/27/woman-inadvertently-becomes-87th-best-glasgow-attraction-after-tripadvisor-mistake4325826/

THE HUFFINGTON POST - 'Mary Johnston Is Ready For Reviews': Woman Listed As Tourist Attraction On Tripadvisor (27/02/2014)

http://www.huffingtonpost.co.uk/2014/02/27/tripadvisor-mary-johnston-

\section{Fuente: Elaboración propia}

Gráfico 39. Valores de la acción Enero-Abril 2014

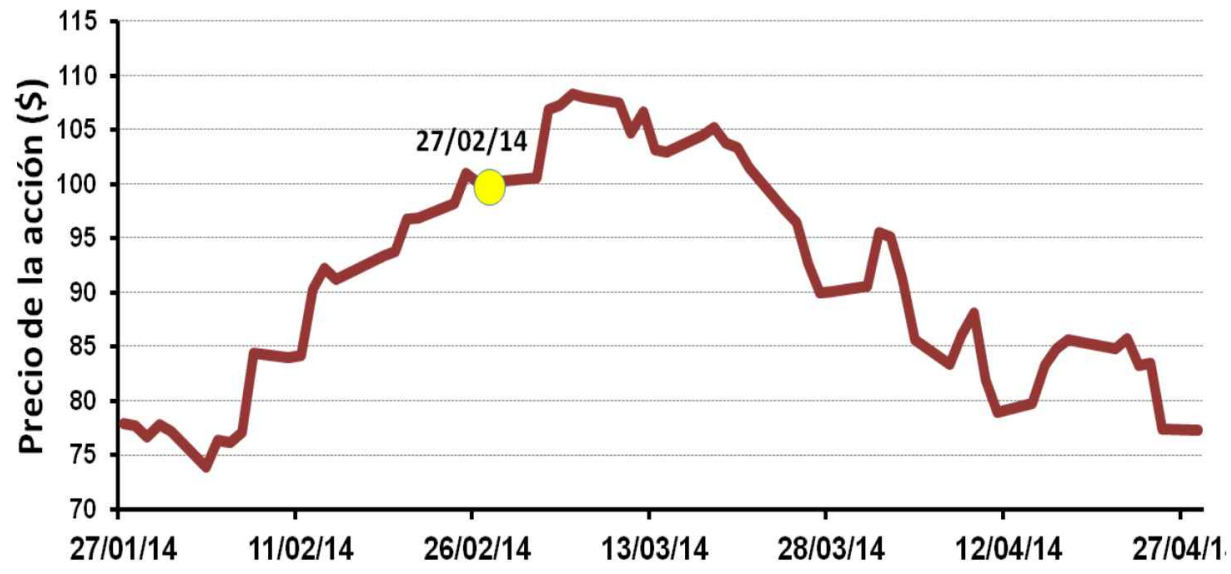

Fuente: Elaboración propia con datos de Nasdaq

En este caso el valor de las acciones tampoco pareció verse afectado por la noticia (Gráfico 39).

\subsubsection{TripAdvisor multada en Italia}

En Mayo de 2014, TripAdvisor está comenzó a ser investigada en Italia, en relación a las sospechas de que la web no está haciendo lo suficiente para evitar la inclusión de opiniones fraudulentas. La autoridad de defensa de la competencia italiana valoró si se incluían opiniones de personas que realmente no han estado en los sitios de los que hablan. Se cuestiona si el sistema es capaz de distinguir entre opiniones de viajeros reales e independientes y contenidos falsos pagados por hoteles o restaurantes. 
Figura 63. Artículo en Financial Times

ft.com > companies > retail\&consumer >

\section{Travel \& Leisure}

\begin{tabular}{|c|c|c|c|c|c|c|c|c|c|}
\hline Home & World - & Companies & 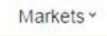 & Globa & al Economy & Lex. & Comment & Management - & Life \& Arts \\
\hline Energy 4 & Financials : & Heathr Industrials & Leaury 360 & Medla & Retall \& Consumerv & Techn & Telecoms Transf & It. By Region - & To \\
\hline
\end{tabular}

TripAdvisor defends anti-fraud measures

amid Italian probe

By Roger Blitz in London and Giulia Segreti in Rome

Fuente: $h$ ttp://www.ft.com/cms/s/0/2006d41e-e0da-11e3-a934-00144feabdc0. html\#axzz3AIOGEZaD

Tabla 48. TripAdvisor investigada en Italia

FINANCIAL TIMES - TripAdvisor defends anti-fraud measures amid Italian probe (21/05/2014) http://www.ft.com/cms/s/0/2006d41e-e0da-11e3-a934-00144feabdc0.html\#axzz3AI0GEZaD

BBC NEWS - Trip Advisor 'fake reviews' investigated in Italy (21/05/2014) http://www.bbc.com/news/technology-27486870

THE TELEGRAPH - TripAdvisor investigated over 'fake reviews' in Italy (21/05/2014)

http://www.telegraph.co.uk/travel/travelnews/10846657/TripAdvisor-investigated-over-fake-reviews-in-Italy.html

REUTERS - Italy's antitrust watchdog investigates TripAdvisor, booking sites (21/05/2014) http://www.reuters.com/article/2014/05/20/italy-antitrust-tripadvisor-idUSL6N0O64PN20140520

Fuente: Elaboración propia

La respuesta oficial de TripAdvisor fué:

"It is important to note that Trip Advisor fights fraud aggressively and we are confident in our systems and process"

"Every single review goes through our tracking system, which maps the how, what, where and when of each review."

"We back that up with a team of over 200 content specialists, who manually investigate every review flagged for inspection by our systems, as well as any reports we receive from owners or travellers."

"Nothing is more important to us than ensuring travellers gain an accurate and useful picture of the businesses and destinations they research on TripAdvisor," 
"Unfortunately every major service industry has to confront the challenge of fraud, but ultimately, if people didn't find the reviews on our site helpful and accurate they wouldn't keep coming back. ${ }^{154}$

Gráfico 40. Valores de la acción Abril-Julio 2014

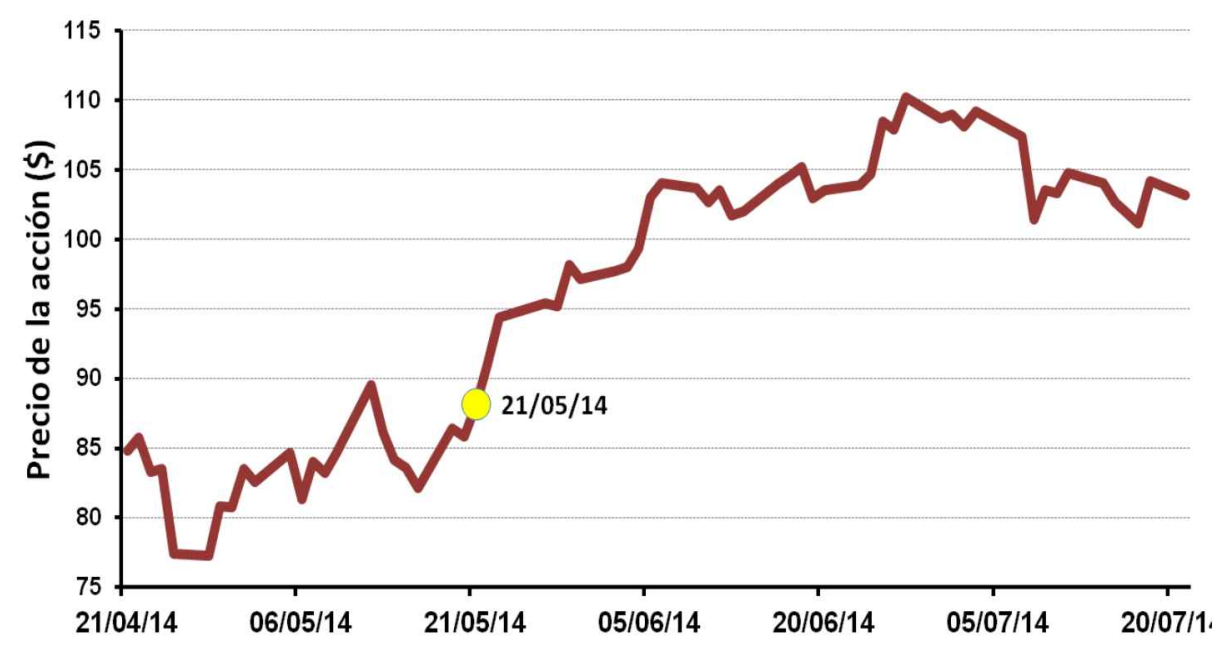

Fuente: Elaboración propia con datos de Nasdaq

Una vez más, la noticia coincide con una importante racha alcista en la cotización de las acciones (Gráfico 40).

El 22 de Diciembre de 2014, la autoridad para la defensa de la competencia en Italia concluyó su investigación, multando con 500.000 euros a TripAdvisor (AGCN, 2014). En las conclusiones se indica que no ha aplicado los controles necesarios para evitar críticas fraudulentas, promocionándolas como "auténticas y genuinas" cuando en realidad no es así.

Aunque TripAdvisor ha anunciado que apelará la decisión, la profunda investigación realizada, que incluyó el registro de las instalaciones de la

\footnotetext{
54 "Es importante tener en cuenta Tripadvisor lucha contra el fraude agresivamente y confiamos en nuestros sistemas y procesos.

Cada opinión pasa por nuestro sistema de seguimiento, que mapea cómo, qué, dónde y cuándo de cada opinión.

Contamos con un equipo de más de 200 especialistas en contenido, que investigan de forma manual cada crítica señalada para su inspección por nuestros sistemas, así como las notificaciones que recibimos de los propietarios o de los viajeros.

Nada es más importante para nosotros que asegurar los viajeros obtienen una imagen precisa y útil de las empresas y los destinos que buscan en TripAdvisor.

Desafortunadamente todas las empresas de servicios importantes tienen que enfrentar el reto de fraude, pero en última instancia, si la gente no encontrara las opiniones de nuestra web útiles y precisas no volvería a visitarnos."
} 
empresa, pone de manifiesto la referida falta de control y podría sentar un controvertido precedente para acciones similares en otros países.

Tabla 49. TripAdvisor multada por las opiniones falsas.

FINANCIAL TIMES - TripAdvisor fined in Italy over false reviews (23/12/2014)

http://www.ft.com/intl/cms/s/0/b01454b6-8a7e-11e4-be0e-00144feabdc0.html\#axzz3NHcMXQPz

CNN NEWS - $\$ 611,000$ fine as TripAdvisor gets bad review in Italy $(23 / 12 / 2014)$ http://edition.cnn.com/2014/12/23/travel/tripadvisor-fine/

NBC NEWS - TripAdvisor Fined $\$ 600,000$ by Italy Regulator Over False Reviews (23/12/2014) http://www.nbcnews.com/business/travel/tripadvisor-fined-600-000-italy-regulator-over-false-reviews-n273466

THE NEW YORK TIMES - TripAdvisor Fined $\$ 600,000$ by Italian Anti-Trust $(22 / 12 / 2014)$ http://www.nytimes.com/aponline/2014/12/22/world/europe/ap-eu-italy-tripadvisor-.html?_r=0

Fuente: Elaboración propia

La respuesta oficial de TripAdvisor fue anunciar su intención de apelar la decisión y declaraciones como:

"We firmly believe that TripAdvisor is a force for good - both for consumers and the hospitality industry,". ${ }^{55}$

"extremely effective in protecting consumers from the small minority of people who try to cheat our system"56

\subsection{Conclusiones}

Las diferentes pruebas aportadas en este epígrafe, demuestran que existen hosteleros que ignoran la norma de no incentivar las opiniones en TripAdvisor. No solo hablamos de pequeños hoteles o restaurantes independientes, sino también de establecimientos pertenecientes a grandes cadenas hoteleras. Nuestra metodología no permite la detección de las promociones que no son difundidas a través de Internet, salvo en los casos puntuales en los que los propios clientes han fotografiado los folletos expuestos en las instalaciones de los hoteles. Pero, aun contando con varios miles de casos, resultaría un porcentaje insignificante entre los más de 4 millones de alojamientos, restaurantes y lugares de interés evaluados en esta web. Por lo

\footnotetext{
${ }^{55}$ Creemos firmemente que TripAdvisor es algo positivo, tanto para consumidores como para la industria hotelera.

${ }^{56}$ Tenemos sistemas extremadamente efectivos en la protección a los consumidores contra la pequeña minoría de personas que tratan de engañar al sistema.
} 
tanto, no podemos tratar de interpretar estos datos desde el punto de vista cuantitativo, sino optar por una visión cualitativa del problema.

Los casos detectados ponen en cuestión los sistemas de control de TripAdvisor, en cuanto a su fiabilidad y celeridad de sus procedimientos. No resulta lógico, que investigadores desde su ordenador, sin formación específica en la detección de fraude, sin interactuar con hoteleros y sin usar un software especializado, detecten tal cantidad y variedad de irregularidades. La situación resulta aún más sorprendente en los casos en que los hechos son reportados por los propios usuarios en la web de TripAdvisor, sin que ni tan si quiera de esta forma parezcan percatarse de las irregularidades.

Ignoramos si se llega a esta situación por deficiencias en los sistemas de monitorización y detección del fraude o si existe una política consciente y voluntaria, de ignorar estás irregularidades, permitiendo que se produzcan, por considerarlas poco relevantes. En ambos casos, la imagen de TripAdvisor y su política de "tolerancia cero" ante el fraude, quedan en entredicho.

La posibilidad de realizar "experimentos naturales" usando los datos de dos hoteles, nos ha permitido confirmar nuestra hipótesis sobre el condicionamiento de las opiniones. Queda demostrado que los contenidos que se generan a cambio de premios, ventajas o participación en sorteos, tienen un sesgo claramente positivo. Resulta muy complicado que un individuo pretenda ser premiado por un establecimiento, tras escribir una crítica negativa sobre éste o que, aunque su experiencia haya sido negativa, desee igualmente obtener un premio que generalmente consiste en servicios gratuitos 0 descuentos futuros en ese lugar.

En este sentido la política de TripAdvisor de prohibir este tipo de actividades resulta muy acertada. En caso contrario el sistema correría el peligro de verse desvirtuado ya que, aquellos establecimientos que optaran por incentivar las opiniones, tenderían a obtener mejores puntuaciones, no por dar un mejor servicio, sino por utilizar una estrategia de promoción más eficiente. Pero si no existe un control efectivo del cumplimiento de la normativa, es 
probable que esta práctica se extienda, al comprobar los hosteleros como su competencia la vulnera sin ser penalizada.

La política de solicitar opiniones únicamente a aquellos huéspedes que tuvieron una experiencia positiva, como en el caso anterior, parece ser una práctica bastante extendida. A esto contribuye el hecho de que ciertas entidades recomienden claramente esta práctica, sin que TripAdvisor habilite sistemas de seguimiento y monitorización de su marca, lo suficientemente efectivos, para identificar estos casos y actuar en consecuencia.

La detección de más casos resulta complicado ya que, como se ha podido observar, normalmente esta estrategia se desarrolla en el ámbito interno del propio hotel, sin que tenga trascendencia a través de Internet u otros medios, salvo en casos puntuales como los descritos. Es una práctica que, sin duda, permite mejorar las puntuaciones en TripAdvisor, aunque suponga una clara violación de las normas del sistema. Además, el riesgo de ser detectado y sancionado por TripAdvisor es muy reducido, siempre que no se documente en ningún soporte físico o informático. Si la implementación de esta estrategia se limita a explicar de forma exclusivamente verbal a los trabajadores de recepción el procedimiento, resulta casi imposible que TripAdvisor pueda obtener pruebas concluyentes a este respecto.

Entendemos que la utilización de Twitter resulta de gran interés, en tanto en cuanto, obtenemos una confirmación por parte de TripAdvisor, de la existencia de una irregularidad. Si no nos hubiéramos puesto en contacto con ellos, podrían quedar dudas sobre si las prácticas detectadas son realmente inadecuadas o pudieran considerarse aceptables por TripAdvisor. Podríamos haber actuado de forma similar utilizando el email y, quizás, haber recibido igual respuesta. Pero hacer públicos emails, con un supuesto carácter privado, podría ser considerado inadecuado o incluso derivar en violaciones de la privacidad. El mantener la conversación en un ámbito público, como es la red social de Twitter, anula cualquier referencia a la privacidad de las personas o las entidades en la difusión de sus conversaciones. 
Existía la posibilidad de haber denunciado la existencia de todas las irregularidades detectadas a TripAdvisor, vía Twitter, pero entendemos más interesante para el resultado final de nuestro estudio, que permanezcan publicadas durante un tiempo. Además, velar por la fiabilidad del sistema, es algo que corresponde a TripAdvisor, que quizás debiera ser más activo en este sentido.

Las pruebas encontradas sugieren que TripAdvisor no tiene habilitado un sistema de verificación humana consistente de cada una de las opiniones. Es decir, que no todas las opiniones son leídas por un empleado antes de ser publicadas, que es lo que también sostiene la autoridad italiana de la competencia en su resolución. A pesar de la colaboración y buena disposición mostrada por TripAdvisor a través de Twitter en dos ocasiones, cuando preguntamos sobre la verificación humana de las opiniones, quedamos sin respuesta de ningún tipo. Ese proceder no difiere demasiado de su actuación cuando desde Hotrec les preguntaron explícitamente sobre la cuestión (Hotrec, 2011), sin obtener una respuesta clara.

De las declaraciones del directivo de TripAdvisor (Williams, 2013) en las que habla de que 13.000 opiniones son investigadas cada día, podemos concluir que únicamente revisan ese $10 \%$ que no pasa sus filtros automáticos. Probablemente se trata de aquellas que utilizan palabras malsonantes, estructuras semánticas sospechosas, puntuaciones muy bajas, procedentes de la misma IP, etc.

El resto sí son publicadas de forma automática, aunque para mantener cierta "estética de control", dejen pasar casi un día. Sin duda, el establecer un sistema manual para la verificación de ese $90 \%$ de opiniones que no son filtradas (45 millones en 2013) supondría un coste económico importante. Pero creemos que también supondría una importante mejora en sus sistemas de control, que les equipararía a otras empresas de la competencia.

Dado que contamos prácticamente todos los datos necesarios, podemos realizar un cálculo aproximado de los costes que esto supondría. Estimamos que para visualizar una opinión, de forma superficial, son necesarios 2 minutos 
de media, lo que nos lleva a 90 millones de minutos al año. Con empleados trabajando una media de 1.500 horas efectivas al año, se traduce en 1.000 empleados adicionales. Con un coste de 50.000 dólares al año por empleado, podríamos estimar un presupuesto de unos 50 millones de dólares/año. Teniendo en cuenta que los beneficios brutos de la compañía en 2013 fueron de 205 millones de dólares, parece que los 50 millones de dólares estimados son un coste totalmente asumible, aunque la reducción en un $25 \%$ del beneficio pueda resultar ser algo inaceptable.

Aunque no es posible cuantificar el porcentaje de críticas falsas en TripAdvisor, es muy probable que la inmensa mayoría de los 170 millones de opiniones registradas sean veraces y honestas y que la existencia de opiniones falsas suponga un mínimo porcentaje sobre el total. Pero la escalada de noticias, protestas, investigaciones y demandas judiciales, pueden estar creando la percepción de que existe un problema real y grave en este sentido. Estamos ante un posible fenómeno de hiperrealidad (Baudrillard \& Evans, 1991), por el cual hoteleros y consumidores, ante el masivo bombardeo de informaciones negativas sobre TripAdvisor, pueden tener dificultades para distinguir entre la realidad y una imagen creada sobre el asunto a través de los medios.

Cabe citar en este sentido el Teorema de Thomas (Merton, 1995), por el cual una situación, independientemente de que sea real o no, si es percibida como real por la sociedad, tendrá las mismas consecuencias que si fuera real. Si los hoteleros perciben que existe un número muy elevado de opiniones manipuladas, que es fácil generarlas y que TripAdvisor no hace nada para evitarlo, se verán fuertemente tentados a generar opiniones falsas, para tratar de defender sus negocios. De la misma forma, si los consumidores perciben que TripAdvisor está lleno de críticas escritas directamente por hoteleros interesados o inducidas por ellos, perderán la confianza en la web y dejarán de consultarla y aportar contenidos.

En última instancia, si la cantidad de informaciones negativas en torno a TripAdvisor no decae, sino que aumenta en los próximos años, podríamos estar ante un caso de "profecía auto-cumplida" (Merton, 1968). Si los hoteleros 
creen que gran parte de sus competidores generan críticas falsas perjudicando sus negocios, muchos de ellos reaccionarán haciendo lo mismo en "defensa propia", para subsanar el desequilibrio que perciben se está produciendo. Finalmente acabaría siendo cierto que TripAdvisor se encuentra plagado de críticas falsas, aunque en un principio solo existiera una percepción errónea de que asi era.

Parece que están presentes todos los ingredientes para una enorme crisis de reputación o, al menos, algún tipo de consecuencias negativas y medibles para TripAdvisor. Pero los resultados muestran que sólo el primer caso (la investigación de la ASA) podría tener un ligero efecto en las cotizaciones, pero en el resto no detectamos evidencia de variaciones significativas, lo que nos hace rechazar la hipótesis $\mathrm{H}_{18}$. El análisis de Forbes (Forbes, 2012) creemos que resulta equivocado, cuando sugirió que el valor de las acciones podría verse afectado por las crecientes dudas en la fiabilidad de TripAdvisor. Pese a que los casos de fraude y la proliferación de noticias no se han detenido desde entonces, las acciones han incrementado su valor en más del $200 \%$.

Una respuesta acertada, o incluso brillante, a cada incidente podría ser la explicación a esta falta de efectos negativos. Pero las respuestas consisten en unas pocas frases simples (repetidas en casi cada incidente), argumentando básicamente que tienen un gran sistema de detección de fraude, que ocasionalmente puede tener pequeños fallos. Incluso considerando que este tipo de reacciones puedan ser las más adecuadas, no parece que tengan la contundencia argumental para anular los efectos sobre la reputación de TripAdvisor, que el carácter de las noticias parece sugerir.

Estas cifras, además de descartar los temores y previsiones de Forbes, indican que no resulta de aplicación el "Teorema de Thomas". Tampoco vemos una "profecía auto-cumplida" en la parte que corresponde a los usuarios, ya que no dejan de usar la web y aumentar la facturación de TripAdvisor. Pero esto no descarta que se esté produciendo alguno de esos fenómenos en lo referido a los hoteleros, que podrían estar infringiendo las normas, cada vez en mayor número, ante la percepción (probablemente equivocada) de que gran parte de sus competidores lo hacen. 
A efectos prácticos, TripAdvisor parece inmune a cualquier hecho que aparentemente debería afectar su reputación empresarial. No tenemos ninguna duda de que la proliferación de noticias negativas, resulta perjudicial para la marca, pero no son el único factor que determina su éxito o fracaso. Consideramos que el factor clave que ha favorecido el desarrollo de TripAdvisor durante este tiempo ha sido crecimiento de todo lo relacionado con la Web 2.0. Casos como los de Facebook, Twitter o YouTube y otros como los de Instragram, Pinterest, Linkedin o las webs chinas Qzone, Weibo y RenRen, demuestran la nueva realidad a la que nos enfrentamos. La pasión por compartir nuestras vivencias y experiencias y la curiosidad por saber lo que otros hacen o dicen, ha encontrado en Internet un desarrollo inusitado, con crecimientos espectaculares.

Entendemos que TripAdvisor ha sabido aprovechar magistralmente esta tendencia en el comportamiento de los internautas, facilitando las herramientas adecuadas a millones de individuos en todo el mundo. En este caso, la pasión por compartir y consultar las opiniones de otros, ha prevalecido holgadamente sobre las noticias que podrían afectar la reputación de TripAdvisor. 


\section{CONCLUSIONES GENERALES, LIMITACIONES, LÍNEAS FUTURAS DE INVESTIGACIÓN Y APORTACIONES}

\subsection{Conclusiones generales}

La primera conclusión, derivada de los capítulos iniciales de esta Tesis, es la creciente importancia que ha cobrado Internet para el sector hotelero en los últimos años. Esto ha generado, de forma indirecta, ingentes bases de datos de opiniones y valoraciones de huéspedes, lo que para los investigadores es una fuente de información de gran interés. La realización de estudios basándose en esta nueva metodología es relativamente reciente, adquiriendo una mayor importancia en los últimos cuatro años, como puede apreciarse en la literatura científica referida a lo largo de este trabajo.

Hasta la fecha, la base de datos de Booking ha sido utilizada de forma frecuente, especialmente en investigaciones dentro del ámbito europeo, por el alto volumen de opiniones registradas y su alta fiabilidad, al permitir opinar exclusivamente a los clientes que han comprado efectivamente a través de su web. Pero la sorprendente escala de 2,5 a 10 descubierta en esta investigación, aunque no invalida a Booking como valiosa fuente de información, hace que se deba replantear su análisis cuantitativo en muchos casos.

Se pone de manifiesto el efecto que esa escala tiene sobre las puntuaciones finales de los hoteles, incrementando las de los hoteles de valoración baja y media, lo que abre ciertos interrogantes en torno a las intenciones de Booking al emplearla. No queremos especular en exceso sobre el tema, pero sabiendo que esta estrategia puede reportar una ventaja evidente sobre los competidores, es probable que pueda ser percibida por algunos agentes como una práctica deshonesta. En todo caso, esperaremos con gran interés las manifestaciones oficiales por parte de Booking y las opiniones de hoteles y clientes al respecto.

Utilizando los datos de Booking, resulta sencillo observar diferencias en la reputación online de los hoteles de las diferentes provincias costeras españolas. Constatamos como la imagen de los destinos vacacionales, no 
corresponde siempre con la valoración de sus hoteles. Observamos a su vez como conviven en el mismo destino establecimientos de lujo, que dan prestigio a la zona, con hoteles de baja calidad que tratan de aprovechar esa imagen. Por el contrario, zonas asociadas a un tipo de turista de nivel más bajo, tienen en realidad una planta hotelera de una excelente calidad.

Estudiamos las correlaciones existentes entre diferentes factores y las puntuaciones obtenidas por los hoteles, tratando de encontrar el factor clave que propicia la mejora de las valoraciones de los éstos. Tras un análisis, identificamos como factor central, el tamaño del hotel y las economías de escala que ello genera, como principal detonante del incremento de ciertas variables, que conducen a una mejora en sus puntuaciones.

Constatamos como, aunque un alto porcentaje de los hoteles usa redes sociales, una parte también significativa de ellos lo hace de forma manifiestamente inadecuada. A su vez, observamos como el nivel de uso de redes sociales es directamente proporcional a las puntuaciones obtenidas por estos establecimientos en portales como Booking y TripAdvisor. Aunque descartamos que el uso de redes sociales favorezca directamente el nivel de satisfacción de los clientes de un hotel, creemos que la adopción de estas nuevas tecnologías es un indicativo de una gestión eficiente. Por el contrario, la falta de formación o de apertura a la utilización de nuevas técnicas, se traslada a toda la gestión del hotel, lo que desemboca en un nivel de satisfacción inferior de los clientes.

La falta de veracidad en parte de las opiniones publicadas en TripAdvisor, es un tema tratado en la literatura científica y que resulta una fuente de preocupación, rumores y polémicas variadas en el sector hotelero. Abordamos esta cuestión desde diferentes vertientes, tratando de aportar una visión novedosa, que permita tanto a investigadores como a hoteleros, obtener una imagen más adecuada de la realidad a la que se enfrentan.

Un análisis cuantitativo, tomando como referencia las puntuaciones de Booking, pone de manifiesto que, aunque puedan existir hoteles que incumplan la normativa, no estamos ante una situación en la que ese tipo de prácticas 
sean generalizadas y desvirtúen por completo el sistema. En los casos de hoteles con un número sustancial de opiniones registradas, existe cierta proporcionalidad entre las puntuaciones de Booking y TripAdvisor, lo que descarta una teórica situación extrema, en la que un número importante de hoteles actúa de forma inadecuada, variando sustancialmente sus puntuaciones o perjudicando las de la competencia. La honradez generalizada de los hoteleros y/o la dificultad para incluir un número elevado de opiniones manipuladas sin ser detectado, contribuyen a que sea así.

Cuando investigamos sobre cierto tipo de irregularidades, relativas a la incentivación de las opiniones por parte de los hoteles, que son consideradas como fraude por TripAdvisor, detectamos cierta laxitud en los sistemas de control. No encontramos una explicación lógica que haga compatible su política de "tolerancia cero" ante el fraude y las decenas de casos encontrados con una metodología bastante sencilla. Los avanzados medios técnicos y humanos que dicen dedicar a estas tareas, deberían permitir atajar estas conductas de forma eficiente, si existiera una voluntad para hacerlo.

Diversos indicios, sugieren que los sistemas de control editorial de TripAdvisor, no incluyen la lectura de cada una de las opiniones publicadas en su web. Pero observamos como empresas, como Zoover o HolidayCheck, también dedicadas a recopilar opiniones de viajeros, dicen incorporar esta importante medida de seguridad, en aras de garantizar la fiabilidad de los contenidos. Tampoco vemos compatible esta situación con una política de "tolerancia cero" ante el fraude, ya que parece dedicar menos esfuerzos a controlar este problema que otras empresas de menor tamaño.

La prensa mundial se hace eco de diversos casos que ponen en cuestión la fiabilidad de los sistemas de control de TripAdvisor. Pero da la impresión de que esta circunstancia, que supuestamente debería afectar negativamente la confianza de usuarios y accionistas en la marca, resulta inocua. Por más escándalos y polémicas que surgen, el valor de las acciones y el número de usuarios de TripAdvisor no deja de aumentar, lo que creemos que tiene una explicación plausible en la pasión por compartir experiencias de los internautas 
y la forma brillante en la que TripAdvisor ha sabido proporcionar una herramienta para hacerlo.

Consideramos que, a pesar de las deficiencias en el control del fraude de TripAdvisor, el gran volumen de contenido albergado en esta web, hace que la información manipulada represente un porcentaje mínimo. Cuando se utiliza esta fuente de información con amplias muestras de establecimientos, que además cuentan con un gran número de opiniones, las posibles distorsiones causadas por manipulaciones en el sistema deben ser mínimas. Ahora bien, si lo que pretendemos es analizar pequeños grupos de establecimientos o no establecer un mínimo de opiniones registradas, se corre un cierto riesgo de trabajar con información manipulada, que lleve a conclusiones inexactas.

\subsection{Futuras líneas de investigación}

La información sobre las experiencias, opiniones y valoraciones de los clientes, permite a los hoteles mejorar los procesos productivos convirtiéndose en un gran activo para aquellas compañías que saben rentabilizar toda esa información que los clientes ponen de forma gratuita a su alcance. Hay empresas que han desarrollado software específico, que recopila y analiza la información diseminada en Internet sobre un establecimiento y su competencia directa: Reviewpro ${ }^{57}$, Revinate ${ }^{58}$, HotelReporting ${ }^{59}$, aboutmihotel ${ }^{60}$, hotelmanager ${ }^{61}$, etc.

Como se ha comentado anteriormente, para el desarrollo de algunos de los estudios citados, se han utilizado herramientas que recopilan de forma automatizada opiniones sobre hoteles en diferentes portales, conocidas como WebCrawler (Gerdes Jr \& Stringam, 2008). Creemos que sería de un gran interés el desarrollo de un software de acceso libre y gratuito que, de manera sencilla y sin conocimientos previos de programación, permitiera a investigadores y hoteleros, poder recopilar esta información de forma masiva.

\footnotetext{
${ }^{57}$ www.reviewpro.com

${ }^{58}$ www.revinate.com

${ }^{59}$ www.hotelreporting.com

${ }^{60}$ www.aboutmyhotel.com

${ }^{61}$ www.hotelmanager.com
} 
Algunos de los estudios desarrollados en esta Tesis, aunque creemos que cuentan con un diseño muestral adecuado, consideramos que resultaría interesante que se repitieran variando algunos de sus parámetros. Se podría utilizar una base de datos que no se limitara a los hoteles de costa, sino que incluyera otras zonas geográficas o tipologías específicas de hoteles. También sería interesante utilizar fuentes de información adicionales a Booking y TripAdvisor, analizando las diferentes puntuaciones obtenidas con cada tipo de web. Adicionalmente el incremento del tamaño muestral, de cualquiera de los apartados de esta Tesis, ayudaría a obtener una información más precisa.

Tras el hallazgo del sorprendente sistema de puntuaciones de Booking, creemos que resultaría de interés, repetir el estudio con otras webs similares, utilizando una metodología análoga.

El propio desarrollo de esta Tesis, deja abiertos ciertos interrogantes que solamente pueden ser respondidos recabando la opinión directa de hoteleros o usuarios. En este sentido destacamos algunas de las posibles vías de desarrollo para investigaciones futuras:

- Desconocemos si el usuario medio, que realiza reservas de hoteles a través de Internet y consulta opiniones en el proceso, es consciente de las diferencias entre webs como Booking y TripAdvisor.

- Sería también interesante conocer las opiniones de los hoteles sobre la posible existencia de opiniones falsas en TripAdvisor y los diferentes aspectos del sistema tratados a lo largo de esta Tesis.

- Nos gustaría conocer cuál es la opinión de los usuarios habituales de Booking, sobre la peculiar escala utilizada por esta web, que hace que las puntuaciones de los hoteles se incrementen de forma sustancial.

Creemos que resultará interesante observar las reacciones, tanto de Booking como de TripAdvisor, a los datos y conclusiones publicados en esta Tesis. En la medida en la que se genere una respuesta pública al respecto, podremos desarrollar un análisis relativo a la gestión de la reputación de estas dos importantes empresas. En el caso de Booking, ya solicitamos confirmación sobre el sistema de puntuaciones que habiamos descubierto, recibiendo una 
respuesta que básicamente nos decía que se trataba de "información confidencial". Como se indica en este trabajo, la interacción con TripAdvisor a través de Twitter ha tenido resultados dispares, pero parece una vía interesante de comunicación pública y abierta.

\subsection{Aportaciones de la investigación}

A continuación presentamos los artículos en revistas científicas y comunicaciones en congresos que se han derivado del trabajo desarrollado para la realización de esta Tesis:

\section{Artículos}

Martínez María-Dolores, S. M., Bernal García, J. J., \& Mellinas, J. P. (2012). Los hoteles de la región de Murcia ante las redes sociales y la reputación online. Revista de Análisis Turístico, (13), 1-10.

Indexada: ISOC, IN-RECS, LATINDEX, DIALNET, CINDOC, RESH. H-index:4

Martínez María-Dolores, S. M., Bernal García, J. J., \& Mellinas, J. P. (2013). Análisis del nivel de presencia de los establecimientos hoteleros de la Región de Murcia en la Web 2.0. Cuadernos de Turismo, (31), 245-261. Indexada: FECYT, ISOC, IN-RECS, LATINDEX, DIALNET, CINDOC, RESH, SCOPUS. IN-RECS $(0,279)$ : Posición 14 ( $1^{\circ}$ cuartil), Economía. Posición 5 ( $1^{\circ}$ cuartil), Geografía. $\mathrm{H}$-index:9

Mellinas, J.P., Martínez María-Dolores, S.M., \& Bernal García, J.J. (2014). Uso de las redes sociales en los hoteles de la costa española. Investigaciones Turísticas, (7), 87-101.

Indexada: LATINDEX, DIALNET, DOAJ, E-REVISTAS. H-index:3

Mellinas, J.P., Martínez María-Dolores, S.M., \& Bernal García, J.J. (2015). Booking.com: The Unexpected scoring system. Tourism Management (Aceptado).

Indexada: SNIP: 2.701. SJR: 1.961. Impact Factor: 2.377. 5-Year Impact Factor: 3.382. H-index:63.

Mellinas, J.P., Martínez María-Dolores, S.M., \& Bernal García, J.J. (2015). El Mito de las opiniones manipuladas en TripAdvisor. Papers de Turisme (en revisión).

Mellinas, J.P., Martínez María-Dolores, S.M., \& Bernal García, J.J. (2015). El uso de redes sociales por los hoteles como indicativo de gestión eficiente. Tourism \& Management Studies (en revisión).

Mellinas, J.P., Martínez María-Dolores, S.M., \& Bernal García, J.J. (2015). Evolución de las valoraciones de los hoteles españoles de costa (20112014). PASOS. Revista de Turismo y Patrimonio Cultural (en revisión)

Mellinas, J.P., Martínez María-Dolores, S.M., \& Bernal Garcia, J.J. (2015). Effects of the Booking scoring system (pendiente de envío para revision) 


\section{Asistencia a congresos}

Martínez María-Dolores, S. M., Bernal García, J. J., \& Mellinas, J. P. (2011): «Análisis del Posicionamiento de los Hoteles de la Región de Murcia Respecto a la Web 2.0 y las Redes Sociales». XVI Congreso de la Asociación Española de Expertos Científicos en Turismo. Málaga (España).

Mellinas, J.P., Martínez María-Dolores, S.M., \& Bernal García, J.J. (2012). Hotel reviews databases. The case of spanish coastal hotels. 4 EMUNI Research Souk The Euro-Mediterranean Student Research Multiconference. 305-309. Murcia (España)

Martínez María-Dolores, S.M., Mellinas, J.P. \& Bernal García, J.J. (2012). Análisis comparativo de las webs que recogen opiniones sobre hoteles. XVII Congreso de la de la Asociación Española de Expertos Científicos en Turismo. Ourense (España).

Martínez María-Dolores, S.M., Mellinas, J.P. \& Bernal García, J.J. (2012). Evolución en el uso de redes sociales por los hoteles de la Región de Murcia. Jornada de Trabajo ASEPUMA. Cartagena (España).

Mellinas, J.P., Martínez María-Dolores, S.M., \& Bernal García, J.J. (2014). Efectos de las opiniones incentivadas en TripAdvisor. XVIII Congreso la Asociación Española de Expertos Científicos en Turismo. Benidorm (España) 


\section{REFERENCIAS BIBLIOGRÁFICAS}

Abram, C. (2006). Welcome to Facebook, everyone. Disponible en:

https://www.facebook.com/notes/facebook/welcome-to-facebook-everyone/2210227130

AGCM (2014). Mezzo Millione di Multa a TripAdvisor. Autorità Garante della Concorrenza e del Mercato. Disponible en: http://www.agcm.it/trasp-statistiche/doc_download/4619ps9345scorrsanz-omi.html

AIMC. (2014). $16^{\circ}$ Navegantes en la red. Febrero 2014. Disponible en: http://www.aimc.es/Navegantes-en-la-Red-.html

Andalucía Lab, C. (2014). Big Data en turismo: primera aproximación a la reputación online en destinos. Disponible en: http://www.bigdata.andalab.org

ASA. (2012). ASA Adjudication on TripAdvisor LLC. Disponible en: http://www.asa.org.uk/Rulings/Adjudications/2012/2/TripAdvisor-

LLC/SHP_ADJ_166867.aspx\#.VAw9-_It2E

Ayeh, J. K., Au, N., \& Law, R. (2013). "Do We Believe in TripAdvisor?" Examining Credibility Perceptions and Online Travelers' Attitude toward Using User-Generated Content. Journal of Travel Research, 52(4), 437-452.

Baudrillard, J., \& Evans, A. B. (1991). Simulacra and Science Fiction (Simulacres et sciencefiction). Science Fiction Studies, 55(18), 309-313.

Bjørkelund, E., Burnett, T. H., \& Nørvla ag, K. (2012). A study of opinion mining and visualization of hotel reviews. In Proceedings of the 14th International Conference on Information Integration and Web-based Applications \& Services (pp. 229-238). ACM. doi: $10.1145 / 2428736.2428773$

Blackshaw, P., \& Nazzaro, M. (2006). Consumer-generated media (CGM) 101: Word-of-mouth in the age of the web-fortified consumer. A Nielsen BuzzMetrics White Paper, Second Edition, Spring.

Booking (2014a). Estructura de Comisión. Disponible en: http://www.booking.com/general.es.html?tmpl=docs/partner_commission

Booking (2014b). Presentación de Booking.com. Disponible en: http://www.booking.com/content/about.es.html

Bouvain, P. (2011). Word-of-mouth amplified: An exploration of hotel customer feedback websites. Dialogmarketing Perspektiven 2010/2011 : Tagungsband 5. wissenschaftlicher interdisziplinärer Kongress für Dialogmarketing.

Bronner, F., \& de Hoog, R. (2011). Vacationers and eWOM: Who Posts, and Why, Where, and What? Journal of Travel Research, 50(1), 15-26.

Buhalis, D., \& Law, R. (2008). Progress in information technology and tourism management: 20 years on and 10 years after the Internet-The state of eTourism research. Tourism Management, 29(4), 609-623.

Catterall, M., \& Maclaran, P. (2002). Researching consumers in virtual worlds: A cyberspace odyssey. Journal of Consumer Behaviour, 1(3), 228-237.

Celaya, J. (2000). La empresa en la Web 2.0. Barcelona: Gestión, 2008, 284.

Cha, M., Haddadi, H., Benevenuto, F., \& Gummadi, P. K. (2010). Measuring User Influence in Twitter: The Million Follower Fallacy. ICWSM, 10, 10-17.

Chaves, M. S., Gomes, R., \& Pedron, C. (2012). Analysing reviews in the Web 2.0: Small and medium hotels in Portugal. Tourism Management, 33(5), 1286-1287.

Chen, Y., \& Xie, J. (2005). Third-party product review and firm marketing strategy. Marketing Science, 24(2), 218-240.

Cheong, H. J., \& Morrison, M. A. (2008). Consumers' reliance on product information and recommendations found in UGC. Journal of Interactive Advertising, 8(2), 38-49. 
Chevalier, J. A., \& Mayzlin, D. (2006). The effect of word of mouth on sales: Online book reviews. Journal of Marketing Research, 43(3), 345-354.

Chua, A. Y., \& Banerjee, S. (2013). Reliability of Reviews on the Internet: The Case of TripAdvisor. In Proceedings of the World Congress on Engineering and Computer Science (Vol. 1).

Ciutat Hotels. (2014). Deja tu opinión en Trip Advisor y gana una estancia para dos personas. Disponible en: http://www.ciutathotels.com/es/ofertas/deja-tu-opinion-en-trip-advisor-ygana-una-estancia-para-dos-personas

Comarela, G., Crovella, M., Almeida, V., \& Benevenuto, F. (2012). Understanding factors that affect response rates in twitter. In Proceedings of the $23 \mathrm{rd}$ ACM conference on Hypertext and social media (pp. 123-132). ACM.

Comegys, C., Hannula, M., \& Váisánen, J. (2009). Effects of Consumer Trust and Risk on Online Purchase Decision-Making: A Comparison of Finnish and United States Students. International Journal of Management, 26(2), 295.

Conrady, R. (2007). Travel technology in the era of Web 2.0. In Trends and Issues in Global Tourism 2007 (pp. 165-184). Springer.

Constable, N. (2003). Romance on a global stage: Pen pals, virtual ethnography, and" mail order" marriages. Univ of California Press.

Correa, T., Hinsley, A. W., \& De Zuniga, H. G. (2010). Who interacts on the Web?: The intersection of users' personality and social media use. Computers in Human Behavior, 26(2), 247-253.

Costantino, G., Martinelli, F., \& Petrocchi, M. (2012a). Priorities-Based Review Computation. In AAAI Spring Symposium: Intelligent Web Services Meet Social Computing.

Costantino, G., Morisset, C., \& Petrocchi, M. (2012b). Subjective review-based reputation. In Proceedings of the 27th Annual ACM Symposium on Applied Computing (pp. 20292034). ACM.

Da Cruz, G., de Albuquerque, T. V., \& Soares, A. E. F. (2011). Twitter, Youtube e innovación en la promoción turística online: Análisis de las estrategias del Ministerio de Turismo de Brasil. Estudios Y Perspectivas En Turismo, 20(3), 627-642.

De Albornoz, J. C., Plaza, L., Gervás, P., \& Díaz, A. (2011). A joint model of feature mining and sentiment analysis for product review rating. In Advances in information retrieval (pp. 55-66). Springer.

Del Chiappa, G. (2011). Trustworthiness of Travel 2.0 applications and their influence on tourist behaviour: an empirical investigation in Italy. Springer.

Del Chiappa, G., \& Dall'Aglio, S. (2012). Factors influencing Travellers'e-Ratings and eComplaints about Hotel Services: Insights from an Italian Tourism Destination. na. Disponible en: http://202.154.59.182/mfile/files/Information\%20System/Information\% 20and\%20Communication\%20Technologies\%20in\%20Tourism\%202012/Chapter\%203 9\%20Factors $\% 20$ influencing $\% 20$ Travellers'\%20e-Ratings $\% 20$ and $\% 20$ eComplaints $\%$ 20about $\% 20$ Hotel\%20Services\%3B\%20Insights\%20from\%20an\%20Italian\%20Tourism $\% 20$ Destination.pdf

Dellarocas, C. (2003). The digitization of word of mouth: Promise and challenges of online feedback mechanisms. Management Science, 49(10), 1407-1424.

Delloite. (2012). Measuring Facebook's economic impact in Europe. Disponible en: http://www.deloitte.com/assets/Dcom-UnitedKingdom/Local\%20Assets/Documents/ Industries/TMT/uk-tmt-media-facebook-europe-economic-impact-exec-summary.pdf

Dickinger, A., \& Mazanec, J. (2008). Consumers' preferred criteria for hotel online booking. Information and Communication Technologies in Tourism 2008, 244-254.

Donaire, J. A., \& Galí Espelt, N. (2011). La imagen turística de Barcelona en la comunidad de flickr. Cuadernos de Turismo, 2011, Vol. 27, P. 291-303.

Drucker, H., Wu, S., \& Vapnik, V. N. (1999). Support vector machines for spam categorization. Neural Networks, IEEE Transactions on, 10(5), 1048-1054. 
Duan, W., Gu, B., \& Whinston, A. B. (2008a). Do online reviews matter?-An empirical investigation of panel data. Decision Support Systems, 45(4), 1007-1016.

Duan, W., Gu, B., \& Whinston, A. B. (2008b). The dynamics of online word-of-mouth and product sales-An empirical investigation of the movie industry. Journal of Retailing, 84(2), 233-242.

Dunas Hotels. (2014). Talk about us. Disponible en: http://www.hotelesdunas.com/es/dunasclub/talk-about-us/

Dutta, S., \& Fraser, M. (2009). When job seekers invade Facebook. The McKinsey Quarterly.

Egatur/Frontur. (2012). Movimientos Turísticos en Fronteras (Frontur) y Encuesta de Gasto Turístico (Egatur) 2012. Instituto de Estudios Turísticos (IET). Disponible en: http://www.iet.tourspain.es/es-ES/estadisticas/egatur/Anuales/Movimientos\%20Tur\% C3\%ADsticos\%20en\%20Fronteras\%20(Frontur)\%20y\%20Encuesta\%20de\%20Gasto\% 20Tur\%C3\%ADstico\%20(Egatur)\%202012.pdf

EGM. (2014). Estudio General de Medios. Audiencia en Internet. Abril/Mayo 2014. Disponible en: http://www.aimc.es/-Audiencia-de-Internet-en-el-EGM-.html

Eime, R. (2013). Traveloscopy Travelblog: Never been there, but l've heard it's good. TripAvisor critics tell. Disponible en: http://www.travel-news-photos-stories.com/2013/08/neverbeen-there-but-ive-heard-its-good.html

El blog de TripAdvisor. (2010). Para propietarios: Tarjetas recordatorio para clientes. Disponible en: http://elblogdetripadvisor.wordpress.com/2010/03/16/para-propietarios-tarjetasrecordatorio-para-clientes/

Estárico, E. H., Medina, L. F., \& Marrero, S. M. (2012). Una aproximación a la reputación en línea de los establecimientos hoteleros españoles. Papers de Turisme, (52), 63-88.

Europa Press. (2012). Las pymes hoteleras son las empresas españolas más activas en redes sociales. Disponible en: http://www.europapress.es/economia/noticia-economiaturismo-pymes-hoteleras-son-empresas-espanolas-mas-activas-redes-sociales20120214133525.html

Expansión. (2010). Sol Meliá vincula los salarios a la opinión de los clientes en Internet. Disponible en: http://www.expansion.com/2010/11/21/empresas/1290373589.html

Fay, S. (2004). Partial-repeat-bidding in the name-your-own-price channel. Marketing Science, 23(3), 407-418.

Fernández-Barcala, M., González-Díaz, M., Prieto-Rodriguez, J., Pestana Barros, C., \& others. (2009). Factors influencing guests' hotel quality appraisals. European Journal of Tourism Research, 2(1).

Filieri, R., \& McLeay, F. (2014). E-WOM and Accommodation An Analysis of the Factors That Influence Travelers' Adoption of Information from Online Reviews. Journal of Travel Research, 53(1), 44-57.

Flickr. (2014). Flickr, ¡Feliz Cumpleaños \#10!. Disponible en: https://blog.flickr.net/es/2014/02/11/flickr-feliz-cumpleanos-10

Floris, R., \& Campagna, M. (2014). Social Media Data in Tourism Planning: Analysing Tourists' Satisfaction in Space and Time. In Proceedings of the 2014 AESOP annual congress. Utrech.

Forbes. (2012). TripAdvisor's \$35 Fair Value Could Suffer From Fake Review Concerns. Disponible en: http://www.forbes.com/sites/greatspeculations/2012/08/28/tripadvisors35-fair-value-could-suffer-from-fake-review-concerns/

Fotis, J., Buhalis, D., \& Rossides, N. (2012). Social media use and impact during the holiday travel planning process. Springer-Verlag.

Fundetec. (2012). Informe ePyme 2011. Disponible en: http://www.fundetec.es/publicaciones/informe-epyme-2011/ 
Gabielkov, M., \& Legout, A. (2012). The complete picture of the Twitter social graph. In Proceedings of the 2012 ACM conference on CoNEXT student workshop (pp. 19-20). ACM.

Gallon, R. (2010). Media behaviour: towards the transformation society. Technoetic Arts, 8(1), 115-122.

Gal-Oz, N., Grinshpoun, T., \& Gudes, E. (2010). Sharing reputation across virtual communities. Journal of Theoretical and Applied Electronic Commerce Research, 5(2), 1-25.

Gerdes Jr, J., \& Stringam, B. B. (2008). Addressing researchers' quest for hospitality data: mechanism for collecting data from web resources. Tourism Analysis, 13(3), 309-315.

Gershon, I. (2008). Email my heart: remediation and romantic break-ups. Anthropology Today, 24(6), 13-15.

Gilbreath, B. (2010). Hotel Seeds TripAdvisor Reviews [Marketing with meaning]. Disponible en:http://www.marketingwithmeaning.com/2010/02/23/hotel-seeds-trip-advisor-reviews/

Goldenberg, J., Libai, B., \& Muller, E. (2001). Talk of the network: A complex systems look at the underlying process of word-of-mouth. Marketing Letters, 12(3), 211-223.

Goldsmith, R. E., \& Horowitz, D. (2006). Measuring motivations for online opinion seeking. Journal of Interactive Advertising, 6(2), 2-14.

Green, J., \& Burgess, J. (2009). YouTube: Online Video and Participatory Culture. Cambridge: Polity Press.

Gretzel, U., \& Yoo, K. H. (2008). Use and impact of online travel reviews. Information and Communication Technologies in Tourism 2008, 35-46.

Grinshpoun, T., Gal-Oz, N., Meisels, A., \& Gudes, E. (2009). CCR: A model for sharing reputation knowledge across virtual communities. In Proceedings of the 2009 IEEE/WIC/ACM International Joint Conference on Web Intelligence and Intelligent Agent Technology-Volume 01 (pp. 34-41). IEEE Computer Society.

Gutierrez Taño, D., Parra López, E., González Wetherill, Y. (2014). La influencia de la autentificación de identidad en las valoraciones online de los hoteles. XVIII Congreso AECIT. Benidorm.

Gyöngyi, Z., Garcia-Molina, H., \& Pedersen, J. (2004). Combating web spam with trustrank. In Proceedings of the Thirtieth international conference on Very large data bases-Volume 30 (pp. 576-587). VLDB Endowment.

Hay, B. (2010). Twitter Twitter-But who is listening? a review of the current and potential use of Twittering as a tourism marketing tool. Disponible en: http://eresearch.qmu.ac.uk/1500/

Hine, C. (2000). Virtual ethnography. Sage.

HolidayCheck. (2012). TripAdvisor in Trouble. Disponible en: http://www.holidaycheck.com/data/common/presse/pm1213.pdf

Holiday Inn. (2011). Fotografía de Holiday Inn Hotel \& Suites Raleigh - Cary. Disponible en: http://www.tripadvisor.es/LocationPhotoDirectLink-g49007-d223369-i36290027Holiday_Inn_Hotel_Suites_Raleigh_Cary-Cary_North_Carolina.htmI\#31805352

HotelReporting. (2012). ¿Perjudican los comentarios falsos la puntuación final de los hoteles en TripAdvisor? [Hotelreporting.com].

Disponible en:http://blog.hotelreporting.com/actualidad-hotelera-y-mas.php/iperjudicanlos-comentarios-falsos-de

Hotrec. (2010). On hotel review providers and the hospitality industry. Disponible en: http://www.hotrec.eu/documents/document/20110908181541-d-1110-322-mlrevised_hotrec_working_paper_on_hotel_review_sites.pdf

Hotrec. (2011). Hotel reviews sites. Disponible en: http://www.hotrec.eu/policy-issues/hotelreview-sites.aspx

Howard Johnson. (2013). Picture of Howard Johnson Inn and Suites Central San Antonio, San Antonio - TripAdvisor. Disponible en: 
http://www.tripadvisor.com/LocationPhotoDirectLink-g60956-d108676-i85092601Howard_Johnson_Inn_and_Suites_Central_San_AntonioSan_Antonio_Texas.ht̄ml\#69234013

Hsu, Y.-L. (2012). Facebook as international eMarketing strategy of Taiwan hotels. International Journal of Hospitality Management, 31(3), 972-980.

Huang, Y., Basu, C., \& Hsu, M. K. (2010). Exploring motivations of travel knowledge sharing on social network sites: an empirical investigation of US college students. Journal of Hospitality Marketing \& Management, 19(7), 717-734.

INE. (2014). Encuesta de ocupación hotelera.

Disponible en: http://www.ine.es/jaxi/menu.do?type=pcaxis\&path=\%2Ft11\%2Fe162 eoh\&file=inebase $\& L=0$

Jacobsen, E. K., \& Groat, R. K. (2009). Become a Fan: Support Your Favorite Element on Facebook. Journal of Chemical Education, 86(10), 1168.

Java, A., Song, X., Finin, T., \& Tseng, B. (2007). Why we twitter: understanding microblogging usage and communities. In Proceedings of the 9th WebKDD and 1st SNA-KDD 2007 workshop on Web mining and social network analysis (pp. 56-65). ACM.

Jeacle, I., \& Carter, C. (2011). In TripAdvisor we trust: Rankings, calculative regimes and abstract systems. Accounting, Organizations and Society, 36(4), 293-309.

Jeong, M., \& Mindy Jeon, M. (2008). Customer reviews of hotel experiences through consumer generated media (CGM). Journal of Hospitality \& Leisure Marketing, 17(1-2), 121-138.

Jiménez, S., \& Prats, L. (2006). El turismo en Cataluña: evolución histórica y retos de futuro. PASOS. Revista de Turismo Y de Patrimonio Cultural, 4(2).

Jindal, N., Liu, B., \& Lim, E.-P. (2010). Finding unusual review patterns using unexpected rules. In Proceedings of the 19th ACM international conference on Information and knowledge management (pp. 1549-1552). ACM.

Kaplan, A. M., \& Haenlein, M. (2010). Users of the world, unite! The challenges and opportunities of Social Media. Business Horizons, 53(1), 59-68.

Keates, N. (2007). Deconstructing tripadvisor. Wall Street Journal, 1, 4.

Kim, S., \& Mattila, A. S. (2011). An examination of electronic video clips in the context of hotel Websites. International Journal of Hospitality Management, 30(3), 612-618.

Koban, H. (2013). Crowdsourcing, TripAdvisor \& the Problem of Bogus Reviews. Disponible en: http://isys6621.com/2013/10/20/crowdsourcing-tripadvisor-the-problem-of-bogusreviews/

Korfiatis, N., \& Poulos, M. (2013). Using online consumer reviews as a source for demographic recommendations: A case study using online travel reviews. Expert Systems with Applications, 40(14), 5507-5515.

Kosar, L., Masic, S. \& Kosar, N. (2014). E-wom as a factor of hotel product quality. VII International Scientific Conference. Gospodarka Regionalna i Turystyka.

Kozinets, R. V. (2002). The field behind the screen: using netnography for marketing research in online communities. Journal of Marketing Research, 39(1), 61-72.

Kozinets, R. V. (2006). Click to connect: netnography and tribal advertising. Journal of Advertising Research, 46(3), 279.

Kuo, K. (2009). Blogs, bulletin boards, and business. China Business Review, 10(1), 28-31.

Las Cumbres. (2014). Nuevo sorteo Facebook-TripAdvisor. Disponible en: https://www.facebook.com/photo.php?fbid=364403870364382

Leung, X. Y., Bai, B., \& Stahura, K. A. (2013). The Marketing Effectiveness of Social Media in the Hotel Industry: A Comparison of Facebook and Twitter. Journal of Hospitality \& Tourism Research, 1096348012471381. 
Levy, A. (2013). Booking.com Challenging Parent Priceline in U.S. Travel (Bloomberg). Disponible en: http://www.bloomberg.com/news/2013-01-22/booking-com-challengingparent-priceline-in-u-s-travel.html

Lewis, D., \& Bridger, D. (2001). The soul of the new consumer: Authenticity-what we buy and why in the new economy. Nicholas Brealey Publishing.

Lewis, J., \& West, A. (2009). "Friending": London-based undergraduates' experience of Facebook. New Media \& Society, 11(7), 1209-1229.

Lovink, G., \& Miles, R. S. (2011). Video Vortex reader II: moving images beyond YouTube. Institute of Network Cultures. Disponible en: http://dare.uva.nl/en/record/416118

Luca, M., \& Zervas, G. (2013). Fake it till you make it: Reputation, competition, and Yelp review fraud. Harvard Business School NOM Unit Working Paper, (14-006).

LX. (2014). Share your experience, stay for free. Disponible en: https://www.facebook.com/lxboutiquehotel/photos/a.509876202387120.1073741825.12 7229127318498/671128642928541/?type=1\&relevant_count=1

Mack, R. W., Blose, J. E., \& Pan, B. (2008). Believe it or not: Credibility of blogs in tourism. Journal of Vacation Marketing, 14(2), 133-144.

Mann, C., \& Stewart, F. (2000). Internet communication and qualitative research: $A$ handbook for researching online. Sage.

Marchiori, E., Eynard, D., Inversini, A., Cantoni, L., \& Cerretti, F. (2011). Harvesting online contents: An analysis of hotel reviews websites. Information and Communication Technologies in Tourism 2011, Innsbruck, Austria, 101-112.

Marina D'or. (2014). Bases del concurso "comenta y gana". Disponible en: http://www.marinador.com/eventos/sorteo-agencias/bases.php?idioma=

Marina suites. (2012). Comparta su experiencia. Disponible en: http://marinasuitesgrancanaria.com/comparta-su-experiencia

Mariscal Robledo. (2013). Disfruta y participa contando tu experiencia. Disponible en: https://www.facebook.com/photo.php?fbid=537205843001345\&l=57e34d8734

Martínez María-Dolores, S. M., Bernal García, J. J., \& Mellinas, J. P. (2012). Los hoteles de la región de Murcia ante las redes sociales y la reputación online. Revista de Análisis Turístico, (13), 1-10.

Mayzlin, D., Dover, Y., \& Chevalier, J. A. (2012). Promotional reviews: An empirical investigation of online review manipulation. NBER Working Papers 18340, National Bureau of Economic Research, Inc.

Meeson, M., \& Parrot, O. (2013). Oscar's Fake Restaurant On TripAdvisor. The Bookman.

Melián-González, S., Bulchand-Gidumal, J., \& López-Valcárcel, B. G. (2013). Online Customer Reviews of Hotels As Participation Increases, Better Evaluation Is Obtained. Cornell Hospitality Quarterly, 54(3), 274-283.

Melnik, M. I., \& Alm, J. (2002). Does a seller's ecommerce reputation matter? Evidence from eBay auctions. The Journal of Industrial Economics, 50(3), 337-349.

Merton, R. K. (1968). Social theory and social structure. Simon and Schuster.

Merton, R. K. (1995). The Thomas theorem and the Matthew effect. Social Forces, 379-422.

Minazzi, R. (2015). The Digitization of Word-of-Mouth. In Social Media Marketing in Tourism and Hospitality (pp. 21-45). Springer International Publishing.

Mkono, M. (2012a). A netnographic examination of constructive authenticity in Victoria Falls tourist (restaurant) experiences. International Journal of Hospitality Management, 31(2), 387-394.

Mkono, M. (2012b). Using net-based ethnography (netnography) to understand the staging and marketing of "authentic African" dining experiences to tourists at Victoria falls. Journal of Hospitality \& Tourism Research. 
Mkono, M., \& others. (2013). Hot and cool authentication: a netnographic illustration. Annals of Tourism Research, 41, 215-218.

Mota, P. (2011). Los hoteles se enganchan a las Redes Sociales: El $73 \%$ de los establecimientos alojativos españoles ya opera en sitios como Facebook o Twitter. Hostelmarket: Revista Mensual de Información Hostelera, (142), 3-15.

Mukherjee, A., Liu, B., Wang, J., Glance, N., \& Jindal, N. (2011). Detecting group review spam. In Proceedings of the 20th international conference companion on World wide web (pp. 93-94). ACM.

Nielsen (2013). Under the influence: Consumer Trust in Advertising. Disponible en: http://www.nielsen.com/us/en/insights/news/2013/under-the-influence-consumer-trustin-advertising.html

Ntoulas, A., Najork, M., Manasse, M., \& Fetterly, D. (2006). Detecting spam web pages through content analysis. In Proceedings of the 15th international conference on World Wide Web (pp. 83-92). ACM.

Oasis hotels. (2012). Sorteo de IPAD para huéspedes que han comentado en TripAdvisor.com. Disponible en:

https://www.facebook.com/photo.php?fbid=519046878111567\&set=p.51904687811156 7\&type $=1$ \& theater

O'Connor, P. (2008). User-generated content and travel: A case study on Tripadvisor. com. Information and Communication Technologies in Tourism 2008, 47-58.

O'Connor, P. (2010). Managing a hotel's image on TripAdvisor. Journal of Hospitality Marketing \& Management, 19(7), 754-772.

O Connor, P. (2011). An analysis of the use of Facebook by international hotel chains. International CHRIE Conference, Denver, Colorado, USA. Disponible en: http://scholarworks.umass.edu/refereed/ICHRIE_2011/Wednesday/9/

O'Mahony, M., Hurley, N., Kushmerick, N., \& Silvestre, G. (2004). Collaborative recommendation: A robustness analysis. ACM Transactions on Internet Technology (TOIT), 4(4), 344-377.

O'Mahony, M. P., Cunningham, P., \& Smyth, B. (2010). An assessment of machine learning techniques for review recommendation. In Artificial Intelligence and Cognitive Science (pp. 241-250). Springer.

O'reilly, T. (2005). Web 2.0: compact definition. Disponible en: http://tcc-web20.googlecode.com/svn/trunk/Pesquisa/O'Reilly\%20Radar\%20\%20Web\%202.0\%20Compact\%20Definition.pdf

Ott, M., Choi, Y., Cardie, C., \& Hancock, J. T. (2011). Finding deceptive opinion spam by any stretch of the imagination. In Proceedings of the 49th Annual Meeting of the Association for Computational Linguistics: Human Language Technologies-Volume 1 (pp. 309-319). Association for Computational Linguistics.

Page, R. (2010). Re-examining narrativity: small stories in status updates. Text \& Talk-An Interdisciplinary Journal of Language, Discourse \& Communication Studies, 30(4), 423444.

Pan, B., \& Fesenmaier, D. R. (2006). Online information search: vacation planning process. Annals of Tourism Research, 33(3), 809-832.

Pan, B., MacLaurin, T., \& Crotts, J. C. (2007). Travel blogs and the implications for destination marketing. Journal of Travel Research, 46(1), 35-45.

Papathanassis, A., \& Knolle, F. (2011). Exploring the adoption and processing of online holiday reviews: A grounded theory approach. Tourism Management, 32(2), 215-224.

Park, C., \& Lee, T. M. (2009). Information direction, website reputation and eWOM effect: A moderating role of product type. Journal of Business Research, 62(1), 61-67. 
Park, E. (2012). How do hotels use social media? The case study of Twitter. In CAUTHE 2012: The new golden age of tourism and hospitality; Book 2; Proceedings of the 22nd Annual Conference (p. 458). La Trobe University.

Phillips, S. (2007). A brief history of Facebook. The Guardian, 25. Disponible en: ftp://65.190.65.233/AiDisk_a1/Crystal/From_Seagate_500GB_External/From\%20Extern al/Seagate\%20Backup/GATTEWAY_TABLET/C/Documents\%20and\%20Settings/Crystal /My\%20Documents/Spring\%202010/Technical\%20Writing\%20-\%20ENGL\%203764 \%20-\%20Combthis/FB\%20Research/A\%20brief\%20history\%20of\%20Facebook\%20 \%20Technology\%20_\%20guardian.co.pdf

Plata-Alf, D. (2013). Marketing Communications in a Virtual Environment-Opportunities and Challenges for Companies in the Tourism Sector. Disponible en: http://repozytorium.wsb-nlu.edu.pl/handle/11199/7412

Playa Senator. (2011). Únase a un club lleno de ventajas. Disponible en: http://www.clubplayavip.com/es/informacion/unase.aspx

Pochampally, R., \& Varma, V. (2011). User context as a source of topic retrieval in Twitter. In Workshop on Enriching Information Retrieval (with ACM SIGIR) (pp. 1-3).

Poynter, R. (2008). Viewpoint-Facebook: The future of networking with customers. Journal of the Market Research Society, 50(1), 11.

Puri, A. (2007). The web of insights-The art and practice of webnography. International Journal of Market Research, 49(3), 387-408.

Puri, A. (2009). Webnography: Its evolution and implications for market research. International Journal of Market Research, 51(2), 273-275.

Reino, S., \& Hay, B. (2011). The Use of YouTube as a Tourism Marketing Tool. In Proceedings of the 42nd Annual Travel \& Tourism Research Association Conference, London, Ontario, Canada. (Vol. 42). Travel \& Tourism Research Association.

Renaissance. (2011). Don't need the bribe, good service always wins.: fotografía de Renaissance Dallas Hotel, Dallas - TripAdvisor. Disponible en: http://www.tripadvisor.es/LocationPhotoDirectLink-g55711-d98710-i35965575Renaissance_Dallas_Hotel-Dallas_Texas.html

Resnick, P., \& Zeckhauser, R. (2002). Trust among strangers in Internet transactions: Empirical analysis of eBay's reputation system. Advances in Applied Microeconomics, 11, 127157.

Rettberg, J. W. (2009). "Freshly Generated for You, and Barack Obama"How Social Media Represent Your Life. European Journal of Communication, 24(4), 451-466.

ReviewPro. (2012). Guía ReviewPro: ¿Cómo pueden los hoteles incrementar su volumen de opiniones? Disponible en: http://www.reviewpro.com/es/guia-reviewpro-\%c2\%bfcomopueden-los-hoteles-incrementar-su-volumen-de-opiniones-6702

ReviewPro. (2013). TripAdvisor and ReviewPro Partner to Provide A Better Review Management Solution. Disponible en: http://www.reviewpro.com/tripadvisor-andreviewpro-partner-to-provide-a-better-review-management-solution-20400

Rhee, M., \& Haunschild, P. R. (2006). The liability of good reputation: A study of product recalls in the US automobile industry. Organization Science, 17(1), 101-117.

Ricci, F., \& Wietsma, R. T. (2006). Product reviews in travel decision making. Information and Communication Technologies in Tourism 2006, 296-307.

Richard, D., \& others. (2012). Do Twitter and Facebook Matter? Examining the Economic Impact of Social Media Marketing in Tourism Websites of Atlantic Canada. Journal of Tourism Research \& Hospitality, 1(4).

Roberts, A. (2010). Tomorrow has arrived. Hospitals and health systems embrace social mediawith mixed results. Marketing Health Services, 30(2), 30. 
Salkhordeh, P. (2010). An exploratory content analysis of the use of Facebook in the lodging industry (Thesis). University of Delaware. Disponible en: http://udspace.udel.edu/handle/19716/5827

Schildgen, B. D. (2011). Social media tools in integrated Marketing strategy: Test case hotel/resort destination Facebook utilization. University of North Carolina Wilmington. Disponible en: http://dl.uncw.edu/etd/2011-1/schildgenb/bryanschildgen.pdf

Segaran, T. (2007). Programming collective intelligence: building smart web 2.0 applications. O'Reilly Media, Inc.

Shani, A., Chen, P.-J., Wang, Y., \& Hua, N. (2010). Testing the impact of a promotional video on destination image change: Application of China as a tourism destination. International Journal of Tourism Research, 12(2), 116-133.

Shih, C. (2009). The Facebook era: Tapping online social networks to build better products, reach new audiences, and sell more stuff. Prentice Hall.

Sichtmann, C. (2007). An analysis of antecedents and consequences of trust in a corporate brand. European Journal of Marketing, 41(9/10), 999-1015.

Sigala, M., Christou, E., \& Gretzel, U. (2012). Social media in travel, tourism and hospitality: Theory, practice and cases. Ashgate Publishing, Ltd.

Smyth, P. C. B., Wu, G., \& Greene, D. (2010). Does tripadvisor makes hotels better. (Technical Report UCD-CSI-2010-06). Dublin: School of Computer Science \& Informatics

University College. Disponible en: http://www.csi.ucd.ie/files/ucd-csi-2010-06.pdf.

Staddon, J., \& Chow, R. (2008). Detecting reviewer bias through web-based association mining. In Proceedings of the 2nd ACM workshop on Information credibility on the web (pp. 510). ACM.

Stokes, D., \& Lomax, W. (2002). Taking control of word of mouth marketing: the case of an entrepreneurial hotelier. Journal of Small Business and Enterprise Development, 9(4), 349-357.

Strangelove, M. (2010). Watching YouTube: Extraordinary videos by ordinary people. University of Toronto Press.

StrategyOne. (2013). TripBarometer de marzo de 2013, edición española. Disponible en: http://www.tripadvisor.es/TripAdvisorlnsights/n2216/tripbarometer-de-marzo-de-2013edicion-espanola

Streitfeld, D. (2011). Ferreting Out Fake Reviews Online. The New York Times. Disponible en: http://www.nytimes.com/2011/08/20/technology/finding-fake-reviews-online.html

Surowiecki, J. (2004). The wisdom of crowds: Why the many are smarter than the few and how collective wisdom shapes business. Economies, Societies and Nations.

Sussin, J., \& Thompson, E. (2012). The Consequences of Fake Fans, "Likes" and Reviews on Social Networks. Disponible en: https://www.gartner.com/doc/2091515/consequencesfake-fans-likes-reviews

Telang, R., \& Wattal, S. (2005). Impact of software vulnerability announcements on the market value of software vendors-An empirical investigation. SSRN 677427. Disponible en: http://papers.ssrn.com/sol3/papers.cfm?abstract_id=677427

Terrell, K. H., \& Kwok, L. (2011). Organizational Impression Management Behaviors in Social Media: A Perspective of a Social Networking Site. Disponible en: http://scholarworks.umass.edu/gradconf_hospitality/2011/Presentation/48/

Trenz, M., \& Berger, B. (2013). Analyzing Online Customer Reviews-An Interdisciplinary Literature Review And Research Agenda. Disponible en: http://aisel.aisnet.org/cgi/viewcontent.cgi?article=1306\&context=ecis2013_cr

TripAdvisor. (2011). Preguntas frecuentes sobre el sistema de moderación de opiniones y detección del fraude de TripAdvisor. Disponible en: http://www.tripadvisor.es/vpages/review_mod_fraud_detect.html 
TripAdvisor. (2013a). España es el octavo país que más comentarios ha generado en TripAdvisor durante 2013. Disponible en: http://blog.tripadvisor.es/2013/12/20/espanaes-el-octavo-pais-que-mas-comentarios-ha-generado-en-tripadvisor-durante-2014/

TripAdvisor. (2013b). ¿Qué constituye una opinión del viajero de primera mano?. Disponible en: https://www.tripadvisorsupport.com/hc/es/articles/200614837--Qu\%C3\%A9-consti tuye-una-opini\%C3\%B3n-del-viajero-de-primera-mano-

TripAdvisor. (2014a). ¿Qué ocurre si se descubre que un negocio tiene opiniones fraudulentas? Disponible en:

https://www.tripadvisorsupport.com/hc/es/articles/200614957--Qu\%C3\%A9-ocurre-sise-descubre-que-un-negocio-tiene-opiniones-fraudulentas-

TripAdvisor. (2014b). Sobre TripAdvisor. Disponible en: http://www.tripadvisor.es/PressCenterc6-About_Us.html

Tripadvisor for business. (2013). Más opiniones, mejor puntuación. Disponible en: http://www.tripadvisor.es/TripAdvisorlnsights/n2086/mas-opiniones-mejor-puntuacion

TripAdvisor Insights. (2013a). 24 datos para estructurar su estrategia en TripAdvisor. Disponible en: http://www.tripadvisor.es/TripAdvisorInsights/n2120/24-datos-para-estructurar-suestrategia-en-tripadvisor

TripAdvisor Insights. (2013b). ¿Cómo pueden ayudar las opiniones a su negocio? Disponible en: $\quad$ http://www.tripadvisor.es/TripAdvisorlnsights/n2150/como-pueden-ayudar-lasopiniones-su-negocio

TripAdvisor Insights. (2013c). Reporting Potential Blackmail to TripAdvisor: Report Threats Immediately. Disponible en:

http://www.tripadvisor.com/TripAdvisorlnsights/n694/reporting-potential-blackmailtripadvisor-report-threats-immediately

TripAdvisor Insights. (2013d). Taking a stand against Organized Boosting. Disponible en: http://www.tripadvisor.com/TripAdvisorlnsights/n622/taking-stand-against-organizedboosting

TripAdvisor Insights. (2014). Política de incentivos de TripAdvisor: Por qué premiar las opiniones de los viajeros va en contra de las reglas. Disponible en: http://www.tripadvisor.com.mx/TripAdvisorlnsights/n692/politica-de-incentivos-detripadvisor-por-que-premiar-las-opiniones-de-los-viajeros-va-en-contra-de

UNWTO. (2014). UNWTO World Tourism Barometer. Disponible en: http://www.siimt.com/work/models/siimt/Resource/c9a74953-565e-4413-9c83c542201549ba/PDF_RankingOMT2014Jun.pdf

Vargas, Á. (2014). Las OTA ganan por goleada a los turoperadores en España | Agencias y Turoperadores. Disponible en: http://www.hosteltur.com/159650_ota-ganan-goleadaturoperadores-espana.html

Vermeulen, I. E., \& Seegers, D. (2009). Tried and tested: The impact of online hotel reviews on consumer consideration. Tourism Management, 30(1), 123-127.

Villa Gesell. (2013). Sorteo comentarios TripAdvisor. Disponible en: https://www.facebook.com/photo.php?fbid=603627849694884\&set=a.36131139059319 9.85704.300920626632276\&type=1\&theater

Vonderau, P., \& Snickars, P. (2009). The youtube reader. Disponible en: http://www.divaportal.org/smash/record.jsf?pid=diva2:289225

Whitty, M. T., \& Joinson, A. (2008). Truth, lies and trust on the Internet. Routledge.

Williams, C. (2013). TripAdvisor borrows anti-fraud techniques from finance industry. Disponible en:

http://www.telegraph.co.uk/finance/newsbysector/mediatechnologyandtelecoms/digitalmedia/9965211/TripAdvisor-borrows-anti-fraud-techniques-from-finance-industry.html

Williams, M. (2007). Avatar watching: participant observation in graphical online environments. Qualitative Research, 7(1), 5-24. 
Wilson, A., Murphy, H., \& Fierro, J. C. (2012). Hospitality and Travel The Nature and Implications of User-Generated Content. Cornell Hospitality Quarterly, 53(3), 220-228.

Wu, G., Greene, D., \& Cunningham, P. (2010a). Merging multiple criteria to identify suspicious reviews. In Proceedings of the fourth ACM conference on Recommender systems (pp. 241-244). ACM.

Wu, G., Greene, D., Smyth, B., \& Cunningham, P. (2010b). Distortion as a validation criterion in the identification of suspicious reviews. In Proceedings of the First Workshop on Social Media Analytics (pp. 10-13). ACM.

Yacouel, N., \& Fleischer, A. (2012). The role of cybermediaries in reputation building and price premiums in the online hotel market. Journal of Travel Research, 51(2), 219-226.

Ye, Q., Gu, B., Chen, W., \& Law, R. (2008). Measuring the value of managerial responses to online reviews-A natural experiment of two online travel agencies. 29th International Conference on Information Systems (ICIS), Paris, France Disponible en: http://aisel.aisnet.org/icis2008/115/

Ye, Q., Law, R., Gu, B., \& Chen, W. (2011). The influence of user-generated content on traveler behavior: An empirical investigation on the effects of e-word-of-mouth to hotel online bookings. Computers in Human Behavior, 27(2), 634-639.

Yin, R. K. (2011). Applications of case study research. Sage.

Yoo, K. H., \& Gretzel, U. (2009). Comparison of Deceptive and Truthful Travel Reviews. Information and Communication Technologies in Tourism 2009, pages 37--47. Springer.

YouTube. (2014). Estadísticas de YouTube. Disponible en: http://www.youtube.com/yt/press/es/statistics.html

Zhu, F., \& Zhang, X. (2010). Impact of online consumer reviews on sales: The moderating role of product and consumer characteristics. Journal of Marketing, 74(2), 133-148. 


\section{ANEXOS}

\section{ANEXO 1: Opiniones de hoteles registradas en Booking}

\section{Hotel Princesa Galiana}

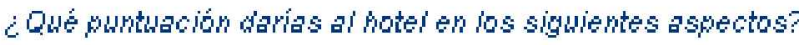

\begin{tabular}{|c|c|c|c|c|}
\hline & Wal & Regular & Bueno & Excelente \\
\hline \multicolumn{5}{|l|}{ Personal del hotel } \\
\hline \multicolumn{5}{|l|}{ Servicios e instalaciones } \\
\hline \multicolumn{5}{|l|}{ Lirnpjera de la habitación } \\
\hline \multicolumn{5}{|l|}{ Confort } \\
\hline \multicolumn{5}{|l|}{ Relación calidad i precio } \\
\hline Lbicación & & & (6) & \\
\hline
\end{tabular}

Juan

Pareja joven

I EL ALGAR

(CARTAGENA), España

26 de octubre de 2011
Está relativamente cerca del casco antiguo y se puede aparcar cerca sin dificultad y sin pagar.

\section{VIK Gran Hotel Costa del Sol}

¿Que puntuacion darias al hotel en los siguientes aspectos?

\begin{tabular}{|c|c|c|c|c|}
\hline & Wal & Regular & Выепо & Excelente \\
\hline Personal del hotel & 0 & ( ) & 0 & 0 \\
\hline Servicios e instalaciones & 0 & () & 0 & $\bigcirc$ \\
\hline Limpieza de la habitación & () & 0 & 0 & 0 \\
\hline Confort & 0 & () & 0 & 0 \\
\hline Relación calidad / precio & $\Omega$ & (6) & 0 & 0 \\
\hline Lا̇icación & 0 & 0 & (9) & 0 \\
\hline
\end{tabular}

Anónimo

Pareja joven

=España

20 de noviembre de 2011
- Está pegado a la playa y no parece muy viejo.

- Hay detalles de la limpieza que no nos gustaron. Hay algunas instalaciones que indican cierta dejadez, además del mal gusto para la decoración. 
2 ¿Cómo valorarías el Hotel Travelodge Montreal Centre en estos aspectos?

\begin{tabular}{|c|c|c|c|c|}
\hline & Mal & Regular & Bueno & Excelente \\
\hline Personal & ○ & (e) & ○ & O \\
\hline Servicios & 0 & O & (2) & O \\
\hline Limpieza & ○ & $\odot$ & 0 & (c) \\
\hline Confort & O & $\odot$ & (2) & O \\
\hline Relación calidad / precio & O & ○ & ○ & (c) \\
\hline Ubicación & O & ○ & O & (c) \\
\hline
\end{tabular}

Juan

Pareja joven

IEl Algar - Cartagena

España

31 de agosto de 2013
๑ El precio está bastante bien, para la zona y la ciudad en la que se encuentra. Además el desayuno está incluido y no está mal.

- La habitación con cama de matrimonio es de 1,35m., que se hace algo pequeña cuando estas acostumbrado a 1,80 .

2 ¿Cómo valorarias el St. Lawrence College Residence Brockville en estos aspectos?

\begin{tabular}{|c|c|c|c|c|}
\hline & Mal & Regular & Bueno & Excelente \\
\hline Personal & 0 & 0 & (5) & 0 \\
\hline Servicios & 0 & (5) & 0 & 0 \\
\hline Limpieza & (6) & 0 & 0 & 0 \\
\hline Confort & 0 & 0 & (6) & 0 \\
\hline Relación calidad/precio & 0 & (6) & 0 & 0 \\
\hline Ubicación & 0 & (6) & 0 & 0 \\
\hline
\end{tabular}

Juan

Pareja joven

IEl Algar - Cartagena,

España

31 de agosto de 2013 $\oplus$ Las instalaciones son amplias y parecen bastante nuevas.

- La limpieza es bastante escasa. Se nota que limpian lo justo. Las puertas, muebles o paredes rotas, no se molestan en arreglarlas. Es barato y las instalaciones son decentes, pero el cuidado y la limpieza son penosos. 
2 ¿Cómo valorarías el The Alexandra Hotel en estos aspectos?

\begin{tabular}{|c|c|c|c|c|}
\hline & Mal & Regular & Bueno & Excelente \\
\hline Personal & 0 & 0 & c) & 0 \\
\hline Servicios & $\ominus$ & 0 & (c) & 0 \\
\hline Limpieza & 0 & 0 & 6 & 0 \\
\hline Confort & 0 & 0 & (6) & 0 \\
\hline Relación calidad/precio & 0 & 0 & (c) & 0 \\
\hline Ubicación & $\varphi$ & 9 & (9) & 8 \\
\hline
\end{tabular}

Juan

Pareja joven

I El Algar - Cartagena,

España

31 de agosto de 2013
๑ Lo mejor el precio y la ubicación relativamente cerca del centro, junto al barrio chino. Además se puede aparcar por $5 \$$ al día.

- Las instalaciones no son muy modernas, pero está limpio y es cómodo.

2 ¿Cómo valorarías el Diplomat Inn en estos aspectos?

\begin{tabular}{|c|c|c|c|c|}
\hline & Mal & Regular & Bueno & Excelente \\
\hline Personal & 0 & 0 & 0 & (c) \\
\hline Servicios & $\odot$ & 0 & () & 0 \\
\hline Limpieza & 0 & 0 & (c) & 0 \\
\hline Confort & 0 & 0 & (i) & 0 \\
\hline Relación calidad/precio & 0 & 0 & 0 & (c) \\
\hline Ubicación & 0 & 0 & 6 & 0 \\
\hline
\end{tabular}

Juan

Pareja joven

IEl Algar - Cartagena España

31 de agosto de 2013 $\oplus$ Es barato y está cerca de la zona de ocio y las cataratas. El aparcamiento es gratis.

- No deja de ser un motel, sin demasiados lujos, pero limpio y amplio.

$$
\text { ¿Te ha resultado útil este comentario? Si No }
$$


ANEXO 2: Ejemplos de puntuaciones individuales de hoteles en Booking
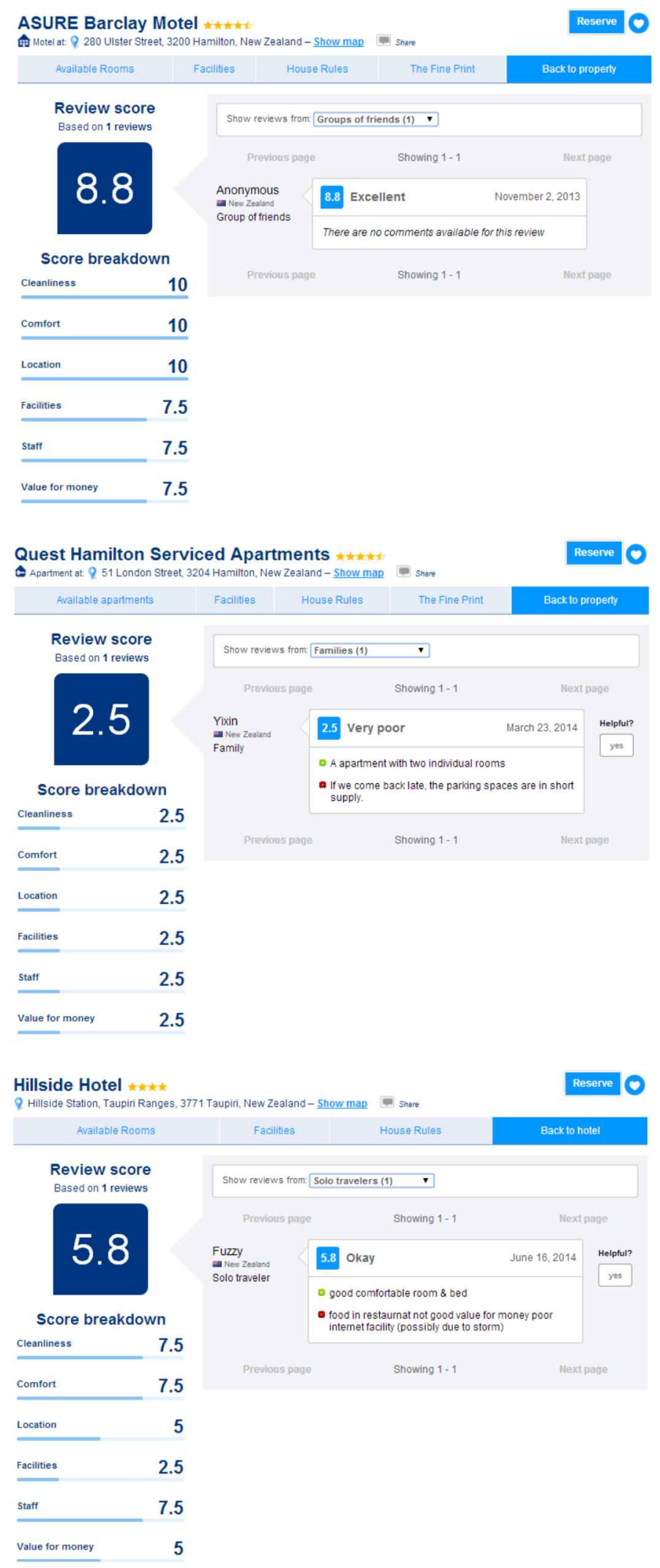
The Narrows Landing Hotel

Q 431 Airport Rd, RD2 Tamahere, 3282 Hamilton, New Zealand - Show map

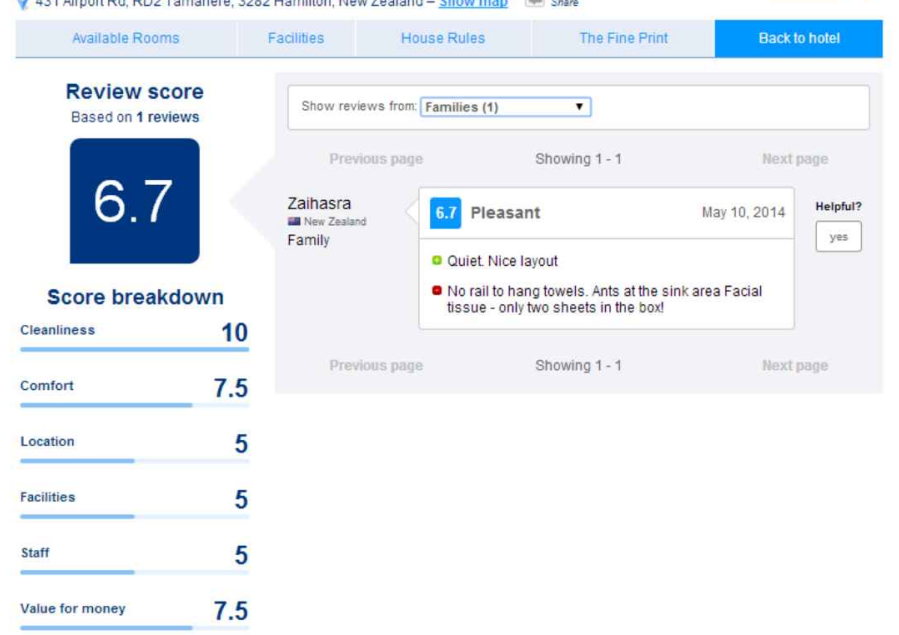

Hyatt Place Kansas City Airport $* * *$

97600 Northwest 97 th Terrace, Kansas City, MO 64153 - Show map $=$ Shase

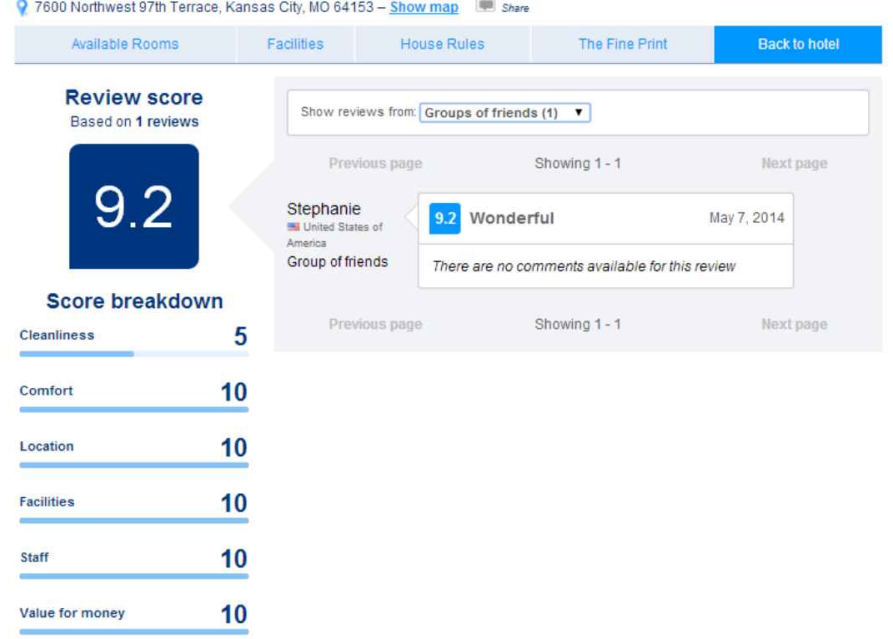
Extended Stay America - Kansas City - South **
550 East 105th Street. Kansas City, MO 64131 - Show map

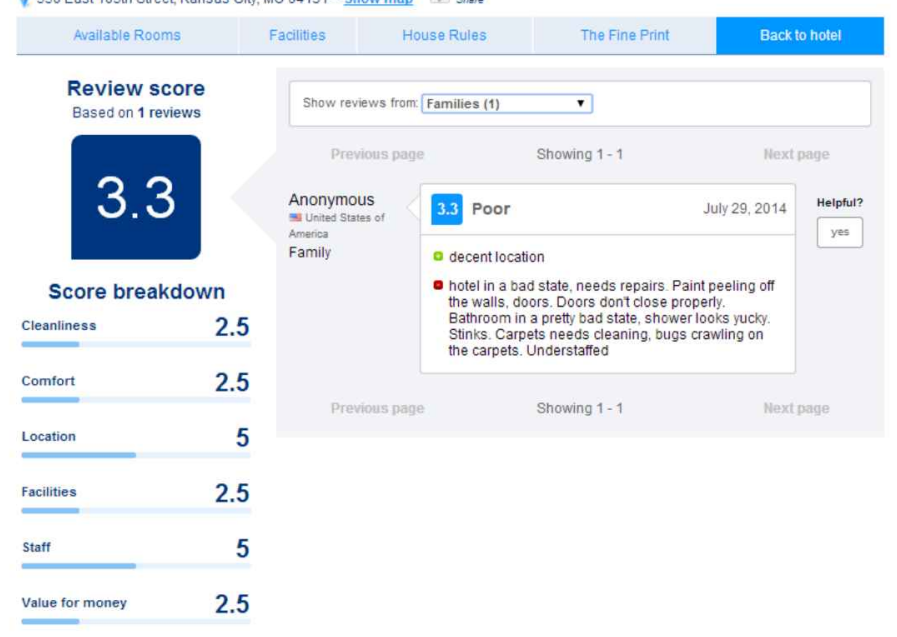


Capital Center Inn

Aut Motel at: Q 6101 East 87th Street, Kansas City, MO 64138 - Show map = Share

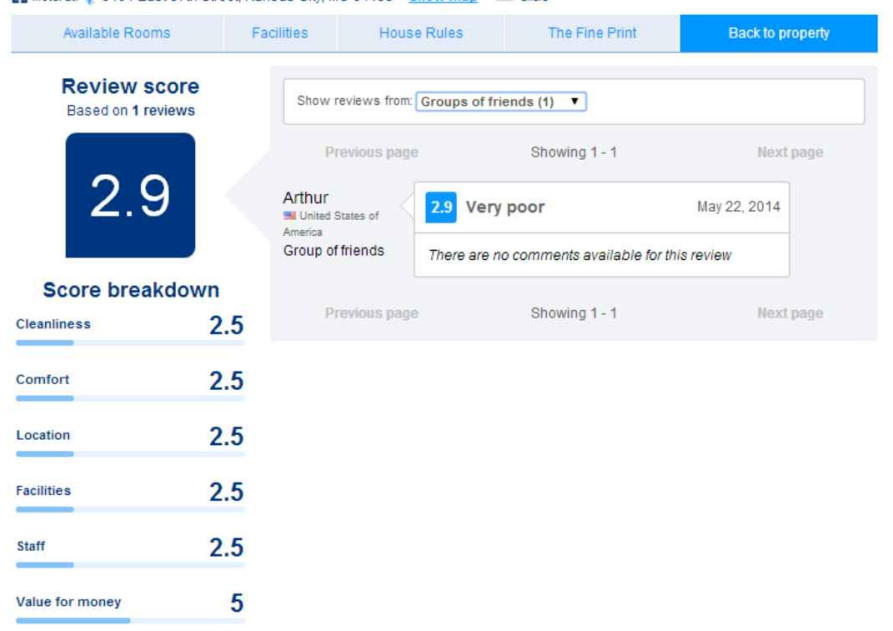

Holiday Inn Kansas City Northeast l-435 North ***** Q 7333 Parvin Road, Kansas City, MO 64117 - Show map snas

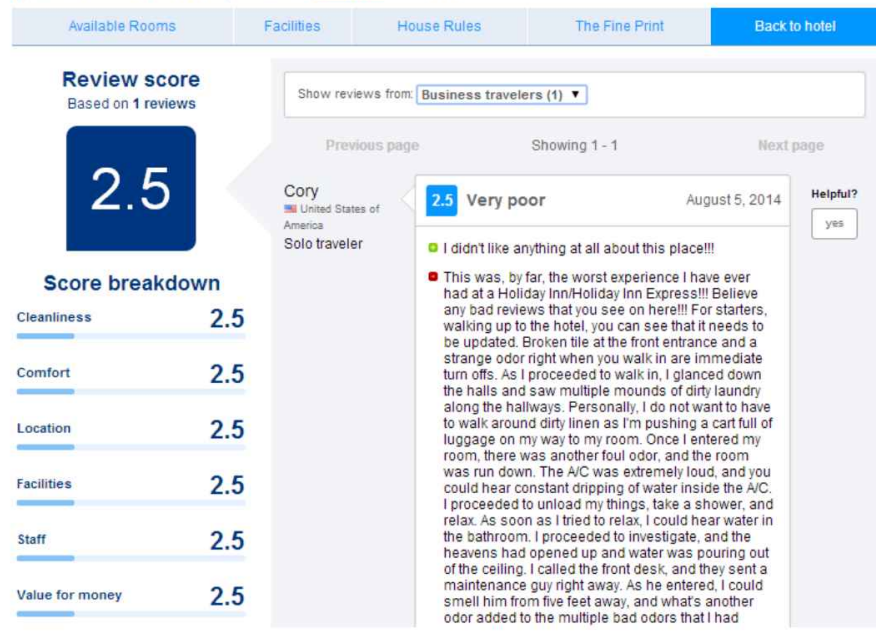

Comfort Inn Kansas City

Q 234 North 78 th Street, Kansas City, KS 66112 - Show map. E- Shate

Reserve 0

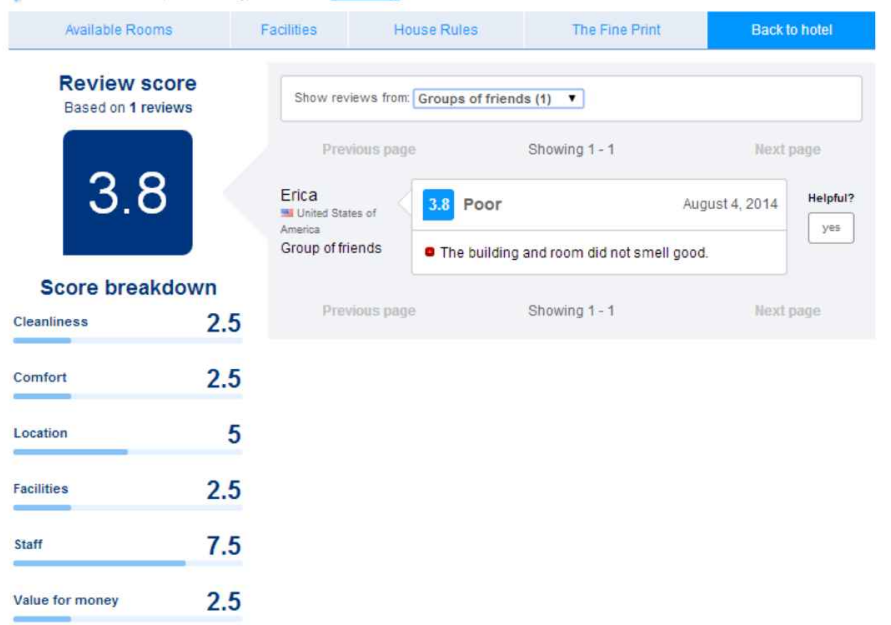


Apartamentos Magic Atrium Plaza

Avenida LAigüera, 3, 03501 Benidoorm (Mostrar mapa) Tomparit

Q volver al alojamiento

\begin{tabular}{|c|c|c|c|}
\hline \multicolumn{4}{|c|}{ Los clientes han escrito sus comentarios después de su estancia en el Apartamentos Magic Atrium Plaza } \\
\hline Todos los clientes 14 & Desglose & & Puntuación \\
\hline Familias 5 & Limpieza & 7,5 & \\
\hline Grupos de amigos 8 & Confort & 7,5 & 54 \\
\hline \multirow[t]{4}{*}{ Personas que viajan solas 1} & Ubicación & 2,5 & \\
\hline & Instalaciones y servicios & 5 & Basada en 1 comentario \\
\hline & Personal & 5 & \\
\hline & Relación calidad - precio & 5 & \\
\hline
\end{tabular}

Casa En La Costa II Playa Los Locos oferta inteligente

Playa Los Locos (Different locations), 03182 Torrevieja (Mostrar mapa) comparitr

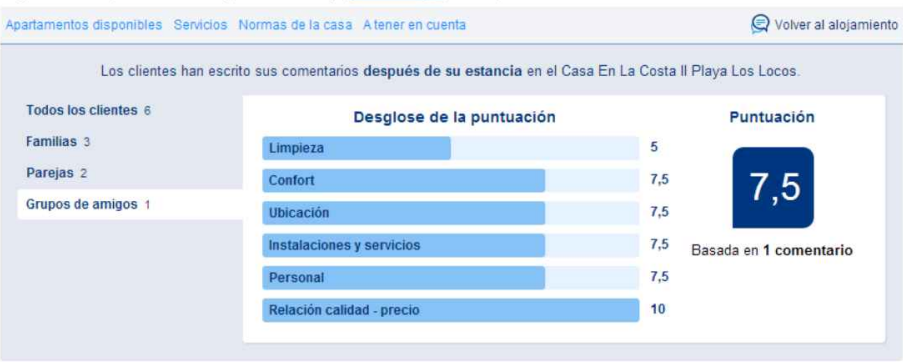

Hotel Fleming

Reseva ahora

Maravall, 11, 03501 Benidorm (Mostrar mapa) Comparti

\begin{tabular}{|c|c|c|c|}
\hline \multicolumn{3}{|c|}{ If a. Habitaciones disponibles Senvidos Normas de la casa } & Q volver a hotel \\
\hline \multicolumn{4}{|c|}{ Los clientes han escrito sus comentarios después de su estancia en el Hotel Fleming. } \\
\hline Todos los clientes 17 & Desglose & & Puntuación \\
\hline Parejas 5 & Limpieza & 7,5 & \\
\hline Grupos de amigos 11 & Contort & 5 & 63 \\
\hline \multirow[t]{4}{*}{ Personas que viajan solas 1} & Ubicación & 7,5 & \\
\hline & Instalaciones y servicios & 7,5 & Basada en 1 comentario \\
\hline & Personal & 2,5 & \\
\hline & Relación calidad - precio & 7,5 & \\
\hline
\end{tabular}

Best Western Plus Milwaukee Airport Hotel \& Conference Center $\star \star \star \star *$ Oferta inteligente

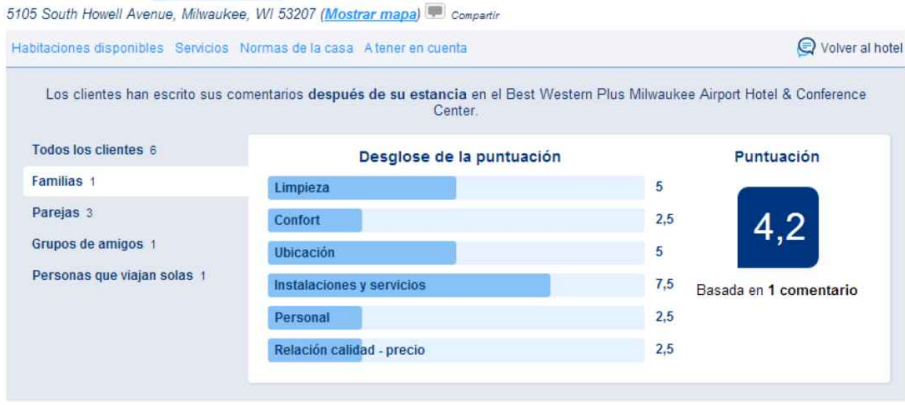

Crowne Plaza Wilmington North

630 Naamans Road, Claymont, DE 19703 (Mostrar mapa) 10 compant

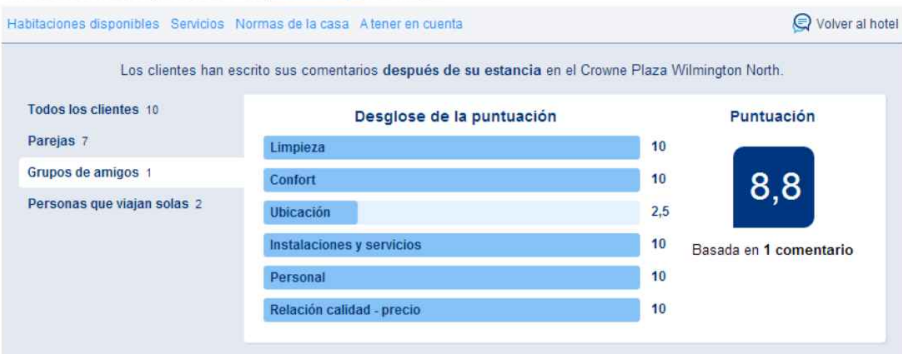




\section{ANEXO 3: Incentivos para opinar en TripAdvisor (Twitter)}

achookis@Chookisiberica-21 de ago

Nos gustaria saber tu opinión y sólo por eso si pones tu comentario en TRIPADVISOR te damos un $2 \times 1$ en el Chookis que eleijas...

Angela Soleno@asoleno.20 de ago

Enter in my raffle. To do so, post your Yelp or Trip Advisor review below. (this is not cheating...) I cannot... fb.me/2GyN5wxyd

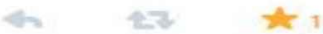

Restaurante Mar Azul @RMARAZUL - 30 de jul

iSOLO QUEDA UN DÍA para que participes en el sorteo de una botella de vino! Haz clic en este LINK y danos tu... fb.me/4izLVB2yg

38 Kendal Wall@realkendalwall-29 de jul.

Last chance to enter our Tripadvisor competition. Leave a review before end of play Thurs, 31 st to go into prize draw.crazyclimbing.co.uk/news/tripadvis.

Despensa1893@1893Gourmet-16 de jul

Opina acerca de la Despensa 1893 en TripAdvisor y participa del sorteo de este set parrillero.... fb.me/74frloavf

औ): Olimar II@OLIMARII-12 de jul.

CONCURSO TRYP ADVISOR: este año tus comentarios en Tripadvisor tienen premio! Lee las instrucciones, participa y... fb. me/6WHosOBOO

Ramada RVC@RamadaRvC-5 de jul

When you leave us a kind review on \#TripAdvisor.com, we e-mail you a discount on your next stay! tripadvisor.com/Hotel_Review-g...

MASTORRENCITO@mastorrent-5 de jul.

NUEVO CONCURSO MAS TORRENCITO - TRIPADVISOR

entre las opiniones escritas en tripadvisor esta semana, desde hoy... $\mathrm{fb}$ me/1us3C2Nbn

Mastropiero GyJ@Mastropierocc-30 de jun

Los ganadores de nuestro concurso por dar su opinión en

(a) TripAdvisor han sido: sanl02014, arual66 y Ferrolana_de_Caceres

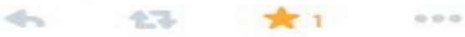

Hotel Port Eugeni @hotelporteugeni-20 de jun

NUEVO CONCURSO TRIPADVISOR: ahora tus comentarios en Tripadvisor tienen premio! Gana una estancia gratis en Port.. $\mathrm{fb}$. me/2h10jo8MF 
JoshuaTree@JoshuaTreeAveda-26 de abr

Review the Joshua Tree - Aveda Concept Salon \& Spa on Trip Advisor and receive a discount on your next... fb.me/29g6tkgKT

Ramada RVC@RamadaRVC-25 de abr

Reviews are SO important to us. Please leave us a review on

TripAdvisor.com \& We will send you a discount for your next stay!...

S

Hotel Las Cumbres@HotelLasCumbres-10 de abr

Nuevo sorteo Facebook - Tripadvisor!!

1) Para participar del sorteo y si ya has sido huésped de nuestro hotel... fb.me/6zQqbi6Mk

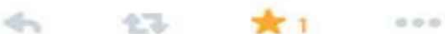

\section{Hotel Puerto Antilla@PuertoAntilla-10 de abr}

Gana una estancia \#gratis en \#PuertoAntilla con el \#Concurso de comentarios "Mis \#Vacaciones en Puerto Antilla" en ow.ly/vDiEL

w. Onahotels@onahotels.4 de abr

¿Conoces nuestra \#Oferta Exclusiva en \#TripAdvisor? UNA NOCHE \#GRATIS \#OnaAucanada \#Alcudia \#Mallorca ow.ly/vqjox

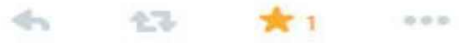

LX Boutique Hotel @lxboutiquehotel.3 de abr

Já ficou connosco? Partilhe a sua Xperiência no TripAdvisor e ganhe uma Estadia Grátis! Saiba aqui como:... fb.me/2g6A9lWkg

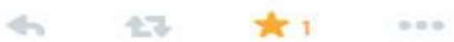

(H) Hotel de Campo Colon@HotelCampoColon-18 de mar

Felicitamos a Letyvali ganador del concurso Tripadvisor del mes de Febrero

The Egyptian Theatre @TheEgyptianPC.14 de mar

REVIEW our venue on@TripAdvisor here: bit.ly/1ne3ahc and be entered to win $4 \$ 50$ gift cards!! Contest ends $3 / 21$ !

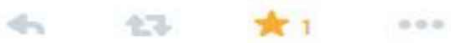

Fres Gastroladelizia@gastroladelizia-13 de mar

Review us on Trip Advisor and get $20 \%$ discount on your next bill! ow.ly/uvFjK

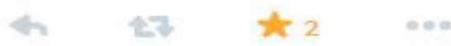

20. Bald Hills@baldhillswines.7 de feb

Dont forget to place a review on Tripadvisor for Bald Hills - you'll go in the draw to win 6 bottles of our award... fb.me $/ 218027 \mathrm{~h} 2 \mathrm{~g}$

2. Project Hawick@projecthawick.9 de ene

Reviewers of JJXpress on TripAdvisor, will be entered into a prize draw: 
Newcastle Greyhounds@NewcastleDogs.3 de ene

Write a review on us of your experience here tripadvisor.co.uk @TripAdvisor@NewcastleDogs and win a prize. You know you want to

\& $271 \quad+1 \quad 00$

- The Bombay Store@thebombaystore-6 de dic

Help us reach 100 reviews on Trip Advisor and stand a chance to win. More at on.fb.me/1cps6v9

Edible Canada@Ediblecanada.4 de dic

Congrats to Heather $M$ for winning our November review contest! She wrote a review on @TripAdvisor and won a wine paired dinner for 4!!

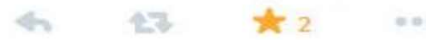

73. Fifteen Barcelona@Fifteenben.26 de nov

Opina sobre nosotros en TripAdvisor, habrá premios para los que nos dejéis vuestra opinión \#concurso \#sorteo ht.ly/rbVyM

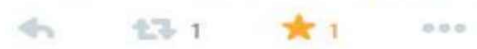

Casa Jose EIda@CASAJOSEELDA-19 de nov

Gracias a todos por vuestra participación en el concurso Tripadvisor Muy pronto daremos el nombre del ganador.

Pavilion Gardens@GardensBuxton-13 de nov.

We are doing a quarterly prize draw to win a meal for two! To be eligible, all you need to do is leave a review here ow ly/qL8Q3

\& $k$ t? $\quad$ i

댈 Villa Gesell Spa@villagesellspa-1 de nov

Jugamos???? Todos los comentarios desde el 30-10 al 30-11 en Trip Advisor estan participando de sorteo por fin de... fb.me/1Y5tjOuGO

Vanilla Pod@Vanillapodling.15 de oct

Post a review of us on Facebook, TripAdvisor, or Urbanspoon to go in our monthly draw to win a Zentveld's Coffee... fb.me/2eebK8drY

\section{Almenara Golf Club @almenararesort -6 de oct}

Raffle 4 \#greenfees for first 20 reviews n our \#tripadvisor site tripadvisor.es/Attraction_Rev...

Q Japón del Lago@japonDelLago-27 de sept.

[CONCURSO] Opina de nosotros! En PVaras goo.gl/wnkNXo y en P.Montt goo.gl/06506L y participa por un Menú NI! @WAINRAIHGT

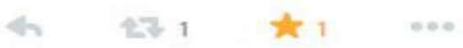

Village Pottery@villagePottery-23 de sept

Thank you Joni, Jackie and Bev for the lovely reviews on Trip Advisor! You have been entered into our draw for a... fb.me/PG8DzGko 
MM Antic Molí @LAnticMoli-6 de sept

Recuerda, comparte con nosotros tu opinión en la web \#TripAdvisor y entrarás en el \#sorteo de un \#premio excelente. ow.ly/oD/4g

Strathspey Railway@StrathspeyRail-6 de sept

Check out our FaceBook page for details of an excellent prize up for grabs for our@TripAdvisor reviewers! ow.ly/onpLI

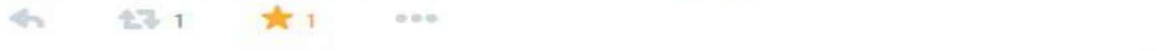

TGI Diving Roatan @tgiroatan-30 de ago.de 2013

We are still missing 17 reviews on Trip Advisor! Just write about your time on $\mathrm{TGl}$ and you are in the raffle of a... fb.me/2WkakQMOC

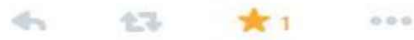

HotelMariscalRobledo@mariscalrobledo-15 de ago. de 2013

Esta semana publicamos el ganador de nuestro concurso en @itripadvisor, los invitamos a estar pendientes de las... fb.me/1VxzOvgsj

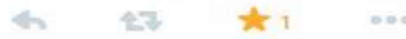

Stravaigin Lodge@stravaiginlodge-12 de ago. de 2013

We're on@TripAdvisor leave us a good review and you'll get a $£ 40$ discount in 2014! :) tripadvisor.co.uk/VacationRental.

Can Curreu@Cancurreu.5 de ago.de 2013

Nos ayuda a obtener 5 estrellas en TripAdvisor? Publica tu opinión en goo.gl/5ETi7d y tendrás un pase gratis en nuestro SPA!

\& 2 th 1 ...

Jessica Lowery@vampirestalkers.31 de jul.de 2013

Our Tripadvisor contest winners have been picked! ck out the list facebook.com/pages/Vampire-..

is ter tion

bow Plaza de Armas @rplazadearmas.24 de jul. de 2013

Haz un comentario de nuestro restaurante en tripadvisor.com.ar y participa por una cena para dos... fb.me/2Jy37mysc

Adventure Peaks@adventurepeaks.22 de jul. de 2013

First Tripadvisor Prize claimed fb.me/2cc9kCzPn

s 27 * 1 -

B Billy's bar @Billysharpenden-10 de jul. de 2013 tripadvisor.com/Restaurant_Rev...

WRITE YOUR REVIEW NOW. Enter our prize draw.. Free Dinner?

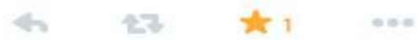

\section{Fratello's Swindon@FratellosSN1.21 de jun. de 2013}

Let us know what you think of a recent experience at Fratello's, and we'll add to you to a draw to win dinner for 2 bit.ly/fratellos

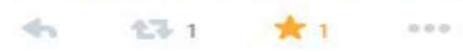


9esign Your Salad @designyoursalad-17 de jun. de 2013

Hola Todos!! Participa en nuestro concurso de la semana: Deja tu comentario en la web de Trip Advisor y participa... fb.me/6iTtDPXmL

\& $13 \quad \neq 2 \quad \infty$

Key West's Finest @KeyWestsfinest-4 de jun. de 2013

Contest for free room at Santa Maria Suites \#keywest! $\mathrm{fb} . \mathrm{me} / 1 \mathrm{wKR} 6 \mathrm{CLLK}$

4 Loxleys Restaurant @Loxleys.15 de may de 2013

Leave us a review on Trip Advisor and enter into a prize draw to win a bottle of champagne! tripadvisor.com/Restaurant_Rev...

207t TrattoriaLaPasta@LAPASTAMERIDA-13 de may. de 2013

Trattorialapasta Merida ha compartido el siguiente enlace y ha comentado esto:

NUEVO CONCURSO TRIP ADVISOR!... fb.me/1HH6tfYIJ

\& 27 t 1 .

Becerrita@Rbecerrita-29 de abr. de 2013

El ganador del sorteo Tripadvisor \#cena para 2 personas recoge su premio en nuestro restaurante. ow.ly/kwfPh \#Sevilla \#comer

1. Water St Fish \& Chip@Waterstfishchip.3 de abr. de 2013

Let us know how we did, and you could win a dinner for 4 tripadvisor.ca/UserReview?qid... contest closes April 30th

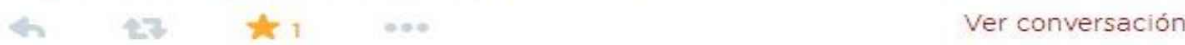

Guthrie Castle@guthriecastle.25 de mar. de 2013

Leave a review for a Prize Draw for a Thornton's Chocolate Hamper,

Bride \& Grooms or even if you were just a guest!

tripadvisor.co.uk/Hotel_Review-g...

\& $27 \quad$ t 1 ...

20.5 Sisai Hotel Boutique@SisaiHotelPunta-20 de mar. de 2013

No dejes de participar del sorteo por una estadía gratis en el 2 do hotel más elegido de TripAdvisor en Punta Imperdible!...

Oliva Restaurante@olivaresto-22 de feb. de 2013

QUEDAN POCAS HORAS! OPINA EN TRIPADVISOR SOBRE OLIVA E INMEDIATAMENTE PARTICIPARAS DEL SORTEO POR UNA CENA! tripadvisor.com.ar/UserReviewEdit.

92. GB Pizza Co @gbizzaCo.30 de dic de 2012

Write us a lovely review on Tripadvisor in the next 10 days \& be entered into a draw to win a meal for 4 . See our FB page for more info. 
A. rompientenorte@rompientenorte-26 de nov. de 2012

Solo queda una semana y tienes muchas oportunidades de que si opinas te toque a TI

SORTEO DE SURFCAMP DE... fb.me/2iI7N2OX2

H 2 औ 2 \& 2

27.20 Majahuitas Resort @Majahuitas.9 de nov. de 2012

Help us pass the 100 review benchmark on Trip Advisor for a chance to win the raffle for $50 \%$ off your next stay! goo.gl/GPt 64

4 27 औ 1 .

(M) HintHunt London @HintHuntLondon-28 de oct. de 2012

Tripadvisor raffle is still on! Write a review till 8pm (Monday) \& win a free $\mathrm{HH}$ ticket! Winner announced at night : )

tripadvisor.co.uk/Attraction_Rev..

4 27 स 1 ...

(4) Villas Flamingos@flamingosholbox-19 de sept. de 2012

¿Te has hospedado en VillasFlamingos? ¿Te gustaría volver? Cuenta tu historia y participa en la rifa de 2 noches ow.ly/dPObT

\& $2 \geqslant 1$ औ 1 ...

Oasis Hotels@Oasis Hotels - 5 de sept. de 2012

Envia tus comentarios a TripAdvisor y a

opinionoasis@oasishoteles.com y participa en la rifa mensual de un IPAD ow.ly/durri

Rusty's Steakhouse@Rustyssteaks.19 de jul. de 2012

A quick link to our Trip Advisor iFrame...write a review and you could win a prize! awe.sm/goZea

EIRanchoMadrid @ElRanchoMadrid-14 de jul. de 2012

iMuchas gracias! Si haces un comentario en Tripadvisor puedes ganar una cenagratis "@karlos_kamacho: Muy recomendado!

@ElRanchoMadrid"

\. Marina Suites@MarinaSuites.28 de jun. de 2012

Finalizado el sorteo "Comparta su experiencia". Hemos recibido en @TripAdvisor más de 100 participantes en los últimos dos meses. iGracias!

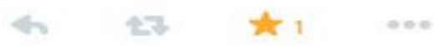

Kanpai Ecuador@kanpaiec.3 de may. de 2012

Te invitamos a que conozcas nuestro nuevo local en Cumbayá iDinos qué te pareció en Tripadvisor owly/aF5r7 puedes ganar una cena!

Hotel La Tour@Hotel_LaTour-1 de may.de 2012

We want your reviews! You have til 30th May to review the hotel \& Aalto on Tripadvisor. We're choosing 1 at random to win a special prize! 
4ku LaVinaQuito@LaVinaQuito.27 de abr. de 2012

Deja tus comentarios de La Viña en Tripadvisor, puedes ganar una cena para 2 ! ow.ly/axPer

Karmairi Hotel Spa@Karmairi - 11 de ene. de 2012

Ya nos visitaste? ingresa a alturl com/4pebh deja tu opinión y participa por una noche gratis en nuestro Hotel Spa!

Toey Na Ranong @toeytoeychuchu-19 de dic. de 2011

First ten ppl to write us a review on Trip Advisor get's $20 \%$ discount at $\mathrm{CHU} .10 \%$ off for everyone after. Go here: tinyurl.com/82wdxyg

Starpoints Hotel @Starpointshotel-28 de oct. de 2011

collect your discount coupons, everytime you leave trip advisor review! facebook.com/\#!/pages/Starp...

\& $17 \neq 1$

Colores Santos@Colores_Santos - 24 de oct. de 2011

Escribe tu opiniòn y podrás GANAR una cena completa para 4 personas, con aperitivo, entrada, fondo, postre y... fb.me/1fYjn31Jc

\& $27 \quad$ t 1 on

Sultana's Istanbul @istanbulShow-13 de sept. de 2011

Been to Sultana's recently? Post a review and we'll give you $20 \%$ discount on your next visit! bit.ly/oicsLZ fb.me/112vqq6yz

Resort de Campo\&Polo@poloresort-21 de dic. de 2010

Dejanos tu crítica en Trip Advisor y iparticipá por una noche de alojamiento! http://fb.me/OI9PRjs8 
ANEXO 4: Guía "reputación online" del Instituto tecnológico hotelero

\section{INSTITUTO TECNOLÓGICO HOTELERO}

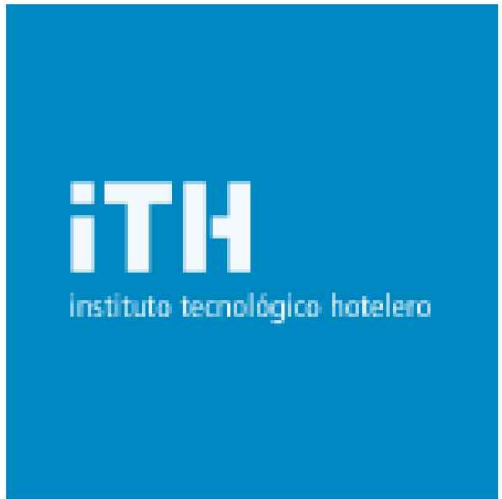

"reputacion line" 


\section{1.- OBJETIVO DE LA INICIATIVA}

El objeto de la iniciativa es motivar a los clientes satisfechos para que dejen comentarios positivos sobre el hotel en las Webs que generan mayor tráfico de comentarios, facilitándoles una tarjeta con las direcciones donde realizar dichos comentarios.

\section{2.- RESULTADOS ESPERADOS}

- Incrementar el volumen de ventas

- Que los clientes satisfechos compartan sus experiencias positivas con clientes potenciales en las Webs de comentarios mas utilizadas en el sector hotelero

- Mejora de la reputación on line del establecimiento

- Aumento del tráfico hacia la Web del hotel, mejorando el posicionamiento orgánico en buscadores.

- Aportar un valor añadido y un elemento diferencial frente a la competencia

\section{3.- JUSTIFICACIÓN DEL PROYECTO}

Existen estudios (Bizrate, CampUSA, Marketing Sherpa ó Foresee) que confirman las tendencias actuales en cuanto a la modificación en la toma de decisiones de compra de los consumidores:

- Una gran mayoría de los consumidores no cree que las empresas digan toda la verdad en sus mensajes corporativos

- El $92 \%$ de los usuarios prefiere una recomendación directa a un anuncio publicitario a la hora de tomar una decisión de compra

- El $60 \%$ estaria dispuesto a compartir una experiencia con otros usuarios

- Portales de opiniones como tripadvisor registran más de 25 millones de visitas al mes y cuentan con más de 20 millones de criticas y opiniones sobre hoteles

Por todo ello, en el ITH estamos convencidos de que un cliente satisfecho es el mejor prescriptor de la marca, y atendiendo al creciente uso de Internet los clientes actuales tienen la opción de llegar a más clientes potenciales que antes. ¡Aprovechémoslo! 


\section{4.- IMPLANTACIÓN DE LA INICIATIVA}

Aquellos establecimientos que quieran implantar ésta iniciativa, únicamente tendrán que:

1. Incluir la iniciativa tanto en los planes de comunicación al cliente externo, como en el de formación al personal del hotel

2. *Descargar el modelo de tarjeta

3. Personalizar las tarjetas insertando el logo del establecimiento en el cuadro reservado a tal efecto

4. Imprimir las tarjetas de tamaño visita

5. Formar a los empleados del hotel para que identifiquen al cliente y el momento adecuado para facilitarles la tarjeta.

6. Repartir las tarjetas entre el personal del hotel, con el fin de que se las entreguen personalmente a aquellos clientes que hayan manifestado su satisfacción con los servicios del hotel

* Todos los documentos necesarios para el desarrollo de la íniciativa, así como el modelo personalizable de la tarjeta, se enviarán a todos los socios por email y se podrắn descargar directamente de la página Web del ITH.

\section{5.- PRESUPUESTO APROXIMADO}

Estimamos que un coste orientativo de maquetación e impresión de las tarjetas personalizadas con el logo del hotel puede ascender a:

- Para 20o tarjetas: $185,00 €$

- Para 500 tarjetas: 200,006

- Para 100o tarjetas: 225,00 €

- Coste asociado a la comunicación al cliente de ésta iniciativa (Folletos, Web)

- Coste asoclado a la comunicación y formación al personal del hotel 
6.- PLAN DE FORMACión la comunicación de éste tipo de iniciativas ha de ser extensible a todo el personal del hotel, y especialmente entre los departamentos cuyo personal esté de cara al cliente, o tenga contacto directo con él, como es la dirección, departamento comercial, departamento de recepción, o de sala:

\section{1. $\iota$ Por qué queremos que dejen comentarios sobre nuestro hotel?}

La valoración de un determinado producto o servicio por parte de alguien de nuestro entorno siempre ha influido en nuestra decișión de compra, con la diferencia de que el efecto antaño conocido como " boca a boca " se difundia únicamente al entorno más próximo de cada consumidor, esto es, familiares, amigos, y conocidos.

Hoy en dia, el uso de Internet ha provocado que el "boca a boca " digital llegue a miles, incluso millones de personas gracias a la normalización en el uso de Internet, por lo que cada dia mas, los comentarios vertidos en Internet acerca de nuestros establecimientos hoteleros tienen mas relevancia a la hora de influir en la decisión de compra de los potenciales clientes.

Por ésta razón, es muy conveniente para el establecimiento posicionarse estratégicamente gracias a los buenos comentarios en las principales Webs de opinión, con el fin de obtener una ventaja competitiva respecto a nuestros competidores directos.

\section{2. ¿Que ventajas ofrecen tener muchos comentarios positivos en éstas Webs?}

- Incrementar el volumen de ventas.

- Que los potenciales clientes se decidan por nuestro hotel al comprobar en éstas Webs que nuestro establecimiento es el más y mejor valorado por los propios clientes.

- Aumento del tráfico en internet hacia la Web del hotel, mejorando el posicionamiento orgánico en buscadores, lo que redundará en una mayor visibilidad de la Web del hotel en los principales buscadores.

- Aportar un valor añadido y un elemento diferencial frente a la competencia. 


\section{3. ¿Dónde llevamos las tarjetas?}

Lo ideal es que el personal lleve siempre consigo las tarjetas, para poder ofrecérselas en el momento apropiado y evitar tiempos de espera al cliente en caso de que tuviéramos que ir a buscarlas.

\section{4. ¿A quien le damos las tarjetas?}

Con el fin de asegurarnos que los comentarios que dejen sobre nuestro hotel sean positivos, es fundamental entregar la tarjeta únicamente a aquellos clientes habituales del hotel, aquellos que tengan un alto grado de repetición.; o que hayan transmitido al personal del hotel, sin dejar lugar a dudas, su satisfacción con los servicios disfrutados y el trato recibido.

\section{5. ¿Cuándo es el mejor momento de entregar la tarjeta?}

Obviamente, el mejor momento para entregar la tarjeta será en el preciso instante que el cliente muestre al personal del hotel la satisfacción, para aprovechar ese momento de "debilidad".

En caso de no ser el cliente el que libremente manifieste sus felicitaciones, será el recepcionista en el momento del check out quien, mostrando sincero interés por el cliente, le pregunte si su estancia en el hotel ha sido satisfactoria. En caso afirmativo y utilizando la diplomacia y experiencia del personal, hacerle entrega de la tarjeta y sugerirle que el hotel agradeceria que compartiera sus comentarios con nosotros en la Web, para așí poder conocer de primera mano los puntos a mejorar.

\section{6.¿Que le tenemos que decir al cliente para convencerle?}

El que un cliente se tome las molestias de visitar una o varias Webs, localice el hotel, y deje sus comentarios requiere su tiempo, por lo que es necesario transmitir correctamente al cliente cual es la causa de nuestro interés. 
Los comentarios de los clientes son fundamentales para conocer su opinión respecto de nuestro hotel ${ }_{\text {, }}$ con el fin de potenciar los aspectos más valorados por ellos y poder conocer aquellos puntos débiles con el fin de tomar las medidas correctoras oportunas.

Nuestra mayor preocupación es que nuestros clientes queden satisfechos, por eso necesitamos su ayuda para mejorar dia a dia.

\section{7.- Plan de Formación Interno}

La comunicación de éste tipo de iniciativas ha de ser extensible a todo el personal del hotel, y especialmente entre los departamentos cuyo personal esté de cara al cliente, o tenga contacto directo con él, como es la dirección, departamento comercial, departamento de recepcion, o de sala:

\section{1. ¿Por qué queremos que dejen comentarios sobre nuestro hotel?}

La valoración de un determinado producto o servicio por parte de alguien de nuestro entorno siempre ha influido en nuestra decisión de compra, con la diferencia de que el efecto antaño conocido como "boca a boca " se difundia únicamente al entorno más próximo de cada consumidor, esto es, familiares, amigos, y conocidos.

Hoy en dia, el uso de Internet ha provocado que el " boca a boca " digital llegue a miles, incluso millones de personas gracias a la normalización en el uso de Internet, por lo que cada día mas, los comentarios vertidos en Internet acerca de nuestros establecimientos hoteleros tienen mas relevancia a la hora de influir en la decisión de compra de los potenciales clientes.

Por ésta razón, es muy conveniente para el establecimiento posicionarse estratégicamente gracias a los buenos comentarios en las principales Webs de opinión, con el fin de obtener una ventaja competitiva respecto a nuestros competidores directos. 


\section{2. $¿$ Que ventajas ofrecen tener muchos comentarios positivos en éstas Webs?}

- Que los potenciales clientes se decidan por nuestro hotel al comprobar en éstas Webs que nuestro establecimiento es el más y mejor valorado por los propios clientes.

- Incrementar el volumen de ventas.

- Aumento del tráfico en internet hacia la Web del hotel, mejorando el posicionamiento orgánico en buscadores, lo que redundará en una mayor visibilidad de la Web del hotel en los principales buscadores.

- Aportar un valor añadido y un elemento diferencial frente a la competencia.

\section{3. ¿A quien le damos las tarjetas?}

Con el fin de aseguramos que los comentarios que dejen sobre nuestro hotel sean positivos, es fundamental entregar la tarjeta únicamente a aquellos clientes habituales del hotel, aquellos que tengan un alto grado de repeticion., o que hayan transmitido al personal del hotel, sin dejar lugar a dudas, su satisfacción con los servicios disfrutados y el trato recibido.

\section{4. ¿Cuando es el mejor momento de entregar la tarjeta?}

Obviamente, el mejor momento para entregar la tarjeta será en el preciso instante que el cliente muestre al personal del hotel la satisfacción, para aprovechar ese momento de "debilidad".

En caso de no ser el cliente el que libremente manifieste sus felicitaciones, será el recepcionista en el momento del check out quien, mostrando sincero interés por el cliente, le pregunte si su estancia en el hotel ha sido satisfactoria. En caso afirmativo y utilizando la diplomacia y experiencia del personal, hacerle entrega de la tarjeta y sugerirle que el hotel agradecería que compartiera sus comentarios con nosotros en la Web, para así poder conocer de primera mano los puntos a mejorar. 


\section{5. ¿Que le tenemos que decir al cliente para convencerle?}

El que un cliente se tome las molestias de visitar una o varias Webs, localice el hotel, y deje sus comentarios requiere su tiempo, por lo que es necesario transmitir correctamente al cliente cual es la causa de nuestro interés.

Los comentarios de los clientes son fundamentales para conocer su opinión respecto de nuestro hotel, con el fin de potenciar los aspectos más valorados por ellos, y poder conocer aquellos puntos débiles con el fin de tomar las medidas correctoras oportunas.

Nuestra mayor preocupación es que nuestros clientes queden satisfechos, por eso necesitamos su ayuda para mejorar día a día.

\section{8.- Modelo Tarjetas}

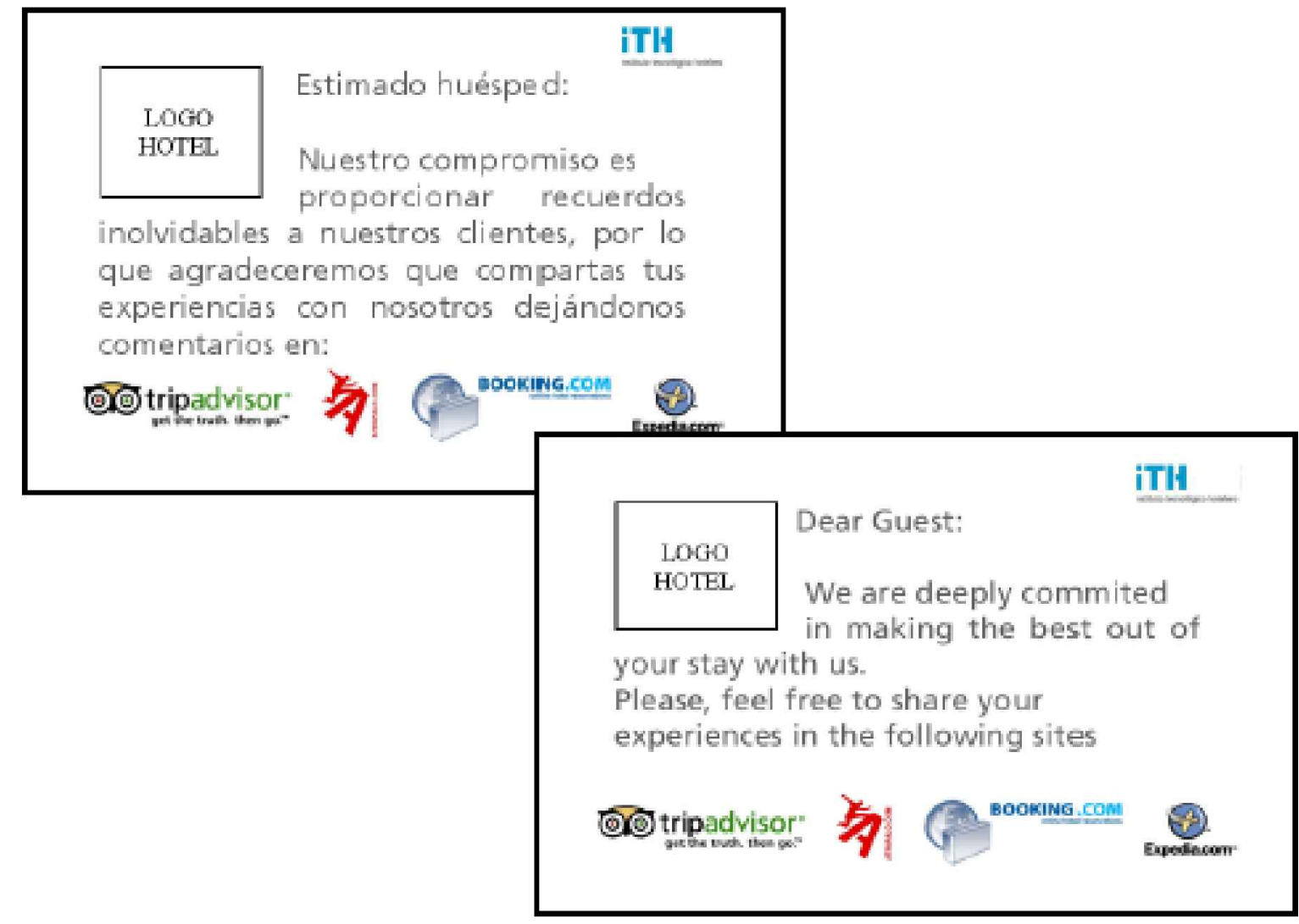


ANEXO 5: Contratación de freelancers para escribir en TripAdvisor

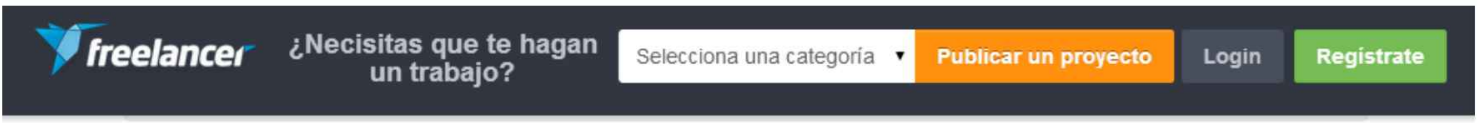

\section{Need reviews on tripadvisor.com}

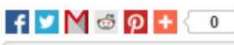

\begin{tabular}{|c|c|c|}
\hline Ofertas & Oferta prom. (USD) & Presupuesto (USD \\
7 & $\$ 149$ & $\$ 30-\$ 250$
\end{tabular}

\section{CANCELADO}

Descripción del proyecto:

I need reviews posted on tripadvisor com for a specific client. i will provide the text and title for the review

Eache review must com from a diferent IP because Tripadvisor tracks IP also each review has a like buton

Well if you have experience with tripadvisor is better .. if not any test of posting a random review for a hotel wil give you the clear picture of the work.

Each review has to be from a diferent IP is very important... i need around 600 reviews.

ill acept bids per review and bulk

Habilidades requeridas:

Varios, Marketing de Facebook, Marketing en Internet Construcción de enlaces, Redes sociales

Ver más: tripadvisor, bulk reviews, posting 600 , bids reviews, review hotel, replicavalley com site reviews, reotrans com job reviews, payasyougoelectronics com good reviews, moneybookers com rewriters reviews, mobilemayhem com website reviews, booking com jobs reviews, ar 32 com website reviews, vb60 project using internetexplorer control windowssystem32shdocwwdll public withevents m_oie internetexplorer need function wil, need hotel booking database samplesa, need hotel reservation

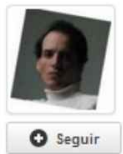

Proyecto publicado por:

neloreis

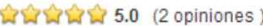

QVierIFICADO

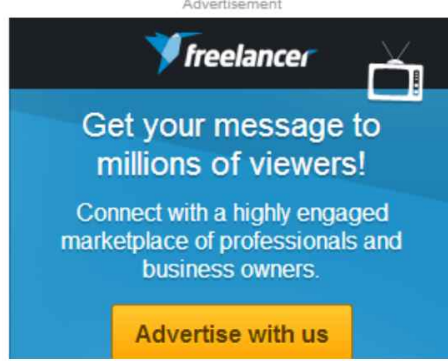

http://www.freelancer.com/projects/Internet-Marketing-Link-Building/Need-reviews-tripadvisorcom.html

\section{freelancer ¿Necisitas que te hagan
un trabajo? \begin{tabular}{c|c|c|c|c|} 
Selecciona una categoria & Publicar un proyecto & Login \\
\hline
\end{tabular}}

Post Reviews for hotel on

tripadvisor.com

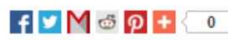

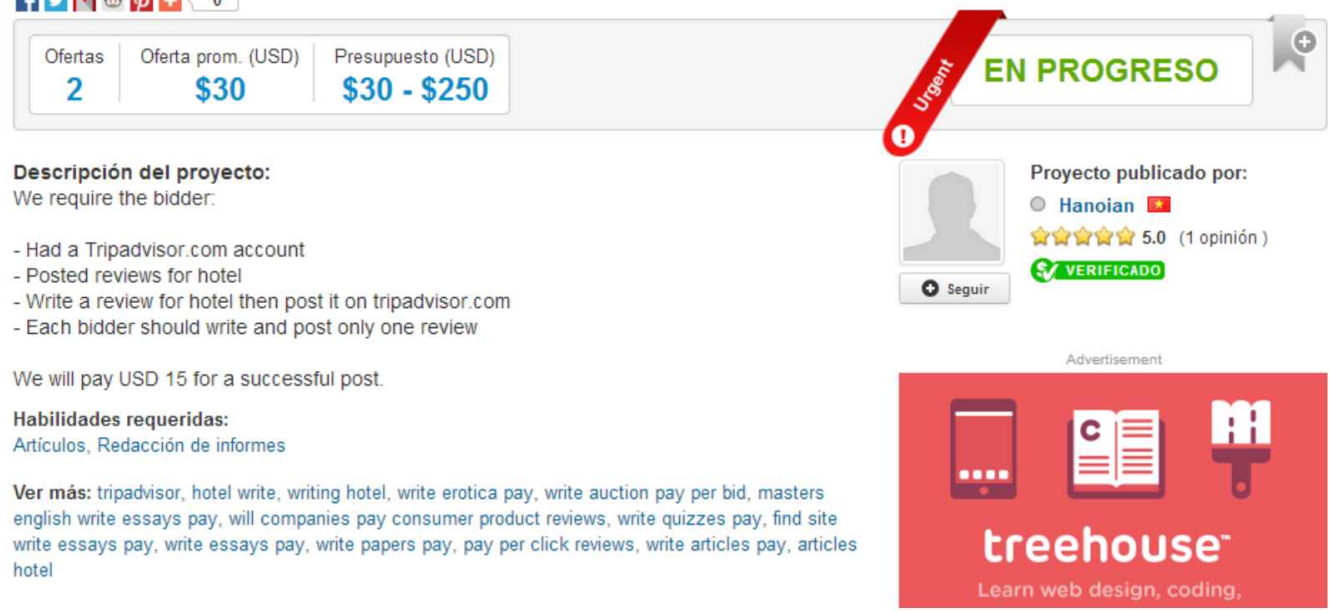

http://www.freelancer.com/projects/Report-Writing-Articles/Post-Reviews-for-hoteltripadvisor.html 


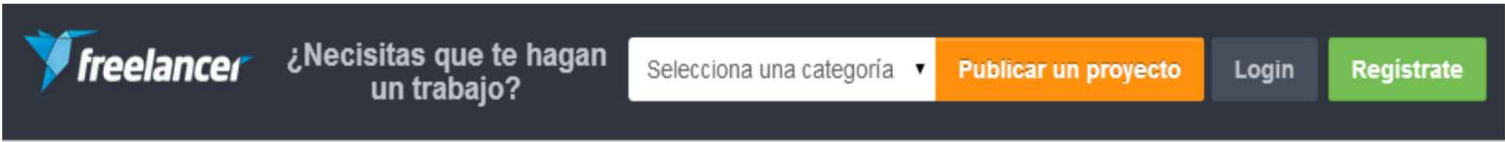

\section{Tripadvisor Review needed

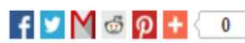

\begin{tabular}{|c|c|c|}
\hline Ofertas & Oferta prom. (EUR) & Presupuesto (EUR) \\
14 & $€ 103$ & $€ 30-€ 150$
\end{tabular}

\section{COMPLETADO}

\section{Descripción del proyecto:}

I need up to 50 english review on tripadvisor, with different text, and user

Payment when the review are published.

Dead Line: $30 / 11 / 2012$

Habilidades requeridas:

Envio de artículos, Artículos, Redacción por encargo

Ver más: tripadvisor, writers needed review website, mortgage payment calculatorwith graphical user interface examples, draw line user color selection net, command line user interface, meant dead line oriented, bloggers needed review product, dead line oriented, reliable dead line oriented, write program java graphical user interface calculate display mortgage payment amount user input amount mortgage term mortgage i, draw line user clicks mouse vbnet

Proyecto publicado por:

- stegavedder $\square$

जिये 5.0 (2 opiniones)

Q verificado

Advertisement:

Yreelancer

Maximise vour earninos with

http://www.freelancer.com/projects/Ghostwriting-Articles/Tripadvisor-Review-needed.html

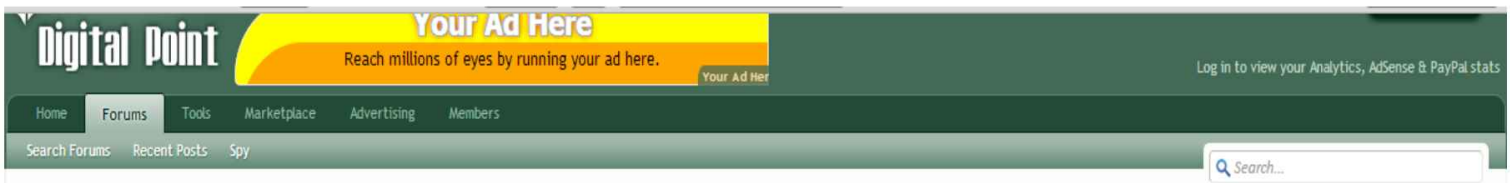

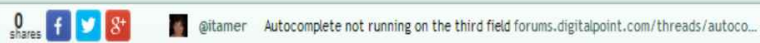

Home Forums Buy, Sell or Trade Services Content Creation

Buying Write and post 5/5 reviews for my property on Tripadvisor

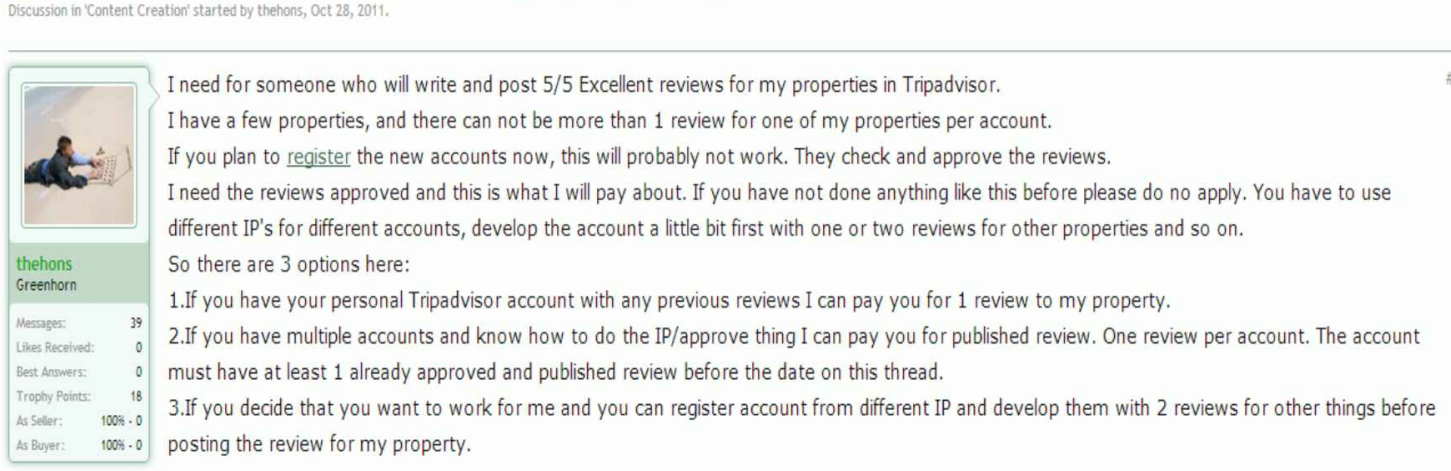

https://forums.digitalpoint.com/threads/write-and-post-5-5-reviews-for-my-property-ontripadvisor.2315716/ 


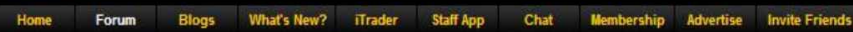

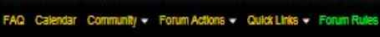

Forum + Making Money + Hire a Freelancer * Looking for someone to do TripAdvisor reviews

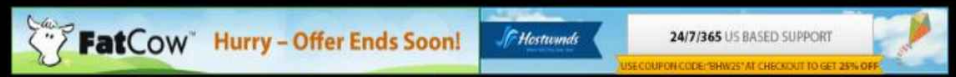

If this is your first visit, be sure to check out the FAO by clicking the link above. You may have to register before you can post: click the register link above to proceed, To start viewing messages, select the forum th

Search

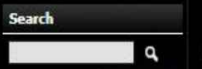

Looking for someone to do TripAdvisor revievs. Looking for quality work from aged accounts. Posts ..

$\checkmark$ Main Menu

alanoss search

Home

101-15-2013, 01:47 PM

Main Forums

Jr.vIP

Black Hat SEO

White Hat SEO

Cloaking

A $\times$ : Don

(longing

D Looking for someone to do TripAdvisor reviews

Black Hat Tools

Looking for someone to do TripAdvisor reviews. Looking for quality work from aged accounts. Posts should look natural and be from aged accounts.

Need someone who knows how to go about doing this without getting it flagged.

Dounlosids

Post here and PM me your skype for further discussions.

Tharketplace

BHW Marketplaco

-sgmoney.

http://www.blackhatworld.com/blackhat-seo/hire-freelancer/522240-looking-someone-dotripadvisor-reviews.html 


\title{
ANEXO 6: Opiniones sin haber estado en hoteles
}

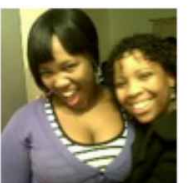

ovayo1212

Cape Town, South Africa

Colaborador Sénior

7 opiniones

(4) 7 opiniones de atracciones

\section{"great< never been there" \\ OOOOO Opinión escrita el 6 enero 2012}

\section{Google Traductor}

would love to go there myself. but what can I say I am gna have to finish studies then that is when I will afford to go there

¿Ha sido útil esta opinión? Sí ¿Algún problema con esta opinión?

Consulta las 7 opiniones de ovayo1212 j para Ciudad del Cabo Centro

Pregunta a ovayo1212 j sobre Great Synagogue

Esta opinión es la opinión subjetiva de un miembro de TripAdvisor, no de TripAdvisor LLC.

http://www.tripadvisor.es/ShowUserReviews-g312659-d310918-r122653023-Great_SynagogueCape_Town_Central_Western_Cape.html

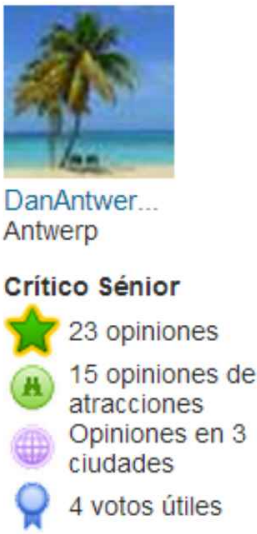

\author{
"Never been there but know..." \\ OOOOO Opinión escrita el 3 diciembre 2012
}

Esta opinión ha sido traducida de forma automática desde el inglés ¿Qué es esto? Mostrar traducciones automáticas si $\bigcirc$ No

this is worth a visit. In fact "The last supper" was painted by the master and can be seen in a calm relaxed way. That other painting in Italy was restorated on the basis of this painting because both paintings are so simular and this one is in very good shape. Problem is that it hangs in a monastery and can be visited in a limited way. It's been in a documentary on Belgian television and from what I saw, it's large and beautifull.

Evalúa esta traducción: Mala $\bigcirc \longleftarrow \bigcirc \rightarrow \bigcirc$ Buena

Visitado el Diciembre de 2012

¿Ha sido útil esta opinión? $\mathrm{Si}$

¿Algún problema con esta opinión?

Consulta las 16 opiniones de DanAntwerp para Amberes

Pregunta a DanAntwerp sobre Da Vinci Museum

Esta opinión es la opinión subjetiva de un miembro de TripAdvisor, no de TripAdvisor LLC.

http://www.tripadvisor.es/ShowUserReviews-g188636-d1536117-r146681630-

Da_Vinci_Museum-Antwerp_Antwerp_Province.html\#mtreview_146681630 


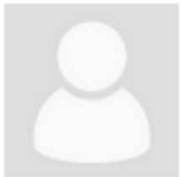

Un miembro de

TripAdvisor en Facebook
"Never Been there but worth a Try!"

OOOOO Opinión escrita el 11 enero 2008

Google Traductor

Never Been there but worth a Try!

¿Ha sido útil esta opinión?

¿Algún problema con esta opinión?

Esta opinión es la opinión subjetiva de un colaborador individual y no de TripAdvisor LLC.

http://www.tripadvisor.es/ShowUserReviews-g154932-d893467-r15243908-AmsterdamKamloops_British_Columbia.html

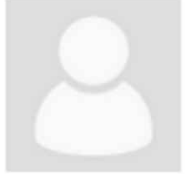

A TripAdvisor reviewer on Facebook
"I heard that is a nice rest. New style Chinese cusine. I have to try it before my grad."

OOOOO Reviewed 14 December 2007

I heard that is a nice rest. New style Chinese cusine. I have to try it before my grad.

Was this review helpful? Yes

Problem with this review?

This review is the subjective opinion of an individual contributor and not of TripAdvisor LLC.

http://www.tripadvisor.com.au/ShowUserReviews-g294217-d800844-r15528936-JasmineHong_Kon.html

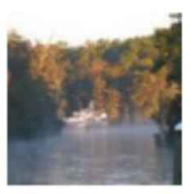

Linda B

Vero Beach, Florida, United

States

Senior Contributor

负 33 reviews

(11) 26 restaurant reviews

Reviews in 4 cities

9 helpful votes

\section{"Never been there, but......"}

OOOOO Reviewed 28 August 2012

We were warned against Joey's Bistro when we moved to Vero. Have never been but friends who hadn't been warned went, got all four meals comped, and two were sick the next day. Joey's has left the space on 21st Street--soon to be a Bonefish. Great change!

Was this review helpful? Yes

Problem with this review?

http://www.tripadvisor.co.uk/Restaurant_Review-g34709-d1641865-Reviews-Joey_s_BistroVero_Beach_Florida.html 


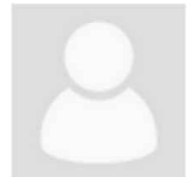

Un miembro de

TripAdvisor en Facebook

\section{"i've never been there, but it's one of the most famous restaurants in vienna!"}

OOOOO Opinión escrita el 4 enero 2008

\section{Google Traductor}

i've never been there, but it's one of the most famous restaurants in vienna!

¿Ha sido útil esta opinión? Si

¿Algún problema con esta opinión?

Esta opinión es la opinión subjetiva de un colaborador individual y no de TripAdvisor LLC.

http://www.tripadvisor.es/ShowUserReviews-g190454-d694450-r15530756-Kim_Kocht-

Vienna.html

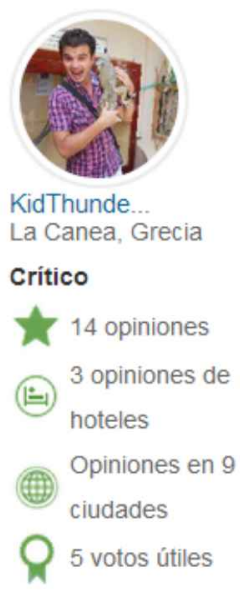

\section{"I have never stayed here" \\ OOOOO Opinión escrita el 27 marzo 2013}

Esta opinión ha sido traducida de forma automática desde el inglés ¿Qué es esto?

Mostrar traducciones automáticas Si $\bigcirc$ No $\bullet$

I understand that this comment may be misleading, since I have never stayed in that hotel, but I am yet writing a review.

However, in my opinion it is as important how the hotels communicate with their customers prior arrival ad it is the place itself.

I was involved in a long exchange of e-mails with the hotel staff trying to clarify all the details about my future stay (due to changes in the plan we did not go) and they are very prompt in replying, very detailed, kind and willing to help.

During my research I was looking for places from one star to four star rated, but I can assure you that high class hotels can not match the communication skills of this tiny hotel.

Evalúa esta traducción: Mala $\bigcirc \leftarrow O \rightarrow O$ Buena

Se alojó el Marzo de 2013, viajó solo

¿Ha sido útil esta opinión? $\mathrm{Si} 1$

Pregunta a KidThunder sobre Hotel Boissiere

http://www.tripadvisor.es/ShowUserReviews-g196574-d313110-r155817954-Hotel_BoissiereLevallois_Perret_Hauts_de_Seine_lle_de_France.html 


\section{"expensive rates" \\ OOOOO Opinión escrita el 7 junio 2011}

\section{Google Traductor}

Hi guys, I've never been in this hotel, but all the time they send me e-mails with their "promotions", as they say so..

Rates are like 600,00 brazilian real per day! I've been in a lot of places all over the world, and in my opinion, this is too much.. we pay this rate for a 5 star hotel. They don't even have a jacuzzi or a heated swimming pool for the use of the guests during the winter.. well, for me this is pretty much abusive. My boyfriend and I were planning a trip to Tiradentes, but prices were so expensive that we've decided to go to Uruguay, for almost the same price.. Thanks,

Andressa

Se alojó el Junio de 2011, viajó en pareja

menos

¿Ha sido útil esta opinión? Si 4

Pregunta a andressavelasco sobre Pousada Dos Inconfidentes

http://www.tripadvisor.es/Hotel_Review-g737098-d862186-Reviews-

Pousada_Dos_Inconfidentes-Tiradentes_State_of_Minas_Gerais.html

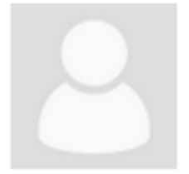

A TripAdvisor reviewer on Facebook "ive never been here but..."

OOOOO Reviewed 28 December 2007

ive never been here but just go....

Was this review helpful? Yes

Problem with this review?

This review is the subjective opinion of an individual contributor and not of TripAdvisor LLC.

http://www.tripadvisor.co.uk/ShowUserReviews-g255100-d728731-r15322512-

Thai_Silk_Restaurant-Melbourne_Victoria.html 


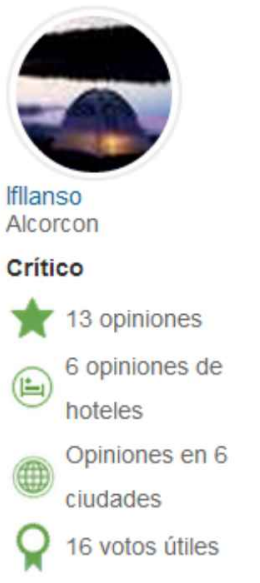

\section{"Inconcebible" \\ OOOOO Opinión escrita el 16 febrero 2011}

Efectuamos y pagamos la reserva de este Hotel para estancia de diez días por el Imserso. A priori y debido a los comentarios vertidos en la red,

manifestamos al Hotel nuestra preocupación por la limpieza, recibiendo del Director y Administrador único un e.mail manifestando, entre otros despropósitos lo siguiente : sic. " .... le comunico que sería bastante saludable que renunciara a su viaje a Mazagón ... ".

Aún con la pérdida de un $24 \%$ de lo aprotado, procedimos a la cancelación del viaje de inmediato. En consecuencia, no hemos estado en el Hotel.

Se alojó el Febrero de 2011, viajó en pareja

¿Ha sido útil esta opinión? Si 4

Pregunta a Ifllanso sobre Hotel Carabela Santa Maria

Esta opinión es la opinión subjetiva de un miembro de TripAdvisor, no de TripAd̛visor LLC.

http://www.tripadvisor.es/ShowUserReviews-g642205-d231596-r161470392-

Hotel_Carabela_Santa_Maria-Mazagon_Costa_de_la_Luz_Andalucia.html

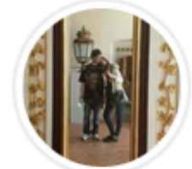

Alba P

2 opiniones

\section{"No nos llegamos a hospedar!" \\ OOOOO Opinión escrita el 25 noviembre 2013}

Al llegar nos dijeron que nos cambiaban al hotel brixen, a unos povos metros de este! Fatal! Impresentables! Y sin darnos explicación ninguna, no son ni de la misma cadena de hoteles, no entendimos nada....

Se alojó el Agosto de 2013, viajó en pareja

¿Ha sido útil esta opinión?

Pregunta a Alba P sobre City Club Hotel

Esta opinión es la opinión subjetiva de un miembro de TripAdvisor, no de TripAdvisor LLC.

http://www.tripadvisor.es/ShowUserReviews-g274707-d280309-r185780220-City_Club_HotelPrague_Bohemia.html 
ANEXO 7: Material gráfico contra TripAdvisor

\section{๑ఠ tripad liars}

GET THE LIES AND GO!! tripadvisor $^{\circ}$ get the lies then go. ${ }^{\text {TM }}$

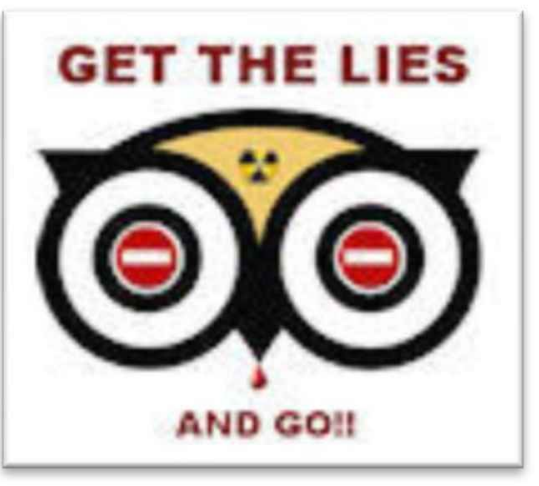

[THAXKS TRIPADVISUR WE ARE BEIXE BLACKMAILED ]

\section{FREE POSTAGE OR WE WILL POST ON}

\section{๑๐ tripadvisor ${ }^{\circ}$}

WORLD'S MOST lled about TRAVEL ADVICE"*

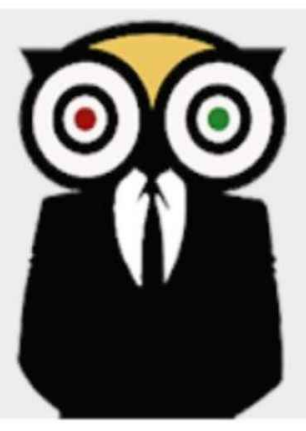

Quality TripAdvisor Reviews $100 \%$ Guaranteed snly pay after the review has been posted on TripAdviso

ALL proceeds go to charity unw.real-tripadvisor-reviews.com
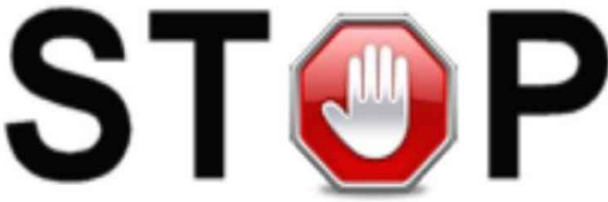

() tripadvisor"

They allow lies and libel comments to be posted on their sites without any form of validation.

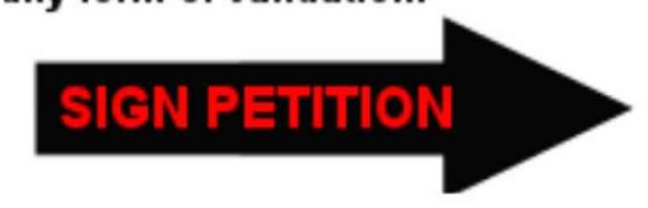

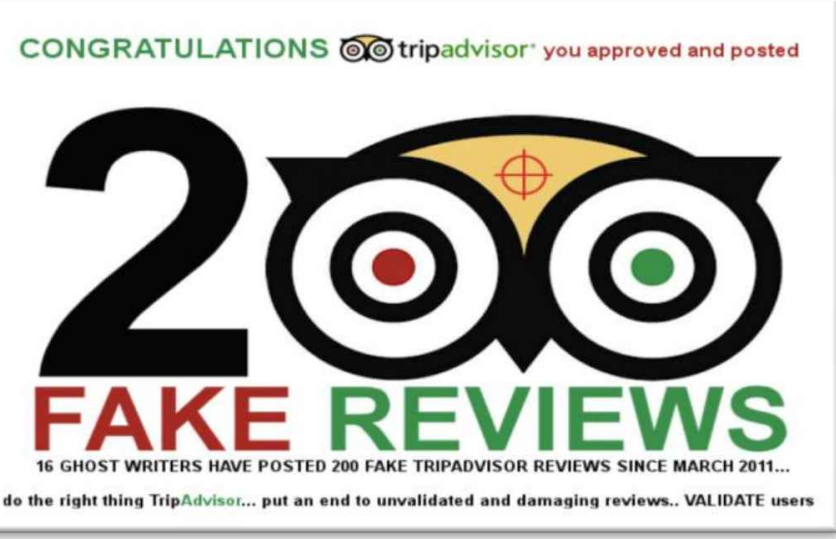

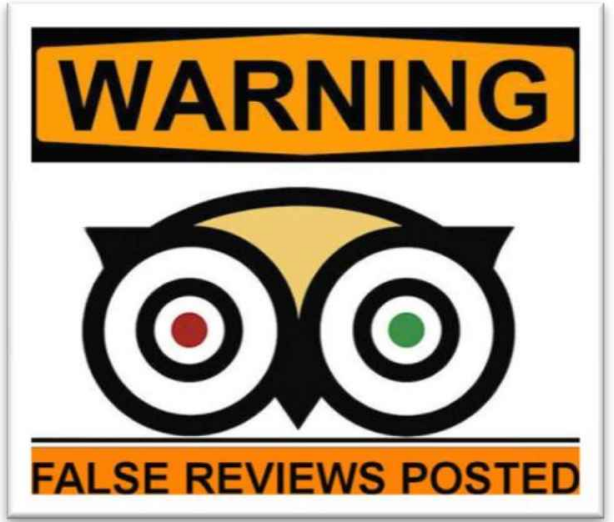




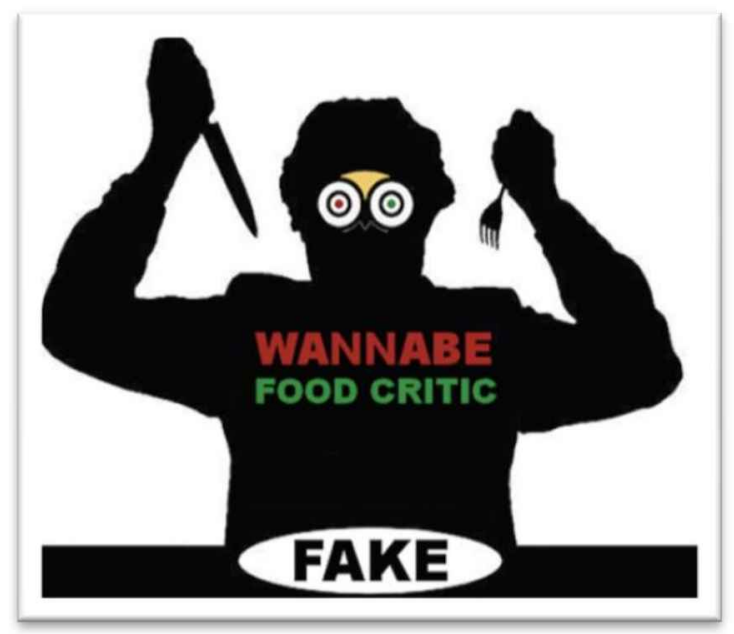

\section{๑ఠtripadvisor}

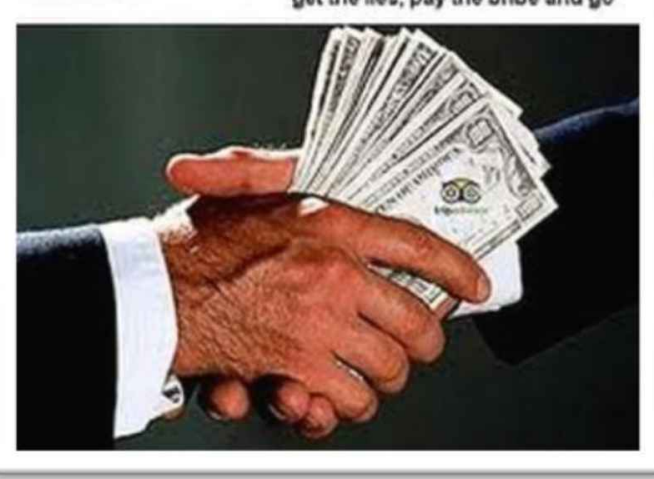

\section{ABSOLUTELY DISGUSTING !!}

TripAdvisor approves and posts a sexual and degrading review

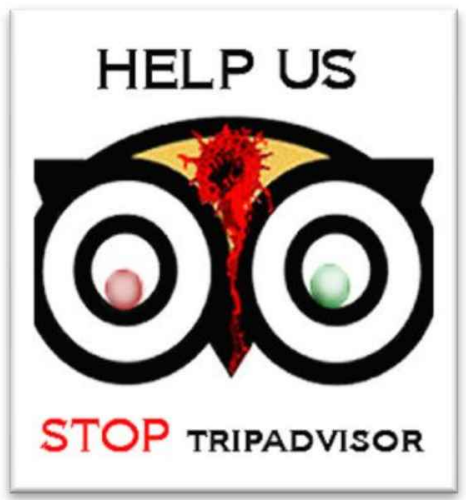

๑ఠ
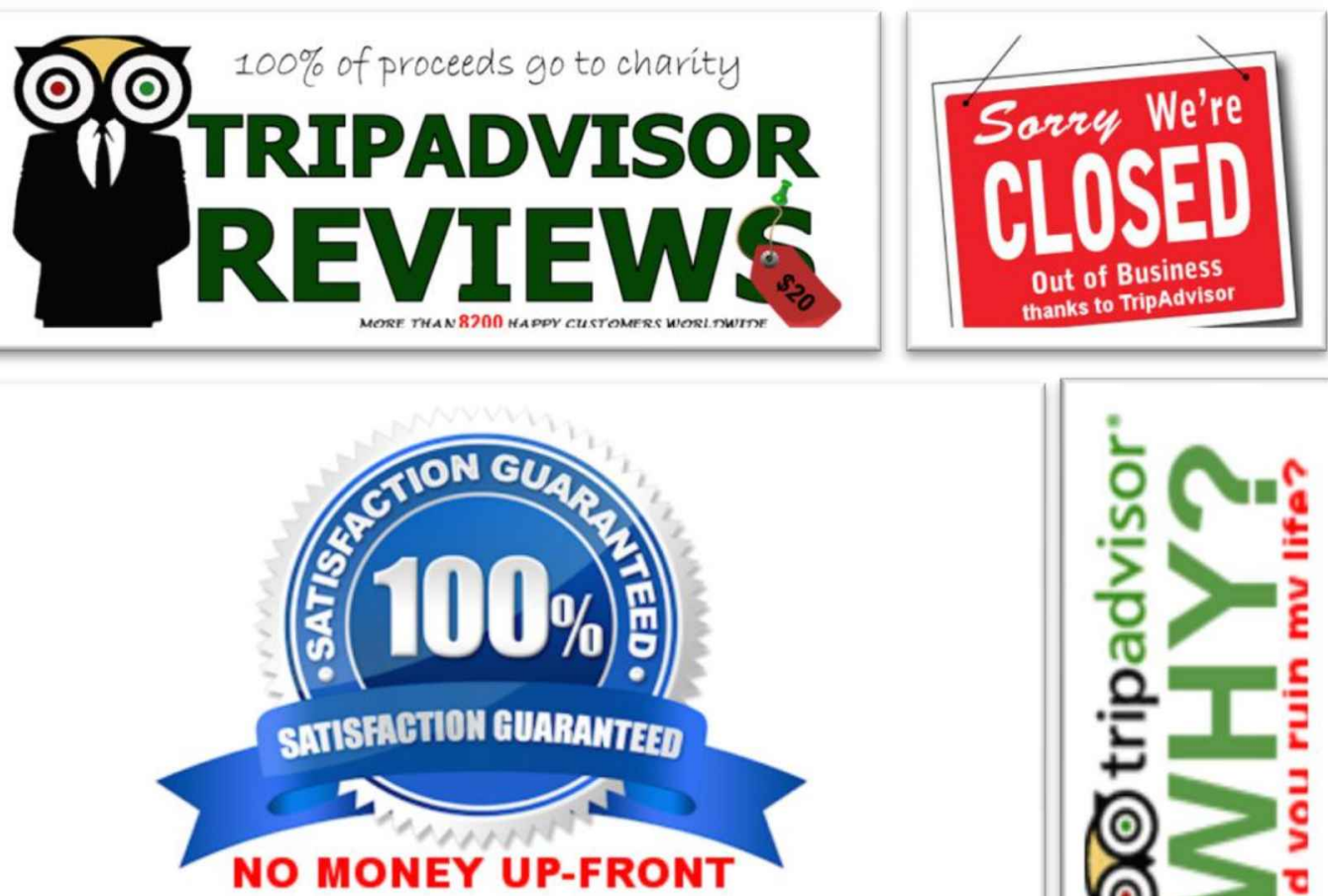

you only pay once the review has been posted on TripAdvisor

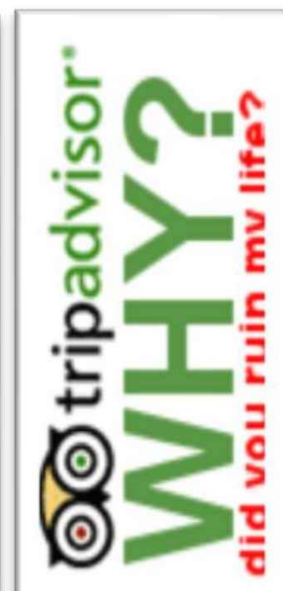



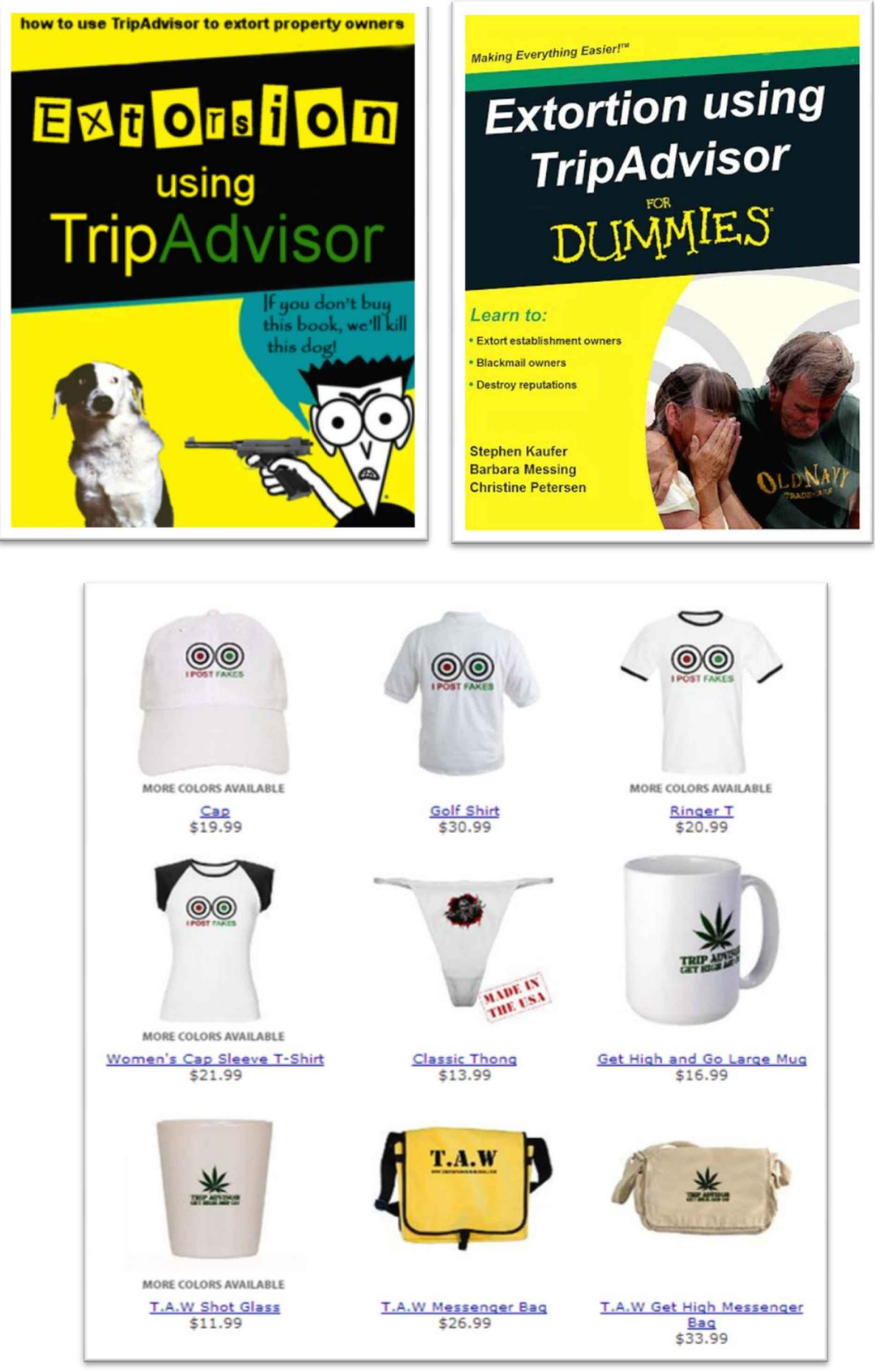